RAZON, DERECHOS Y VALIDEZ. UN ANALISIS DE LA EILOSOFIA DEL DERECHO DE ROBERT ALEXY
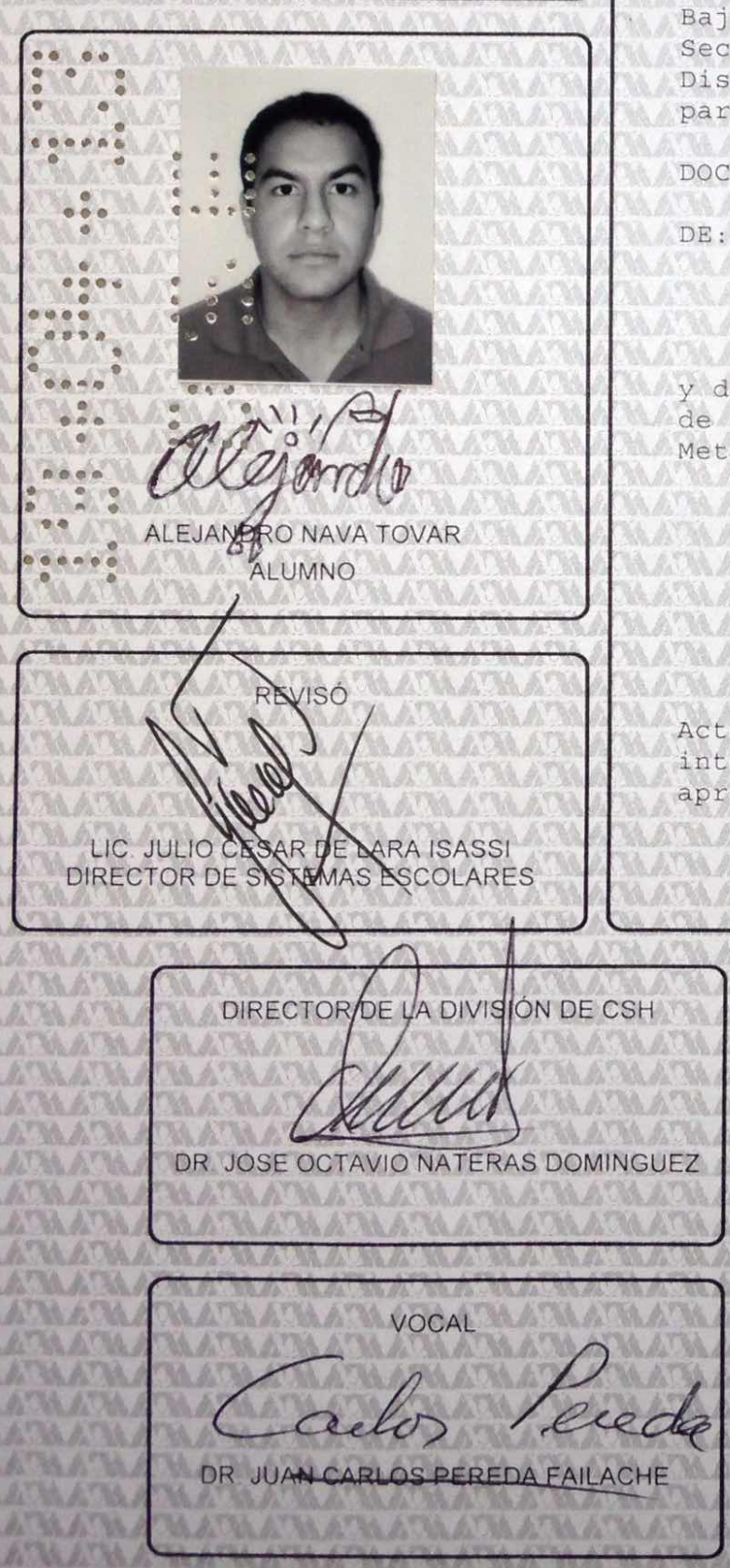

En México, D.F., se presentaron a las 11:00 horas del día 15 del mes de abril del año 2013 en la Unidad Iztapalapa de la Universidad Autónoma Metropolitana, los suscritos miembros del jurado:

\section{DR. JESUS RODRIGUEZ ZEPEDA \\ DR. JUAN CARLOS PEREDA FAILACHE \\ DR. GUSTAVO LEYVA MARTINEZ}

Bajo la Presidencia del primero y con carácter de Secretario el último, se reunieron a la presentación de la Disertación pública cuya denominación aparece al margen, para la obtención del grado de:

DOCTOR EN HUMANIDADES (FILOSOFIA)

DE: ALEJANDRO NAVA TOVAR

de acuerdo con el articulo 78 fracción IV del Reglamento de Estudios Superiores de la Universidad Autónoma Metropolitana, los miembros del jurado resolvieron:

\section{elprobar}

el presidente del jurado comunicó al aprobatorio, le fue tomada la protesta. 


\title{
RAZÓN, DERECHOS Y VALIDEZ \\ LA FILOSOFÍA DEL DERECHO DE ROBERT ALEXY
}

TESIS QUE PRESENTA ALEJANDRO NAVA TOVAR

PARA OBTENER EL GRADO DE DOCTOR EN HUMANIDADES

(FILOSOFÍA)

LÍNEA: FILOSOFÍA MORAL Y POLÍTICA

\author{
DIRECTORES: \\ Dr. JESÚS RODRÍGUEZ ZEPEDA \\ Dr. GUSTAVO LEYVA MARTÍNEZ
}

MÉXICO, MAYO DE 2013 
Para Alicia Tovar, mi madre, por todo el amor que nos has dado a Javier y a mí 


\section{Índice General}

Presentación. La institucionalización de la razón en un mundo desencantado. La filosofía del derecho de Robert Alexy.

\section{Primera Parte. LA teoría de la ARgumentación PRÁCtica Y JURÍdICA}

Capítulo primero. Razón y derecho. En torno al pensamiento alexyano....................12

1.1. Robert Alexy y la Escuela Moderna de Kiel. Contexto biográfico...............................14

1.2. El sistema de filosofía del derecho de Alexy ..............................................20

1.3. Estructura y metodología del programa de la filosofía jurídica alexyana.....................23

Capítulo segundo: Del discurso práctico racional al discurso jurídico ................26

2.1. Los orígenes de las teorías modernas de la argumentación jurídica..........................26

2.2. El giro comunicativo: de la ética del discurso a la filosofía del derecho......................33

2.3. La tesis del caso especial del discurso jurídico............................................43

Capítulo tercero: Hacia un código de racionalidad práctica y jurídica ...................51

3.1. Las reglas y formas de la argumentación práctica.................................................51

3.2. Las reglas y formas de la argumentación jurídica.........................................70

3.3. Teoría de la argumentación jurídica y Estado de derecho.....................................86

\section{SEgunda PARTE. LA TEORÍA DE LOS DERECHOS huMANOS Y FUNDAMENTALES}

4. La fundamentación filosófica de los derechos fundamentales ......................87

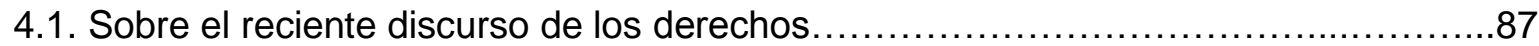

4.2. La fundamentalidad de los derechos fundamentales........................................91

4.3. La estructura de los derechos fundamentales: reglas y principios............................106

5. La institucionalización política de los derechos fundamentales...................122

5.1. El problema de la positivización de los derechos.....................................122

5.2. El sistema de derechos fundamentales a algo, libertades y competencias.............125

5.3. Sobre los derechos generales de libertad, igualdad y a acciones positivas............135

6. La aplicación jurídica de los derechos fundamentales...............................155

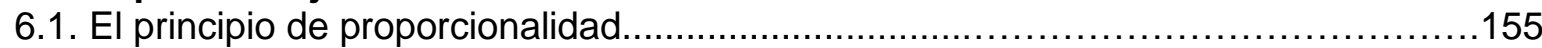

6.2. Las objeciones al principio de proporcionalidad................................................177

6.3. Teoría de los derechos fundamentales y Estado de Derecho..........................190 
Capítulo Siete: Moral y derecho. La tragedia conceptual del derecho...............195

7.1. El problema conceptual de la vinculación entre moral y derecho....................196

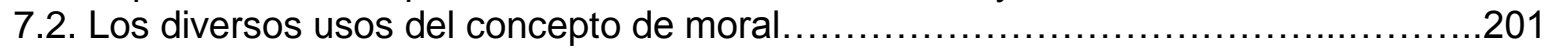

7.3. Las relaciones conceptuales y necesarias entre derecho y moral...................209

Observadores y participantes. La naturaleza del derecho según Alexy............... 214

8.1. La perspectiva del observador y la del participante..........................................215

8.2. Las objeciones a los argumentos de Alexy: la embestida positivista..................... 235

8.3. En defensa del no-positivismo alexyano: la doble naturaleza del derecho...........246

Capítulo nueve: eficacia, vigencia y validez del derecho.........................261

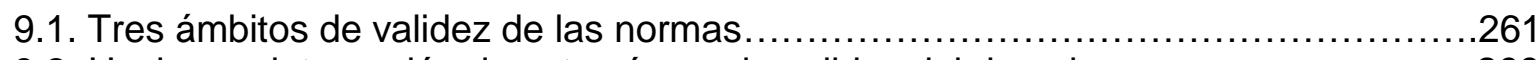

9.2. Hacia una integración de estas áreas de validez del derecho.......................268

9.3. Validez integral de las normas y Estado de derecho............................279

Conclusiones. Entre la utopía y la institucionalización de la razón. Robert Alexy y la

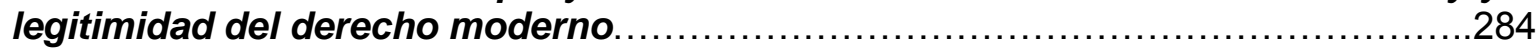

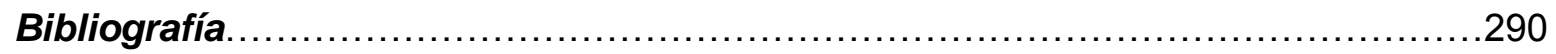




\section{Siglas de los textos alexyanos citados}

\section{A) Obras de Alexy (publicadas originalmente en alemán)}

TAJ Teoría de la argumentación jurídica

TDF Teoría de los derechos fundamentales

CVD Concepto y la validez del derecho

DRD Recht, Vernunft, Diskurs (Derecho, razón, discurso)

\section{B) Ensayos de Alexy (y textos compilados en español)}

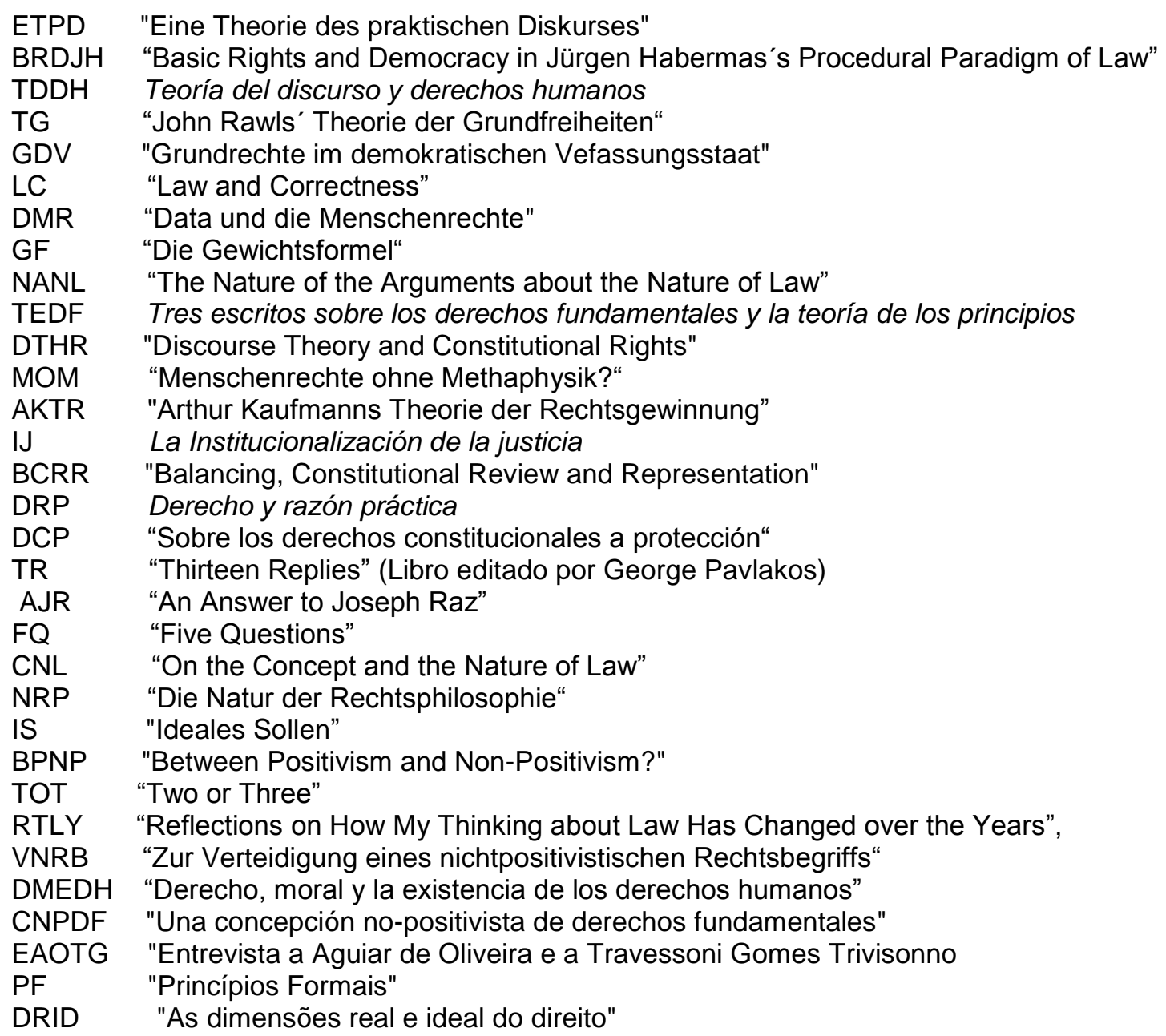

\section{C) Textos escritos o compilados con otros autores}

$\begin{array}{ll}\text { FLR } & \text { "The Foundation on Legal Reasoning" } \\ \text { CDR } & \text { "Coherence and Discursive Rationality" } \\ \text { PRDM } \quad \text { La polémica sobre la relación entre derecho y moral }\end{array}$


"Man muß seiner Fahne treu bleiben, auch wenn das Schiff sinkt; und kann in die Tiefe nur die Hoffnung mitnehmen, daß das Ideal der Freiheit unzerstörbar ist und $\mathrm{da} ß$ es, je tiefer es gesunken, um so leidenschaftlicher wieder aufleben wird."

Hans Kelsen Verteidigung der Demokratie 


\section{Introducción}

\section{La institucionalización de la razón en un mundo desencantado. La filosofía del derecho de Robert Alexy}

En 1978 fue publicada en Alemania la obra Teoría de la argumentación jurídica. La teoría del discurso racional como teoría de la fundamentación jurídica, escrita por Robert Alexy. A partir de la publicación de ésta comenzó el programa de fundamentación de una de las construcciones teóricas más importantes de nuestro tiempo: la filosofía jurídica de Robert Alexy.

No sería exagerado afirmar que, desde la publicación de este Opus magnum, la filosofía jurídica de Alexy marcaría el inicio de una profunda reflexión en torno al derecho. En 1985 fue publicada la obra Teoría de los derechos fundamentales y en 1992 fue publicada la obra Concepto y validez del derecho. Estas tres obras, junto con un centenar de artículos en los que conecta, afina y complementa las tesis principales de éstas, bien podrían formar un sistema de filosofía no-positivista del derecho. Un sistema de filosofía del derecho siempre en constante y crítico cambio, pero con una esencia normativa lo suficientemente sólida como para erigirse como un pensamiento dedicado a institucionalizar la razón y la justicia en los Estados democráticos de derecho. Por ello, esta filosofía del derecho, qua sistema de filosofía del derecho, también podría contar como una filosofía de la razón práctica institucionalizada o como una teoría jurídica no-positivista de la justicia.

Ahora bien, ¿por qué es necesaria una filosofía de la razón práctica institucionalizada en nuestro tiempo? El espíritu del tiempo parece exigirla de manera reiterada. En las últimas décadas hemos presenciado una serie de procesos económicos, políticos, científicos y culturales que han transformado nuestra comprensión del mundo y los sistemas sociales que lo conforman. Dentro de esta serie de procesos y eventos, lo que hoy se menciona como globalización es mucho más que un proceso económico, cuyas dimensiones de violencia, cooperación, miseria y sufrimiento ${ }^{1}$ han traído nuevos y complejos retos al derecho.

\footnotetext{
${ }^{1}$ Cfr., Höffe, Otfried, Demokratie in Zeitalter der Globalizierung, Verlag C. H. Beck, Múnich,1999, pp. 14 ss.
} 
Esta serie de procesos recientes a los que nos referimos antes corresponden a una imagen del mundo occidental que rechaza todo tipo de vestigios metafísicos como fundamento del orden social y apela a la visión de un mundo desencantado y desdivinizado $y$, con ello, a la secularización de los valores y las normas. ${ }^{2}$ El desencantamiento del mundo moderno (Die Entzauberung der Welt), expresión acuñada por Max Weber ${ }^{3}$ y objeto de diversas interpretaciones, ${ }^{4}$ la usamos para referirnos a una forma de configuración de las sociedades secularizadas modernas en las que se le da una mayor prioridad al conocimiento científico que al mundo antiguo de las creencias e imágenes místicoreligiosas. ${ }^{5}$

El mundo desencantado en que vivimos requiere, tanto a nivel local y global, de una configuración jurídica vinculada a principios normativos para legitimar al derecho moderno. De este modo, es posible plantear la pregunta respecto al problema que ha motivado nuestras reflexiones filosóficas en torno al derecho: ¿cómo es posible la legitimidad del derecho moderno en un mundo desencantado, un mundo que, en buena medida, ha renunciado a fundamentos metafísicos como criterios de validez de las normas morales y jurídicas?

\footnotetext{
${ }^{2}$ Habermas, Jürgen, Der philosophische Diskurs der Moderne. Zwölf Vorlesungen, Fráncfort del Meno, Suhrkamp, 1986, p. 10.

${ }^{3}$ Según Wolfgang Schlüchter, Weber habló por primera vez del concepto de desencantamiento en la obra de 1913, Sobre algunas categorías de la sociología comprensiva (Über einige Kathegorien der verstehenden Soziologie), y parece que este concepto fue tomado a partir del libro de Emil Cohn -escrito bajo el pseudónimo de Emil Ludwig-, Wagner o el desencanto (Wagner oder die Entzauberten), publicado en ese mismo año. Al respecto, cfr., Schlüchter, Wolfgang, Die Entzauberung der Welt. Sechs Studien zu Max Weber, Tubinga, Mohr Siebeck, 2009, p 1-2.

${ }^{4}$ En nuestro caso, nos apegamos a la interpretación positiva de este proceso emancipatorio de las sociedades modernas respecto a las visiones tradicionales del mundo, la cual, en gran medida está representada por el programa de la Teoría Crítica. Por ello, no entendemos el proceso de desencantamiento como una resignación ante las patologías de la razón, sino como una manera de diagnosticar e intentar resolver estos problemas provocados e intensificados durante el proceso de modernización.

${ }^{5}$ Para dar una definición más precisa acerca de esta frase weberiana compartimos la opinión de Hartmut Lehmann: "¿[Q]ué quiere decir Weber cuando habla de "Entzauberung der Welt"? La respuesta a esta pregunta consta de dos partes. En primer lugar, para Weber, "Entzauberung der Welt" es un proceso de dimensiones globales en el que todos los medios mágicos que conceden la salvación están descartados y expulsados [...] En segundo lugar, por lo tanto, "Entzauberung der Welt" equivale a una decisión fundamental sobre la eliminación de la magia en el mundo, y por lo tanto la racionalización de todas las cosas del mundo [...] Se puede ir un paso más allá y sostiener que "Entzauberung der Welt", es el mismo proceso que llevó a la victoria del racionalismo occidental y, al final, a la existencia claustrofóbica del hombre moderno en una jaula de hierro" (Lehmann, Hartmut, Die Entzauberung der Welt. Studien zu Themen von Max Weber, Gotinga, Wallstein Verlag, 2009, pp. 10-11).
} 
Una posible respuesta al reto de la legitimidad del derecho moderno reside en la filosofía del derecho de Robert Alexy. La filosofía jurídica de Alexy ha sido vista por diversos especialistas como un proyecto que pretende erigirse como una reflexión sistemática acerca de todo aquello que concebimos como derecho. Tal y como lo veremos en el primer capítulo, diversos estudiosos y críticos de la obra de Alexy han coincidido en que esta reflexión filosófica y jurídica acerca de la pregunta básica del derecho, la quid iuris, está asociada a la pretensión de construir un sistema de filosofía del derecho, sustentado en tres pilares fundamentales: el estudio de la argumentación práctica y jurídica, los derechos humanos y fundamentales y el concepto, naturaleza y validez del derecho.

Esta pretensión de concebir a la filosofía del derecho de Alexy como un sistema o como una conpceción no-positivista del derecho no sólo ha sido expuesta por sus estudiosos y críticos. También el autor de tal filosofía jurídica así lo ha manifestado:

La mayoría de mi trabajo ha estado dedicada a tres temas: primero, al razonamiento jurídico y a la argumentación, segundo, a los derechos humanos y constitucionales, $y$, tercero, al concepto y naturaleza del derecho. La idea primordial es la institucionalización de la razón práctica. Si los tres temas pueden ser unidos mediante esta idea, el resultado bien podría ser un sistema. ${ }^{6}$

Estos ejes han sido expuestos en las tres grandes obras de Alexy, y refinados y desarrollados en los más de cien artículos que han acompañado a tales obras. Los estudiosos y críticos del pensamiento de Alexy han expresado en diversas obras y artículos que esta filosofía del derecho bien puede ser concebida como una institucionalización de la razón práctica. ${ }^{7}$ Esta profunda y sólida sistematización filosófica y jurídica nos motivó a reconstruir sistemáticamente esta filosofía del derecho, esta teoría jurídica no-positivista de la justicia, esta institucionalización de la razón. Por tal razón, esta obra estará compuesta por tres secciones en las que serán presentados estos tres ejes temáticos. Sobre este

\footnotetext{
${ }^{6}$ Alexy, Robert, "Five Questions", en, Ebbe Morten y Nielsen, Juul, Legal Philosophy. Five Questions, Nueva York, Automatic Press, 2007, p. 2. En adelante, FQ.

${ }^{7}$ Según Jan Sieckmann, el punto de partida de Alexy para explicar la naturaleza dual del derecho "es la «institucionalización de la razón». Esto incluye tanto elementos reales, representados por la institucionalización, y elementos ideales, pues están referidos a la razón". Esta idea rectora, bajo la cual estará representado esta sistematización de la obra de Alexy, será desarrollada a lo largo de esta obra. al respecto, cfr., Sieckmann, Jan-Reinard, "La tesis de la naturaleza dual en la teoría de Robert Alexy", en, Bernal, Carlos (Ed.), La doble dimensión del derecho. Autoridad y razón en la obra de Robert Alexy, Lima, Palestra Editores, 2011, p. 114.
} 
programa desearíamos expresar dos aclaraciones. Una está vinculada a la naturaleza de la filosofía jurídica y otra respecto a los fines de esta obra.

Sobre la cuestión acerca de la naturaleza de la filosofía del derecho, Alexy ha procurado ser claro: "[L]a filosofía del derecho, en cuanto filosofía, es una reflexión de índole general y sistemática, y tiene, exactamente como la filosofía en general, una dimensión normativa, analítica y holística. Su differentia specifica consiste en su objeto, el derecho". ${ }^{8}$ Según Alexy, la filosofía del derecho, en tanto razonamiento acerca de la naturaleza del derecho, está enfocada en los argumentos que giran en torno a tres grandes problemas. El primer problema es definido mediante la pregunta siguiente: ¿en qué tipo de entidades consiste el derecho, y cómo están conectadas estas entidades de tal modo que conforman la entidad global que llamamos «derecho»? El segundo problema está vinculado a la comprensión de la dimensión real o fáctica del derecho, y un tercer problema está vinculado a la corrección o legitimidad del derecho. Esta tríada de problemas, según Alexy, define el núcleo del problema acerca de la naturaleza del derecho, comprendida como una reflexión filosófica. $^{9}$

Este modelo triádico debe confirmar cuatro tesis. La primera es la «tesis de la naturaleza dual», según la cual todos los problemas de la filosofía pueden presentarse en la filosofía del derecho. La segunda es la «tesis del carácter específico», según la cual existen problemas específicos de la filosofía del derecho. La tercera es la «tesis de la relación especial», según la cual existe una relación especial entre la filosofía del derecho y otras áreas de la filosofía práctica, en especial, las áreas de la filosofía moral y política. La cuarta es la «tesis del ideal comprensivo», según la cual la filosofía del derecho puede tener éxito si combina las tres tesis anteriores. ${ }^{10}$ Sobre este trasfondo estudiaremos el programa de la teoría no-positivista del derecho de Alexy.

En la obra de Alexy, centrada en torno a la argumentación práRehg

ctica y jurídica, los derechos humanos y fundamentales y el concepto, naturaleza y validez del derecho, veremos cómo aparecerán los grandes temas de la filosofía del derecho. Estos temas serán esenciales para comprender el pensamiento de este filósofo

\footnotetext{
${ }^{8}$ Alexy, Robert, "Die Natur der Rechtsphilosophie", en, Brugger, Winfried, Neumann, Ulfrid y, Kirste, Stephan, Rechtsphilosophie im 21. Jahrhundert, Fráncfort del Meno, Suhrkamp, 2008, pp. 13-14. En adelante NRP

${ }^{9}$ Cfr. Alexy, Robert, NRP, pp. 15-16.

${ }^{10} \mathrm{Cfr}$. Alexy, Robert, NRP, p. 17.
} 
del derecho. Pero no sólo aparecerán los grandes problemas de la filosofía jurídica. La pretensión de Alexy de constituir un sistema de filosofía del derecho lo llevará a entablar debates con filósofos del derecho y de la filosofía moral y política. De este modo, veremos en esta obra cómo Alexy vinculará sus reflexiones filosófico-jurídicas con las de notables filósofos del ámbito de la filosofía práctica. Estos temas también nos llevarán a releer a notables pensadores de la filosofía del derecho clásica y moderna, con quienes Alexy mantendrá un diálogo constante; a diversos representantes de la filosofía moral, especialmente en las vertientes de la metaética analítica y de la ética del discurso, así como a otros destacados filósofos políticos clásicos y modernos, cuyas contribuciones a la filosofía jurídica son innegables.

Ahora deseamos explicar un aspecto fundamental de esta obra. En primer lugar, es pertinente señalar que ésta pretende mostrar por vez primera un panorama completo y sistemático de la filosofía del derecho de Alexy, útil para quienes quieran conocer este pensamiento, ya sea un público académico (estudiantes e investigadores de teoría y filosofía del derecho, o de derecho constitucional) o perteneciente al ámbito institucional (jueces de tribunales ordinarios, cortes constitucionales o estudios parlamentarios). Este objetivo, por supuesto, no ha sido fácil. Estamos hablando de una reflexión sistemática que abarca muy diversos temas de la filosofía del derecho y el derecho constitucional, por lo cual esta obra pretende ser una introducción para el público hispanohablante. Por tanto, si ésta contribuye a difundir el pensamiento de Alexy en este ámbito, así como promover un debate más informado respecto a sus premisas fundamentales, nuestro objetivo habrá sido cumplido.

Antes de terminar con esta presentación, deseamos aclarar una idea que aparecerá durante esta obra, si bien no siempre de manera explícita. Si bien vivimos aparentemente en un mundo desencantado y posmetafísico, no por ello éste es un mundo irracional y posmoral. ${ }^{11}$ Precisamente, el sistema de filosofía del derecho de Alexy intentará sostener

11 Sobre el concepto de "metafísica" usado por Alexy, es pertinente aclarar que al usar este concepto nos referimos a todas aquellas aproximaciones hacia las cuales es preciso mantener una posicion escéptica justificada. Alexy ha argumentado que autores como John Rawls, Jürgen Habermas y Günther Patzig "tenían en mente formas altamente especulativas de metafísica cuando declararon la exclusión de la metafísica de sus respectivos programas." (Alexy, Robert, "Reflections on How My Thinking about Law Has Changed over the Years", conferencia presentada en el Tampere Club Symposium organizado por Aulis Aarnio, Law, Democracy and Legal Argumentation. A Seminar dedicated to the Thinking of Professor Robert Alexy, en Finlandia, el Febrero 9 de 2010, p. 16. En adelante RTLY). En nuestro caso, usamos el concepto de metafísica 
que la razón y corrección son posibles en el discurso jurídico. Si la razón y la corrección en el discurso jurídico son posibles, entonces es posible comprender la tesis de la doble naturaleza del derecho. Si es posible comprender esta tesis de la doble naturaleza del derecho, entonces es posible dar criterios de validez de la legitimidad del derecho en los modernos Estados de derecho. Esto nos llevaría a concluir que la filosofía del derecho de Alexy, qua institucionalización sistemática de la razón práctica, constituye un garante esencial de un Estado democrático y social de derecho.

en un sentido próximo al de Habermas, esto es, como el intento injustificado de fundamentar normas jurídicas y morales por medio de argumentos basados en visiones premodernas e irracionalistas del mundo. 


\section{Primera parte}

\section{Capítulo primero. Razón y derecho. En torno al pensamiento alexyano}

\section{Introducción}

En las últimas décadas hemos presenciado un renovado y notable interés de especialistas en filosofía política y moral por aspectos relacionados con la filosofía del derecho. Como afirma Jürgen Habermas, después del esfuerzo sistemático de Wilhelm Hegel la filosofía del derecho, que durante un tiempo considerable fue un ámbito de interés exclusivo para filósofos, emigró hacia las escuelas de derecho, intentando entrar en contacto con la realidad. ${ }^{12}$ No obstante, en los últimos años este panorama ha cambiado debido al interés de los filósofos por cuestiones jurídicas. Por una parte, esto les permitió a algunos filósofos morales y políticos ver en los sistemas jurídicos una forma institucional de incorporar los fundamentos de sus teorías normativas. Por otra parte, algunos juristas dedicados a reflexiones de corte moral se percataron de las deficiencias de los presupuestos teóricos de los modelos hechos por juristas-filósofos ${ }^{13}$ y recurrieron a la filosofía moral y política con la intención de fundamentar normativamente al derecho.

Este intercambio reciente de preocupaciones entre juristas y filósofos por temas jurídicos trajo consigo una renovación de los planteamientos tradicionales: de una teoría pura del derecho, se ha pasado a otra teoría que gira en torno a teorías de filosofía moral y política; asimismo, de una filosofía del derecho ocupada meramente en el concepto de derecho, se ha pasado a otra enfocada en principios, reglas, valores, juicios morales, fundamentación, institucionalización y aplicación de los derechos fundamentales en sus

\footnotetext{
12 Habermas, Jürgen, Faktizität und Geltung. Beiträge zur Diskurstheorie des Rechts und des demokratischen Rechtstaats, Fráncfort del Meno, Suhrkamp 1992, p. 9.

${ }^{13}$ Retomamos la distinción clásica hecha por Bobbio acerca de la filosofía del derecho hecha por filósofos y la filosofía del derecho hecha por juristas. Ambas tienen sus ventajas y desventajas respectivas, pero creemos que en el intercambio reciente de posturas entre la filosofía jurídica con la filosofía moral y política, los juristas comprendieron la importancia de tomar en serio a la filosofía moral y política, debido a que en muchas ocasiones sus argumentos filosóficos no contaban con el rigor propio del quehacer filosófico. Sobre este tema, cfr. Bobbio, Norberto, Contribución a la teoría del derecho, Madrid, Debate, 1990, pp. 91-101.
} 
diversas caracterizaciones. Por tanto, ahora "puede decirse de nuevo lo que quizá nunca debió ser negado: no se puede ser filósofo del derecho si no se es filósofo moral y filósofo político, por la sencilla razón de que el pensamiento sobre la justicia se desarrolla, quizás predominantemente, en esos ámbitos". ${ }^{14}$ Del mismo modo, Robin Celikates y Stefan Gosepath afirman que si quiere comprenderse normativamente a la filosofía política no sólo hay que llevar a cabo cruces con la filosofía moral, sino con la filosofía jurídica y social. ${ }^{15}$

El vínculo entre las diversas esferas de la filosofía práctica, durante buena parte del siglo $\mathrm{XX}$, se hizo a un lado en buena medida gracias a una notable falta de interés de algunos filósofos modernos hacia la filosofía del derecho y el Estado, debido a ciertas concepciones unidimensionales acerca de la normatividad del derecho. Afortunadamente, reflexiones más críticas acerca de la filosofía práctica reconocieron la deuda moral con los clásicos de la filosofía política y enfatizaron que la justicia política requiere de una teoría crítica del derecho y del Estado, tal y como lo muestra una obra filosófica que consiguió ofrecer un certero diagnóstico acerca de la posibilidad de comprender el proyecto político de la modernidad como una filosofía política que legitime al derecho y el Estado modernos:

Si nos remontamos a Platón y Aristóteles, pasando por Agustín, Tomás de Aquino y Guillermo de Occam y, en la modernidad, por Hobbes, Spinoza, Locke, Rousseau, Kant, Hegel y Marx, hasta llegar más allá de la época de la llustración europea, los grandes filósofos se han ocupado también del derecho y el Estado y, viceversa, han sido fundamentalmente los filósofos quienes han elaborado la teoría del derecho y del Estado, y la perspectiva ética, es decir, la justicia política, ocupa en ella un lugar principal. [...] Pero esta tradición se interrumpe durante el siglo XIX, cuando los grandes filósofos de esa época se centran en el discurso sobre el derecho y el Estado sólo de un modo lateral. Más interesados en la crítica social, la hermenéutica, la fenomenología y la teoría de la ciencia, dejan en manos de los juristas la teoría del derecho y del Estado. [...] En el ámbito de la justicia política hay que considerar ambos distanciamientos y volver a reconciliar, por una parte, la filosofía con la teoría del derecho y del Estado y, por otra, a ambas con la ética. ${ }^{16}$

La reconciliación de la filosofía práctica con la teoría del derecho, y la de ambas con la ética, ha influido en la pretensión normativa de comprender la legitimidad del derecho moderno. Esta reflexión de Otfried Höffe, que en su momento fuera recibida con simpatía

\footnotetext{
${ }^{14}$ García, Alfonso (Ed.), Racionalidad y derecho, Centro de Estudios Políticos y Constitucionales, Madrid, 2006, p. 17.

${ }^{15}$ Cfr., Celikates, Robin, y Gosepath, Stefan, Grundkurs Philosophie, Band 6 Politische Philosophie, Stuttgart, Reclam, 2013, p. 33.

${ }^{16}$ Höffe, Otfried, Politische Gerechtigkeit. Grundlegung einer kritischen Philosophie von Recht und Staat, Fráncfort del Meno, Suhrkamp, 1987, pp. 13-14.
} 
por Habermas ${ }^{17}$ por reconquistar "un terreno que desde los días de Hegel la filosofía había cedido casi sin lucha a los juristas", ${ }^{18}$ nos sirve para comprender mejor la importancia de vincular al derecho con la filosofía y a ambas disciplinas con la ética, ya que toda investigación acerca de la racionalidad jurídica pertenece al ámbito de la ética jurídica, ${ }^{19}$ y esta ética jurídica pertenece al ámbito de la filosofía práctica. ${ }^{20}$ Precisamente, esta obra estará enfocada en un filósofo del derecho que ha centrado sus reflexiones en el problema de la relación entre la filosofía práctica y jurídica.

\subsection{Robert Alexy y la Escuela Moderna de Kiel. Contexto biográfico}

Robert Werner Alexy nació el 9 de septiembre de 1945 en Oldenburg, Alemania. Después de terminar sus estudios de bachillerato, estuvo tres años en el ejército federal alemán, y durante el último año alcanzó el grado de teniente. En 1968 comenzó sus estudios de derecho y filosofía en la universidad Georg-August de Gotinga; en ese mismo año también llevaría a cabo una participación activa en el movimiento estudiantil de dicha universidad. En las facultades de derecho y filosofía Alexy conocería a dos profesores que tendrían una notable influencia en su pensamiento. Estos profesores son Günther Patzig y Ralf Dreier. La influencia de ambos será descrita sintéticamente.

\subsubsection{La influencia filosófica y jurídica de Patzig y Dreier}

Por un lado, en el ámbito filosófico Patzig fue la principal influencia de Alexy, a quien conoció desde el comienzo de sus estudios en filosofía. Patzig introduciría a Alexy en el estudio de filósofos clásicos como Aristóteles, Immanuel Kant y sobre todo Gottlob Frege, así como otros filósofos en el ámbito de la filosofía analítica. Por otro lado, en el ámbito jurídico Ralf Dreier fue la principal influencia de Alexy, a quien, contrariamente al caso de Patzig, conocería casi al final de sus estudios. Al igual que Patzig, Dreier introduciría a Alexy en el

\footnotetext{
17 Cfr. Höffe, Otfried, Kategorische Rechtsprinzipien. Ein Kontrapunkt der Moderne, Fráncfort del Meno, Suhrkamp, 1995, p. 380.

18 Habermas, Jürgen, La necesidad de revisión de la izquierda, Madrid, Tecnos, 1991, p. 101.

${ }^{19}$ Cfr., Höffe, Otfried, "Vernunft im Recht?", en, Fulda, Hans y Horstmann, Rolf-Peter, Vernunftbegriffe in der Moderne, Stuttgart, Klett-Cotta, 1994, p. 573.

${ }^{20}$ Sobre la visión de Höffe acerca de la filosofía jurídica como filosofía política, cfr., "Rechtsphilosophie als Politische Philosophie“, en Kühl, Kristian (Ed.), Zur Kompetenz der Rechtsphilosophie in Rechtsfragen, Archiv für Rechts-und Sozial philosophie Nr. 126, Stuttgart, Franz Steiner Verlag, 2011, p 11.
} 
estudio de filósofos importantes para su formación, sólo que ahora sería el caso de filósofos del derecho como Hans Kelsen, Gustav Radbruch, Herbert Hart y Alf Ross. Ambos profesores trazarían un camino que Alexy seguiría posteriormente por nuevas rutas.

También puede notarse en Alexy la influencia vertiente normativa de la filosofía práctica de Kant y de la ética del discurso, así como la vertiente analítica de notables filósofos pertenecientes a la tradición de la metaética, dedicada al análisis del lenguaje normativo. El estudio de la metaética llevaría a Alexy al estudio de la ética del discurso, en la forma en la que Jürgen Habermas —quien le sugirió que su tesis doctoral fuera publicada en Suhrkamp - y Karl-Otto Apel la han desarrollado, con el objeto de incorporar las premisas normativas de esta ética de corte universalista en el discurso jurídico. Es por ello que la filosofía jurídica de Alexy suele considerarse también como una teoría discursiva del derecho. Sobre la ética del discurso volveremos más adelante en esta obra.

Del mismo modo, desde la perspectiva positivista es posible ver en Alexy la influencia del pensamiento de Kelsen, sobre todo la influencia de la etapa "clásica o neokantiana", ${ }^{21}$ si bien es cierto que lo ha estudiado para formular el no-positivismo incluyente, propuesta opuesta al positivismo jurídico kelseniano, acaso el modelo positivista más conocido en el pensamiento jurídico contemporáneo. Respecto al positivismo jurídico anglosajón, el pensamiento de Hart no le es desconocido, y hasta puede decirse que la distinción entre los puntos de vista interno y externo la ha asumido con ciertas distinciones. De cualquier manera, el positivismo jurídico hacia el cual estará más enfocada la propuesta alexyana será el formulado por Kelsen. Ahora bien, la filosofía jurídica de Radbruch también será importante para la comprensión del no-positivismo de Alexy. Del pensamiento de Radbruch dos aspectos serán relevantes para esta filosofía del derecho. En primer lugar la idea del derecho del Radbruch, contenida en sus escritos del periodo de preguerra, y, en

\footnotetext{
${ }^{21}$ Stanley Paulson ha hecho una periodización de la obra de Kelsen en tres etapas que abarcan el pensamiento kelseniano. La primera etapa, llamada "constructivismo crítico", empieza en 1911 y en ella intenta responder al positivismo jurídico que buscaba fundamentar al derecho en lo fáctico. En la segunda etapa, llamada "clásica o neokantiana", la cual empieza en 1920 y termina en 1960, intenta, por un lado, fundamentar los conceptos básicos del derecho mediante una argumentación trascendental con ayuda de diferentes doctrinas que se remontan hasta Kant y los neokantianos y, por otro lado, adopta la doctrina del escalonamiento jurídico de Julius Merkl. Finalmente, en la tercera etapa, llamada "escéptica", la cual empieza después de 1960, Kelsen asume posiciones escépticas respecto a diversos temas, entre ellos, el de la aplicabilidad de las reglas de la lógica al derecho. Sobre este tema, cfr., Paulson, Stanley, "Four Phases in Hans Kelsen's Legal Theory? Reflections on a Periodization", en, Oxford Journal of Legal Studies, Vol. 18, Oxford, 1998, pp. 153 ss.
} 
segundo lugar, la Fórmula de Radbruch, contenida en uno de sus escritos de posguerra, "Arbitrariedad legal y derecho supralegal", en el cual se aleja supuestamente de la tendencia positivista y del relativismo axiológico que había caracterizado su pensamiento anterior. ${ }^{22}$ De acuerdo con esta fórmula:

[E]l conflicto entre la justicia y la seguridad jurídica debió resolverse con la primacía del derecho positivo sancionado por la ley y la fuerza, aun cuando por su contenido sea injusto e inconveniente, a no ser que por la contradicción de la ley positiva con la justicia alcance una medida tan insoportable que deba considerarse como "derecho incorrecto" y deba ceder el paso a la justicia [...] Cuando no se procuró la justicia, donde la igualdad, que integra el núcleo de la justicia, se negó conscientemente mediante el establecimiento del derecho positivo, allí la ley no es sólo derecho incorrecto, sino que carece por completo de la naturaleza de derecho. ${ }^{23}$

De esta manera, podemos comprender la influencia de la ética discursiva y analítica, así como las versiones respectivas de positivismo y no-positivismo que marcarán, como se verá más adelante, la concepción del derecho de Alexy. A partir de estas bases surgiría no sólo una filosofía jurídica de proporciones sistemáticas, esto es, una concepción nopositivista del derecho, sino una escuela de pensamiento jurídico, enfocada en el estudio de muchos de los problemas clásicos y contemporáneos del derecho.

\subsubsection{La Moderna Escuela de filosofía del derecho de Kiel}

Después de aprobar su primer examen estatal para terminar la licenciatura en derecho en 1973, Alexy trabajó hasta 1976 en su tesis doctoral, en la Teoría de la argumentación jurídica. Esta tesis sería publicada posteriormente en 1978 y por ella recibiría en 1982 el premio de la Academia de la ciencia de Gotinga. Después de superar el segundo examen estatal en 1978, Alexy se mantendría hasta 1984 en Gotinga, tiempo en el que terminaría su tesis de habiitación en el ámbito de derecho público y filosofía del derecho, la Teoría de los derechos fundamentales. Después de rechazar una propuesta de la Universidad de Regensburg aceptó la propuesta de la Universidad Christian-Albrecht de Kiel, para ocupar

\footnotetext{
${ }^{22}$ Sobre la difundida idea de que Radbruch era un positivista Cfr., Atienza, Manuel, Curso de Argumentación Jurídica, Madrid, Trotta, 2013, p. 77. No obstante, Paulson ha indicado en variadas ocasiones que esta conversión no es de ninguna manera cierta, ya que Radbruch no era un positivista jurídico. Al respecto, cfr., Paulson, Stanley, "Ein ewiger Mythos: Gustav Radbruch als Rechtspositivist - Teil 1", en Juristen Zeitung, Nr. 3, Tubinga, Mohr Siebeck, 2008, pp. 105-116.

${ }^{23}$ Radbruch, Gustav, "Gesetzliches Unrecht und übergesetzliches Recht", en Rechtsphilosophie, Heidelberg, C. F. Müller, 2003, p. 216.
} 
la cátedra de derecho público y filosofía del derecho. Posteriormente, Alexy rechazaría propuestas de otras universidades, como la de Graz en 1991 (para ocupar la cátedra de Ota Weinberger) y la de Gotinga en 1998 (para ocupar la cátedra de Dreier). En 1992 publicaría la obra Concepto y validez del derecho, con la cual presentaría su concepción filosófica del derecho y quedaría así definida la tríada temática de su pensamiento. También con ello quedaría delineado el programa filosófico-jurídico de la Escuela Moderna de Kiel.

¿Qué se entiende por Escuela Moderna de Kiel? Tal expresión puede resultar confusa, ya que, en términos históricos, por "Escuela de Kiel" suele entenderse el conjunto de juristas nacionalsocialistas que durante la era del nacionalsocialismo ocuparon las cátedras de derecho en dicha universidad, siendo acaso Karl Larenz el representante más conocido de esta escuela. ${ }^{24}$ Tampoco, como lo ha mencionado Matthias Jestaedt, debe entenderse por "Escuela de Kiel" la descripción o "afirmación de la existencia de una comunidad cerrada de conversos, sino simplemente indicar que Alexy ha encontrado un grupo de seguidores de la teoría de los principios entre sus pupilos y colaboradores". ${ }^{25}$ Pero esta escuela no sólo abarca a seguidores y críticos de la teoría principialista, sino también de la teoría de la argumentación jurídica y del concepto y naturaleza del derecho elaborada por Alexy.

De este modo, podemos definir como "Escuela Moderna de Kiel" a todos los estudiosos del pensamiento alexyano, esta definición incluye a quienes se han formado con él en Kiel y a quienes han seguido con atención las tesis centrales de esta filosofía del derecho. La cátedra (Lehrstuhl) de derecho público y filosofía del derecho que Alexy dirigió en la universidad de Kiel comenzó en 1986 y terminó en septiembre de 2013, fecha en la cual se retiró, terminando así una era maravillosa y productiva en dicha universidad. Durante estos años Alexy tuvo una gran cantidad de notables seguidores y críticos de su obra en el ámbito del derecho constitucional y la filosofía del derecho, muchos de ellos estudiantes alemanes y extranjeros, quienes han contribuido a la recepción de la obra de Alexy en diversos ámbitos.

\footnotetext{
${ }^{24}$ Para una comprensión más adecuada de la Escuela de Kiel durante el periodo nacionalsocialista, cfr., Eckert, Jörn, "Was war die Kieler Schule?", en, Säcker, Franz Jürgen, Recht und Rechtslehre im Nationalsozialismus, Baden, Baden, Nomos Verlagsgesellschaft, 1992, pp. 37-70.

${ }^{25}$ Jestaedt, Matthias, "The Doctrine of Balancing -its Strengths and Weaknesses", en, Klatt, Matthias (Ed.), Institutionalized Reason. The Jurisprudence of Robert Alexy, Nueva York, Oxford University Press, 2012, p. 152.
} 


\subsubsection{Recepción de la obra de Alexy}

La obra de Alexy ha tenido una recepción extraordinaria. Esto se debe a la tríada temática a la que nos hemos referido, al rigor con el que Alexy ha escrito su obra, a los debates que ha tenido y, no menos importante, al considerable número de seguidores y estudiantes que ha tenido, los cuales han contribuido a difundir su pensamiento. De acuerdo con Alexy, de 1986 a 2013 su cátedra de derecho público y filosofía del derecho recibió a 148 invitados internacionales, una cifra grande pero entendible. Cabe señalar que buena parte de estos estudiantes e invitados internacionales pertenecieron al ámbito hispanoparlante y latinoamericano.

A partir de las traducciones tempranas al español por parte Manuel Atienza, Isabel Espejo ${ }^{26}$ y Ernesto Garzón Valdés, ${ }^{27}$ así como la traducción de diversos artículos por parte de otros traductores, la obra de Alexy tuvo una recepción notable en España y Latinoamérica. De este modo, el pensamiento de Alexy comenzó a estudiarse en España, mientras que en Latinoamérica tuvo un impacto inmediato en países como Colombia, Argentina y Brasil. En dichos países la recepción de la obra de Alexy no se ha limitado a la filosofía del derecho, sino que ha tenido un impacto notorio en el derecho constitucional, lo que ha provocado que con frecuencia Alexy sea citado en diversas controversias constitucionales. Mientras que en Alemania la obra de Alexy ha tenido una recepción crítica a través de estudiosos y alumnos como Martin Borowski, ${ }^{28}$ Jan-Reinard Sieckmann, ${ }^{29}$ Carsten Bäcker, ${ }^{30}$ Matthias Klatt, ${ }^{31}$ Mattias Kumm, Nils Jansen, Nils Teifke, Fiete Kalscheuer ${ }^{32}$ y otros, en países hispanohablantes y latinoamericanos la recepción crítica respectiva ha estado a cargo de autores como Alfonso García Figueroa (España), Carlos

\footnotetext{
${ }^{26}$ Manuel Atienza e Isabel Espejo llevaron a cabo la traducción de Teoría de la argumentación jurídica en 1989, para el Centro de Estudios Constitucionales.

${ }^{27}$ Ernesto Garzón Valdés Ilevó a cabo la traducción de Teoría de los derechos fundamentales para el Centro de Estudios Constitucionales en 1993 y El Concepto y la validez del derecho para la editorial Gedisa en 1994. En 2007 la Teoría de los derechos fundamentales fue traducida de nuevo por Carlos Bernal Pulido para el Centro de Estudios Políticos y Constitucionales.

${ }^{28}$ Cfr., Borowski, Martin, Grundrechte als Prinzipien, Baden-Baden, Nomos Verlagsgesellschaft, 2007.

${ }^{29}$ Cfr., Sieckmann, Jan-Reinard, Regelmodelle und Prinzipienmodelle des Rechtssystems, Baden-Baden, Nomos Verlagsgesellschaft, 1990.

${ }^{30}$ Cfr., Bäcker, Carsten, Begründen und Entscheiden. Kritik und Reconstruction der Alexyschen Diskurstheorie des Rechts, Baden-Baden, Nomos Verlagsgesellschaft, 2012.

31 Cfr., Klatt, Matthias, Theorie der Wortlautgrenze. Semantische Normativität in der juristischen Argumentation Baden-Baden, Nomos Verlagsgesellschaft, 2004.

32 Cfr., Kalscheuer, Fiete, Autonomie als Grund und Grenze des Rechts: Das Verhaltnis zwischen dem kategorischen Imperativ und dem allgemeinen Rechtsgesetz Kants, Berlín, Walter de Gruyter, 2014.
} 
Bernal Pulido, Rodolfo Arango (Colombia), Laura Clérico, Eduardo Sodero, Paula Gaido (Argentina) y Virgilio Afonso da Silva (Brasil), ${ }^{33}$ por mencionar algunos. También, la cátedra de Alexy fue un importante punto de convergencia de la filosofía jurídica, debido a la presencia de invitados de reconocida trayectoria internacional, como el caso de Stanley Paulson, quien desarrollaría vínculos permanentes con la universidad de Kiel, para beneficio de los estudiosos de la obra de Alexy.

La recepción de esta filosofía del derecho en los países latinoamericanos ha venido acompañada de un diálogo productivo y constante entre Alexy y sus estudiosos, quienes han incorporado en sus reflexiones los debates que éste ha tenido con otros autores de gran importancia para la filosofía jurídica y política contemporánea. Aunque los debates que Alexy ha tenido con autores de las más diversas tradiciones filosófico-jurídicas serán expuestos en esta obra, podemos mencionar por ahora que los tres pilares en los que está fundamentada su filosofía jurídica han sido sometidos a severas críticas.

Algunas de las tesis de la teoría de la argumentación jurídica llevaron a Alexy a debatir con Ota Weinberger, Ernst Tugendhat y Ulfrid Neumann, mientras que la teoría de los derechos fundamentales suele ser vista como la obra que más debates ha provocado en el ámbito constitucional y jurídico-filosófico, debido a las objeciones formuladas a la teoría principialista, llevadas a cabo por críticos como Habermas, Ernst-Wolfgang Böckenförde, Bernhard Schlink, entre otros. No obstante, las tesis de Alexy en torno al concepto y naturaleza del derecho también han sido objeto de crítica por parte de autores positivistas, representados principalmente por Eugenio Bulygin y Joseph Raz, así como recientemente por autores no-positivistas, como John Finnis.

En síntesis, la recepción de la obra de Alexy ha sido amplia y productiva en diversos lugares, pero en el ámbito hispanoamericano ha tenido una recepción especial, debido, en buena medida, a diversos procesos de constitucionalización y expansión de los derechos fundamentales en algunos Estados latinoamericanos; del mismo modo, el auge de una creciente cultura jurídica en torno a la argumentación jurídica, el proceder correcto de los

\footnotetext{
${ }^{33}$ Aunque Brasil no es un país de habla hispana, el pensamiento de Alexy tuvo un impacto temprano tan grande en este país que sus obras, a pesar de no estar traducidas al portugués, eran leídas en español. Aunque esta obra está pensada para el público hispanohablante, deseamos indicar que, junto con da Silva, diversos académicos brasileños han contribuido a difundir el pensamiento alexyano a través de traducciones y artículos críticos, tales como Cláudia Toledo, Júlio Aguiar de Oliveira, Alexandre Travessoni Gomes Trivisonno, entre otros.
} 
jueces y los derechos humanos ha permitido ver en el pensamiento de Alexy a un garante de estos ideales. Ahora es momento de explicar a grandes rasgos el sistema de filosofía del derecho de Alexy.

\subsection{El sistema de filosofía del derecho de Alexy}

El discurso filosófico de la modernidad ha intentado dar cuenta de la legitimidad de nuestro tiempo, reconociendo con ello la pluralidad de concepciones del mundo y el fin de los grandes relatos. ${ }^{34}$ Dentro de este contexto, el derecho puede incluirse entre uno de los criterios de legitimidad del mundo moderno, en tanto puede contribuir a institucionalizar la razón práctica en las sociedades contemporáneas. Ahora bien, la propuesta acaso más desarrollada hasta ahora de una teoría no-positivista del derecho es la filosofía jurídica de Robert Alexy, cuyas aportaciones a la teoría de la argumentación práctica y jurídica, la teoría de los derechos humanos fundamentales, y a la comprensión del concepto, naturaleza y validez del derecho permiten considerar a su obra de gran relevancia para nuestro tiempo, en tanto busca fundamentar racionalmente al derecho, tal y como lo propusieron en su tiempo las filosofías del derecho de Kant y Hegel.

Ahora bien, ¿qué es lo que ha hecho Alexy para institucionalizar la razón en los Estados democráticos y sociales? A continuación expondremos, en una pequeña síntesis, en qué consiste este planteamiento que ha llevado a diversos expertos a considerarlo una de las formulaciones teóricas más sólidas en el ambito jurídico. Aunque la idea de un sistema filosófico no es algo que esperaría encontrarse en la obra de un filósofo del derecho, el pensamiento de Alexy constituye una excepción admirable, como lo enfatiza George Pavlakos en una obra dedicada al pensamiento de Alexy:

[D]urante los últimos treinta años Alexy ha desarrollado, con una considerable claridad y consistencia, una filosofía sistemática que cubre áreas esenciales de la filosofía jurídica. De inspiración kantiana, su trabajo admirablemente combina el rigor de la filosofía analítica con un repertorio de ideales humanísticos de la tradición de las humanidades (Geisteswissenchaften), incorporándolas en una de las filosofías del derecho de mayor alcance e influencia de nuestro tiempo. ${ }^{35}$

\footnotetext{
${ }^{34}$ Cfr., Honneth, Axel, Pathologien der Vernunft. Geschichte und Gegenwart der Kritischen Theorie, Fráncfort del Meno, Suhrkamp, 2007, p. 29.

${ }^{35}$ Pavlakos, George, Law, Rights and Discourse. The Legal Philosophy of Robert Alexy (introducción), Portland, Hart Publishing, 2007, p. 1.
} 
Pavlakos no ha sido el único en notar esta cualidad distintiva del pensamiento de Alexy. Otros filósofos del derecho también han visto en éste la pretensión de fundamentar un sistema de filosofía del derecho sustentado bajo los pilares de sus tres obras principales, dedicadas a la argumentación práctica y jurídica, los derechos humanos y fundamentales y el concepto, naturaleza y validez del derecho, un sistema al que diversos expertos en filosofía del derecho han resumido bajo la frase "la institucionalización de la razón, acuñada por el mismo Alexy. Especialistas como Borowski y Bäcker así lo han considerado:

Aunque Alexy ha refinado y desarrollado después muchos elementos de su teoría en numerosos artículos y capítulos de libros, estos tres tratados representan el núcleo de su trabajo. Estos sientan las bases de las tres principales líneas de su $œ u v r e:$ la teoría del discurso, la teoría de los principios y un concepto no-positivista del derecho [...] A pesar de las dificultades para capturar el trabajo de Alexy en su complejidad plena con una simple frase, el mejor esfuerzo podría consistir en usar la propia expresión de Alexy, "la Institucionalización de la razón". ${ }^{36}$

Entretanto, a partir de esas tres ideas centrales Alexy ha elaborado a lo largo de más de cien ensayos una amplia e interconectada filosofía del derecho, cuyo núcleo central ha sido planteado mediante la expresión "Institucionalización de la razón". Bajo el título de institucionalización de la razón, o más precisamente institucionalización de la razón práctica, Alexy entiende el proceso para desarrollar la corrección práctica entre facticidad e idealidad. ${ }^{37}$

Igualmente, respecto a la sistematización del pensamiento de Alexy a partir de sus tres obras y diversos artículos, en los cuales ha refinado los planteamientos de éstas, es posible encontrar argumentos que apoyen esta consideración. Filósofos del derecho como Klatt, Sodero y García Figueroa lo han considerado así:

Toda la obra de Alexy puede ser ordenada en torno a tres lineamientos principales, relacionados con la teoría de la argumentación jurídica, la teoría de los derechos constitucionales, y el concepto y validez del derecho. Él toma estos tres lineamientos en sus tres obras principales. De hecho, las tres obras principales de Alexy no representan el sistema plenamente desarrollado de su filosofía jurídica tal y como él la ha desarrolado durante todos estos años. Por una parte, su sistema está en un estado de cambio, sometido constantemente a refinamientos y desarrollos posteriores. Por otra parte, sus tratados están complementados por un notable número de artículos en revistas especializadas. ${ }^{38}$

En 1978 Alexy publicó su «Teoría de la Argumentación Jurídica». Treinta años después puede afirmarse sin lugar a dudas que el fundador de la «segunda escuela de Kiel» ha desarrollado no sólo una de las más significativas teorías del discurso

\footnotetext{
${ }^{36}$ Borowski, Martin, “Discourse, Principles, and the Problem of Law and Morality: Robert Alexy's Three Main Works", en, Jurisprudence, 2 (2), 2011, pp. 575-595.

${ }^{37}$ Bäcker, Carsten, "Recht als institutionalisierte Vernunft", en, Archiv für Rechts- und Sozialphilosophie, Vol. 97, 2011, Heft 3, pp. 346-347.

${ }^{38}$ Klatt, Mathias, "Robert Alexy's Philosophy of Law as a System", en Klatt, Mathias (Ed.), Institutionalized Reason. The Jurisprudence of Robert Alexy, Nueva York, Oxford University Press, 2012, p. 2.
} 
jurídico, sino también esencialmente casi un sistema de filosofía del derecho, lo cual representa una rara avis en la filosofía jurídica de nuestro tiempo. ${ }^{39}$

Los trabajos de Robert Alexy forman un sistema. Este sistema se asienta sobre una filosofía moral, una teoría de la argumentación jurídica, una teoría del derecho y una teoría de los derechos fundamentales. ${ }^{40}$

Esta pretensión de desarrollar un sistema, en cuanto busca abarcar la totalidad del fenómeno jurídico, aspira a presentarse como una concepción sistemática no-positivista del derecho. Si tomamos en cuenta que un sistema es, tout court, un conjunto de elementos cuya relación e interacción entre sí, de tal modo que pueden contemplarse como una unidad de objetivos o tareas, entonces es posible afirmar que estamos ante un sistema normativo del derecho, en tanto los elementos de este pensamiento están relacionados entre sí e interactúan constantemente con el objetivo de mostrar la doble dimensión del derecho. Esto se verá durante el transcurso de esta obra. Ante el declive del derecho natural ${ }^{41}$ y las limitaciones normativas del positivismo jurídico el pensamiento de Alexy buscará plantear una solución al problema de la normatividad del derecho. ${ }^{42}$ Tales exigencias normativas propiciarán que los juristas teóricos y prácticos se interesen por la obra de Alexy, ya que en ella encontraremos el desarrollo de los problemas más importantes de la filosofía del derecho. El interés de Alexy por estos temas estará conectado con la pretensión de rehabilitar a la razón práctica en el ámbito jurídico.

\subsection{Estructura y metodología del programa de la filosofía jurídica alexyana}

\footnotetext{
39 Sodero, Eduardo, "Alexy und die Rehabilitierung der Frage nach dem Rechtsphilosophie", en, Laura y Sieckmann, Jan-Reinard (Eds.), Grundrechte, Prinzipien und Argumentation. Studien zur Rechstheorie Robert Alexys, Baden-Baden, Nomos Verlagsgesellschaft, 2009, p. 195.

${ }^{40}$ García Figueroa, Alfonso, “¿Existen diferencias entre reglas y principios en el Estado constitucional? Algunas notas sobre la teoría de los principios de Robert Alexy", en, Alexy, Robert, Derechos sociales y ponderación, Madrid, Fundación Coloquio Jurídico Europeo, 2007, p. 334. En este trabajo, Figueroa cita una entrevista de Manuel Atienza a Alexy, en la cual este último afirma querer articular un sistema de filosofía jurídica.

${ }^{41}$ En este sentido, tal vez Bernhard Windscheid fue el primero de los grandes juristas del siglo XIX en declarar tal declive al considerar que el sueño del derecho natural terminó, a pesar de los esfuerzos titánicos titánicos de los filósofos por tomar el cielo por asalto. Cfr., Winscheid, Bernhard, "Über Recht und Rechtswissenschaft, 1854, en, Gesammelte Abhandlungen, Leipzig, Duncker \& Humblot, 1904, p. 9

42 En el ámbito de la filosofía práctica el concepto de normatividad posee una carga moral, es decir, este concepto se refiere a la fuerza normativa de los argumentos ofrecidos en los ámbitos de la moral, la política y el derecho. No obstante, en el ámbito jurídico a veces el concepto de normatividad se refiere a la mera existencia de normas, independientemente de su fundamentación moral. Agradezco a Jesús Rodríguez sus comentarios sobre este tema, ya que contribuyeron a aclarar estos malentendidos conceptuales creados en el cruce de las reflexiones filosóficas y jurídicas. Para una mejor comprensión del concepto de normatividad en la filosofía y las ciencias sociales, y en especial en el caso del derecho, cfr., Turner, Stephen, Explaining the Normative, Cambridge, Polity Press, 2010, pp. 66-94.
} 
Ahora explicaremos brevemente la estructura y metodología de esta filosofía jurídica. Primero comenzaremos con la estructura y luego con la metodología. Durante los siguientes capítulos comenzaremos con el análisis sistemático de la filosofía jurídica de Alexy, contenida en sus tres pilares: 1. la teoría de la argumentación práctica y jurídica, 2. la teoría de los derechos humanos y fundamentales y 3 . el concepto, naturaleza y validez de derecho. La estructura de esta filosofía del derecho estará basada en las relaciones existentes entre estos tres pilares. También, durante esta obra podremos notar cómo Alexy ha ido conectando las premisas principales de cada uno de estos pilares. Esto es, veremos cómo una teoría de la argumentación práctica y jurídica presupone una teoría de los derechos humanos y fundamentales, y cómo una teoría de los derechos humanos y fundamentales presupone una teoría de la argumentación práctica y jurídica. También, ambas teorías presuponen una concepción no-positivista de derecho, sustentada en la tesis de la doble naturaleza del derecho, concepción esencial del proyecto alexyano.

La tesis de la doble naturaleza del derecho, según la cual el derecho tiene una doble dimensión, será un elemento necesario de esta concepción no-positivista. A pesar de que esta tesis ha cobrado notoriedad en los últimos años, ${ }^{43}$ el núcleo normativo de ésta es reconocible en el punto de vista moral asumido en las reflexiones de Alexy en torno a la argumentación jurídica, los derechos fundamentales y su concepción del derecho, sólo que ahora esta dimensión ha sido presentada de forma explícita. Efectivamente, el derecho posee una dimensión fáctica, expresada mediante la coerción institucional, un primer elemento necesario en todo ordenamiento jurídico, pero del mismo modo el derecho posee una dimensión ideal, expresada mediante la pretensión de corrección, un segundo elemento necesario, según Alexy, en todo ordenamiento jurídico. Ante esta dimensión ideal, racional del derecho, los positivistas plantearán una serie de objeciones que analizaremos con mayor calma, en tanto ésta formará parte de esta reflexión sistemática.

Dentro de esta estructura sistemática, serán incorporaradas las pretensiones de seguridad jurídica y de justicia, las cuales forman parte del positivismo y no-positivismo. Por un lado, la teoría de Alexy aceptará la exigencia del no-positivismo excluyente de que la

\footnotetext{
${ }^{43}$ Esta tesis acerca de la doble naturaleza del derecho podemos encontrarla en trabajos relativamente recientes como "La naturaleza de la filosofía del derecho" (2004), "Acerca de dos yuxtaposiciones: concepto y naturaleza, derecho y filosofía. Algunos comentarios acerca de ¿Puede haber una teoría del derecho? De Joseph Raz" (2007), "Sobre el concepto y la naturaleza del derecho" (2008) y “La naturaleza dual del derecho" (2010). No obstante, este tema será de nuevo desarrollado en el capítulo noveno de esta obra.
} 
pretensión de justicia sea un elemento constitutivo del derecho, Ésta representará a la dimensión ideal del derecho; por otro lado, la teoría de Alexy integrará del positivismo jurídico la exigencia de que la seguridad jurídica ayude a proveer a los sistemas jurídicos de un mínimo de eficacia, sin que ello implique que la seguridad jurídica sea imponderable ante otros criterios, como es el de la justicia. Ésta representará a la dimensión fáctica del derecho.

Ahora bien, explicaremos qué postura metodológica estará presente a lo largo de esta filosofía jurídica. Alexy partirá de una metodología tridimensional, la cual consiste en tres perspectivas que constantemente aparecerán en la obra de Alexy. En la Teoría de la argumentación jurídica ${ }^{44}$, la Teoría de los derechos fundamentales ${ }^{45}$ y Concepto y validez del derecho ${ }^{46}$ encontraremos la tesis de la tridimensionalidad, la cual vincula con la obra Derecho, moral, ideología. Estudios sobre teoría del derecho de Dreier. ${ }^{47}$ Para Alexy la dimensión normativa tendrá como objetivo la fundamentación y crítica de la praxis jurídica, la dimensión analítica la estructuración sistemática del sistema jurídico y el análisis de los conceptos fundamentales y, finalmente, la dimensión empírica el conocimiento del derecho positivo vigente.

La tesis de la tridimensionalidad del derecho funcionará como un criterio distintivo de tres ramas distintas del derecho: la filosofía del derecho, la teoría del derecho y la sociología del derecho. ${ }^{48}$ La ventaja de usar esta metodología reside en comprender al derecho en sus diversas dimensiones. De acuerdo con una obra dedicada al análisis de este enfoque, el derecho significa, en un primer sentido, normatividad, es decir, en algo debido, prescrito y deóntico, expresado en un lenguaje moral; en un segundo sentido,

\footnotetext{
${ }^{44}$ Alexy, Robert, Teoría de la argumentación jurídica. La teoría del discurso racional como teoría de la fundamentación jurídica, Lima, Palestra, 2007, p. 346. En adelante, TAJ.

45 Alexy, Robert, Teoría de los derechos fundamentales, Madrid, Centro de Estudios Políticos y Constitucionales, 2008, p. 13. En adelante, TDF.

${ }^{46}$ Alexy, Robert, El concepto y la validez del derecho, Barcelona, Gedisa, 2008, p. 87. En adelante, CVD En este caso, aquí Alexy habla de tres conceptos de validez del derecho, los cuales, están asociados con las tres perspectivas metodológicas del derecho: la perspectiva normativa con la validez ética del derecho, la perspectiva analítica con la validez jurídica o sistemática del derecho y la perspectiva empírica con la validez sociológica del derecho. Este punto será retomado en la sección tercera de esta obra.

${ }^{47}$ Cfr., Dreier, Ralf, Recht-Moral - Ideologie. Studien zur Rechtstheorie, Fráncfort del Meno, Suhrkamp, 1981, p. 10 ss.

${ }^{48}$ Sobre esta distinción, Alexy remite no sólo a la obra previamente citada de Dreier, sino a las obras de sociología jurídica de Hans Rottleuthner (Rechtstheorie und Rechtssoziologie) y Manfred Rehbinder (Rechtssoziologie).
} 
derecho significa razón, es decir, en una sistematicidad lógica compuesta de términos precisos; en un tercer sentido, derecho significa facticidad, en decir, en un regulador y resultado de las relaciones entre el derecho y la sociedad. ${ }^{49}$ Aunque en Teoría de la argumentación jurídica Alexy ha expresado que la postura empleada por él en esa obra fue de corte analítico-normativa, ${ }^{50}$ en la Teoría de los derechos fundamentales ha expresado que si la ciencia del derecho tiene que cumplir racionalmente con su tarea práctica, entonces debe vincular a estas tres dimensiones. ${ }^{51}$ De hecho, veremos cómo Alexy ha recurrido a casos concretos para explicar los problemas respectivos de la ponderación y de la Fórmula de Radbruch. Ahora explicaremos la pretensión alexyana de institucionalizar la razón práctica en el derecho, o, dicho de otro modo, de otorgarle legitimidad al derecho mediante la institucionalización.

Alexy intentará dar respuesta al problema de la legitimidad del derecho moderno mediante la institucionalización de la razón práctica en los sistemas jurídicos. Si Niklas Luhmann consideraba que la legitimidad es posible mediante procedimientos, ${ }^{52}$ en el caso de Alexy la legitimidad estará mediada por la pretensión de corrección. Esta pretensión la ha dejado clara en sus tres obras principales, y en el centenar de artículos en los cuales ha refinado sus argumentos, al mismo tiempo que los ha integrado en una reflexión sistemática en torno al derecho. Hemos optado por presentar esta reflexión como un sistema porque, en primer lugar, los temas de la tríada alexyana se encuentran profundamente relacionados entre sí e interactúan de tal manera en su obra que pueden contemplarse como una unidad normativa que busca hacer explícita la doble naturaleza del derecho, y, en segundo lugar, porque tales temas abarcan los núcleos básicos de la teoría y filosofía del derecho. En la filosofía jurídica es posible encontrar un núcleo de problemas básicos universales que han sido presentados en todas las reflexiones sobre el derecho, y la filosofía del derecho de Alexy ha planteado una postura comprensiva respecto a estos problemas que, tout court, se refieren a lo que es y debe ser el derecho, con el objeto de institucionalizar la razón práctica.

\footnotetext{
${ }^{49}$ Cfr. Kunz, Karl-Ludwig y Mona, Martino, Rechtsphilosophie, Rechtstheorie, Rechtssoziologie, Berna, UTB, 2006, p. 5 ss.

${ }^{50}$ Alexy, Robert, TAJ, p. 46.

${ }^{51}$ Alexy, Robert, TDF, p. 17.

${ }^{52}$ Cfr., Luhmann, Niklas, Legitimation durch Verfahren, Fráncfort del Meno, Suhrkamp, 1997, p. 27 ss.
} 
Esta pretensión sistemática, siempre abierta a nuevas determinaciones, también tendrá otro objetivo: desarrollar una teoría discursiva no-positivista del derecho, en oposición al positivismo jurídico en sus diversas variantes. ${ }^{53}$ Esta "etiqueta" podría provocar algunos malentendidos conceptuales, ya que, en muchas ocasiones, el no-positivismo suele ser identificado como derecho natural, algo que no debe interpretarse como tal. La doctrina del derecho natural puede comprenderse como una forma de no-positivismo, pero no todo no-positivismo es derecho natural. En todo caso, en buena parte de sus concepciones, la doctrina clásica del derecho natural es un ejemplo de no-positivismo excluyente del elemento de la seguridad e incertidumbre jurídicas ${ }^{54}$ o una especie de nopositivismo súper incluyente como el representado por John Finnis, según el cual la validez jurídica no es afectada por defecto moral alguno, razón por lo cual, respecto a la validez jurídica, no existen diferencias entre el positivismo y el no-positivismo súper incluyente. ${ }^{55}$ En cambio, la reflexión de Alexy sobre filosofía del derecho intentará fundar un nopositivismo incluyente que incluya tanto a la seguridad jurídica como a la pretensión de corrección. Podemos finalizar este capítulo sosteniendo que estas serán las premisas fundacionales de la institucionalización de la razón, ${ }^{56}$ la cual será el objeto de estudio de esta obra. Ahora es momento de analizar el discurso práctico racional, base del discurso jurídico.

\footnotetext{
53 Dentro del positivismo jurídico moderno existen dos categorías: el positivismo excluyente de la moral y el positivismo incluyente de la moral. El positivismo incluyente de la moral podría parecer idéntico al nopositivismo incluyente, pero esto no es así, ya que, a diferencia del no-positivismo incluyente -el cual sostiene que la moral está necesariamente incluida en la naturaleza del derecho-, el positivismo incluyente, en la versión sostenida por Jules Coleman, sostiene que la moral no está excluida ni incluida necesariamente, sino que esta inclusión es un asunto contingente o convencional. Sobre este positivismo incluyente, cfr., Coleman, Jules, "Authority and Reason", en, George, Robert, The Autonomy of Law, Oxford, Clarendon Press, 1996, p. 316.

${ }^{54}$ Alexy ha mencionado que un ejemplo de no-positivismo excluyente lo encontramos en la obra de Deryck Beyleveld y Roger Brownsword, quienes han sostenido, casi del mismo modo de Radbruch, que "[L]as reglas inmorales no son jurídicamente válidas". (Beyleveld, Deryck y, Brownsword, Roger, Law as Moral Judgement, Sheffield, Sheffield Academic Press, 2001, p. 76).

${ }^{55} \mathrm{Cfr}$., Alexy, Robert, "Some Reflections on the Ideal Dimension of Law an on the Legal Philosophy of John Finnis, en, The American Journal of Jurisprudence, Vol. 58, No. 2, 2013, p. 105. En adelante, SRIDL.

${ }^{56}$ También, en algún momento Alexy se ha referido a su filosofía del derecho como "liberalismo analítico" (analytischen Liberalismus), pero ya no lo ha hecho después. Al respecto, cfr., Alexy, Robert, Recht, Vernunft, Diskurs. Studien zur Rechtsphilosophie, Fráncfort del Meno, Suhrkamp, 1995, p. 2. En adelante, DRD.
} 


\section{Capítulo segundo. Del discurso práctico racional al discurso jurídico}

\section{Introducción}

En este capítulo señalaremos cómo comenzó a plantearse el interés por la argumentación jurídica a través de algunas obras de Perelman, Viehweg y Toulmin, analizaremos la influencia de la metaética analítica y la ética del discurso en la obra de Alexy, y terminaremos con el análisis de la tesis del caso especial. Precisamente, el paradigma argumentativo obtuvo un impulso notable por parte de juristas y filósofos que intentaron justificar la racionalidad de las valoraciones morales en el derecho, y, con ello, prepararon el camino de esta reflexión en torno al auge actual de la argumentación jurídica.

\subsection{Los orígenes de las teorías modernas de la argumentación jurídica}

A partir de los años setenta, década en la que el interés por la argumentación jurídica comenzó a crecer por parte de los abogados y teóricos del derecho ${ }^{57}$ se ha hecho explícita una preocupación de los juristas por comprender la naturaleza del razonamiento práctico y jurídico para fundamentar soluciones a los problemas surgidos en la esfera de lo jurídico. Ahora bien, ¿en qué consiste resolver un problema jurídico y qué relación tiene con el tipo de razonamiento requerido? Una posible respuesta es la siguiente:

Resolver un problema jurídico $(\mathrm{P})$ significa que la norma jurídica $(\mathrm{N})$ se aplica al caso (C) constituida por los hechos $(\mathrm{H})$. Si es necesaria una solución, ésta tiene que justificarse por medio de razones $(R)$ ya sean provenientes de la autoridad o sustantivas. Estas razones dan apoyo en diferente medida a la solución (S) en cuestión. Esta actividad, la de fundamentar una solución, es llamada comúnmente razonamiento jurídico. ${ }^{58}$

Por ahora la idea de Aaulis Aarnio nos servirá para explicar esta actividad. La idea de razonamiento jurídico, está intrínsecamente vinculada con la práctica de dar razones acerca de cuestionamientos vinculados a acciones humanas, en las cuales nos vemos a diario implicados. En términos generales, por argumentar "cabe entender la manera de dar cuenta y razón de algo a alguien con el propósito de lograr su comprensión y asentimiento.

\footnotetext{
${ }^{57}$ Feteris, Eveline, Fundamentals of Legal Argumentation. A Survey of Theories on the Justification of Judicial Decisions, Dordrecht, Springer, 1999, p. 13.

${ }^{58}$ Aarnio, Aulis, Derecho, Racionalidad y Comunicación Social. Ensayos sobre Filosofía del Derecho, México, D. F., Fontamara, 2000, p. 47.
} 
La argumentación es la acción de argumentar o el propósito de esta actividad." 59 Ahora bien, esta aplicación de la práctica de dar razones en el ámbito jurídico tendrá sus diferencias con las argumentaciones que se dan en otros ámbitos, sin embargo, para Alexy la argumentación racional en el ámbito jurídico será posible siempre y cuando tenga ciertas características, que veremos con mayor atención.

En el derecho la argumentación tiene efectos en la teoría y práctica. En el aspecto teórico podríamos decir que, grosso modo, la argumentación jurídica sirve para fundamentar modelos explicativos o valorativos del derecho, configurar las bases de una rama específica del derecho y darle coherencia sistemática al ordenamiento jurídico de una sociedad política. En el aspecto práctico la argumentación jurídica aparece primeramente en el campo de la fundamentación de normas jurídicas por parte del poder legislativo, posteriormente en el aspecto de la positivización de las normas, es decir, en la forma en la cual el derecho es establecido legalmente. Finalmente, la argumentación jurídica es necesaria para la interpretación y aplicación de las normas jurídicas al caso concreto mediante la subsunción, ponderación y comparación de casos por parte de quienes tienen la obligación de fundamentar sus juicios frente a otros.

Es en este último aspecto práctico de la argumentación jurídica, dirigido a la comprensión de los fundamentos de la racionalidad de la interpretación y aplicación de las normas, en donde surgen cuestionamientos respecto a la posibilidad de fundamentar racionalmente las valoraciones inherentes a los argumentos jurídicos. Es por ello que comenzaremos ahora con la rehabilitación de la filosofía práctica en el ámbito del derecho. La teoría de la argumentación jurídica de Alexy, sin embargo, no ha sido la única que ha sido elaborada en el ámbito jurídico, así como tampoco la única que ha hecho explícita la compatibilidad que existe entre la argumentaciones hechas en el ámbito jurídico y las que se realizan en otros ámbitos prácticos, como son el ámbito moral y el político, pero sí es la que ha llevado más lejos las consecuencias del razonamiento jurídico y la que más ha enfatizado en retomar elementos de otras formas de argumentación racional e incorporado en una teoría moral-procedimental. Es por ello que ahora explicaremos cómo fue desarrollada esta teoría.

\footnotetext{
59 Vega, Luis, "Argumento/Argumentación", en, Reñón, Luis y Olmos Paula (Eds.), Compendio de lógica, argumentación y retórica Madrid, Trotta, 2011, p. 66.
} 
Lo que hoy se entiende por teoría de la argumentación jurídica, indica Atienza, tiene su origen en una serie de obras de los años cincuenta que tienen en común el señalar la insuficiencia de la lógica formal como instrumento para analizar los razonamientos jurídicos en casos complejos. Las tres concepciones más relevantes de esta rehabilitación de la racionalidad práctica en el derecho son la tópica de Theodor Viehweg, la nueva retórica de Chaim Perelman y la analogía jurídica de Stephen Toulmin. ${ }^{60}$ Independientemente de sus diferencias metodológicas, en las obras principales de Viehweg y Perelman dedicadas a la argumentación jurídica, y en la obra de Toulmin dedicada a la argumentación práctica, es posible notar la crítica a la lógica deductiva por su incapacidad de fundamentar las valoraciones en todo el campo del derecho.

Como sabemos, en los ámbitos del derecho y de la ética existen algunos casos que tratan con enunciados que no son verdaderos o falsos, y es por ello que al intentar establecer criterios para determinar cómo deben solucionarse los conflictos es posible proponer, por un lado, que las argumentaciones del juez estén determinadas sólo por la intención del autor de la ley y el significado del texto legal y, por otro lado, que la discrecionalidad del intérprete decidirá el criterio último del discurso. De cara a estas posturas será necesario fundamentar racionalmente la argumentación jurídica.

Perelman, desde una postura que llamará la nueva retórica, la cual tendrá por objetivo rehabilitar el uso de la retórica, criticará al positivismo por "limitar el papel de la lógica, el método científico y de la razón a problemas de conocimiento puramente teórico y negar el uso práctico de la razón”, ${ }^{61}$ y llegará a la conclusión de que no existe una lógica formal de los juicios de valor, sino que en todos aquellos prácticos es necesario recurrir a técnicas argumentativas llevadas a cabo mediante razonamientos dialécticos que establecezcan un acuerdo entre quien proporciona argumentos y el Auditorium (concepto de importancia especial para la ética del discurso) el cual deberá mostrarse convencido y no persuadido- de las razones dadas. Para Perelman la argumentación será necesaria a falta de técnicas de razonamiento universalmente válidas. Por ello definirá a la tópica como un conjunto de "técnicas discursivas que tratan de provocar y acrecentar la adhesión de los espíritus a tesis que se presentan para su asentimiento". ${ }^{2}$ Aunque la valoración del

${ }^{60}$ Cfr., Atienza, Manuel, Las razones del derecho. Teorías de la argumentación jurídica, Lima, Palestra, 2006, p. 67.

${ }^{61}$ Perelman, Chaim, La lógica jurídica y la nueva retórica, Madrid, Civitas, 1979, p. 134.

62 Perelman, Chaim, op. cit. p. 139. 
positivismo jurídico de Perelman es reduccionista, es meritorio rescatar su intento de señalar "la importancia de la nueva retórica como instrumento de la razón práctica y especialmente enfatizar en el significado de ésta para la lógica jurídica” ${ }^{63}$

Por otra parte, Viehweg partirá de la convicción de que no se ha logrado hasta ahora formular un sistema de fundamentación lógica del derecho, puesto que no es posible poner todos los "ámbitos jurídicos bajo unos axiomas y conceptos fundamentales unitarios", ${ }^{4}$ ya que el ordenamiento jurídico es una pluralidad de sistemas en donde el alcance de las deducciones formales es muy limitado. Por ello sostendrá la tesis de que la tópica, concepto que retoma tanto de Aristóteles como de Cicerón, ${ }^{65}$ no puede ser eliminada del mundo del derecho, ya que es imprescindible para el cálculo lógico. Por esta razón, Viehweg concebirá a la tópica como una técnica cuya finalidad radicará en orientar la acción frente a razonamientos en los cuales surjan contradicciones o paradojas (aporías). Aunque la obra de Viehweg subestima la importancia de la ley, la dogmática y los precedentes, y tampoco penetra en la estructura de los argumentos ni en el concepto de discusión, es rescatable la tesis de la tópica acerca de no permitir que las fundamentaciones jurídicas queden abandonadas en el campo de la decisión irracional. ${ }^{66}$

Toulmin, desde el ámbito de la argumentación práctica, sostendrá en Los usos de la argumentación que en los procesos jurídicos la aceptabilidad de la argumentación no depende de su validez lógica. ${ }^{67}$ Para sostener esta pretensión, Toulmin apelará a tomar el modelo propio del derecho, porque la lógica no es otra cosa más que una jurisprudencia generalizada. ${ }^{6}$ Esta afirmación justificará la creencia posterior de que "los procesos judiciales son sólo una clase especial de debates racionales en los que los procedimientos y reglas de la argumentación se han fosilizado al convertirse en instituciones". ${ }^{69}$ Aunque

\footnotetext{
63 Perelman, Chaim, Juristische Logik als Argumentationslehre, Friburgo/Múnich, Verlag Karl Alber, 1979, p. 137.

${ }^{64}$ Viehweg, Theodor, Tópica y jurisprudencia, Madrid, Taurus, 1964, p. 113

65 Cfr., Viehweg, Theodor, Topik und Jurisprudenz. Ein Beitrag zur rechtswissenschaftlichen Grundlagenforschung, Múnich, C. H. Beck'sche Verlagsbuchhandlung, 1978, p. 6

${ }^{66}$ Cfr., Alexy, Robert, TAJ, p. 57.

${ }^{67}$ Cfr., Feteris, Eveline, op. cit., p. 40.

68 Según Toulmin, "[L]a lógica, podríamos decir, es una jurisprudencia generalizada: los argumentos pueden compararse con las demandas judiciales, y las afirmaciones que se realizan y argumentan en contextos extralegales, con afirmaciones hechas ante los tribunales, mientras que en los casos presentados para apoyar cada tipo de afirmación pueden ser comparados entre sí". Toulmin, Stephen, Los usos de la argumentación, Barcelona, Península, 2003, p. 24.

${ }^{69}$ Toulmin, Stephen, op. cit., p. 25.
} 
Toulmin no fue un filósofo del derecho, las relaciones que estableció entre la argumentación práctica y jurídica sirvieron como un referente para que ambas puedan verse como compatibles, es por ello que el modelo toulminiano de argumentación es de gran utilidad para la argumentación práctica y jurídica.

Estas teorías de la argumentación, sin embargo, fueron insuficientes para comprender el funcionamiento de los argumentos jurídicos ante casos difíciles en los que una norma debe interpretarse o en los que dos o más normas pueden ser aplicables al caso, porque si bien es un hecho que la lógica deductiva, criticada por estas teorías, no es adecuada para dar cuenta de la totalidad del razonamiento jurídico, es necesario agregar otro tipo de premisas. Dichas teorías de la argumentación, a pesar de sus diferencias entre sí, mostraron que el derecho posee una racionalidad crítica, la cual implica un uso propio de la razón, y que tiene semejanzas con la de otras disciplinas pertenecientes al ámbito de la filosofía práctica, anticipándose así a lo que en los años sesenta en el ámbito alemán y después hacia otros países del centro de Europa se moverá bajo el signo de la "rehabilitación de la razón práctica". ${ }^{70}$ Esta rehabilitación de la razón práctica en el ámbito del derecho permitió concebir a la argumentación jurídica como una útil "forma de razonamiento, y por ello un recurso de gran interés para los filósofos. ${ }^{71}$ Precisamente, la búsqueda de la racionalidad jurídica logró que surgieran a finales de los años setenta diversas obras sobre la argumentación jurídica a las que Manuel Atienza ha llamado teorías estándar de la argumentación jurídica, ${ }^{72}$ destacando entre ellas la obra de Alexy.

En 1978 son publicadas dos obras fundacionales para el ámbito de la argumentación jurídica: la primera de ellas es Razonamiento jurídico y teoría del derecho de Neil MacCormick y la segunda es la Teoría de la argumentación jurídica. La teoría del discurso racional como teoría de la fundamentación jurídica de Alexy, cuyo manuscrito fue presentado como tesis doctoral en 1976. Cada uno de estos autores proviene de tradiciones filosóficas y jurídicas distintas: en el caso de MacCormick, quien junto con su doctoranda

\footnotetext{
${ }^{70} \mathrm{Cfr}$. , Höffe, Otfried, El proyecto político de la modernidad, Buenos Aires, FCE, 2008, p. 9. Podemos señalar como manifiesto de este movimiento a la obra de Manfred Riedel, Rehabilitación de la razón práctica.

${ }^{71}$ MacCormick, Neil, Legal Reasoning and Legal Theory, Oxford, Oxford University Press, 1994, p. 7.

${ }^{72}$ Atienza, Manuel, Las razones del derecho. Teorías de la argumentación jurídica, Lima, Palestra, 2006, p. 167.
} 
Ruth Adler hizo la traducción de la obra de Alexy al inglés, ${ }^{73}$ las referencias fundamentales son Hume, Hart y la tradición del common law, en el caso de Alexy, los referentes son Kant, Habermas y la dogmática jurídica alemana; ${ }^{74}$ sin embargo, ambas teorías llegan a los mismos resultados en algunos puntos esenciales ${ }^{75}$ y concluyen en formular teorías normativas de la argumentación jurídica, en tanto están enfocadas en distinguir los argumentos correctos de los incorrectos, analíticas, porque se preocupan por estudiar la estructura de los argumentos, y, hasta cierto grado, empíricas, porque incorporan elementos existentes en el ámbito jurídico. ${ }^{76}$

El interés de Alexy por la argumentación lo llevó a elaborar previamente con Aulius Aarnio y Alexander Pekzecnik una obra que suele considerarse como el "manifiesto de la teoría de la argumentación jurídica", ${ }^{77}$ La fundamentación del razonamiento jurídico. ${ }^{78}$ Pero entre ellos habrán diferencias notables: mientras que para Aarnio el concepto wittgensteniano de forma de vida juega un papel decisivo, y en Pekzecnik el de cultural progress, en la teoría de Alexy veremos una orientación definitiva por el concepto de racionalidad práctica; ${ }^{79}$ realizar esta concepción en el ámbito de la argumentación jurídica llevará a Alexy a elaborar un imponente sistema filosófico jurídico, objeto de esta obra.

\footnotetext{
${ }^{73}$ De hecho, a partir de un encuentro en 1979 con Alexy, Peczenik y Aarnio, MacCormick indica que para él fue claro que los cuatro tenían puntos en común respecto al razonamiento jurídico y esto lo llevó a escribir el primer escrito en inglés dedicado a la obra de Alexy, titulado, "Legal Reasoning and Practical Reason". Al respecto, cfr., MacCormick, Neil, "Five Questions, Ebbe Morten y Nielsen, Juul, Legal Philosophy. Five Questions, Nueva York, Automatic Press, 2007, p. 177.

${ }^{74}$ Atienza, Manuel, “Argumentación jurídica”, en El derecho y la justicia, Edición de Ernesto Garzón Valdés y Francisco Laporta, Madrid, Trotta, 2000, p 234.

75 "La cuestión acerca de hasta qué punto las tesis aquí expuestas son conciliables o hasta coinciden con las de Neil Maccormick quedará aquí abierta. Sin embargo, sin necesidad de llevar a cabo un detallado análisis comparativo, puede afirmarse que ambas teorías llegan a los mismos resultados en algunos puntos esenciales, tales como el que la argumentación jurídica no siempre exactamente proporciona una respuesta correcta" (Alexy, Robert, Derecho y razón práctica, México, D. F., Fontamara, 2006, p. 72. en adelante, DRP).

${ }^{76}$ En este punto podemos ver una aplicación de la metodología tridimensional que indicábamos al final del capítulo pasado.

${ }_{77}^{7}$ Farrali, Carla, La filosofía del derecho contemporánea. Temas y desafíos, Bogotá, UEC, 2007, p.68.

${ }^{78}$ Esta obra fundacional tuvo su impulso a partir de cuatro momentos claves: la rehabilitación de la filosofía práctica, el debilitamiento de la división entre posiciones analíticas y hermenéuticas, la inclusión de aspectos históricos y sociológicos en cuestiones concernientes a la teoría de la ciencia y al contacto entre la filosofía analítica y la teoría crítica. Estas posturas, que llevan al estudio de filósofos de corrientes tan diversas como Manfred Riedel, Henrik von Wright, Thomas Kuhn, Imre Lakatos y Habermas, serán tomadas en cuenta para la fundamentación de esta perspectiva. Al respecto, cfr., Alexy, Robert, Aarnio Aulis y Peczenik Aleksander, "The Foundation on Legal Reasoning", en Rechtstheorie 12, Berlín, Duncker \& Humblot, 1981, p. 134. En adelante, FLR.

${ }^{79}$ Alexy, Robert, DRP, p. 72.
} 
Para Alexy, el objeto de su tesis doctoral, la Teoría de la argumentación jurídica, está constituido por tres preguntas fundamentales: ¿dónde y en qué medida son necesarias las valoraciones? ¿Cómo actúan estas valoraciones en los argumentos jurídicos? y ¿son racionalmente fundamentables estas valoraciones ${ }^{80}$ Estas tres preguntas corresponden a un intento de combinar aspectos jurídicos con posturas filosóficas para construir una teoría capaz de dar cuenta de la racionalidad del discurso jurídico.

Alexy propondrá, en síntesis, que las razones que lo que cuente en las decisiones judiciales sean las razones de los argumentos fundados y justificados racionalmente, de las razones válidas expresadas hacia los otros como fundamentación de las decisiones jurídicas, Ahora serán explicados dos aspectos básicos de la teoría de la argumentación jurídica de Alexy. El primero consiste en explicar la influencia de la teoría discursiva de Habermas, y después definir qué quiere decir Alexy cuando sostiene que la argumentación jurídica es un caso especial de argumentación práctica.

\subsection{El giro comunicativo: de la ética del discurso a la filosofía del derecho}

Para comprender la teoría de la argumentación jurídica de Alexy es indispensable conocer sus fundamentos. En este sentido, Alexy ha expresado de manera sintética los fundamentos filosóficos de su pensamiento:

"Quien eche un vistazo a mi libro Teoría de la argumentación jurídica se da cuenta enseguida de que hay, esencialmente, dos corrientes que me han marcado: la filosofía analítica y la teoría crítica, en la forma que le ha dado Habermas. En la época en la que escribí el libro, las dos corrientes eran ampliamente percibidas como posiciones contrapuestas. Hoy la cosa es de otra forma". ${ }^{81}$

Aunque existen diversas corrientes filosóficas que convergen en la teoría de la argumentación jurídica de Alexy, y es posible sostener, de acuerdo con él mismo, ${ }^{82}$ que buena parte de los razonamientos normativos desarrollados en esta obra estuvieron influidos por la teoría del discurso de Habermas y en menor medida por la metaética de

\footnotetext{
${ }^{80}$ Alexy, Robert, TAJ,p. 36.

${ }^{81}$ Atienza, Manuel, "Entrevista a Robert Alexy", incluida en TAJ, p. 501.

${ }^{82}$ Al respecto, esto ha expresado Alexy: "[L]a teoría del discurso, tal y como fue concebida en Teoría de la argumentación jurídica, se inspiró no solamente en Habermas, sino también en la metaética analítica (especialmente la de Hare), en la escuela de Erlangen (en particular por el constructivista Lorenzen) y en la nueva retórica de Perelman" (Alexy, Robert, RTLY p. 2).
} 
Hare ${ }^{83} \sin$ duda existe un pensamiento filosófico que merece especial importancia para la formulación de esta filosofía jurídica. Nos referimos a la ética del discurso desarrollada por Habermas. Por esta razón plantearemos en términos esenciales la aportación de la ética del discurso al discurso jurídico.

En su inspiración original, la ética del discurso representó una respuesta al escepticismo proveniente de la reducción positivista de la razón a los dominios científicos y tecnológicos. En cierta manera, pensadores como Habermas y Apel pertenecen a una corriente filosófica que se ha negado a renunciar a fundamentar el proyecto filosófico de la modernidad, y por ello han combatido las concepciones escépticas que reducen el uso práctico de la razón a una postura emotivista. William Rehg ha explicado el esfuerzo de la ética del discurso del siguiente modo:

No obstante, para la ética del discurso tales esfuerzos fueron motivados por la esperanza de suministrar a la teoría crítica de fundamentos de un concepto amplio de racionalidad suficiente para escapar a las paradojas sustentadas por la anterior Escuela de Fráncfort. En todo caso, las especies particulares de escepticismo moral encontradas en los anteriores oponentes científicos han sido reemplazadas en el nivel filosófico por formas de pensamiento agrupadas en términos generales bajo la etiqueta de "posmodernismo". Cualesquiera que hayan sido las posiciones que el cognitivismo moral haya ganado en contra del escepticismo valorativo positivista, son una vez más amenazadas por variantes derivadas de Nietzsche. ${ }^{84}$

El postulado principal de la ética del discurso consiste en la pretensión de evitar que la razón capitule ante la crítica de posturas escépticas o posmodernas, y esto llevará a Habermas a plantear una serie de formulaciones éticas de alcance universal, en el sentido de que ellas pretenden ser válidas para todos los seres humanos, en todas partes y para todos los tiempos, inmanentes en los contextos comunicativos, pero con una validez

${ }^{83}$ Consideramos que en el campo de la filosofía jurídica Alexy ha hecho un proyecto parecido en ciertos aspectos no sólo al de Habermas, sino también al de Hare. Por una parte, así como Hare intenta responder a la pregunta acerca de si es posible o no fundamentar racionalmente los enunciados morales, Alexy intenta responder a la pregunta acerca de si es posible fundamentar racionalmente los argumentos jurídicos. Por otra parte, así como Alexy intenta exponer en la Teoría de la argumentación jurídica un conjunto de reglas de razón práctica y jurídica, como uno de los resultados de esta investigación, Hare tuvo un objetivo parecido en el desarrollo de su obra: "[M]i propia estrategia ha sido la de presentar la lógica de los conceptos morales como los tenemos, y mostrar que ellos pueden generar ciertos cánones de razonamiento moral que pueden llevarnos a adoptar cierto método de razonamiento moral sustancialmente normativo" (Hare, Richard, Moral Thinking. Its Levels, Method and Point, Oxford, Clarendon Press, 1988, p. 20). Por otra parte, según David Richards, "Hare es la influencia central de la teoría semántica del razonamiento práctico de Alexy, mientras que la ética del discurso de Habermas es la inspiración de su teoría normativa" (Richards, David, "Review: Robert Alexy, A Theory of Legal Argumentation", en, Ratio Juris No. 2, 1989, p. 306).

${ }^{84}$ Rehg, William, Insight and Solidarity. The Discourse Ethics of Jürgen Habermas, California, University of California Press, 1994, pp. 21 y 22. 
trascendente a tales contextos. La teoría del discurso parte de postulados de corte universalista al afirmar que todos los seres humanos a) participamos a diario en las prácticas de argumentar, b) estas prácticas presuponen ciertos elementos universales que pueden ser expresados mediante reglas, y c) estas prácticas argumentales, mediadas por reglas, están orientadas por los ideales regulativos de la verdad o corrección.

El reconocer que a diario participamos en formas de vida universales supone que debemos recurrir a aserciones mediadas a través de reglas que plantean pretensiones de verdad o corrección, lo cual implica encuadrar la teoría de los actos del habla en una teoría racional de la comunicación, capaz de distinguir entre acciones, entendidas como juegos de lenguaje, en los que las pretensiones de validez de los actos de habla se reconocen tácitamente, y discursos, en los cuales las pretensiones de validez problemáticas deben justificarse ante todos los participantes. La diferenciación entre discurso y acción le permitirá a la ética del discurso sostener que una proposición normativa puede fundamentarse racionalmente.

Esto constituye un avance importante en el ámbito de la filosofía moral, pues permite reconocer que a pesar de que las proposiciones normativas no son susceptibles de verdad ${ }^{85}$ no implica que éstas no puedan fundamentarse. Dicho en otras palabras, la ética del discurso intentará evitar que la fundamentabilidad de las normas morales y jurídicas caiga en alguno de los cuernos del Trilema de Münchhausen en los respectivos campos éticos y jurídicos.

Para Habermas, el método principal de comunicación es mediante actos de habla, expresión que retoma de John Austin y John Searle. Para los tres tipos de actos de habla hay tres tipos de modos de comunicación caracterizados por su respectivo contenido. El modo cognitivo de comunicación se relaciona con los actos de habla constativos que establecen un hecho, el modo expresivo de comunicación con actos de habla expresivos relacionados con el mundo interno del hablante, y el modo interactivo de comunicación con actos de habla regulativos. Estos tres tipos de acto de habla representan algo, expresan la intención del hablante y establecen conexiones entre el hablante y el oyente. Ahora bien,

\footnotetext{
${ }^{85}$ No obstante, a partir de las críticas de Albrecht Wellmer, Cristina Lafont y Lutz Wingert, Habermas se desistió de la idea acerca de una relación entre verdad y consenso (Cfr., Heidemann, Carsten "The Concept of Validity in a Theory of Social Action", en Pavlakos, George (Ed.), Law, Rights and Discourse. The Legal Philosophy of Robert Alexy, Oxford, Hart Publishing, 2007, p. 306).
} 
para que el acto de habla pueda ser entendido, el hablante debe garantizar tres pretensiones: para la función cognitiva debe entablar una pretensión de verdad, justificándola dando razones; para el componente expresivo debe sostener una pretensión de sinceridad, justificándola al actuar consecuentemente; finalmente, para la función interactiva, debe sostener una pretensión de corrección normativa, justificándola en caso de que sea necesario. El reconocimiento de estas pretensiones en los actos de habla permite comprender que "entendemos un acto de habla cuando sabemos qué es lo que lo hace aceptable" ${ }^{86}$

El descubrimiento, siguiendo a Wittgenstein y Austin, de una doble estructura proposicional-performativa del habla referida a un estado de cosas y a la relación del hablante con el oyente, fue el primer paso de Habermas para traer elementos pragmáticos al análisis formal del lenguaje. ${ }^{87}$ Según Habermas, entender un acto de habla al considerarlo "aceptable" demuestra que la existencia de la sociedad sólo es posible gracias el entendimiento entre los sujetos a través de la mediación lingüística, cuyo objetivo tiende al telos del entendimiento; sin embargo, para alcanzarlo se requieren plantear pretensiones de validez que el oyente pueda aceptar como válidas.

Basándose en el esquema funcional del lenguaje de Karl Bühler, quien clasifica las expresiones lingüísticas de acuerdo a sus relaciones con el hablante, el mundo y el oyente, Habermas establece tres criterios de validez de acuerdo a las aserciones hechas en los actos de habla. De esta manera, el hablante establecerá una pretensión de verdad al hablar del mundo objetivo o de un estado de cosas determinado, una pretensión de sinceridad al referirse al mundo subjetivo de experiencias al que sólo el hablante tiene acceso, y, finalmente, una pretensión de corrección al referirse al mundo intersubjetivo regulado por normas vinculantes, dejando de lado la pretensión de inteligibilidad y la pretensión de

\footnotetext{
${ }^{86}$ Según Habermas, "[L]a aceptabilidad no se define en sentido objetivista, desde la perspectiva de un observador, sino desde la actitud realizativa de un participante de la comunicación. Llamaremos «aceptable» a un acto de habla cuando cumple las condiciones necesarias para que un oyente pueda tomar postura con un sí frente a la pretensión que a ese acto vincula el hablante. Estas condiciones no pueden quedar cumplidas de forma unilateral, es decir, ni sólo relativamente al hablante, ni sólo relativamente al oyente; sino que más bien son condiciones del reconocimiento intersubjetivo de una pretensión lingüística que, de forma típica a los actos de habla, establece un acuerdo, especificado en cuanto a su contenido, sobre las obligaciones relevantes para la interacción posterior" (Habermas, Jürgen, Teoría de la acción comunicativa, I. Racionalidad de la acción y racionalización social, México, D. F., 2005, p. 382).

${ }^{87}$ Cfr., Habermas, Jürgen, Postmetaphysical Thinking. Philosophical Essays, Cambridge, The MIT Press, 1994, p. 46 .
} 
adecuación a estándares de valor. Estas pretensiones de validez aspiran a ser universales respecto a lo que debe considerarse como verdadero, veraz y correcto, a diferencia de las acciones estratégicas, las cuales no cumplen con estos requisitos. Habermas cita como ejemplo de acciones estratégicas las argumentaciones planteadas por sujetos particulares ante los tribunales de justicia. Sin embargo, la lectura posterior que hizo Habermas de la Teoría de la argumentación jurídica de Alexy lo convenció de dejar de lado esta visión unilateral hacia la argumentación jurídica:

La argumentación ante un tribunal (al igual que otras formas de discusión jurídica como, por ejemplo, las deliberaciones de los jueces, las discusiones dogmáticas, los comentarios a las leyes) se distingue de los discursos prácticos generales por su vinculación al derecho vigente y también por otras restricciones especiales que les impone el orden procesal, las cuales explican la necesidad de una decisión dotada de autoridad y que en la litispendencia las partes puedan orientarse en función del éxito. ${ }^{88}$ No obstante lo cual, la argumentación ante un tribunal contiene elementos esenciales que sólo pueden ser aprehendidos según el modelo de la argumentación moral y, en general, de la discusión sobre la rectitud de enunciados normativos. De ahí que todas las argumentaciones, ya versen sobre cuestiones de derecho o de moral, o sobre hipótesis científicas u obras de arte, exijan la misma forma de organización básica de una búsqueda cooperativa de la verdad que subordine los medios de la erística al objetivo de obtener convicciones intersubjetivas basadas en los mejores argumentos. ${ }^{89}$

En esta cita puede apreciarse que Habermas no sólo reconoce que las argumentaciones ofrecidas ante los tribunales no pueden reducirse a meros discursos estratégicos, sino que también poseen elementos compatibles con el esquema de un modelo de argumentación moral. De esta manera, Habermas admitirá que el discurso jurídico contiene elementos morales, si bien estos elementos no pueden sustituir las características específicas de la argumentación jurídica. La inclusión de postulados de la ética del discurso a la teoría del discurso jurídico de Alexy es de una importancia notable. Sin embargo, las premisas universalistas de la ética del discurso pueden ser puestas en duda por escépticos que consideren que el discurso racional es imposible de justificar, ya

\footnotetext{
${ }^{88}$ En esta parte Habermas escribe la siguiente nota: “[E]sta circunstancia me había movido en un principio a considerar la vista de una causa como una acción estratégica (HABERMAS, LUHMANN, Theorie der Gesellschaft, 1971, 200 s.). Mientras tanto R. ALEXY (1978), 263 ss., me ha convencido de que las argumentaciones jurídicas, en todas sus acuñaciones institucionales, han de entenderse como un caso especial de discurso práctico".

${ }^{89}$ Habermas, Jürgen, Teoría de la acción comunicativa, I. Racionalidad de la acción y racionalización social, México, D. F., 2005, p. 59.
} 
que detrás de la idea de universalidad pueden esconderse una especie de dictadura de la racionalidad ${ }^{\rho 0}$ o una falta de fundamentación racional.

Uno de los argumentos escépticos más recurridos para refutar a los cognitivistas éticos se encuentra en la obra de Hans Albert, Tratado de la razón crítica, en la cual Albert presenta un trilema que enfrentan los cognitivistas éticos al intentar otorgarle validez universal a determinados principios morales. En esta obra, Albert expone el trilema de Münchhausen, el cual surge cuando la fundamentación moral de determinados argumentos cae en alguno de los siguientes cuernos, basados en el concepto de la secuencia lógica: éstos consisten en que, en la búsqueda por fundamentar un principio moral, el cognitivista puede caer en el error de aceptar un regreso infinito a los fundamentos, recurrir a un razonamiento circular en el cual el fundamento y su prueba se fundamentan recíprocamente, o quebrar arbitrariamente la secuencia de inferencias mediante la ruptura del proceso en un punto determinado. ${ }^{91}$ Ante las consecuencias negativas de caer en alguno de los cuernos de este trilema, ¿qué es lo que puede ofrecer la ética del discurso?

Uno de los objetivos de la ética discursiva consiste en la fundamentación racional de las argumentaciones éticas o jurídicas sin caer en un corte dogmático, un regreso infinito o un razonamiento circular planteados por este trilema; para lograrlo, la ética discursiva ha recurrido a un argumento de corte pragmático-trascendental, basado en el "hecho de la razón”. Es así como Apel explicará la idea de la contradicción performativa. Como Habermas indica en Ética del discurso. Notas sobre un programa de fundamentación, Apel tiene el mérito de liberar la dimensión de la fundamentación no deductiva de las normas éticas elementales y refutar las críticas de los escépticos y promotores de la razón derrotista. $^{92}$ La salida posible de los cuernos del citado trilema es posible, según Apel, si recurrimos al uso de la contradicción performativa. Esta idea consiste en que en el momento en el cual un escéptico ético afirma que no es posible dar una fundamentación de algún postulado universal incurre en una contradicción performativa, esta es realizada cuando el cognitivista le señala al escéptico que "en la medida en que éste participa en la discusión,

\footnotetext{
${ }^{90}$ Tomamos este término a partir de las objeciones planteadas por Carsten Bäcker respecto a los problemas de la fundamentación última (Letztbegründung). Sobre estas objeciones, cfr., Bäcker, Carsten, Begründen und Entscheiden. Kritik und Reconstruction der Alexyschen Diskurstheorie des Rechts, Baden-Baden, Nomos Verlagsgesellschaft, 2012, p. 175 ss

${ }_{91}$ Albert, Hans, Traktat über kritische Vernunft, Tubinga, J. C. B. Mohr, 1991, p. 15.

${ }^{92} \mathrm{Cfr}$., Habermas, Jürgen, Conciencia moral y acción comunicativa, Barcelona, Planeta - De Agostini, 1994, p. 102.
} 
tiene que establecer presupuestos inevitables en cada discusión sometida a comprobación práctica y cuyo contenido propositivo contradice el postulado del falibilismo". ${ }^{93}$

Efectivamente, con el simple hecho de participar en una discusión con el cognitivista, ya sea para continuar manifestando que no puede hablarse de nada "universal" ni "válido", o que cada quién puede creer y hacer lo que desee con el otro, ${ }^{94}$ el escéptico debe reconocer y aceptar como válidas una cantidad mínima de reglas necesarias para seguir adelante con la discusión en términos de un procedimiento argumentativo. En caso de que el escéptico niegue la validez de esas normas, acabaría por refutarse a sí mismo y caería en una contradicción performativa., ya que ni siquiera sus argumentos en contra del cognitivista podrían sostenerse o tomarse en serio.

En caso de que no estemos ante un escéptico consecuente o un fanático dispuesto a morir en aras de sus ideales, ${ }^{95}$ éste debe reconocer un mínimo de argumentos para que el otro pueda entenderlo. Esto presupone un punto de vista procedimental-moral acerca de las reglas de un discurso racional. La introducción de la idea de la contradicción performativa, considerada por Alexy como un método que tiene el objeto de "hacer explícito lo implícito", 96 permite fundamentar valoraciones jurídicas. Pero no sólo eso. La idea de la contradicción performativa también será usada por Alexy en su crítica al positivismo jurídico para mostrar que un contenido extremadamente injusto del derecho constituye una falla conceptual en el derecho mismo.

De acuerdo con los teóricos de la ética del discurso, el trilema de Münchhaussen puede ser refutado al fundamentar ciertos presupuestos discursivos necesarios mediante una argumentación de tipo trascendental, ya que la validez de estas reglas es condición necesaria de la comunicación lingüística entre los participantes. En Teoría de la argumentación jurídica Alexy se inclina por el concepto de "fundamentación pragmático universal" de Habermas, quien a diferencia de Apel niega que los argumentos de los principios de universalidad y discurso puedan considerarse como trascendentales. Alexy toma en consideración la duda de Habermas respecto al uso que Apel le da al concepto de

\footnotetext{
${ }^{93}$ Habermas, Jürgen, ob. cit., p. 103.

${ }^{94}$ Para ver más críticas al relativismo moral-cultural, cfr., Rojas, Mario, la razón ético-objetiva y los problemas morales del presente. Crítica ético-racional del relativismo moral-cultural, México, D. F., Ítaca, 2011, p. 57 ss.

${ }^{95}$ Sobre el argumento del fanatico, para quien los argumentos están de más, cfr., Hare, Richard, Freedom and Reason, Oxford, Oxford University Press, 1963, p. 170 ss.

${ }^{96}$ Alexy, Robert, NRP, p. 22.
} 
"trascendental". El malentendido conceptual reside en que el concepto "trascendental" no tiene en la ética discursiva el sentido kantiano atribuido usualmente (condiciones de posibilidad de la experiencia), sino el sentido de condiciones de posibilidad de la argumentación (mediación de la filosofía trascendental kantiana con el giro lingüístico). ${ }^{97}$ Es tal vez por ello que Alexy en el Postfacio vuelve a retomar el término "trascendental" de Apel y deja de lado la concepción de Habermas:

Hoy prefiero la expresión «pragmático-trascendental», pues se trata de una variante de un tipo de argumentación general, es decir, de una variante del argumento trascendental. El argumento pragmático trascendental se apoya en dos premisas. La primera dice que aquel que efectúa afirmaciones y fundamentaciones se inserta necesariamente en un juego que se define a través de reglas del discurso. La segunda dice que es necesario efectuar afirmaciones y fundamentaciones en el siguiente sentido: quien a lo largo de su vida no plantea ninguna afirmación seria y no da ninguna fundamentación seria, no toma parte de lo que podría llamarse la «la forma de vida más general de los hombres».98

Independientemente del tipo especial de fundamentación del discurso jurídicopragmático al que se referirá Alexy — aunque se inclina por la concepción de Apel—y los problemas normativos que esto podría tener, el argumento pragmático-trascendental será indispensable para fundamentar premisas universalistas frente a objeciones escépticas. Es por esta razón que Alexy insistirá en una fundamentación pragmático-trascendental débil. Las reglas del discurso, desarrolladas en el próximo capítulo, serán universales por estructurar un código de la razón práctica inherente a toda forma de vida humana.

Del mismo modo, la ética del discurso recurrirá a la filosofía del derecho para fortalecer la filosofía moral y política que sustenta. Si bien desde los primeros escritos de Habermas encontramos referencias sobre el derecho, como en Cambio estructural del espacio público. Investigaciones sobre una categoría de la sociedad burguesa, ${ }^{99}$ y también es posible encontrar estas referencias en la tradición de la Teoría crítica, ${ }^{100}$ éste no ocupaba

\footnotetext{
${ }^{97}$ Cfr., Vigo, Rodolfo, La injusticia extrema no es derecho. De Radbruch a Alexy, México, D. F., Fontamara, 2008, pp. 104 y 105.

${ }^{98}$ Alexy, Robert, TAJ, p. 437.

99 Cfr., Habermas, Jürgen, Strukturwandel der Öffentlichkeit.Untersuchungen zur einer Kategorie der bürgerlichen Gesellschaft, Fráncfort del Meno, Suhrkamp, 1971, p. 94 ss.

100 Sobre este punto, nos ha llamado la atención el trabajo de Gustavo Leyva, "Pasado y presente de la teoría crítica. Tres vertientes de reflexión para la crítica en el presente" en el que afirma lo siguiente: "[L]as reflexiones en torno a la Filosofía del Derecho y a la Filosofía Política han acompañado a la Teoría Crítica desde sus inicios. No hay que pensar más que en el vasto espectro que se abre con los trabajos de colaboradores del "círculo externo» como Franz Neumann y Otto Kirchheimer, pasa por el diálogo de Jürgen Habermas con John Rawls y abarca incluso la incorporación de Hanna Arendt en una línea que la coloca al lado de Claude Lefort y
} 
un lugar sobresaliente. Sin embargo, después de algunas críticas formuladas a la Teoría de la acción comunicativa, según las cuales esta teoría sería "ciega ante la realidad de las instituciones —una objeción de cuño hegeliano planteada en Alemania entre otros por Rüdiger Bubner-, ${ }^{101}$ o bien tendría consecuencias de carácter anarquista al someter a una justificación comunicativa principios irrenunciables del Estado de derecho moderno", ${ }^{102}$ Habermas comienza a desarrollar un tipo de planteamientos que intentarán dar respuesta a la ceguera institucional y jurídica de la ética del discurso.

Como es sabido, a partir de Conciencia moral y acción comunicativa Habermas utiliza el esquema de las seis etapas del desarrollo moral de Lawrence Kohlberg ${ }^{103}$ como una referencia fundamental para entender los sistemas morales y jurídicos. Ahora bien, en la etapa sexta del nivel post-convencional, Kohlberg explica que en ella se da una orientación de la conciencia moral de los sujetos hacia principios éticos universales. Según esta etapa:

A principios del mundo moderno ciertas esferas de la interacción están estructuradas postconvencionalmente - esferas de acción estratégica (tales como la empresa capitalista) son reguladas en términos universalistas, y existen inicios de una formación de la voluntad política basada en principios (democracia formal); las doctrinas legitimadoras del dominio responden a esquemas universalistas (derecho natural racional, por ejemplo); los conflictos se regulan desde el punto de vista de una estricta separación de legalidad y moralidad (derecho general, formal, y racionalizado; moralidad privada guiada por principios). ${ }^{104}$

\footnotetext{
Cornelius Castoriadis, para corroborar la verdad de esta afirmación". (Leyva, Gustavo, "Pasado y presente de la teoría crítica. Tres vertientes de reflexión para la crítica en el presente", en, Leyva, Gustavo (Ed.) La Teoría Crítica y las tareas actuales de la crítica, Barcelona, Anthropos, 2005, p. 110).

${ }^{101}$ Bubner, Rüdiger, Antike Themen und ihre moderne Verwandlung, Fráncfort del Meno, Suhrkamp, 1992, p. 188 ss.

102 Leyva, Gustavo, "Jürgen Habermas: espacio público y democracia”, en, Rendón, Jorge (Ed.), filosofía política: sus clásicos y sus problemas actuales, México, D. F., Casa Juan Pablos y UAM Iztapalapa, 2007, p. 261. ${ }^{103}$ De acuerdo con Elliot Turiel, a pesar de las notables semejanzas entre los proyectos de Jean Piaget y Kohlberg respecto al problema del desarrollo de la conciencia moral de los invididuos durante el transcurso de sus vidas, Kohlberg fue más explícito acerca de la necesidad de una epistemología moral que implicase propiedades definitorias en los análisis del desarrollo moral. También, a diferencia de Piaget, Kohlberg reconoció que el problema del tránsito del "ser al deber ser" debía ser abordado por los psicólogos desarrollistas para comprender mejor al desarrollo moral. Al respecto, cfr., Turiel, Elliot, "The Multiplicity of Social Norms: The Case for Psychological Constructivism and Social Epistemologies", en, Smith, Leslie, y Vonèche, Jacques, Norms in Human Development, Cambridge, Cambridge University Press, 2009, p. 192.

${ }^{104}$ McCarthy, Thomas, La teoría crítica de Jürgen Habermas, Madrid, Tecnos, 2002, p. 295. Esta diferenciación entre la legalidad y moralidad en el nivel postconvencional de Kohlberg será de gran importancia comprender uno de los argumentos a favor de la distinción normativa entre derecho y moral por parte del positivismo jurídico.
} 
La separación estricta entre el derecho formal y la moral guiada por principios constituye una forma racional de regular los conflctos que ocurren en la sociedad. No obstante, la ética del discurso requiere del derecho para no quedar impotente ante la falta de coacción moral. Es en este punto en el que el derecho cumple una función básica de acuerdo con la ética del discurso. Por esta razón Habermas ha reconocido que la tesis doctoral de Alexy lo llevó a "extender la ética del discurso, la cual fue diseñada originalmente para el ámbito de lo moral, al derecho y al Estado constitucional". Adicionalmente, "su Teoría de los derechos fundamentales me ayudó a entender la dialéctica de la igualdad jurídica y fáctica". ${ }^{105}$ Sin embargo, la incursión que Habermas tuvo en temas centrales de la filosofía jurídica provocará una tensión entre ambas teorías discursivas del derecho, sobre todo, respecto a la ponderación de las normas fundamentales, en tanto son concebidas por Alexy como mandatos a optimizar. ${ }^{106}$ Eso lo veremos con mayor atención en el capítulo sexto de esta obra.

Respecto a la comprensión del derecho como un elemento de la ética de la discurso, Höffe ha sostenido que la ética del discurso tiene menos dificultades cuando se concibe el objeto de la naturaleza social de ésta: una "ética del derecho y del Estado", ${ }^{107}$ tal y como lo mostró Facticidad y validez de Habermas. De igual manera, Alexy ha sostenido que "el discurso necesita del derecho para alcanzar la realidad, y el derecho necesita del discurso para lograr legitimidad". ${ }^{108}$ Después del análisis de las premisas básicas de la ética del discurso, veremos bajo qué bases Alexy fundamenta la argumentación jurídica. Para

105 Habermas, Jürgen, "Reply to Simposium Participants", en Rosenfield, Michel y Arato, Andrew (Eds.), Habermas on Law and Democracy, Massachussetts, MIT, 1998, p. 428.

${ }^{106}$ Si desea obtenerse una visión de la filosofía jurídica de Habermas pueden consultarse las siguientes obras: Lieber, Tobias, Diskursive Vernunft und formelle Gleichheit. Zu Demokratie, Gewalteinteilung und Rechtsanwendung in der Rechtstheorie von Jürgen Habermas, Tubinga, Mohr Siebeck, 2007. Wagner, Andreas, Recht - Macht - Öffentlichkeit. Elemente demokratischer Staatlichkeit bei Jürgen Habermas und Claude Lefort, Stuttgart, Franz Steiner Verlag, 2010. Schaal, Gary (Ed.), Das Staatsverständnis von Jürgen Habermas, BadenBaden, Nomos Verlagsgesellschaft, 2009. Neves, Neves, Marcelo, Zwischen Themis und Leviathan: Eine schwierige Beziehung. Eine Rekonstruction des demokratischen Rechtstaates in Auseinandersetzung mit Luhmann und Habermas, Baden-Baden, Nomos Verlagsgesellschaft, 2000; Sobrevilla, David, La filosofía del derecho alemana actual de orientación racionalista. Estudios sobre R. Alexy, K. Günther, J. Habermas y $O$. Höffe, México, D. F., Fontamara, 2008; Arato, Andrew y Rosenfeld, Michel (eds), Habermas on Law and Democracy. Critical Exchanges, California, California University Press, 1998; y Castillejos, Francisco, La Ratio luris en la era de la postmetafísica. Jürgen Habermas y la nueva fundamentación teórico-discursiva de la filosofía del derecho, México, D. F., UAM/Tirant lo Blanch, 2014.

107 Cfr., Höffe, Otfried, Kategorische Rechtsprinzipien. Ein Kontrapunkt der Moderne, Fráncfort del Meno, Suhrkamp, 1995, p. 379

${ }^{108}$ Alexy, Robert, "La institucionalización de la razón", en, Persona y derecho, Navarra, Universidad de Navarra, número 43, 2000, p. 237. 
ello, especificaremos las tres características de la argumentación jurídica, entendida como un caso especial de discurso práctico.

\subsection{La tesis del caso especial del discurso jurídico}

Según la tesis del caso especial, el derecho es una especie de discurso práctico, el cual está sujeto en todo momento a las limitaciones que el mismo sistema jurídico le impone. Esta tesis es de especial importancia para la obra de Alexy. En una entrevista reciente, Alexy ha dicho que en Teoría de la argumentación jurídica intentó defender dos tesis aparentemente contradictorias. Según la primera tesis, la argumentación jurídica no es posible sin argumentos prácticos generales, mientras que según la segunda tesis, la argumentación jurídica debe tomar en serio la validez del derecho positivo. Esta relación de tensión entre ambas tesis puede deshacerse por medio de la tesis del caso especial. ${ }^{109}$ Para comprender los diversos tipos de perspectivas sobre el discurso jurídico, Alexy presentará las perspectivas empírica, analítica y normativa, aplicadas al ambito de la argumentación.

\subsubsection{Las diversas perspectivas de los discursos jurídicos}

La perspectiva será empírica cuando en ella se describan o expliquen la frecuencia, uso y efecto de determinados argumentos, la motivación que se ofrece para utilizarlos y, sobre todo, las concepciones dominantes en determinados grupos sobre la validez de los argumentos. La perspectiva analítica consistirá en que en ella se comprenda la estructura lógica de los argumentos llevados a cabo, o posibles en un discurso jurídico. La perspectiva normativa consistirá en establecer y fundamentar criterios para la racionalidad del discurso jurídico. El método que escogerá Alexy estará guiado por un modelo "analítico-normativo" que partirá de la plausibilidad de la fundamentación racional del discurso jurídico, así como del análisis de la estructura lógica de las fundamentaciones ofrecidas. Para esta perspectiva será importante comprender la al discurso jurídico como una especie especial de discurso práctico; para desarrollar esta perspectiva, pasaremos a la siguiente parte.

\footnotetext{
${ }^{109}$ Alexy, Robert, "Entrevista a Aguiar de Oliveira e a Travessoni Gomes Trivisonno, en, Alexy, Robert, Teoría discursiva do direito, Forense Universitaria, Rio de Janeiro, 2014, p. 359. En adelante, EAOTG
} 


\subsubsection{El contenido de la tesis del caso especial}

Según Ulfrid Neumann, "[Q]uien argumenta como jurista toca inevitablemente con el trasfondo de determinados conceptos de derecho, así como con la base de una determinada posición filosófica-jurídica. Esta relación entre la argumentación prácticojurídica y un concepto de derecho se mantiene típicamente latente". ${ }^{110}$ La tesis del caso especial será de importancia central no solamente para la argumentación jurídica, sino para la teoría de los derechos fundamentales y el concepto no-positivista de derecho, esto es, para la teoría no-positivista del derecho de Alexy. Como lo ha sostenido recientemente Alexy, "el núcleo de la teoría de la argumentación jurídica es la tesis del caso especial. La tesis del caso especial expresa una conexión necesaria entre derecho y moral". ${ }^{111}$

De esta manera Alexy considerará que lo que tienen en común los razonamientos jurídicos y prácticos es la corrección de los enunciados normativos, así como características especiales que diferenciarán al discurso jurídico del moral. Estas características especiales crearán tres formas de relacionar los argumentos jurídicos con los prácticos. La primera y más deficiente relación es la de la tesis de la secundariedad, según la cual la fundamentación jurídica sólo legitima secundariamente un resultado obtenido primeramente por medio de los criterios prácticos generales. La segunda relación es la llamada tesis de la adición, según la cual ante las limitaciones del discurso jurídico debemos recurrir a la argumentación práctica. La tercera relación, que será la adoptada por Alexy, es la tesis de la integración, la cual consiste en unir en todos los niveles el uso de los argumentos jurídicos con los prácticos para lograr una fundamentación racional. ${ }^{112}$

La tesis de la integración de los argumentos jurídicos con los prácticos requiere una explicación del contenido de la tesis del caso especial. Los tres elementos definitorios de la idea alexyana de concebir la argumentación jurídica como un caso especial se sustentan en tres características constitutivas. La primera afirma que el derecho necesita del ejercicio de la razón práctica, ya que éste trata siempre con cuestiones prácticas; en segundo lugar,

\footnotetext{
${ }^{110}$ Neumann, Ulfrid, „Theorie der juristischen Argumentation“, en, Brugger, Winfried, Neumann, Ulfrid, y Kirste, Stephan (Eds.) Rechtsphilosophie im 21. Jahrhundert, Fráncfort del Meno, Suhrkamp, 2008, p. 233.

${ }^{111}$ Alexy, Robert, "As dimensões real e ideal do direito", en, Princípios formais e outros aspectos da Teoria Discursiva do Direito, Forense Universitaria, Rio de Janeiro, 2014 p. 136. Discurso llevado a cabo por Robert Alexy durante la concesión del doctorado Honoris Causa por la UFMG, en la ceremonia realizada en la facultad de derecho, el día 10.02.2014. En adelante, DRID.
}

${ }^{112}$ Alexy, Robert, TAJ, p. 51 
que la argumentación jurídica, como toda argumentación práctica en general, establece una pretensión de corrección; y, en tercer lugar, que la argumentación jurídica tiene limitaciones especiales que la distinguen de otras formas de argumentación práctica. Estos tres contenidos serán expuestos como la referencia a cuestiones prácticas, la pretensión de corrección y las diferencias o limitaciones institucionales.

La referencia a cuestiones prácticas en el derecho. En ocasiones, cuando se habla de un tema jurídico controvertido en la sociedad, cualquier persona es capaz de expresar su respectivo sentir al recurrir a la "razón práctica", mediante la cual es posible resolver conflictos en los diversos ámbitos humanos. Precisamente, esto es lo que quiere decir Alexy en la primera parte de la tesis del caso especial. En cuestiones de derecho siempre se tratan cuestiones prácticas, es decir, sobre lo que en una sociedad es ordenado, prohíbido o permitido.

En las controversias jurídicas el tema de fondo son cuestiones prácticas, y con frecuencia, cuando los argumentos jurídicos son insuficientes para dar una respuesta razonable, los argumentos provenientes de un sentido moral pueden ayudar a fundamentar racionalmente los discursos jurídicos. Es por ello que la referencia en el derecho a cuestiones prácticas es poco discutible actualmente. El concepto de razón práctica de Alexy conecta el derecho a problemas cotidianos en los cuales el sistema jurídico, normas jurídicas individualizadas o fallos jurídicos, están vinculados con aspectos en los que se ordena, prohíbe o permite una acción.

La pretensión de corrección. Si la referencia a cuestiones prácticas es poco discutible, todo lo contrario sucede con el elemento de la pretensión de corrección. El término "corrección" (Richtigkeit) no solamente aparecerá en esta obra, sino que será uno de los tres argumentos de la perspectiva del participante. Este concepto lo retomaremos en el capítulo octavo, dedicado a la comprensión alexyana del derecho. Por el momento nos basaremos en el significado de esta pretensión en el contexto de la Teoría de la argumentación jurídica. Tal y como lo ha notado Sieckmann, el concepto de corrección es bastante confuso porque pueden encontrarse varios sentidos de este concepto en la obra de Alexy. Sieckmann ha notado cuatro criterios latentes en la obra de Alexy que son otorgados al concepto de corrección: el primero relacionado con la verdad, o algo semejante a la verdad, de las aserciones normativas, el segundo como posibilidad discursiva, el 
tercero como un criterio de evaluación relacionado con la justicia y un cuarto como sentido de corrección moral. ${ }^{113}$

Probablemente, la razón principal por la que el término corrección suele provocar confusiones en la obra de Alexy reside en que durante el desarrollo de su pensamiento Alexy ha incorporado ideas contenidas en la Teoría de la argumentación jurídica en otras obras, pero con nuevas determinaciones, así como también ha introducido ideas que debieron incluirse en ésta y que no las encontramos desarrolladas en este Opus Magnum. Si consideramos que la pretensión de corrección es uno de los presupuestos fundamentales de la filosofía del derecho de Alexy, y que este concepto lo utiliza tanto en la tesis del "caso especial" como en la justificación discursiva de los derechos humanos y la concepción nopositivista del derecho, entonces es posible concebirla por el momento en un sentido cercano al tercer criterio de Sieckmann, es decir, como un criterio normativo de evaluación de las expresiones jurídicas, lo cual permite considerar como correctos a los sistemas jurídicos, normas o decisiones judiciales que pudieran concebirse como resultado de un discurso ideal, distinguiéndose así las normas que son producto de un Estado de derecho de las del mero ejercicio desnudo de poder.

La equiparación de la pretensión de corrección a un criterio normativo que nos permite evaluar como justas e injustas a las normas nos servirá para considerar a esta pretensión como una regla constitutiva de la filosofía del derecho de Alexy. La tesis del caso especial, a grandes rasgos, afirma que debe interpretarse la racionalidad jurídica de acuerdo con la teoría del discurso; en este sentido, según la pretensión de corrección las aserciones deben fundamentarse de acuerdo con un criterio de verdad o de rectitud; esto es, en toda decisión judicial debe plantearse "necesariamente la pretensión de que el derecho se aplica rectamente, aunque esta pretensión pueda cumplirse en muy escasa medida". ${ }^{114}$ La pretensión de corrección será analizada más adelante en esta obra.

Diferencias o limitaciones institucionales. El tercer elemento de la tesis del caso especial está determinado por las diferencias que tienen ambos tipos de discurso. Este contenido es muy importante, ya que si bien es cierto que hay semejanzas entre ambos tipos de discurso, tampoco pueden equipararse sin más, para bien del derecho mismo. El

\footnotetext{
${ }^{113}$ Cfr., Sieckmann, Jan-Reinard, El modelo de los principios del derecho, Bogotá, UEC, 2006, pp. 219 y 220.

${ }^{114}$ Alexy, Robert, op. cit., p. 449.
} 
derecho debe delimitar sus límites para lograr una mayor eficacia y legitimidad; entre esos límites está el de separarse de otros ámbitos que de modos distintos regulan las acciones humanas; no obstante, las tesis de Alexy del caso especial y de la vinculación del derecho con la moral pueden provocar confusiones y con ello críticas agudas. Un ejemplo de ambas consecuencias lo encontramos en el siguiente comentario de Habermas, quien a partir de la crítica a la tesis del caso especial ${ }^{115}$ ha tomado distancia de la postura de Alexy. En Facticidad y validez Habermas señala lo siguiente:

No hay duda de que alguien puede usar discursos morales de aplicación como un modelo para investigar las argumentaciones jurídicas en cuanto a que ambas tienen que ver con la lógica de aplicar normas. Pero la más compleja dimensión de validez de las normas jurídicas prohíbe que se asimile la legitimación de las decisiones jurídicas a la validez de los juicios morales. Para este punto uno no debería concebir el discurso jurídico como un caso especial de discursos morales (de aplicación) [...] Aunque la tesis del caso especial, en una versión u otra, es posible desde el punto de vista heurístico, esta sugiere que el derecho está subordinado a la moralidad. Esta subordinación es errónea, porque todavía está cargada por connotaciones iusnaturalistas. Esta tesis se vuelve menos problemática tan pronto como alguien toma en serio las diferencias paralelas del derecho y la moralidad que suceden en el nivel postconvencional de justificación. ${ }^{116}$

Aquí encontramos dos críticas de Habermas a la tesis del caso especial. Indudablemente tiene razón Habermas cuando afirma que el discurso jurídico no puede asimilarse al discurso moral por su complejidad, ya que si en la Teoría de la acción comunicativa le reconoce a Alexy el mérito de mostrarle que la argumentación jurídica es una especie de discurso práctico, en Facticidad y validez, Habermas le recrimina ahora a Alexy que subsuma un discurso jurídico de aplicación a uno moral. Esta crítica es refutada si tomamos en cuenta que deben destacarse no sólo las semejanzas que existen entre ambos discursos, sino también las diferencias.

El discurso jurídico, al erigirse dentro de una teoría normativa del derecho y del Estado, fija sus límites mediante tres elementos internos a todo discurso jurídico: "la ley, el precedente, la dogmática, y —en el caso del proceso—, por las leyes procedimentales". ${ }^{117}$ Por una parte, las leyes mismas establecen criterios generales según los cuales el discurso jurídico necesita de ciertos requisitos constitutivos para poder crear los precedentes

\footnotetext{
115 Sobre este tema, cfr., Lieber, Tobias, Diskursive Vernunft und formelle Gleichheit. Zu Demokratie, Gewalteinteilung und Rechtsanwendung in der Rechtstheorie von Jürgen Habermas, Tubinga, Mohr Siebeck, 2007, p. 235.

${ }^{116}$ Habermas, Jürgen, op. cit., p. 286.

${ }^{117}$ Alexy, Robert, TAJ, p. 49.
} 
jurídicos que sirven para establecer los límites del discurso jurídico. Estos precedentes, conocidos también como jurisprudencia, son decisiones jurídicas anteriores que sirven para que las decisiones judiciales futuras se tomen conforme a ellas, o que los criterios usados en una decisión busquen aplicarse nuevamente.

Si la ley y el precedente no son suficientes limitantes del discurso jurídico, también está la dogmática, la cual proporciona directrices para producir, aplicar y sistematizar al derecho, así como para delimitar el discurso jurídico y distinguirlo de discursos morales o políticos. Finalmente, en el caso de un proceso legal, las leyes procedimentales también limitan al discurso jurídico. La institucionalización de ciertos requisitos legales impiden que se subsuma el complejo discurso jurídico al moral, así que la primera objeción de Habermas de "asimilar la legitimación de las decisiones jurídicas a la validez de los juicios morales" no es válida si consideramos la función de la ley, los precedentes, la dogmática y las leyes procedimentales en la delimitación del discurso jurídico.

Pero, por otra parte, la segunda crítica de Habermas, que sugiere que la tesis del caso especial está cargada de connotaciones de derecho natural que subordinan el derecho a la moralidad, no merece descartarse de la misma manera, ya que la conexión entre el derecho y la moral, tanto en la tesis del caso especial, como en la búsqueda de un concepto de derecho que incluye su validez moral, puede caer en una confusa vinculación, que puede dar lugar a ciertos malentendidos conceptuales sobre el significado de "moral", confundiendo así a la propuesta de Alexy con algún otro modelo de derecho natural. En el capítulo octavo de esta oobra desarrollaremos el argumento sobre el que gira esta conexión. Sin embargo, la crítica de Habermas ha hecho explícita la necesidad de aclararlo.

\subsubsection{Vías de fundamentación de la argumentación jurídica}

Tal y como se ha visto anteriormente, la idea de una teoría moral procedimental parte de la búsqueda de una fundamentación racional de los enunciados normativos. Si en el ámbito de la filosofía moral vimos que la fundamentación pragmática trascendental puede evadir los cuernos del trilema de Münchhausen, ${ }^{118}$ en el ámbito de la filosofía jurídica esta teoría deberá hacer lo mismo con el dilema de Jörgensen, de acuerdo con el cual, "si se

\footnotetext{
118 No obstante, David Fusfield sostiene que el argumento pragmático-trascendental fracasa en el tercer cuerno del Trilema de Münchhausen. Al respecto, cfr., Fusfield, Daniel, "Can Jürgen Habermas' «Begründungsprogramm» Escape Hans Albert's Münchhausen-Trilema", en, Jahrbuch Rethorik 8, 1989, p. 27 ss.
} 
considera a la lógica como «la ciencia de las leyes más generales de la verdad» y se entiende además que las proposiciones normativas no son susceptibles de verdad, se podría llegar al convencimiento de que las leyes de la lógica no valen para las proposiciones normativas". ${ }^{119}$

En este sentido, el dilema de Jörgensen, según el cual las proposiciones normativas no son válidas porque en ellas las leyes de la lógica tradicional no pueden operar, puede superarse si puede fundamentarse una racionalidad inherente a los proposiciones normativas, referida a la corrección e incorrección de éstas. Para dar un primer paso hacia las reglas de razón es necesario explicar las diferentes vías de fundamentación de los discursos jurídicos. Por esta razón serán analizadas las diversas vías de fundamentación.

Fundamentación técnica: esta vía considera las reglas del discurso como reglas técnicas que prescriben los medios para determinados fines. Esta vía no es viable porque, por una parte, se debe fundamentar el fin, y si las reglas sólo prescriben los medios, entonces ya no es posible fundamentarlo; por otra parte, un fin que fundamente todas las reglas podría ser tan abstracto que normas totalmente incompatibles entre sí podrían proponerse para cumplir determinado fin, o este mismo fin se definiría por medio del cumplimiento de estas reglas.

Fundamentación empírica: esta consiste en que se compruebe que determinadas reglas que rijen de hecho correspondan con las convicciones normativas existentes. Este modo de fundamentación posee el problema de posibilitar el tránsito incorrecto de un deber ser a partir de un ser, es decir, paga el precio de reducir la validez normativa de la fundamentación de las reglas a la mera existencia de las que se encuentren presentes, independientemente de si son las mejores posibles. Tampoco esta forma de fundamentación es suficiente, pues la fundamentación no debe reducirse a la mera constatación de las reglas existentes.

Fundamentación definitoria: aquí lo que importa es que en la presentación del sistema de reglas que definen la praxis alguien proponga la aceptación de estas reglas, es decir, que la presentación de estas reglas motive la decisión de aceptarlas. Esta vía, aunque permite la implementación de sistemas nuevos de reglas, posee el defecto de que las reglas

${ }^{119}$ Alexy, Robert, TAJ, p. 267. 
sean presentadas sin que se ofrezcan razones suficientes, lo que permitiría un grado notable de arbitrariedad. Este modelo también es insuficiente.

Fundamentación pragmática (trascendental): Esta última vía, construida a partir de premisas normativas de la ética del discurso, consiste en demostrar que la validez de determinadas reglas es condición necesaria de la posibilidad de la comunicación lingüística. La "variante débil" de esta vía fundamentadora consiste, según Alexy:

En mostrar que (1) la validez de determinadas reglas es constitutiva de la posibilidad de determinados actos de habla y que (2) no podemos renunciar a estos actos de habla sin abandonar formas de comportamiento que consideramos como específicamente humanas. Las aserciones podrían pertenecer a tales actos de habla. ${ }^{120}$

Para la vía de fundamentación pragmática es indispensable que las aserciones formuladas se guíen por reglas aceptables por cualquier ser humano en cualquier tiempo y situación. El significado de "aserción" es importante, debido a que contribuye al reconocimiento explícito de que "alguien que hace una aserción se representa a sí mismo como creyendo en lo que dice, y probablemente como si estuviese justificado en su creencia. $Y$ como queremos que nuestras creencias sean verdaderas, parece correcto que cuando alguien hace una aserción se represente él mismo como intentando decir que esta es cierta”. ${ }^{121}$ Estas reglas de razón fundamentadas mediante la pragmática trascendental serán desarrolladas en el siguiente capítulo, dedicado al análisis de las reglas y formas de los argumentos prácticos y jurídicos.

\footnotetext{
${ }^{120}$ Alexy, Robert, TAJ, p. 262.

${ }^{121}$ Davidson, Donald, Inquiries into Truth and Interpretation, Oxford, Oxford University Press, 1988, p. 268.
} 


\section{Capítulo tercero. Hacia un código de racionalidad práctica. El modelo de las reglas de razón de la argumentación práctica y jurídica}

\section{Introducción}

La fundamentación pragmática-trascendental tendrá una función importante en la argumentación jurídica propuesta por Alexy, ya que ésta puede ofrecer una respuesta racional a los cuernos del trilema de Münchhausen, los cuales surgen cuando alguien pretende fundamentar una proposición normativa mediante otra proposición. A través de la fundamentación pragmática universal/trascendental, Habermas y Apel mostrarán que cuando un escéptico dialoga sobre cuestiones normativas debe asumir implícitamente la validez de ciertos principios morales. Del mismo modo, Alexy retomará de la ética discursiva la contradicción performativa, para su futura réplica al positivismo jurídico. De este modo el uso de la razón no se reducirá al ámbito teórico, sino también es parte del ámbito práctico, es decir, de la esfera de lo que debe hacerse, prohibirse o sugerirse; este uso práctico de la razón será el que permita justificar que los juicios éticos sobre normas morales y jurídicas puede poseer el estatus de racional. Ahora serán explicadas las reglas y formas de la argumentación práctica y jurídica.

\subsection{Las reglas y formas de la argumentación práctica. Las bases de una teoría moral-procedimental}

La idea de un fundamento pragmático-trascendental permite vincular a la argumentación jurídica y moral con aquellos actos de habla dirigidos a la interacción con otro $\mathrm{u}$ otros sujetos con la finalidad de lograr un entendimiento respecto a determinadas cuestiones normativas. A pesar de que Alexy en un principio sostenía una concepción discursiva cercana a la idea de una pragmática universal en sentido habermasiano (débil), y después se sintió más cercano a la concepción de Apel $^{122}$ y a la idea de una

\footnotetext{
${ }^{122}$ Aunque Apel no ha sido estudiado en el ámbito de la filosofía jurídica, la ética discursiva delineada por él posee un peso fundamental en el pensamiento de Alexy, tanto en la elaboración de las reglas discursivas y en la aportación de la idea de la contradicción performativa, como en la vinculación necesaria entre la idea de comunicación lingüística y el concepto de persona. Según Apel, "[T]odos los seres capaces de comunicación lingüística deben ser reconocidos como personas, puesto que en todas sus acciones y expresiones son interlocutores virtuales, y la justificación ilimitada del pensamiento no puede renunciar a ningún interlocutor
} 
fundamentación trascendental (fuerte), lo cierto es que para los fines que persigue la fundamentación de las reglas del discurso de Alexy, "la diferencia entre argumentos pragmáticos trascendentales y universales es sencillamente irrelevante". ${ }^{123}$

De acuerdo con Logi Gunnarsson la diferencia entre pragmática universal y trascendental es poco relevante ya que sólo debe ser de interés que las reglas discursivas puedan ser consideradas aceptables por cualquier participante en cualquier tiempo y situación, tanto al nivel de su fundamentación universal, como por su consiguiente institucionalización y aplicación en el ámbito jurídico, es por eso que "si el argumento pragmático-trascendental ha de tener éxito, hay que demostrar que estas reglas son presupuestos necesarios de la posibilidad de las aseveraciones. No puede haber ninguna alternativa a ellas". ${ }^{124}$ Por estas razones lo importante será que el fundamento pragmático trascendental/universal pueda tomarse como base de las reglas de razón práctica y jurídica. Ahora bien, ¿qué relación tiene esta ética normativa con el resultado de un procedimiento racional?, ¿en qué consisten los criterios de corrección de esta ética discursiva?

De acuerdo a la teoría del discurso, un enunciado normativo será correcto cuando pueda ser resultado de un determinado procedimiento, es decir, del discurso racional. Según Alexy:

La relación entre corrección y procedimiento es característica de todas las teorías procesales. Si a es el representante de una teoría procesal que ha de ser construida sobre el procedimiento $P$, a la pregunta acerca de si un enunciado normativo $N$ es correcto responde diciendo:

D: Un enunciado normativo $N$ es correcto si y sólo si puede ser el resultado de un procedimiento $P .125$

¿Pero cómo Alexy llega a formular esta teoría procedimental como una de las bases de su teoría no-positivista del derecho? Antes de que Alexy utilice a la pragmática trascendental para fundamentar las proposiciones normativas de esta teoría del discurso

\footnotetext{
y a ninguna de sus aportaciones virtuales a la discusión" (Apel, Karl-Otto, La transformación de la filosofía II, Madrid, Taurus, 1984, p. 380). Si buscar estudiarse una aproximación de Apel al discurso jurídico, cfr., "Diskursethik vor der Problematik von Recht und Politik: Können due Rationalitätsdifferenzen zwischen Moralität, Recht un Politik selbst noch durch Diskursethik normativ-rational gerechtfertigt werden" (en, Apel, Karl-Otto und Kettner, Mathias, Zur Anwendung der Diskursethik in Politik, Recht und Wissenschaft, Fráncfort del Meno, Suhrkamp, 1992, 29-61).

${ }^{123}$ Gunnarsson, Logi, Making Moral Sense: Beyond Habermas and Gauthier, Cambridge, Cambridge University Press, 2003, p. 262.

${ }^{124}$ Alexy, Robert, CVD, p. 144.

${ }^{125}$ Alexy, Robert, DRP, p. 73.
} 
jurídico, menciona algunos resultados provisionales a los que ha llegado mediante un detallado análisis de algunas corrientes del campo de la metaética analítica, dejando de lado algunas teorías que no pudo analizar, como son los casos de la ética utilitarista y la teoría de la justicia de Rawls. ${ }^{126}$ Entre estos filósofos que analizó críticamente para construir una teoría de la argumentación práctica, base de la argumentación jurídica, destacan George Edward Moore, Charles Leslie Stevenson, Wittgenstein, Austin, Hare, Kurt Baier y Toulmin; algunos de los resultados provisionales que Alexy extrajo en términos generales de estas teorías son los siguientes:

En primer lugar, la función del lenguaje moral no puede reducirse a la descripción de objetos, propiedades o relaciones, tal y como el naturalismo e intuicionismo suponen.

En segundo lugar, el discurso moral es una actividad guiada por reglas de un tipo específico, el cual trata del equilibro racional de intereses.

En tercer lugar, de estas reglas de la argumentación práctica deben diferenciarse diversas formas de argumento.

En cuarto lugar, las proposiciones normativas son universalizables.

En quinto y último lugar, las reglas de la argumentación práctica son una actividad racional, a pesar de no guiarse por las reglas de las ciencias naturales. ${ }^{127}$

Los primeros resultados obtenidos por Alexy después de analizar las teorías mencionadas le permitirán sustentar una teoría del razonamiento práctico. Esto es, una teoría que explique que el lenguaje no se agota en la descripción de las cosas, lo cual permitiría reconocer, usando la terminología de Hare, la existencia de un "lenguaje de la moral"; también, Alexy reconoce que el lenguaje es una actividad guiada por reglas que pueden manifestarse en diferentes formas, de acuerdo con los usos del lenguaje; también, que los actos de habla normativos poseen un contenido capaz de alcanzar una aceptación universal; y finalmente, esta teoría hará explícita la validez de la racionalidad práctica, la cual permitiría, entre otras cosas, superar el dilema de Jorgensen, ya que la racionalidad del lenguaje normativo es posible a pesar de no estar basada en el modelo de las ciencias naturales; además, este conocimiento de Alexy de la filosofía moral le permitirá adentrarse

\footnotetext{
${ }^{126} \mathrm{Si}$ consideramos que la filosofía jurídica de Alexy no sólo es una teoría de la argumentación jurídica, sino un sistema de filosofía del derecho, podría extrañarle a más de uno que la obra de Rawls no aparezca citada con más frecuencia. No obstante, Alexy reconoce que esta teoría de la justicia, en cuanto variante de una teoría contractualista de claro influjo kantiano, tiene bastantes puntos en común con la suya, sólo que considera que una discusión más detallada entre ambas teorías supondría una investigación propia. Al respecto, cfr., Alexy, Robert, TAJ, pp. 154 y 155 (nota 296).

${ }^{127}$ Alexy, Robert, TAJ, pp. 155 y 156.
} 
en concepciones éticas más avanzadas que las empleadas por los juristas no-positivistas y positivistas clásicos. Después de mostrar estos primeros resultados, Alexy retomará las bases de la ética discursiva habermasiana y apeliana, así como las reflexiones de otros filósofos como Perelman, Paul Lorenzen y Oswald Schwemmer, siendo los dos últimos representantes de la Escuela constructivista de la deliberación racional de Erlangen.

El esfuerzo de rescatar diversas ideas de tan variados filósofos le permite a Alexy desarrollar un código de la razón práctica. Esta fundamentación del derecho influída por la ética del discurso estará enfocada en mostrar la validez de determinadas reglas como condición necesaria de la posibilidad de la comunicación humana. Esto implica que la fuerza normativa de esta fundamentación reside en rescatar de la ética discursiva el hecho de la razón, consistente en extraer las bases normativas de las condiciones pragmáticas mínimas de la comunicación humana y de la propia comprensión de los sujetos que participan a diario en prácticas discursivas en cualquier sociedad y tiempo.

\subsubsection{Primeras objeciones: formalismo moral-procedimental y sometimiento a las condiciones empíricas}

Este modelo discursivo buscará fundamentar reglas del discurso comunes a todas las formas de vida; no obstante, la teoría del discurso ha sido criticada de muy diversas maneras. Ahora analizaremos las objeciones dirigidas al formalismo moral y a la idea de una fundamentación última.

Sobre la primera crítica, dirigida al universalismo de la ética del discurso, sabemos que esta es, en cierto modo, parecida a la que se le suele plantear al formalismo moral de corte kantiano, en cuanto ambas posturas son acusadas de imponer o encubrir bajo el ropaje del universalismo humanista la imposición de una determinada concepción ética, jurídica y política, así como también considerarla una postura filosófica vacía, incapaz de llevar a cabo una fundamentación material para resolver problemas concretos y reales. Como puede verse, se tratan de críticas frecuentes que desde hace algún tiempo le son planteadas a la teoría del discurso en nombre de lo material y de lo vinculado con lo "real y 
lo concreto", objeciones parecidas a las críticas de Hegel a la ética kantiana, por considerarla formal, universalmente abstracta, impotente y puramente intencional. ${ }^{128}$

Este tipo de críticas pueden refutarse si se considera que, en primer lugar, el procedimentalismo formal de la ética del discurso no intenta definir como absolutas y universales las reglas de una determinada comunidad política, sino reglas comunes a todas las formas de vida. Para la ética del discurso hablar de universalismo en un sentido normativo implica reafirmar el carácter inmanente y trascendente de ciertos cuestionamientos y presupuestos básicos del lenguaje que se dan dentro de las diferentes comunidades políticas, y que al mismo tiempo las trascienden: "[L]os universales sólo desaparecerían del todo si los miembros de una forma de vida perdieran completamente y de manera definitiva la capacidad para plantear seriamente la cuestión “¿por qué?»" ${ }^{129}$

El ejemplo del cuestionamiento “¿por qué?” de Alexy, señala que éste es usado por todas las culturas para que todo aquel sujeto que afirme algo dé razones para lo dicho. Precisamente, reglas como ésta son las que permiten comprobar la existencia de reglas normativas del lenguaje que pueden alcanzar un estatus de universales sin caer en un etnocentrismo moral o jurídico. El hecho de que una comunidad política afirme que sus normas y principios deben valer incondicionalmente como las normas y principios de todos no está vinculado con las tesis universalistas de esta teoría ética, sino que, por lo contrario, esta teoría puede servir para evaluar críticamente estos intentos de dominio político y jurídico, ya sean que estos sean expresados en el interior de un Estado o en el plano internacional.

Sobre la crítica, dirigida al "formalismo vacío" de esta teoría moral procedimental, debe mencionarse que ésta es considerada por sus representantes como moralmente procedimental por razones morales, ya que la vinculan con la autonomía de todos los sujetos para decidir, sobre la base de reglas racionales accesibles para todas las formas de vida, cuestiones referentes al contenido material o sustancial de las normas, es decir, estas reglas sí tienen un contenido ético. Esto significa que son reglas ético-discursivas válidas aquellas que posibilitan un consenso, pero no un consenso cualquiera, como el que

\footnotetext{
128 Sobre estas críticas puede consultarse el trabajo de Habermas ¿Afectan las objeciones de Hegel a Kant también a la ética del discurso?, en, Habermas, Jürgen, Erläuterungen zur Diskursethik, Fráncfort del Meno, Suhrkamp, 1991, pp. 9-30.

${ }^{129}$ Alexy, Robert, TAJ, p. 438.
} 
puede surgir rápidamente de una situación de psicosis de masas, sino un consenso que presupone reglas morales en el punto inicial de la discusión acerca de las normas.

Aunque existen diversas posturas que acusan a este tipo de paradigmas discursivofilosóficos de desvincularse de la ética por no poder dar cuenta de un contenido concreto, no es cierto que no exista en esta teoría una preocupación por cuestiones materiales, sólo que los teóricos de esta postura buscarán fundamentar y precisar reglas que permitan constituir formas racionales de consenso en el cual todas las formas de vida sean capaces de ser escuchadas, y que después de ponderar las razones de todos, predomine la coerción no coercitiva del mejor argumento. Es por esta razón que la ética del discurso puede definirse como una teoría ética procedimental que le da una prioridad a la autonomía de todos los sujetos, mientras que al mismo tiempo proporciona reglas que impiden que ciertos intereses paticulares se impongan como constitutivos del consenso. Para ello es muy importante que las reglas de razón estén regidas por los principios de igualdad, incoercibilidad y universabilidad.

Ahora bien, sobre las críticas hacia la teoría del discurso en tanto es considerada un formalismo impotente ante los problemas de la vida real, ${ }^{130}$ Alexy se ha pronunciado en diversas ocasiones. En la réplica a Philippos Vasiloyannis, quien sostiene que el discurso procedimental, en tanto "formalismo", puede llevar a "reproducir la separación positivista entre derecho y moral, y terminar así como una mera apología del discurso jurídico", ${ }^{131}$ Alexy responde de la siguiente manera:

"Esto suena como si dos versiones de la ética de discurso fueran posibles; una formalista que carece de referencias a la moral sustantiva y una no formalista que incluye razones morales. Mi contestación sería que el discurso, por su naturaleza, está siempre intrínsecamente conectado con la moral. Una concepción puramente formal de la ética del discurso es, por ello, imposible". ${ }^{132}$

\footnotetext{
130 Para ver críticas a los postulados de la ética del discurso en nombre de una ética material cfr., Dussel, Enrique, Ética de la globalización en la era de la globalización y de la exclusión, Madrid, Trotta, Madrid, Trotta, 2006, pp. 180 ss

${ }^{131}$ Cfr., Vassiloyannis, Philippos, "Discourse Ethics, Legal Positivism and the Law", en Pavlakos, George (Ed.), Law, Rights and Discourse. The Legal Philosophy of Robert Alexy, Oxford, Hart Publishing, 2007, p. 109. En esta crítica también notamos de nuevo la confusión entre derecho y moral, la cual esperamos aclarar en la tercera sección.

132 Alexy, Robert, "Thirteen Replies" en, Pavlakos, George (Ed.), Law, Rights and Discourse. The Legal Philosophy of Robert Alexy, Oxford, Hart Publishing, 2007, p. 339. En adelante, TR
} 
Para Alexy la ética del discurso es la que permite conectar al derecho con la reflexión moral, esto es, la dimensión fáctica con la dimensión ideal. Las reglas de razón no sólo contribuirán decisivamente a "poner algo de carne teleológica no-heterónoma sobre los huesos desnudos de la universalidad", ${ }^{133}$ sino que podrá dotar al derecho de un contenido crítico-moral. Antes de terminar con esta objeción, vale la pena indicar que la crítica al formalismo es muy importante, ya que Alexy con su postura racionalista se opondrá al grito de guerra del positivismo kelseniano, según el cual "cualquier contenido puede ser derecho", ${ }^{134}$ pero hay una diferencia entre la crítica de Alexy y las posturas que conciben a todo formalismo como una apología del poder, ya que éstas muestran una notoria falta de comprensión sobre la filosofía práctica contemporánea, y, al final, resultan ser posturas fácilmente refutables. ${ }^{135}$

La segunda crítica tiene que ver con un malentendido conceptual, en el cual, si bien los argumentos son correctos, estos no son aplicables al punto de partida de Alexy. En el Postfacio de la Teoría de la argumentación jurídica, Alexy menciona una condición de posibilidad de que el argumento pragmático-trascendental tenga efectividad. Esta condición la formula de la siguiente manera:

"El argumento pragmático-trascendental tiene éxito, sin embargo, si es completado con la premisa empírica de que existe un número tan grande de personas que tienen un interés en llevar a cabo el discurso no estratégicamente, que para aquéllos que quieren dirigirlo estratégicamente merece la pena actuar como si para ello las reglas del discurso valieran también subjetivamente". ${ }^{136}$

Esto parecería indicar que la posibilidad de que este argumento sea efectivo socialmente sería vista como una importante vinculación de la ética del discurso con la naturaleza discursiva de los seres humanos, sólo que la forma y el contexto como es presentada esta argumentación da lugar a confusiones. Atienza ha señalado una crítica al respecto:

El problema aquí no es sólo el que puedan darse situaciones en que no exista un número suficiente de personas que tengan el interés mencionado (esto es, que falle la premisa empírica), sino que yo no veo que se pueda combinar de la forma que Alexy sugiere el modo pragmático-trascendental y el modo empírico de

\footnotetext{
133 Riley, Patrick, Kant's Political Philosophy, Nueva Jersey, Rowman and Littlefield, 1983, p. 43.

${ }^{134}$ Kelsen, Hans, Reine Rechtslehre. Zweite, vollständig neu bearbeitete und erweiterte Auflage 1960, Viena, Österreichische Staatsdruckerei, 1992, p. 201.

135 "La crítica a los "formalismos» es una patente de imbécil", Dávila, Nicolás, Escolios a un texto implícito, Madrid, Ediciones Atalanta, 2009, p. 250.

${ }^{136}$ Alexy, Robert, op. cit., pp. 422 y 423 (p. 442).
} 
fundamentación. Si el argumento pragmático trascendental depende, en efecto, de una premisa empírica, entonces el fundamento no es ya pragmático-trascendental, sino empírico. La fundamentación pragmático-trascendental 0 bien es la fundamentación última, o no es fundamentación. ${ }^{137}$

La crítica de Atienza a la premisa empírica introducida por Alexy —que además ha sido retomada por otros autores- ${ }^{138}$ tiene razón en cuanto sostiene que ésta falla al no existir un número relevante de personas con un interés en llevar a cabo el discurso comunicativamente, pero no en cuanto afirma que Alexy parece reducir la validez del argumento pragmático-trascendental a las condiciones empíricas de fundamentación, ya que Alexy ha expresado que la dimensión ideal no puede reducirse a la fáctica, porque de ser así haría depender la esfera del deber ser de las normas de la esfera del ser.

Esta crítica parece mostrar una contradicción en Alexy. No obstante, tal y como se vio en el capítulo pasado, la fundamentación empírica es criticada por Alexy porque no es posible derivar un deber ser a partir de un ser, debido a que el precio que habría de pagarse por reducir la dimensión normativa a la mera positividad de las reglas existentes sería el de justificar como razonables a todas las instituciones jurídicas por el mero hecho de ser creadas mediante una determinada forma legal. Esta derivación podría hacerse si todas las reglas e instituciones existentes fueran enteramente racionales, pero sabemos que de ningún modo esto es así.

La anterior cita de Alexy, que sólo indica la posibilidad de aumentar las posibilidades de éxito del argumento pragmático-trascendental al incluir una variable empírica, no reduce la fuerza normativa a la fuerza de lo fáctico porque, en primer lugar, la premisa empírica introducida tiene como objetivo en este contexto reconocer que más personas estarán dispuestas a entablar un discurso con fines comunicativos, que quienes entrarán en comunicación persiguiendo fines estratégicos, y por esta razón las segundas no tendrán de otra más alternativa más que actuar como lo indican las reglas discursivas, porque si

\footnotetext{
${ }^{137}$ Atienza, Manuel, Las razones del derecho. Teorías de la argumentación jurídica, Lima, Palestra, 2006, p. 284.

138 Sobre esta crítica de Atienza a Alexy cfr., Vigo, Rodolfo (Ed.), La injusticia extrema no es derecho. De Radbruch a Alexy, México, D. F., Fontamara, 2008, pp. 103 y 104, y Sobrevilla, David, La filosofía del derecho alemana actual de orientación racionalista. Estudios sobre R. Alexy, K. Günther, J. Habermas y O. Höffe, México, D. F., Fontamara, 2008, p. 84-86. En este sentido, Bäcker ha reformulado considerablemente las dudas de Atienza respecto al carácter pragmático-trascendental del argumento de Alexy. Al respecto, cfr., Bäcker, Carsten, Begründen und Entscheiden. Kritik und Reconstruction der Alexyschen Diskurstheorie des Rechts, Baden-Baden, Nomos Verlagsgesellschaft, 2012, p. 47 ss.
} 
hicieran "explícito lo implícito" (esto es, manifestar sus intenciones reales), difícilmente podrían ser tomados en cuenta por los demás como participantes de un discurso que pretende tener consecuencias universalizables para todos. En este sentido, la premisa empírica sólo tiene una función reforzadora del argumento pragmático-trascendental que previamente se ha instituido y no fundamentadora de este tipo de argumento. En segundo lugar, Alexy señala con claridad antes de este pasaje que "[U]na reducción del argumento pragmático-trascendental a la fundamentación únicamente de la validez objetiva 0 institucional de las reglas del discurso no es ciertamente posible sin más". ${ }^{139}$ Si la premisa empírica qua refuerzo fáctico no es condición de garantía del argumento trascendental, entonces la objeción de Atienza es superada. No obstante, si ésta garantiza el argumento trascendental, entonces hay una contradicción en la fundamentación de Alexy.

Es posible reconocer que, en términos empíricos, el seguimiento de las reglas del discurso contará con una notable aceptación si asentimos que son normas válidas en virtud de reconocer su contenido como correcto, y que, por ello, estas reglas pueden aprehenderse como válidas por sujetos racionales, independientemente de su aceptación o no aceptación; por lo tanto, la crítica de Atienza es correcta respecto a aquellas posturas que reducen el fundamento del deber ser al del ser, sólo que Alexy no cae en esta postura. Una vez que hemos expuesto los primeros resultados de la teoría moral procedimental del discurso y sus primeras objeciones respectivas, pasaremos al análisis de las reglas del discurso práctico.

\subsubsection{Análisis de Las reglas y formas del discurso práctico general}

Tal y como hemos señalado antes, una de las preocupaciones principales de Robert Alexy consiste en mostrar la fundamentación de la racionalidad práctica, y, después, señalar la vinculación que tiene con el derecho, especialmente con la argumentación jurídica. Para emprender este objetivo Alexy partirá de la concepción kantiana de racionalidad práctica, en cuya base se encuentra el postulado de universabilidad, interpretado a la luz de la teoría del discurso.

De acuerdo con esta teoría procedimental-universalista, si es posible fundamentar racionalmente un enunciado normativo, entonces también es posible reprobar racionalmente una norma de corte moral o jurídico. Dicho de otro modo, Alexy buscará la

${ }^{139}$ Alexy, Robert, TAJ, p. 441. 
forma de encontrar un equilibro entre las posturas objetivistas y subjetivistas respecto a la fundamentación del razonamiento moral, y con tal propósito desarrollará un sistema de reglas del discurso que permitan reconocer como racional un discurso práctico general si cumple con las condiciones de la argumentación práctica.

Esta idea de un código de razón de Alexy será presentada en un sistema de 28 reglas del discurso - divididas en seis tipos- que permitan afrontar problemas prácticos, entendidos estos como concernientes a lo que es debido y prohibido, y lo que es permitido, bueno y malo. Afrontar razonablemente estos problemas permitiría plantear un camino entre teorías objetivistas y cognitivistas, de una parte, y teorías subjetivistas y no cognitivistas, de la otra. ${ }^{140}$ La pretensión de corrección también estará presente en el discurso jurídico en el sentido de que las proposiciones normativas pueden ser racionalmente fundamentadas en el marco de un ordenamiento jurídico vigente, lo que llevará a Alexy a formular la siguiente pregunta: ¿[P]ero qué es una fundamentación racional en el marco del ordenamiento jurídico vigente? ${ }^{141}$

Para responder a esta interrogante, Alexy desarrollará un sistema de reglas que mostrarán la necesidad de reconocer el carácter universalista de la concepción discursiva de la racionalidad práctica y el contenido moral de éstas. Estas reglas, parecidas en diversos aspectos al Principio de cooperación y máximas de la conversación de Paul Grice, ${ }^{142}$ no definirán una forma particular de vida, pero tampoco podrán ser consideradas como vacías, ya que institucionalizarán el deber de fundamentar un discurso frente a otro, deber inherente a cualquier forma humana de vida conocida. A continuación será expuesta la tabla de las reglas y formas elaboradas formulada por Alexy en su intento de mostrar la racionalidad de las reglas del discurso práctico, para que posteriormente sea fundamentado el discurso jurídico. Para ello, comenzaremos primero con el análisis de Las reglas y formas del discurso práctico general.

De acuerdo con la ética discursiva, "[U]na norma únicamente puede aspirar a tener validez cuando las personas a las que afecta consiguen ponerse de acuerdo en cuanto participantes de un discurso práctico (o pueden ponerse de acuerdo) en que dicha norma

\footnotetext{
${ }^{140}$ Alexy, Robert, Teoría del discurso y derechos humanos, Bogotá, UEC, 1995, p. 47. En adelante, TDDH.

${ }^{141}$ Alexy, Robert, TAJ, p. 305.

142 Cfr., Grice, Paul, "Logic and Conversation", en, Cole, Peter, y Morgan, Jerry (Eds.), Syntax and Semantics, Vol. 3, Speech Acts, Nueva York, Academic Press, 1975, pp. 41-58.
} 
es válida". ${ }^{143}$ Conforme a la validez de este postulado ético discursivo (D), debe sostenerse racionalmente que el contenido normativo del lenguaje prescriptivo debe ser capaz de universalizarse para que una norma sea válida. Este principio de universalización (U) podrá ser aprobado cuando todos los afectados puedan aceptar las consecuencias que el respeto a estas normas conlleva, siempre que estas consecuencias sean preferibles a las de las otras alternativas posibles. ${ }^{144}$

Precisamente, para que el contenido de las normas pueda alcanzarse de un modo racional, esto es, para que los participantes puedan deliberar en condiciones de libertad e igualdad, necesitarán de un código de razón práctica como base de la argumentación jurídica. Por esta razón Alexy elaborará un conjunto de reglas discursivas referidas tanto a aspectos semánticos como a aspectos pragmáticos, es decir, reglas que, por una parte, fijarán el significado de una expresión lingüística y reglas que, por otra parte, determinarán cómo el hablante y el interlocutor las usarán en un discurso.

Comenzaremos, entonces, con el análisis y crítica de las reglas y formas de la argumentación práctica, lo cual nos llevará posteriormente a plantear un tipo de argumentación más técnica, la argumentación jurídica. Estas reglas tendrán distintas funciones en el discurso práctico, por tanto serán divididas en seis categorías, que son las siguientes: 1. Reglas fundamentales, 2. Reglas de razón. 3. Reglas de la carga de la argumentación, 4. Formas de los argumentos 5. Reglas de fundamentación. 6. Reglas de transición. De estas categorías los grupos de reglas más destacados por Alexy serán los primeros dos tipos, por lo cual serán desarrollados con mayor atención. ${ }^{145}$

\subsubsection{Las reglas fundamentales}

(1.1) Ningún hablante puede contradecirse.

(1.2) Todo hablante sólo puede afirmar aquello que él mismo cree.

(1.3) Todo hablante que aplique un predicado $\mathrm{F}$ a un objeto "a" debe estar dispuesto a aplicar $\mathrm{F}$ también a cualquier otro objeto igual a "a" en todos los aspectos relevantes.

\footnotetext{
${ }^{143}$ Habermas, Jürgen, Conciencia moral y acción comunicativa, Barcelona, Planeta-de Agostini, 1994, p. 86.

${ }^{144}$ Sobre el principio de universalización (U) y la fórmula discursiva (D), cfr., Habermas, Jürgen, Erläuterungen zur Diskursethik, Fráncfort del Meno, Suhrkamp, 1991, p, 32.

${ }^{145}$ Esto puede verse reflejado en menciones posteriores a estas reglas en trabajos como Teoría del discurso y derechos humanos y una concepción teórico-discursiva de la razón práctica. También, estas dos categorías son las que Habermas retoma principalmente de Alexy.
} 
(1.3') Todo hablante sólo puede utilizar aquellos juicios de valor y de deber que afirmaría así mismo en todas las situaciones en las que afirmase que son iguales en todos los aspectos relevantes.

(1.4) Distintos hablantes no pueden usar la misma expresión con significados distintos.

Para Alexy estas reglas son la base constitutiva de cualquier discurso humano, a tal grado, que es imposible sustraerse de llevar a cabo actos de habla sin presuponerlas porque su validez es condición de verdad o corrección de cualquier comunicación lingüística. La intención de la formulación de estas reglas consiste en hacer explícitos los principios de la lógica (1.1), esto es, que el hablante no puede contradecir lo que él mismo afirma; de la sinceridad (1.2) en cuanto a que toda aserción implica inherentemente una creencia, ${ }^{146}$ principio relacionado con el anterior; y el de la universalidad (1.3 y 1.3') porque, de acuerdo con Hare, el principio de universalidad es fundamentable a partir del contenido de las proposiciones normativas. Esto implica que al designar a "a" como bueno es porque "a" posee propiedades que muestran que el lenguaje moral" es universalizable y racional, ya que el lenguaje, en tanto es compartido por una comunidad, niega la posibilidad de que los hablantes le atribuyan a una expresión significados arbitrarios.

\subsubsection{Las reglas de razón}

(2) Todo hablante debe, cuando se le pide, fundamentar lo que afirma, a no ser que pueda dar razones que justifiquen el rechazar una afirmación.

(2.1) Quien pueda hablar puede tomar parte en el discurso

(2.2) (a) Todos pueden problematizar cualquier aserción.

(b) Todos pueden introducir cualquier aserción en el discurso.

(c) Todos pueden expresar sus opiniones, deseos y necesidades.

(2.3) A ningún hablante puede impedírsele ejercer sus derechos fijados en (2.1) y (2.2), mediante coerción interna o externa al discurso.

Estas reglas definen las condiciones más importantes para que el discurso sea considerado racional, y en las que encontramos toda una serie de ideas referidas a los derechos de los participantes del discurso. La primera regla (2) introduce el principio de fundamentación, necesario para que los hablantes sostengan como verdadero o correcto lo que afirman en las aseveraciones hechas en el discurso. En consonancia con una

\footnotetext{
${ }^{146}$ Esta idea puede verse mejor expresada con el clásico ejemplo de Austin, que consiste en mostrar que no es posible decir «el gato está sobre el felpudo» y añadir "pero yo no lo creo», ya que la primera "aserción implica una creencia". (Austin, John, cómo hacer cosas con palabras, Barcelona, Paidós, 2008, pp. 94 ss).
} 
reflexión de Toulmin, ${ }^{147}$ el principio de fundamentación exige que el hablante dé argumentos a favor de lo que dice frente a los demás participantes del discurso racional y los incluya seriamente en el proceso de deliberación, ya sea para aceptar o no lo que dice, a menos de que rechace dar razones para dar una fundamentación y éstas puedan entenderse y justificarse ante los participantes.

La exigencia de que el hablante fundamente sus pretensiones frente a otros llevará a Alexy a establecer a implementar otras reglas (2.2) que podrán considerarse como las bases de la situación ideal de habla o de comunidad de diálogo, que consistirán en introducir las ideas de igualdad de derechos, de universalidad y, finalmente, de no coerción, o, dicho de otro modo, los principios rectores de igualdad, universalidad y no coerción (2.3). En Conciencia moral y acción comunicativa Habermas hace uso de estas reglas formuladas por Alexy, aunque con algunos cambios conceptuales. La primera regla que según Alexy que establece el principio de universalidad, Habermas le llamará principio de publicidad, el cual abrirá el discurso a todos aquellos hablantes con interés en el problema, sin excepción alguna. La segunda regla que expresa el principio de igualdad de derechos, Habermas la conceptualizará como regla de igualdad de los participantes, la cual permite asegurar oportunidades simétricas de participación en el diálogo por parte de todos los participantes. La tercera regla, que será la misma para ambos, consistirá en introducir el principio de no coerción, indispensable para que al debatir ningún participante intente ejercer coerción sobre otro ya sea mediante actos explícitos o sutiles.

Estas reglas permiten que las condiciones mínimas del discurso sean posibles, es por ello que éstas pueden servir como un poderoso instrumento de crítica ${ }^{148}$ respecto a las prácticas dominantes de un determinado ámbito humano, público o privado, o a la exigencia de que la lucha por nuevos derechos esté exenta de coerciones hacia los participantes. Sin embargo, Alexy reconoce que estas reglas tienen un sentido normativo, por lo tanto sólo pueden cumplirse de manera aproximada, llegando inclusive a cuestionarse si alguna vez

\footnotetext{
147 "Quien formula una aseveración está formulando una pretensión: reclama nuestra atención o que le creamos". (Toulmin, Stephen, Los usos de la argumentación, Barcelona, Península, 2007, p. 29)

${ }^{148}$ Alexy, Robert, TAJ., p. 273-74. También cfr., Alexy, Robert, "Eine Theorie des praktischen Diskurses", en, OelMüller, Willi (Ed.), Normenbegründung-Normendurchsetzung, Paderborn, UTB Schöningh, 1978, p. 52. En adelante, ETPD.
} 
puede alcanzarse la inexistencia de la coerción desnuda o sutil, por lo que pueden considerarse como ideales regulativos.

El concepto de idel regulativo no siempre es claro. Por ello, cuando Alexy afirma que estas reglas de razón sólo pueden cumplirse de manera aproximada, en tanto en un discurso empírico estas reglas son violadas con frecuencia, pueden considerarse como reglas con poca o nula utilidad. Como Alexy usa con frecuencia ideales regulativos es indispensable saber qué entiende por idea regulativa:

El concepto de una idea regulativa, tal y como se usa aquí, proviene de Kant. Kant subraya el punto de que las ideas regulativas no pueden jamás constituir un objeto. Ellas 'no pueden decirnos qué es el objeto, sino solo cómo el regressus empírico debe ser realizado por nosotros para alcanzar el concepto completo del objeto.' Esto aplica no sólo para el conocimiento empírico. Las ideas regulativas no expresan lo que está 'dado'; sino que ellas nos dicen que es lo que merece 'establecerse como una meta'. ${ }^{149}$

De hecho, estas metas normativas son las que nos permiten intentar configurar un objeto -en este caso el derecho-, de acuerdo con una concepción de lo que debe hacerse, a pesar de que esa aproximación no se realice del todo; es por eso que señalarlas como metas permite criticar las prácticas sociales imperantes y demostrar la invalidez o falsedad de sus fundamentos. Sin los ideales regulativos no sería posible hacer una crítica o proponer una filosofía normativa en el ámbito social, moral, político y jurídico. Finalmente, la importancia de estas reglas para Alexy reside en que ellas proporcionan una explicación de la pretensión de verdad o de corrección, de ahí su importancia como "reglas de razón".

\subsubsection{Las reglas de carga de la argumentación}

(3.1) Quien pretende tratar a una persona A de manera distinta que a una persona B está obligado a fundamentarlo.

(3.2) Quien ataca una proposición o una norma que no es objeto de discusión debe dar una razón para ello.

(3.3) Quien ha aducido un argumento sólo está obligado a dar más argumentos en caso de contraargumentos.

(3.4) Quien introduce en el discurso una afirmación o manifestación sobre sus opiniones, deseos o necesidades que no se refiera como argumento a una anterior manifestación, tiene si se le pide, que fundamentar por qué introdujo esa afirmación o manifestación.

${ }^{149}$ Alexy, Robert, TR, p. 339. 
Estas reglas son intriducidas para evitar que sin mediar razones de por medio se cuestione indefinidamente cualquier afirmación, ya que quien cuestiona algo también debe dar razones para ello. Los deberes de fundamentación deben ser por iguales, es decir, tanto para el hablante como los que lo escuchan y quieren cuestionarlo, de este modo se evita que un participante cuestione todas las fundamentaciones sin que dé razones relevantes, consiguiendo así un deber recíproco de fundamentar lo dicho.

\subsubsection{Las formas de los argumentos}

(4) $G$

$$
\frac{\mathrm{R}}{\mathrm{N}} \text {. }
$$

(4.1) $\mathrm{T}$

(4.2) $\mathrm{F}$

(4.3) $\mathrm{F}_{\mathrm{R}}$

$\frac{R^{\prime}}{R}$

(4.4) T'

$\frac{\mathrm{R}}{\mathrm{R}}$

(4.5) $R_{\mathrm{i}} \mathrm{P} \mathrm{R}_{\mathrm{k}}$ o bien $\mathrm{R}_{\mathrm{i}}^{\prime} \mathrm{P}_{\mathrm{k}}^{\prime}$

(4.6) $\left(R_{\mathrm{i}} \mathrm{P} \mathrm{R}_{\mathrm{k}}\right)$ C o bien $\left(\mathrm{R}_{\mathrm{i}}^{\prime} \mathrm{P} \mathrm{R}_{\mathrm{k}}^{\prime}\right) \mathrm{C}$

Influido por el modelo de argumentación de Toulmin (4), Alexy formula dos modos de fundamentar las formas de los argumentos $(G)$ del discurso práctico, ya sea que la proposición normativa singular $(\mathrm{N})$ sea fundamentada mediante una referencia a una regla $(R)$ en la cual se presuponga un hecho que describa las condiciones de aplicación de ésta (4.1), o que sean señaladas las consecuencias lógicas de ese enunciado (4.2). Como es posible que puedan surgir cuestionamientos sobre los hechos (T) o sobre las consecuencias $(F)$, es indispensable que la discusión continúe en el marco de un discurso teórico, pero si el cuestionamiento tiene que ver con las reglas de la proposición normativa singular, tendrán que plantearse dos formas distintas de la argumentación (4.3 y 4.4).

Con la aplicación de las reglas 4.1 - 4.4 es posible llegar a resultados distintos con fundamentaciones similares y diferentes, por lo que debe decidirse qué regla o reglas deberán tener prioridad (P) bajo una condición cualquiera o condiciones determinadas (C); es por esta razón que Alexy establecerá las reglas de prioridad (4.5 y 4.6). Estas últimas reglas demuestran que no todas las reglas tienen que justificarse en el discurso a la vez, 
sino sólo toda regla del discurso práctico que puede ser objeto de justificación por parte de los participantes.

\subsubsection{Las reglas de fundamentación}

(5.1.1) Quien afirma una proposición normativa que presupone una regla para la satisfacción de los intereses de otras personas, debe poder aceptar las consecuencias de dicha regla también en el caso hipotético de que él se encontrara en la situación de aquellas personas.

(5.1.2) Las consecuencias de cada regla para la satisfacción de los intereses de cada uno deben poder ser aceptadas por todos.

(5.1.3) Toda regla debe poder enseñarse en forma abierta y general.

(5.2.1) Las reglas morales que sirven de base a las concepciones morales del hablante deben poder pasar la prueba de su génesis histórica-crítica. Una regla moral no pasa semejante prueba:

a) Si aunque originariamente se pudiera justificar racionalmente, sin embargo, ha perdido después su justificación, o

b) si originariamente no se puede justificar racionalmente y no se pueden aducir tampoco nuevas razones que sean suficientes.

(5.2.2) Las reglas morales que sirven de base a las concepciones morales del hablante deben poder pasar la prueba de su formación histórica individual. Una regla moral no pasa semejante prueba si se ha establecido sólo sobre la base de condiciones de socialización no justificables.

(5.3) Hay que respetar los límites de realizabilidad realmente dados.

Si un grupo de sujetos argumentan con las formas anteriores, pueden evitarse en gran medida usos estratégicos y violentos del lenguaje en el discurso, como pueden ser las adulaciones, acusaciones o amenazas explícitas o sutiles, pero también es posible justificar casi cualquier proposición normativa. Esta necesidad conduce a la formulación de reglas de fundamentación que, en primer lugar, estén formadas por diversas variantes del principio de universalidad, que pueden reducirse a argumentar que cualquiera debe poder estar de acuerdo con tales reglas y sus consecuencias afirmadas o presupuestas. Estas reglas determinarán el contenido de las proposiciones y reglas a fundamentar.

Para ello, Alexy planteará tres variaciones del principio de universalidad a partir de algunas reflexiones de Habermas, Hare y Baier (5.1.1 - 5.1.3), variaciones importantes, pero limitadas para alcanzar un acuerdo racional debido a la ausencia de un procedimiento que aumente la posibilidad de transformación de concepciones morales incompatibles existentes, por lo que serán requeridas otro grupo de reglas que garanticen la racionalidad por vía de la génesis crítica e individual. Este segundo grupo de reglas (5.2.1 - 5.2.3), desarrolladas a partir de ideas de Lorenzen, Schwemmer y Habermas, darán cuenta de la 
génesis crítica (5.2.1) e individual (5.2.2) del desarrollo de los sistemas de reglas morales por parte de los participantes del discurso. Pero también es necesaria una tercera regla (5.2.3) que resulte del hecho de que el discurso práctico debe realizarse para que sus resultados sean vinculados con cuestiones existentes y no con situaciones hipotéticas.

\subsubsection{Las reglas de transición}

(6.1) Para cualquier hablante y en cualquier momento es posible pasar a un discurso teórico (empírico).

(6.2) Para cualquier hablante y en cualquier momento es posible pasar a un discurso de análisis del lenguaje.

(6.3) Para cualquier hablante y en cualquier momento es posible pasar a un discurso de teoría del discurso.

En el discurso práctico pueden surgir cuestionamientos especiales cuya resolución requiere pasar a cuestiones de hecho de análisis del lenguaje y cuestiones referidas a la teoría del discurso misma. Por ello Alexy formula reglas (6.1 - 6.3) que permitan transitar hacia este tipo de cuestionamientos, tomando en cuenta que esta transición es relevante, como es el caso de los hechos en disputa, que tanto en la argumentación práctica como en la jurídica tienen una función fundamental para alcanzar un acuerdo lo más racional posible.

Con las reglas de transición terminamos el análisis de las reglas y formas del discurso práctico, y con ellas hemos dado un paso decisivo para alcanzar un consenso racional por todos los participantes. Las exigencias de no contradicción, universalidad, igualdad de derechos, no coerción, fundamentación y contraargumentación, muestran claramente que estas reglas contienen un contenido moral y no pueden reducirse a las habituales críticas que etiquetan este tipo de teorías procedimentales bajo el rótulo de "formalismo moral". Incluso, Atienza se pregunta si existen diferencias relevantes entre estas reglas del discurso racional y el código de conducta desarrollado por Frans van Eemeren y Rob Grootendorst. ${ }^{150}$

Asimismo, estas reglas y formas de argumentos parten de presupuestos inherentes a toda comunicación humana, a tal grado, que podemos afirmar que quien considere que no puede hablar de afirmaciones serias sin dar razones, así como escuchar a sus interlocutores, es porque no ha tomado parte en la forma de vida más elemental de los

150 Cfr., Atienza, Manuel, Curso de argumentación jurídica, Madrid, Trotta, 2013, p. 387. 
seres humanos. Es por eso que Apel considera que las consecuencias de no tomar parte de esta forma de vida conducirían a la pérdida de la "autocomprensión y de la autoidentificación", ${ }^{151}$ mientras que, Habermas considera, en Conciencia moral y acción comunicativa, que "[E]sta posibilidad supondría la retirada en el aislamiento monádico de la acción estratégica o en la esquizofrenia y el suicidio. A largo plazo, la posibilidad es destructora". 152

Sin embargo, estas reglas tienen defectos que limitan la fuerza normativa del discurso práctico en general, algunos de estos son claros: diversas reglas sólo pueden cumplirse parcialmente — problema muy importante en el caso de la ausencia de todo tipo de coerción-, no todos los pasos están determinados con total precisión, la pretensión de corrección de los argumentos presentados tampoco puede asegurarse, los participantes pueden partir de concepciones normativas distintas, el tiempo para la resolución del conflicto puede ser limitado, la solución final del procedimiento puede no ser correcto, y en caso de que se llegue a ella, no existe una garantía de que el resultado final será obedecido por todos los participantes. Estas posibles objeciones minimizan las aportaciones de esta teoría procedimental. Según Weinberger:

La discusión actual se centra en la teoría procedimental que sigue las ideas de Habermas y cuyo principal proponente Alexy ha introducido en la teoría del derecho. De acuerdo a esta postura la racionalidad está basada en un discurso intersubjetivo que sigue ciertas reglas sobre cómo llevar a cabo una discusión. Esta teoría se basa en la presuposición -que yo encuentro muy problemática- de que estos discursos y el consenso alcanzado a través de éstos necesariamente lleva a la verdad y a la concepción correcta. Pero el problema esencial de lo que son las buenas razones, y cómo pueden establecerse métodos apropiados de prueba y evidencia en su apoyo, es difícilmente considerado por esta teoría. ${ }^{153}$

De la crítica de Weinberger podemos reconocer que de la observancia se las reglas discursivas no puede garantizarse la bondad de los argumentos que se presenten, ni mucho menos que el procedimiento pueda fundamentar una respuesta última a los problemas morales y jurídicos de la sociedad moderna. Si la teoría del discurso estuviera solamente enfocada en que una norma sea aceptable cuando se cumpla con un procedimiento consensual, podríamos considerar que una situación de psicosis de masas cumple con esos requisitos sin problemas. sin embargo, la ética del discurso considera una situación

\footnotetext{
151 Apel, Karl-Otto, La transformación de la filosofía II, Madrid, Taurus, 1984, p. 381.

152 Habermas, Jürgen, op. cit., p. 127.

153 Weinberger, Ota, Law, Institution and Legal Politics: Fundamental problems of Legal theory and Social Philosophy, Dordrecht, Kluwer Academic Publishers, 1991, p. 72.
} 
diferente, ya que no basta con sostener que la validez de las normas reside en el consenso, sino que es indispensable alcanzar un punto de vista moral que nos permita distinguir aquellos consensos que poseen un carácter racional de los que no lo poseen.

Precisamente, las reglas del discurso permiten distinguir a este consenso de otros posibles, aunque no exista una adecuación plena entre procedimiento y resultado correcto, en virtud de que no existe un procedimiento discursivo que pueda garantizar una corrección última. Respecto a la pretensión de corrección como ideal regulativo del discurso práctico, Weinberger también le recrimina a Alexy que si ésta se plantea en términos débiles, entonces casi cualquier resultado del discurso puede postularse como correcto, por lo que si esta objeción debe refutarse, es indispensable dar una serie de pasos más para que no todo resultado del procedimiento tenga tal carácter.

Las reglas del discurso práctico han contribuido a la fundamentación racional de las proposiciones normativas, pero también son insuficientes para dar cuenta de los problemas de los problemas jurídicos, diferentes a los del discurso práctico. Esto es comprobable tanto a nivel empírico, analítico y normativo. En el plano normativo esto adquiere una dimensión importante porque el discurso jurídico no puede subsumirse sin más al discurso práctico, pues le faltarían elementos que le otorguen una mayor certeza a los resultados obtenidos, además de que los argumentos jurídicos deben guardar distancia de los argumentos morales. Esto quiere decir que la argumentación jurídica, por los fines que persigue y los medios con los que opera, necesita de una precisión mayor que la argumentación práctica. Los problemas prácticos que surgen en la sociedad pueden no resolverse por medio de las reglas y formas de la argumentación práctica. Este tipo de problemas son más notables cuando salen a flote dos deficiencias de los discursos prácticos: la falta de precisión para alcanzar un resultado y la falta de la dimensión coactiva, déficiencias que pueden subsanarse mediante la institucionalización del discurso jurídico.

Serán estas dos deficiencias, entre otras más, las que harán que pasemos al discurso jurídico, ya que, según Alexy, "[l]os debates morales pueden ser interminables, a menudo en la vida social no puede alcanzarse un consenso mediante el discurso. Por razones de necesidad práctica, entonces, debe tomarse una decisión autoritativa", ${ }^{154}$ y es

${ }^{154}$ Alexy, Robert, NRP, pp. 24 y 25. 
esta decisión revestida de autoridad institucional la que intentará conseguirse mediante las reglas y formas de la argumentación jurídica.

\subsection{Las reglas y formas de la argumentación jurídica}

La falta de una dimensión autoritativa es una deficiencia elemental del discurso práctico. Esto puede comprobarse a diario. En muchas ocasiones no es posible garantizar en todas las situaciones un acuerdo sobre cuestiones morales, mientras que en otras la falta de imponibilidad institucional del resultado de un discurso puede provocar nuevos problemas. Existen situaciones sencillas e ideales que pueden resolverse mediante el discurso práctico; otras en las que la falta de certeza plena de la corrección del resultado puede poner en duda la racionalidad del discurso y otro tipo de situaciones en las que la falta de imposición del resultado por parte de un tercero ausente apuntarían a la necesidad de institucionalizar ciertos procedimientos para resolver los conflictos sociales.

En muchos casos el discurso racional puede lograr en sus participantes una aceptación cognitiva y volitiva del resultado del discurso, en otras situaciones los participantes pueden tener puntos de vista inconciliables, y finalmente, en otros casos es posible que los participantes reconozcan el resultado del discurso como correcto, y, sin embargo, pueden no aceptar las consecuencias de éste y violentarlo por motivos que tengan un mayor peso subjetivo, debido a la ausencia de modo alguno de obligarlo a respetar lo pactado, provocando así una injusticia o un conflicto mayor entre ambos.

Dicho de otro modo, en ocasiones el resultado alcanzado mediante estas reglas puede no considerarse correcto por uno de los participantes, o considerarse correcto sin respetarse tal resultado. En el discurso moral existe la posibilidad de que los participantes caigan en vértigos argumentales. Según Carlos Pereda, los vértigos argumentales son aquellos vicios epistémicos y procesos de violencia interna que se dan cuando quien argumenta prolonga, confirma e inmuniza al punto de vista ya adoptado en la discusión, sin preocuparse de las posibles opciones a ese punto de vista, llegando, inclusive, hasta a prohibirlas, aunque esto sea hecho, en general, de forma no intencional. Estos vicios epistémicos los sintetiza Pereda del siguiente modo: 
[...] a) prolongar la discusión en cierta dirección, y sólo en ella, sin atender argumentos alternativos pertinentes e ignorando cualquier exploración; b) reafirmar los presupuestos básicos de la dirección ya tomada, sin admitir un serio cuestionamiento de ellos; c) inmunizarse frente a los ataques no cooperadores que se introduzcan en la discusión. ${ }^{155}$

Estas situaciones justifican el tránsito hacia la argumentación jurídica para resolver institucionalmente los conflictos sociales y, dicho sea de paso, justificar al derecho. La institucionalización del derecho tiene entre sus funciones, darle fuerza de ley al resultado para que sea reconocido como tal frente a quienes intenten aprovecharse de las deficiencias del discurso y las "buenas intenciones". En ocasiones, ningún argumento puede convencer a un egoísta "refinado" de que le es ventajoso actuar racionalmente. Los "refinados" son así forzados a obedecer el derecho. Con el tiempo, la fuerza puede hasta desarrollar en estos sujetos un hábito de obediencia voluntaria. Pues la coacción voluntaria promueve la educación moral de los egoístas. Para otra gente, este hecho proporciona una razón moral importante para obedecer el derecho. ${ }^{156}$

Si reiteramos el carácter coactivo-institucional del discurso jurídico, no es para justificar de manera sutil forma alguna de legalismo, sino para fundamentar la normatividad institucional del discurso jurídico. Esta fundamentación no debe causar sorpresa alguna, ya que es posible la existencia de situaciones en las cuales un sujeto puede reconocer una norma como válida para todos (no robar), y al mismo tiempo violarla, ya sea justificando o relativizando sus actos (afirmar que su acción es válida porque "todos lo harían si pudieran"), o evitar que las consecuencias del incumplimiento a ésta lo afecten en caso de que él mismo se vea afectado. Este carácter institucional no agota la "doble naturaleza del derecho", sino que, en tanto dimensión fáctica del derecho, sólo complementa la dimensión ideal del derecho, expresada bajo la pretensión de corrección. ${ }^{157}$

En este tipo de situaciones el problema es todavía mayor, porque estamos considerando que aun y cuando todas las personas pudieran reconocer como correcto el resultado de un procedimiento discursivo en el que participaron, no por ello lo respetarán.

\footnotetext{
155 Pereda, Carlos, Vértigos argumentales. Una ética de la disputa, Barcelona, Anthropos, 1994, pp. 107 y 108

${ }^{156}$ Cfr., Peczenik, Aleksander, Derecho y razón, México, D.F., Fontamara, 2003, p. 20

157 Por ahora es suficiente señalar que el carácter coactivo-institucional del discurso jurídico conforma la dimensión fáctica del derecho, pero no agota la doble dimensión del derecho. En el capítulo octavo de esta obra haremos explícita la conexión entre coerción y corrección como dimensiones necesarias de la doble naturaleza del derecho.
} 
La falta de certeza y de una autoridad que pueda controlar en cierta medida la latente posibilidad de que algunos sujetos no cumplan lo pactado será suplida cuando el discurso práctico se institucionalice en normas jurídicas establecidas por una autoridad, la cual, en ejercicio de una coacción legítima, resolverá problemas sociales que, de no plantearse en el ámbito jurídico, conducirían a una peligrosa fragilidad del orden jurídico. Por ello pasaremos al análisis de la argumentación jurídica.

Alexy considera diversos tipos de procedimientos jurídicos en los que la argumentación juega un papel destacado; estos procedimientos están vinculados a determinadas normas jurídicas y deben resolverse en un tiempo determinado, mientras que en otros casos la vinculación a las normas y la búsqueda de una solución temporal no es necesaria. Lo importante en ambos casos será señalar que cuando se argumenta, se hace jurídicamente. Esto implica que las discusiones que ahora se vinculan al derecho vigente tendrán tres características que ya mencionamos a finales del capítulo segundo, vinculadas a la tesis del caso especial. La pregunta que recordábamos a principios de este capítulo, acerca de qué es una fundamentación racional en el marco de un ordenamiento jurídico vigente, ahora será respondida mediante la justificación de las decisiones jurídicas. Esta justificación será realizada de manera interna y externa. Esta terminología Alexy la retomará a partir de algunos trabajos de Jerzy Wróblewski en torno a la justificación del razonamiento jurídico.

\subsubsection{Las reglas y formas de la justificación interna}

\subsection{Formas}

1.1.1 Forma más simple

(J.1.1) .(1) (x) (Tx $\rightarrow$ ORx $)$

(2) $\mathrm{Ta}$

(3) ORa (1), (2)

1.1.2 Forma más general

(J.1.2) .(1) (x) (Tx $\rightarrow$ ORx)

.(2) $(x)\left(M^{1} x \rightarrow T x\right)$

.(3) $(x)\left(M^{2} x \rightarrow M^{1} x\right)$
.(4) $(x)\left(S x \rightarrow M^{n} x\right)$
.(5) $\mathrm{Sa}$
.(6) Ora
(I) - (5)

\subsection{Reglas}


(J.2.1) Para la fundamentación de una decisión jurídica debe aducirse por lo menos una norma universal.

(J2.2) La decisión jurídica debe seguirse lógicamente al menos de una norma universal, junto con otras proposiciones.

(J2.3) Siempre que exista duda sobre si a es un T o un M', hay que aducir una regla que decida la cuestión.

(J2.4) Son necesarios los pasos de desarrollo que permitan formular expresiones cuya aplicación al caso en cuestión no sea discutible.

(J2.5) Hay que articular el mayor número posible de pasos de desarrollo.

La justificación interna está representada por la aplicación del silogismo jurídico a través de reglas y formas específicas. La justificación interna busca que la decisión se siga lógicamente de las premisas que se aducen como fundamentación. El uso de la lógica formal deductiva para el análisis de las proposiciones jurídicas ya había sido criticado por el Kelsen de la etapa escéptica en Teoría general de las normas, al sostener que el silogismo no funciona con las normas, ya que las reglas de la lógica son aplicables al silogismo teórico, vinculado con enunciados, pero no al silogismo normativo o práctico en el que al menos una premisa y la conclusión son normas. ${ }^{158}$

En favor de la justificación interna podemos decir que en su forma más general, establecida mediante la subsunción, puede resolver problemas jurídicos en los que un hecho se adecúa a una norma y así la conclusión puede extraerse. En muchas situaciones el silogismo basta para aplicar el derecho vigente a un caso específico, por lo cual éste es muy útil para casos en los que no se presenta mayor dificultad. Pero no toda fundamentación de las proposiciones jurídicas puede resolverse con este modelo de justificación. Dicho de otro modo, éste presenta dificultades cuando se presentan casos difíciles en los que (1) una norma contiene diversas propiedades alternativas en su supuesto de hecho, (2) su aplicación exige un complemento a través de normas jurídicas aclarativas, limitativas o extensivas, (3) son posibles diversas consecuencias jurídicas, y (4) en la formulación de la normas se usan expresiones que admiten diversas interpretaciones. ${ }^{159}$

\footnotetext{
${ }^{158}$ Para una crítica más detallada de Kelsen al uso de la lógica deductiva pueden consultarse los capítulos 58 y 59 de Teoría general de las normas.

${ }^{159}$ Cfr., Alexy, Robert, op. cit., 276 (p. 309).
} 
Dicho de otra manera, el silogismo puede funcionar cuando pensamos en casos sencillos en los que un hecho particular debe adecuarse a lo que prescribe una norma, pero no cuando los hechos no son claros y las normas a interpretar requieren de otras premisas que no encontramos en este modelo de justificación interna, de manera que un fundamento racional de la argumentación jurídica va más allá de este modelo simple. Por ello, ante los límites de la justificación interna la fundamentación jurídica debe fundamentarse mediante la justificación externa, la cual será analizada ahora.

\subsubsection{Las reglas y formas de la justificación externa}

Como vimos, el silogismo jurídico no es suficiente cuando se presentan casos difíciles que no pueden resolverse mediante el razonamiento silogístico, por lo tanto, debe buscarse otro modelo de fundamentación, consistente en la justificación externa. Estos conceptos de justificación tanto Alexy como MacCormick los retoman de un influyente artículo de Jerzy Wróblewski, quien dio cuenta de la insuficiencia del silogismo jurídico como justificación plena de la argumentación jurídica. ${ }^{160}$ El objeto de la justificación externa será la fundamentación de sus premisas, las cuales se dividirán en (1) reglas de derecho positivo; justificadas cuando entran en vigencia según criterios jurídicos formales, (2) enunciados empíricos, justificados según diversos métodos de las ciencias empíricas; y por último, (3) premisas que no son derecho positivo ni enunciados empíricos, justificadas mediante las reglas y formas respectivas. Las siguientes formas de argumentos estarán dedicadas a este tipo de premisas.

Al igual que con la argumentación práctica, Alexy dividirá las reglas y formas de la justificación externa en seis grupos, que si pudieran ser designados mediante una sola palabra se referirían a la (1) ley, (2) dogmática, (3) precedentes, (4) razón, (5) empirie y (6) formas especiales de argumentos jurídicos. De estos seis grupos, el cuarto, el de la razón o argumentación práctica general, ya ha sido visto al exponerse las reglas y formas de la argumentación práctica, así que ahora pasaremos al análisis de los otros grupos.

\subsubsection{Reglas y formas de la argumentación empírica}

${ }^{160}$ Cfr., Wróblewski, Jerzy, "Legal Syllogism and Rationality of Judicial Decision", en Rechtstheorie, n. 5, 1974, p. 39. 
Rige [6.1]. No se elaboraron reglas y formas especiales.

Las reglas y formas de la argumentación empírica son las mismas que vimos al final de las de la argumentación práctica, las reglas de transición (6.1), lo cual podría explicar de alguna manera el tránsito del discurso práctico al jurídico. Alexy no entra en detalle sobre los diversos tipos de argumentación empírica - porque para ello se necesitaría abordarla desde una perspectiva interdisciplinaria-y sólo señala su importancia porque en casi todos los problemas jurídicos la controversia sobre este tipo de argumentos es posible. En ocasiones, la discusión sobre diversos conflictos jurídicos suele resolverse a través del análisis de las las evidencias empíricas. Es por ello que el análisis de los argumentos empíricos no debe ser subestimado por las teorías de la argumentación jurídica, aunque también es cierto que la racionalidad de las premisas no debe reducirse al mero estudio de los hechos o de los argumentos empíricos. En todo caso, la argumentación jurídica requiere en algunos casos de argumentos científicos o técnicos para ser complementada.

\subsubsection{Reglas y formas de interpretación}

2.2.1 Formas de la interpretación semántica

[J.3.1] R' debe aceptarse como interpretación de R' sobre la base de $W_{i}$.

[J.3.2] R' no puede aceptarse como una interpretación de R' sobre la base de $\mathrm{W}_{k}$.

[J.3.3] Es posible aceptar R' como interpretación de R, y es posible no aceptar R' como interpretación de $\mathrm{R}$, pues no rigen ni $W_{i}$ ni $W_{k}$.

2.2.2 Forma fundamental de la interpretación genética

[J.4.1] (1) R' (= I $\frac{R}{W}$ ) es querido por el legislador.

(2) R'

[J.4.2] (1) Con $R$ el legislador pretenderá alcanzar Z

(2) $\neg R^{\prime}\left(=I \frac{R}{W}\right) \rightarrow \neg Z$

(3)R'

2.2.3. Forma fundamental de la interpretación teleológica

[J.5] (I) OZ

(2) $\neg R^{\prime}\left(=I \frac{R}{W}\right) \rightarrow \neg Z$

(3) R'

2.2.4. No se elaboraron formas de la interpretación histórica, comparada y sistemática.

\subsubsection{Reglas}

[J.6] Debe resultar saturada toda forma de argumento que haya de contar entre los cánones de la interpretación. 
[J.7] Los argumentos que expresan una vinculación al tenor literal de la ley o a la voluntad del legislador histórico prevalecen sobre otros argumentos, a no ser que puedan aducirse otros motivos racionales que concedan prioridad a los otros argumentos.

[J.8j La determinación del peso de argumentos de distintas formas debe tener lugar según reglas de ponderación.

[J.9] Hay que tomar en consideración todos los argumentos que sea posible proponer y que puedan incluirse por su forma entre los cánones de la interpretación.

Sobre las reglas y formas de interpretación existen dificultades para definirlas, debido a la existencia de diversas escuelas, métodos y argumentos en favor y en contra de usarlas. El modelo discursivo de interpretación surge ante las debilidades de los modelos más importantes, los cuales son el deductivo, poco efectivo ante la vaguedad del lenguaje; el decisorio, representado por Kelsen, ${ }^{161}$ según el cual la decisión del juez es un mero acto de voluntad; el hermenéutico, el cual, a pesar de incorporar la contribución del intérprete a la interpretación, poco o nada dice acerca de los criterios de confirmación o rechazo de la hipótesis de interpretación; y el de coherencia, representado por Ronald Dworkin, el cual termina en un holismo jurídico, ya que todas las premisas ya están en el sistema y sólo se necesita descubrirlas. ${ }^{162}$ Las funciones principales de los cánones de interpretación consistirán en fundamentar las interpretaciones de las normas y otros enunciados jurídicos. Estos cánones los agrupará Alexy en los siguientes argumentos:

(2.2.1) Argumento semántico: este consiste en aceptar (J.3.1), no justificar (J.3.2) o afirmar como posible (J.3.3) una interpretación en términos semánticos. Los primeros dos argumentos serán definitivos (aceptar o no aceptar), mientras que el último señala que con medios semánticos no puede alcanzarse una decisión definitiva. Los términos semánticos no serán suficientes para explicar los criterios para aceptar plena o parcialmente una norma o no, por lo cual los demás cánones servirán para justificar estas tres determinaciones.

(2.2.2) Argumento genético: este consiste en justificar una interpretación de una regla adicional ( $\left.\mathrm{R}^{\prime}\right)$ de una regla $(\mathrm{R})$, porque corresponde con la voluntad originaria del legislador, es decir, justificar una interpretación de acuerdo a lo que el legislador quería al momento de la positivización de la norma. Las dos formas en las que Alexy lo desarrolla

${ }^{161} \mathrm{Cfr} .$, Kelsen, Hans, Reine Rechtslehre. Einleitung in der rechtswissentschaftliche Problematik, Tubinga, Mohr Siebeck, 2008, p. 107.

162 Cfr., Alexy, Robert, TDDH, pp. 36-46. 
consisten en expresar primero una interpretación querida por el legislador (J.4.1) y otra con la que el legislador pretende alcanzar un fin (Z). Un análisis del argumento genético comprueba que posee debilidades normativas y que, al igual que el argumento semántico, se asemeja a un tipo especial de argumentación empírica, porque se trata en ambos casos de establecer cuál fue la intención real del legislador, es decir, es posible que se expresen opiniones contrarias que aludan a la voluntad originaria del legislador.

(2.2.3) Argumento histórico: este consiste en justificar razones a favor o en contra de una interpretación a partir de hechos que tuvieron determinadas consecuencias. Este argumento presupone diversos conocimientos históricos, económicos y sociológicos, así como diversas premisas normativas.

(2.2.4) Argumento comparativo: este consiste en justificar una interpretación a partir de un estado de cosas de otra sociedad. Este tipo de argumento es polémico porque parte de premisas empíricas que pueden criticarse por referirse a mejores o peores condiciones sociales, económicas, políticas e históricas muy distintas, aunque tenga intenciones normativas el uso de los argumentos comparativos.

(2.2.5) Argumento sistemático: este consiste en justificar una interpretación a partir de la referencia a la situación de una norma en un cuerpo legal o a la referencia a la relación lógica o teleológica de ésta con otras normas, fines y principios jurídicos. La fuerza de este argumento ha llevado a juristas como Dworkin a considerarlo idóneo para resolver diversos problemas de interpretación.

(2.2.6) Argumento teleológico: este argumento consiste en justificar una interpretación a partir de fines "racionales" o "prescritos objetivamente en el contexto del ordenamiento jurídico vigente". Este argumento que se corresponde con la forma (J.5) suscita problemas cuando se pregunta por saber en qué consisten esos fines racionales, porque podríamos caer en argumentos objetivo-cognitivos o en argumentos subjetivoarbitrarios sobre lo que debe entenderse como racional. Alexy considera que la teoría del discurso puede dar una respuesta a esta interrogante porque para ésta son "fines racionales o prescritos objetivamente en el marco del ordenamiento jurídico vigente aquellos que 
establecerían quienes deben tomar decisiones en el marco del ordenamiento jurídico sobre la base de la argumentación racional". ${ }^{163}$

Todos los anteriores cánones de interpretación pueden usarse en una misma situación y por ello es posible llegar a resultados distintos y contradictorios (por ejemplo, un argumento comparativo se puede aducir contra uno teleológico sobre el pago de un determinado impuesto y llevar así a un debate interminable), por lo cual Alexy introduce reglas (J.7) mediante las cuales se le dé prevalencia prima facie a los argumentos semánticos y genéticos, pondere el peso de los argumentos (J.8), ${ }^{164}$ consideren todos los argumentos propuestos y busque la manera de incluirlos en algún tipo de interpretación.

\subsubsection{Reglas de la argumentación dogmática}

[J.10] Todo enunciado dogmático si es puesto en duda debe ser fundamentado mediante el empleo al menos de un argumento práctico de tipo general.

[J.11] Todo enunciado dogmático debe poder pasar una comprobación sistemática, tanto en sentido estricto como en sentido amplio.

[J.12] Si son posibles los argumentos dogmáticos, deben ser usados.

El grupo de las reglas y formas de interpretación tampoco resulta satisfactorio por sí solo para poder comprobar la racionalidad del discurso jurídico, porque es posible que se puedan usar diferentes tipos de argumentos y llegar así a conclusiones contradictorias; por ello pasaremos a la argumentación dogmática. La dogmática jurídica, a la que Alexy le otorga una notable importancia, la entiende, como (1) enunciados que (2) están relacionados con las normas establecidas y con la jurisprudencia, (3) para formar un todo coherente (4), formados y discutidos en el marco de una ciencia jurídica institucionalizada y cuyo (5) contenido es normativo.

La dogmática jurídica tiene como tareas el análisis lógico de los conceptos jurídicos, (2) la reconducción de este análisis a un sistema jurídico, y (3) la aplicación de los

\footnotetext{
163 Alexy, Robert, TAJ, p. 332.

${ }^{164}$ En esta regla encontramos por primera vez en el pensamiento de Alexy la idea de que ante un conflicto entre dos tipos de interpretación debe ponderarse el peso de los argumentos, es decir, debe llevarse a cabo un ejercicio de ponderación para determinar qué argumentos deben tener prioridad sobre otros.
} 
resultados de este análisis en la fundamentación de las decisiones jurídicas. Para que los argumentos dogmáticos puedan utilizarse es necesario que deban fundamentarse mediante un argumento práctico general (J.10) y comprobarse tanto en un sentido estricto como en un sentido amplio (J.11).

Alexy le confiere a la dogmática seis funciones positivas, que son las siguientes: (1) de estabilización, porque por medio de enunciados dogmáticos institucionalizados se fijan y reproducen soluciones a cuestiones prácticas; (2) de progreso, porque posibilita ofrecer comprobaciones y diferenciar los enunciados dogmáticos en una medida mayor de lo que sería posible en discusiones puntuales; (3) de descarga, porque en discusiones jurídicas y en el campo de aplicación de justicia se puede renunciar a discutir todas las cuestiones valorativas cada vez; (4) de técnica, para construir conceptos básicos generales, formas de enunciados, instituciones jurídicas de forma unificada y sistémática; (5) de control, al permitir resolver casos de conformidad con cómo fueron resueltos casos similares, acrecentando con ello la eficacia del principio de universalidad y servir con ello a la justicia; (6) y de heurística, al sugerir preguntas y respuestas que de otra manera serían imposibles de plantear. Por estas razones, la dogmática jurídica posee una función instrumentalpositiva que contribuye a que puedan conseguirse resultados que no serían posibles con los medios del discurso práctico general. Como consecuencia directa de estas consecuencias positivas Alexy formula la regla de acuerdo con la que deben usarse los argumentos dogmáticos si son posibles (J.12).

\subsubsection{Las reglas más generales del caso de los precedentes}

[J.13] Cuando pueda citarse un precedente en favor o en contra de una decisión, debe hacerse.

[J. 14] Quien quiera apartarse de un precedente asume la carga de la argumentación.

El uso de los precedentes constituye uno de los aspectos más importantes de la praxis jurídica moderna. Usualmente suele decirse que los precedentes son una parte de la Teoría de las fuentes del derecho. Esta teoría, ocupada de los orígenes de las normas y factores que influyen de hecho en las decisiones de los jueces, considera como fuentes del derecho a la ley, la costumbre, la doctrina y la jurisprudencia. La jurisprudencia o precedentes consisten en el conjunto de principios y criterios contenidos en las resoluciones judiciales que determinan las decisiones emitidas por los tribunales y a los que se les 
reconoce fuerza vinculatoria, en términos de interpretación de la Constitución, tratados internacionales y demás leyes de inferior jerarquía. Estas razones le otorgan a los precedentes una importancia fáctica imprescindible para cualquier teoría de la argumentación jurídica.

Bajo los presupuestos de la teoría del discurso el uso de los precedentes está fundamentado bajo el principio de universalidad (1.3'), que exige tratar de igual manera a lo igual, lo cual no nos dice mucho porque no todos los problemas son totalmente iguales y es por eso que la obligación de usar al precedente no es absoluta, sino condicionada a que si una parte desea usarlo, debe aducir razones para fundamentar que, sí pueden tratarse algunos casos como si fueran iguales, apelando así al principio de igualdad (3.1). A partir de esta reflexión Alexy formulara dos reglas para citarse los precedentes cuando esto pueda hacerse (J.13) y aceptarse la carga de la argumentación en caso de que alguien decida apartarse de éstos (J.14) al no considerarlos aplicables al caso concreto.

\subsubsection{Formas de argumentos jurídicos especiales}

2.5.1. Formas

[J. 15] .(1) (x) (OGx $\rightarrow \mathrm{Fx})$

(2) $(x)(\neg F x \rightarrow \neg O G x)$

[J. 16] .(1) (x) (Fx v F sim $x \rightarrow O G x)$

(2) $(x)(H x \rightarrow F \operatorname{sim} x)$

.(3) $(x)(H x \rightarrow O G x)(1),(2)$

[J.17] .(1) $0 \neg Z$

(2) $R^{\prime} \rightarrow Z$

(3) $\neg R^{\prime}$

2.5.2. Reglas

[J. 18] Las formas de argumentos jurídicos especiales tienen que resultar saturadas.

Finalmente, los tipos especiales de argumentos son aquellos usados especialmente en la metodología jurídica y que pueden expresarse como formas de inferencia, válidas en términos lógicos, como lo ha explicado Jan Joerden mediante el uso del Modus Barbara. ${ }^{165}$ Estos argumentos son el argumentum e contrario, el argumentum a fortiori, el argumentum

${ }^{165}$ Cfr., Joerden, Jan-Reinard, Logik im Recht. Grundlagen und Andwendungbeispiele, Heidelberg, Springer, 2010, pp. 351 ss. 
ad absurdum y la analogía, ${ }^{166}$ siendo esta última, en tanto operación de aplicación del derecho, una forma de argumentación que ha comenzado a tener desarrollos notables en el ámbito del derecho constitucional, como lo muestra un trabajo reciente de Laura Clérico. ${ }^{167}$ Las formas de argumentos especiales resultan ser casos especiales de la argumentación práctica porque son de esquemas de inferencia de la lógica deductiva (J.15), exigidos por el principio de universalidad (J.16) y toman en cuenta las consecuencias (J.17) obtenidas de los casos en los que sean usados. El uso de estas formas prácticas se considerará racional cuando resulten saturadas y cuando los enunciados jurídicos que se propongan para la saturación puedan fundamentarse en el discurso jurídico (J.18). Estas inferencias lógicas serán explicadas a continuación.

Según el argumentum e contrario, sólo proceden las consecuencias jurídicas previstas en una norma cuando se cumplan todos y cada uno de los requisitos previstos en el supuesto como condición de la materialización de tales consecuencias. Es decir, si no se cumplen todos los requisitos establecidos por la normas, no existirá la consecuencia jurídica de tal norma.

Según el argumentum a fortiori o de mayoría de razón, es posible inferir de la validez de una norma jurídica prevista expresamente en la ley, la validez de otra norma menos amplia no prevista de manera expresa en la ley. Este argumento se divide en maiori ad

\footnotetext{
${ }^{166}$ Recientemente, a partir del trabajo "Arthur Kaufmanns Theorie der Rechtsgewinnung", Alexy conjeturó que existía, al lado de la subsunción y la ponderación, una tercera operación básica en la aplicación del derecho, la analogía entre casos o la comparación entre ellos (Cfr., "Arthur Kaufmanns Theorie der Rechtsgewinnung", en, Neumann, Ulfrid, Hassemer, Winfried, y Schroth, Ulrich, Verantwortetes Recht. Die Rechtsphilosophie Arthur Kaufmanns, ARSP-Beiheft 100, Stuttgart, Nomos Verlagsgesellschaft 2005, pp. 65 y 66. En adelante, AKTR.). Esta conjetura, criticada posteriormente por Bäcker y Bastosz Brozek, llevó a Alexy a realizar un trabajo en el cual fundamenta con mayor detalle a la analogía, ya que "el esquema de la analogía no sólo es formal y necesario, sino específico. Esto es más que suficiente para calificar a la analogía (comparación) como una tercera operación básica del derecho". (Alexy, Robert, "Two or Three", en Borowski, Martin, On the Nature of Legal Principles, ARSP-Beiheft 119, Stuttgart, Nomos Verlagsgesellschaft, 2010, p. 18. en adelante, TOT). Para un análisis más detallado de la crítica a Alexy, cfr., Bäcker, Carsten, op. cit., p. 318 ss.

${ }^{167}$ Sobre este punto, en el ámbito del derecho constitucional nos ha llamado la atención el esfuerzo de Clérico por "rescatar la importancia de los casos en el modelo de la ponderación alexyano que, a mi entender, quedó opacado por su preocupación en el desarrollo de la ponderación como forma de argumento" (Clérico, Laura, "Los casos en el modelo de la ponderación orientado por reglas. El modelo alexyano de la ponderación en comparación con el modelo "especificionista» de Moreso", en, Bernal, Carlos (Ed.), La doble dimensión del derecho. Autoridad y razón en la obra de Robert Alexy, Lima, Palestra Editores, 2011, p. 207).
} 
minus (la norma que autoriza lo más también autoriza lo menos) y minore ad maius (extiende la prohibición de la norma hacia determinados actos a otros que habría que prohibir también). Estos argumentos, sin embargo, no pueden aplicarse en el ámbito del derecho penal, en virtud de que no pueden castigarse acciones a las que la ley no se refiera como delitos.

Según el argumentum ad absurdum la validez de una interpretación es confirmada al demostrar que otra posibilidad de interpretación resulta irracional si sus consecuencias fuesen aceptadas. Este argumento es un tipo de demostración indirecta de la validez de un argumento jurídico al confirmar la invalidez del argumento contrario al tomarlo como si fuese correcto. Finalmente, de acuerdo con la analogía o argumentum a pari, al cual nos referimos antes, las consecuencias jurídicas de una norma pueden aplicarse a otros hechos diferentes previstos en dicho supuesto, con los que existen ciertas semejanzas. Esto lleva a extender las consecuencias jurídicas a hechos que coincidan con las características previstas de la primera norma.

Con la exposición de los argumentos especiales terminamos el análisis de las reglas y formas de la argumentación jurídica. Como puede verse, con la exposición de las reglas y formas de la argumentación jurídica puede alcanzarse un mayor refinamiento argumentativo en comparación con la argumentación práctica; no obstante, los argumentos jurídicos tampoco ofrecen una certeza última.

Por lo tanto, la pretensión de corrección planteada en el discurso jurídico se vislumbra como limitada, esto es, no es posible defender una conexión lógica entre el procedimiento jurídico-discursivo y una respuesta siempre correcta. Por fortuna, Alexy no ha defendido tal conexión, en tanto es imposible. Las reglas y formas de la argumentación jurídica no pueden brindarnos una respuesta única, sin que por ello renunciemos a fundamentar racionalmente las normas y valoraciones en el derecho, ya que "no es la producción de seguridad lo que constituye el carácter racional de la jurisprudencia, sino el cumplimiento de una serie de condiciones, criterios o reglas" ${ }^{168}$ las que pueden otorgarle racionalidad al sistema jurídico. Sin embargo, estas reglas y formas de la argumentación

${ }^{168}$ Alexy, Robert, TAJ, p. 400. 
pueden concebirse como un elemento esencial del Estado de derecho. Gracias a esto puede afirmarse lo siguiente:

Los juristas pueden ciertamente contribuir a la realización de la razón y de la justicia, pero esto, en el sector que ellos ocupan, no pueden realizarlo aisladamente, ello presupone un orden social racional y justo. ${ }^{169}$

Para que "un orden racional y justo" pueda plantearse como posible serán necesarios otros elementos que no se encuentran en la Teoría de la argumentación jurídica, pero sí en otras obras de Alexy. Por ejemplo, ¿qué hay acerca de la distinción entre principios y reglas?, ¿tienen los derechos un fundamento?, ¿cuáles derechos deben tener el estatus de fundamentales?, ¿cómo serán resueltos los conflictos normativos entre derechos? Estas preguntas serán las que nos harán hacer el tránsito hacia la siguiente sección. Pero antes de hacer este tránsito, se hará una vinculación entre la argumentación jurídica y el Estado de derecho.

\subsection{Teoría de la argumentación jurídica y Estado de derecho}

Antes de terminar con esta sección, haremos una reflexión que tendrá por objeto establecer la relación normativa entre argumentación jurídica y Estado de derecho, y con ello, será explicado por qué la argumentación jurídica es parte indispensable de todo Estado democrático y social de derecho.

Tal y como lo indicamos en el capítulo primero, en diversos ámbitos filosóficos hemos presenciado en las últimas décadas una serie de obras de filosofía práctica en las cuales temas sobre derechos humanos y Estado de derecho han tenido una notable importancia. Sobre estos temas también han girado obras en las que la argumentación jurídica ha estado presente como un tópico esencial. Además de obras contemporanéas como las de Alexy y MacCormick, en Derecho y razón de Luigi Ferrajoli se encuentra un modelo garantista de argumentación basado en la idea de verdad procesal.

En esta obra, Ferrajoli establece una serie de principios garantistas tanto dogmáticos como procesales para que pueda alcanzarse lo que él ha llamado verdad procesal, término medio entre la verdad jurídica y la fáctica. Una de las preocupaciones de

${ }^{169}$ Alexy, Robert, TAJ, p. 402. 
Ferrajoli consiste en mostrar que la pretensión de alcanzar una verdad objetiva no es garantizable. Las razones expresadas por Ferrajoli son las siguientes:

[E]l hecho de que la investigación judicial no esté en condiciones de alcanzar la verdad objetiva, que esté condicionada por la subjetividad y hasta por la noneutralidad del juez, que, en fin, haya lugar allí para momentos de decisión puede en realidad empujar a conclusiones decisionistas sobre todo a quienes no consiguen concebir la búsqueda de la verdad en el proceso más que según el viejo espejismo ilustrado de la aplicación mecánica de la ley al hecho infaliblemente comprobado. ${ }^{170}$

De igual modo, el juez no puede ni debe ser un aplicador mecánico de la ley, ya que ésta siempre tiene problemas de interpretación, ante los cuales subyace en el fondo un problema de equidad. Ante estos problemas ningún modelo de argumentación práctica o jurídica es capaz de brindar una certeza absoluta a partir del seguimiento de determinadas reglas o formas de la argumentación práctica y jurídica. No obstante, sí es posible usar estas reglas y formas para reducir los niveles de irracionalidad presentes en los ámbitos en los que se argumenta jurídicamente. Esto es de suma importancia para el Estado de derecho, porque no sólo debemos explicar cómo es que son positivizadas las normas y decididas las controversias judiciales, sino saber si estas prácticas pueden considerarse racionales por los participantes del discurso jurídico.

Uno de los criterios de legitimidad de las decisiones jurídicas en un Estado de derecho reside en que la argumentación jurídica tenga una pretensión de imparcialidad, la cual es posible cuando ésta sea lo más parecida a un diálogo entre tres partes. ${ }^{171} \mathrm{~A}$ diferencia de un discurso practico, en el que un hablante intenta convencer a la otra parte, el discurso jurídico presupone la existencia de una tercera parte que debe ser neutral respecto a las pretensiones de las otras dos partes en conflicto, y es tal postura imparcial la que le confiere al derecho su carácter autoritativo, cuya resolución final deberá ser acatada por las partes. No obstante, cuando la argumentación jurídica deja de ser un diálogo entre tres partes porque el juez u operadores jurídicos están predispuestos en favor de una de éstas, entonces renuncian a una condición del juego de la argumentación jurídica.

Otro problema vinculado con la teoría de la argumentación jurídica de Alexy consiste en que esta teoría puede tener un interés limitado para algunos juristas, ya que no hace

\footnotetext{
${ }^{170}$ Ferrajoli, Luigi, Derecho y razón, Teoría del garantismo penal, Madrid, Trotta, 2006, pp. 62 y 63.

171 Sobre esta idea, de la que somos deudores, cfr., Gorman, Jonathan, "Three Person Justification", en, Pavlakos, George, Law, Rights and Discourse. The Legal Philosophy of Robert Alexy, Oxford, Hart Publishing 2007, p, 207 ss.
} 
énfasis en los hechos y las pruebas, y descuida, según Atienza, que en realidad la mayoría de los conflictos se resuelven mediante una negociación más o menos estratégica. ${ }^{172}$ No obstante, si esta teoría aspira a poseer un enfoque prescriptivo, no puede basarse en los elementos fácticos o en la forma en como se deciden realmente los problemas jurídicos. Los elementos normativos son parte de la crítica y del establecimiento de ideales regulativos para que la argumentación jurídica sea racional.

Los señalamientos anteriores, sin embargo, no le restan mérito alguno al planteamiento de Alexy. Incluso, puede afirmarse que sus postulados críticos pueden servir para cuestionar diversas decisiones jurídicas cuyo resultado final puede ser objeto de crítica. Sobre todo, debe procurarse que en un Estado democrático y social de derecho la argumentación jurídica racional constituya un eje rector de todos los ámbitos en los cuales esté involucrada, evitando así que cause agravios morales para los ciudadanos del Estado al favorecer a intereses ilegítimos, ya sea que tales agravios provengan de autoridades estatales o de poderes del ámbito civil. Estos agravios morales ocurren cuando el discurso jurídico es usado de modo ilegítimo por autoridades estatales o "poderes salvajes o inciviles", ${ }^{173}$ los cuales usan los argumentos jurídicos como intrumento de dominación. Precisamente es ante estas situaciones que la teoría de la argumentación de Alexy puede proveernos de una importante fuente de reducción de criterios discrecionales por parte de los jueces y demás operadores del sistema jurídico, quienes podrían encontrar en las reglas y formas de la teoría del discurso un instrumento valioso para deliberar lo más correctamente posible de acuerdo con sus posibilidades jurídicas y fácticas. Esta teoría del discurso se devela así como un garante del Estado de derecho, siempre y cuando sea usada de modo correcto.

La teoría del discurso práctico y jurídico, tal y como es elaborada por Alexy, establece un conjunto de reglas y formas de la argumentación destinadas a fundamentar, institucionalizar y aplicar los principios de no coerción, igualdad y libertad para los participantes del discurso, en este caso, los ciudadanos de un Estado de derecho. De esta manera, la teoría del discurso acaba por presuponer una forma estatal asociada con el Estado de derecho, en la cual las reglas y formas de la argumentación deben

\footnotetext{
172 Cfr., Atienza, Manuel, op. cit., pp. 304 ss.

${ }^{173}$ Al referirnos a "poderes salvajes o inciviles", nos referimos a la caracterización que hace de ellos Luigi Ferrajoli, entendidos como poderes salvajes ilegales y extralegales, poderes salvajes privados y públicos. Cfr., Ferrajoli, Luigi, El garantismo y la filosofía del derecho, Bogotá, UEC, 2000, pp. 126 a 131.
} 
institucionalizarse para racionalizar el discurso jurídico en tanto es asociado con una forma estatal vinculada al Estado de derecho:

[L]a teoría del discurso presupone, en este sentido, una forma estatal, la cual en sus condiciones fundamentales garantiza la capacidad de comunicación de sus ciudadanos. Determinantes son aquí las reglas del discurso que Alexy denomina reglas de razón, según las cuales en el discurso debe haber igualdad y libertad. ${ }^{174}$

En tiempos en los que la argumentación jurídica goza de un auge formidable, en buena parte gracias a la obra de Alexy, las decisiones judiciales han sido sometidas a un escrutinio mayor por parte de conocedores del sistema jurídico y de la opinión pública informada, en busca de que éstas sean objetivas y, por tanto, legítimas. Con seguridad, puede afirmarse que si analizamos las deciciones jurídicas a la luz de las teorías contemporáneas de la argumentación jurídica nos daremos cuenta de que hay una brecha entre la teoría de Alexy y los razonamientos jurídicos que suelen terminar en una decisión o argumento jurídico relevante, ya sea en sus aspectos lógicos, retóricos o dialógicos. ${ }^{175}$

En este sentido, la objetividad en el ámbito jurídico puede alcanzarse, si bien existirán situaciones en las que será más fácil comprender la posibilidad de este ideal que en otras en las cuales una sola respuesta no aparecerá como la única posible. También, la teoría de Alexy ha dejado claro que la argumentación jurídica no es posible sin la argumentación práctica. Esto también será claro durante la reconstrucción del principio de proporcionalidad. Por ahora es suficiente con indicar que el estudio de la teoría de la argumentación jurídica nos ha permitido llevar a cabo un análisis importante de la filosofía del derecho de Alexy, pero no es posible quedarnos aquí. Es necesario análizar aquellos derechos que son constitutivos de un Estado democrático y social de derecho.

La relación entre el razonamiento jurídico y los derechos fundamentales será de especial importancia para el sistema de fillsofía jurídica de Alexy y para el análisis de la argumentación en el ámbito constitucional. El fundamento de los derechos humanos, la distinción entre principios y reglas, el sistema de posiciones fundamentales y el principio de proporcionalidad son temas que serán tratados en los siguientes capítulos.

\footnotetext{
174 Bäcker, Carsten, "Recht als institutionalisierte Vernunft. Zu Robert Alexys diskurstheoretischer Konzeption des Rechts", en, Archiv für Rechts- und Sozialphilosophie, Vol. 97, Franz Steiner Verlag, 2011, p. 351.

175 Sobre estas tres aproximaciones a la argumentación jurídica, cfr., Feteris, Eveline, op. cit., pp. 15-20.
} 


\section{Segunda parte}

\section{Capítulo cuarto. La fundamentación filosófica de los derechos fundamentales}

\section{Introducción}

En la primera sección fue expuesta la teoría de la argumentación jurídica de Robert Alexy. Ahora daemos inicio a la segunda sección de esta obra, la cual gira en torno a los derechos humanos y fundamentales en la obra de Alexy. La institucionalización exige la positivización de normas que configuren un marco de respeto a la libertad, igualdad y dignidad de las personas, configurar libertades y garantías básicas a los ciudadanos de un Estado, delimitar estrictamente las facultades de los poderes públicos, proteger a los individuos de los abusos de autoridades estatales y poderes fácticos, y, finalmente, reducir las desigualdades sociales provocadas por una sociedad de mercado.

El tránsito de una teoría de la argumentación jurídica a una teoría de los derechos fundamentales lo ha hecho explícito Alexy mediante la tesis de la conexión entre ambas teorías. Esta tesis es la siguiente:

[M]i tesis es que hay una relación interna entre la teoría de los derechos y la teoría del razonamiento jurídico. No puede haber una teoría de los derechos fundamentales sin tener una teoría del razonamiento jurídico, y una teoría del razonamiento jurídico adecuada, presupone una teoría de los derechos fundamentales. ${ }^{176}$

Esta tesis explica la conexión entre la teoría del razonamiento jurídico, que se expuso en la primera sección, y la de los derechos fundamentales, que se expondrá en esta segunda sección, y cuyo objetivo será el de introducir el problema del razonamiento moral en torno al fundamento, positivización (o institucionalización) y aplicación de normas fundamentales de un sistema jurídico. A partir de ahora será analizada la obra Teoría de los derechos fundamentales, así como toda una serie de artículos en los cuales Alexy ha refinado y complementado su visión en torno a ellos.

${ }^{176}$ Alexy, Robert, DRP, p. 21. 


\subsection{Sobre el reciente discurso de los derechos}

Los derechos humanos han sido objeto de un discurso moral, político y jurídico muy amplio en las últimas décadas. En el ámbito de la filosofía del derecho autores como Alexy, Ferrajoli y Dworkin han contribuido a enriquecer los debates contemporáneos en torno a los derechos humanos. Las reflexiones de Alexy sobre el concepto, naturaleza y estructura de los derechos fundamentales serán el objeto de su tesis de habilitación en derecho público y filosofía del derecho que realizó en 1984 en la Facultad de Derecho de la Universidad de Gotinga, y publicada en 1985 con el título Teoría de los derechos fundamentales. Esta obra será el eje central sobre el que se desarrollará esta sección segunda dedicada a la teoría de los derechos fundamentales. Teoría de los derechos fundamentales no tiene como objeto principal los derechos humanos en el plano moral o filosófico-político, sino los derechos fundamentales estructurados en la Ley Fundamental de Bonn, aunque sin duda apoyada en un potente análisis filosófico. ${ }^{177}$

Es cierto que la Teoría de Los derechos fundamentales está enmarcada dentro del contexto de la teoría analítica del derecho y en el contexto práctico de la mencionada Ley Fundamental de la República Federal de Alemania, ${ }^{178}$ y que fue desarrollada como una reconstrucción de la práctica jurídica de los tribunales constitucionales alemanes, pero también "es ampliamente reconocida como una teoría que ayuda a arrojar luz sobre la práctica de los derechos humanos y fundamentales más en general". ${ }^{179}$ También, es sabido que esta teoría ha ejercido una notable influencia en la interpretación de las normas fundamentales de derecho de la Unión Europea, como fruto de las tradiciones constitucionales comunes a los Estados Miembros y en la proclamada Carta de Derechos Fundamentales de la Unión Europea. ${ }^{180}$ Como afirma Jan Henrik Klement, en los últimos

\footnotetext{
${ }^{177}$ Cfr., Hierro, Liborio, "Los derechos económico-sociales y el principio de igualdad en la teoría de los derechos de Robert Alexy", en Alexy, Robert, Derechos sociales y ponderación, Madrid, Fundación Coloquio Jurídico Europeo, 2007, p. 171.

${ }^{178}$ Cfr., Bernal, Pulido, Estudio Introductorio a Alexy, Robert, Teoría de los derechos fundamentales, Madrid, Centro de Estudios Políticos y constitucionales, 2008, p. XXVII.

179 Kumm, Mattias, "Political Liberalism and the Structure of Rights", en, Pavlakos, George (Ed.), Law, Rights and Discourse. The Legal Philosophy of Robert Alexy, Portland, Hart Publishing, 2007, p. 136.

180 Menéndez, Agustín "Introduction", en, Menéndez, Agustín y Eriksen, Erik, Fundamental Rights through Discourse. On Robert Alexy's Legal Theory. European and Theoretical Perspectives, Oslo, Arena, 2004, p. 2.
} 
treinta años, nigún escrito científico en el ámbito del derecho público alemán ha provocado una atención tan persistente como la obra de Alexy. ${ }^{181}$

Estos comentarios merecen algunas observaciones. En primer lugar, esta obra trata sobre derechos fundamentales, los cuales están conectados con los derechos humanos. En segundo lugar, el que la reflexión de Alexy se base en la Ley Fundamental de Alemania no implica que sus alcances normativos se reduzcan al análisis de un sistema jurídico con prácticas incompatibles con los demás sistemas jurídicos, sino que puede servirnos para comprender cómo un Tribunal constitucional u ordinario debe decidir en caso de conflictos normativos. A pesar de notables diferencias entre los diferentes sistemas jurídicos, la forma en como son resueltos los conflictos jurídicos en los diversos Estados de derecho no los hace tan ajenos, por lo cual esta teoría constituye una obra de referencia obligada en torno al fundamento, contenido, estructura, sistematización, interpretación y aplicación de los derechos fundamentales.

Para llevar a cabo esta reconstrucción serán usados otros escritos de Alexy sobre derechos fundamentales, porque en desarrollos posteriores éste ha complementado aquellos puntos que han provocado controversia y crítica por parte de algunos filósofos del derecho. Pero el motivo acaso más importante para ello reside en que, tal y como se planteó antes, el pensamiento jurídico de Alexy será expuesto como lo más cercano a un sistema de filosofía del derecho; es por esta razón que sólo cuando se comprenda la relación que tiene la teoría de la argumentación jurídica con la de los derechos fundamentales, y ambas con una teoría de la naturaleza del derecho, es como podrá verse con mayor claridad la idea de presentar una teoría no-positivista del derecho, basada en la tríada "argumentación, derechos y naturaleza dual del derecho".

La estructura del sistema de derechos humanos y fundamentales de Alexy posee tres dimensiones, vinculadas entre sí. Las dimensiones en que se dan estas relaciones abarcan en primer lugar una dimensión filosófica, en segundo lugar una dimensión política y en tercer lugar una dimensión jurídica. ${ }^{182}$ Estas dimensiones bien pueden verse como una

\footnotetext{
${ }^{181}$ Klement, Jan-Reinard, "Vom Nutzen einer Theorie, die alles erklärt", en Juristen Zeitung, vol. 63, No. 15, Tubinga, 2008, p. 756.

182 Alexy, Robert, "Discourse Theory and Constitutional Rights", en, Menéndez, Agustín y Eriksen, Erik, Fundamental Rights through Discourse. On Robert Alexy's Legal Theory. European and Theoretical Perspectives, Oslo, Arena, 2004, p 35. En adelante, DTCR.
} 
concepción no-positivista de los derechos humanos y fundamentales. De este modo, comenzaremos con la fundamentación filosófica de los derechos fundamentales, luego con la reconstrucción de la institucionalización política y al final con la aplicación jurídica de los derechos fundamentales. A continuación será expuesta una reflexión sobre el reciente discurso de los derechos.

Con bastante frecuencia se escucha hablar ahora de un lenguaje de los derechos, de un ámbito de los derechos, de una era de los derechos. Las instituciones gubernamentales suelen hacer énfasis en que lo más importante es defender los derechos fundamentales de los ciudadanos y en crear una conciencia social sobre la importancia de ejercerlos de modo responsable. Las organizaciones no gubernamentales parecen más que nunca empeñadas en luchar por los derechos tanto de los ciudadanos de los Estados, como de los ciudadanos globales. Cada vez que un ciudadano tiene un conflicto contra el Estado, considera que posee una protección especial cuando afirma que acudirá a alguna comisión especial para hacer valer sus derechos. En la práctica política, buena parte del discurso electoral hace énfasis en la institucionalización de más y mejores derechos, a tal grado, que una campaña política que no recurra a la fuerza mágica de este concepto corre el riesgo de cometer un suicidio en términos electorales. Como lo señala Joseph Raz en un tono irónico al referirse a una cita de John Tassioulas, "El discurso de los derechos humanos ha adquirido en tiempos recientes el estatus ético de una lingua franca". ${ }^{183}$ La importancia de esta lingua franca es evidente en casi todos los ámbitos de las ciencias sociales:

Un nuevo ideal ha triunfado en la escena global mundial: los derechos humanos; ellos unen a la izquierda con la derecha, unen al púlpito y al Estado, al ministro y al rebelde, al mundo en desarrollo y a los liberales de Hampstead y Manhattan. Los derechos humanos se han convertido en el principio que libera la opresión y la dominación, grito que aglutina a los indigentes y a los desposeídos, el programa político de revolucionarios y disidentes. Sin embargo, su atracción no está limitada a los desdichados de la tierra. Los estilos de vida alternativa, los consumidores codiciosos de bienes y cultura, los buscadores de placer y los playboys del mundo occidental, el dueño de Harrod's, el antiguo director de Guinness PLC, hasta el destronado rey de Grecia, todos han dado lustre a sus reclamos a través del lenguaje de los derechos humanos. ${ }^{184}$

Este auge que tienen los derechos en el actual discurso político, cultural y contracultural es entendible. En el campo de la teoría y filosofía políticas, el concepto de

\footnotetext{
183 Raz, Joseph, "Humans Rights without Foundations", en, Besson, Samantha y Tassioulas, John, The Philosophy of International Law, Oxford, Oxford University Press, 2010, p. 321.

${ }^{184}$ Douzinas, Costas, El fin de los derechos humanos, Bogotá, Legis, 2008, p. 1.
} 
"derechos" he ganado un terreno formidable gracias a los efectos institucionales que puede provocar la positivización de reivindicaciones sociales, morales y políticas en normas exigibles y especialmente protegidas; gracias a este efecto tanto la izquierda como la derecha han incorporado el "lenguaje de los derechos" en sus pretensiones.

Es comprensible que tanto la derecha e izquierda políticas retomen el discurso de los derechos; sin embargo, es posible notar que el discurso sobre la fundamentación de los derechos a veces se queda en niveles escépticos o superficiales, sin poder trascender a modelos más comprensivos que abarquen una postura crítica, la cual podría plantear en sus dimensiones correctas el discurso, tiempo y ámbito de los derechos. La idea de que los sujetos de una comunidad política tienen un conjunto de derechos inviolables tiene un trasfondo histórico tan importante para la sociedad moderna que Alexy no vacila en concederle un lugar central no sólo para la configuración de sus reflexiones, sino como un caso especial de vinculación entre las ideas filosóficas y los hechos: "[L]a historia de la institucionalización de los derechos humanos como derechos fundamentales es un caso paradigmático del intercambio entre las ideas y la realidad y, así, entre la teoría y la praxis". 185

El interés creciente por el discurso de los derechos humanos ha provocado que algunos filósofos se refieran a los derechos humanos como la religión civil de la modernidad, ${ }^{186}$ mientras que otros detecten en el tratamiento frívolo de los derechos una retórica que de poco sirve para darles el lugar normativo que les corresponde: "[N]o hay duda de que la retórica de los derechos humanos está llena de hueca hipocresía. Este discurso está infectado por el cinismo egoísta y el auto-engaño, pero no niega totalmente el valor de la creciente aceptación de los derechos humanos en el desarrollo de las relaciones internacionales". ${ }^{187}$ Ante este tipo de críticas a los derechos humanos es importante desarrollar un programa de fundamentación moral de los derechos humanos, el cual será reconstruido en el siguiente apartado.

\footnotetext{
185 Alexy, Robert, Tres escritos sobre los derechos fundamentales y la teoría de los principios, Bogotá, UEC, 2003, p. 32. En adelante, TEDF.

${ }^{186}$ Cfr., Höffe, Otfried, Derecho intercultural, Barcelona, Gedisa, 2008, p. 165.

${ }^{187}$ Raz, ibid.
} 


\subsection{La fundamentalidad de los derechos fundamentales}

\subsection{1. ¿Derechos fundamentales sin metafísica o derechos fundamentales con metafísica analítica?}

Ante los cuestionamientos surgidos contra aquello que surge en Occidente y pretende exigirse a las demás culturas, esto es, los derechos humanos, algunos filósofos han intentado ir más allá de posturas superficiales para fundamentarlos a partir de un interés en necesidades humanas imprescindibles para cualquier cultura, en cualquier tiempo y en cualquier lugar. Después de todo, como afirma Hegel, el principio de la subjetividad, constituido en fundamento de la modernidad, reclama la conciencia universal de que el hombre valga como hombre, sin importar sus características contingentes. ${ }^{188}$ Esta característica normativa de los derechos nos lleva a la pregunta en torno a cómo puede fundamentarse esta validez universal de los derechos humanos, y si ésta es independiente o no del contenido de los derechos y sus condiciones. ${ }^{189}$

Las preguntas acerca de qué derechos tiene el individuo como persona y ciudadano de una comunidad política y global, de a qué principios está sujeta la legislación estatal y qué es aquello que exige la realización de la dignidad humana, la libertad y la igualdad, constituyen grandes temas de la filosofía práctica, ${ }^{190}$ el motivo de las luchas políticas y sociales pasadas y presentes por el reconocimiento de nuevos derechos y uno de los problemas centrales de la validez integral del derecho, tanto a nivel estatal como supraestatal. Estas preguntas, vinculadas con aspectos formales y materiales de los derechos han sido abordadas tanto por filósofos políticos y morales como por filósofos del derecho.

Por parte de algunos de los más importantes filósofos morales y políticos, los derechos humanos han adquirido una importancia crucial para establecer la legitimidad de

\footnotetext{
188 "Pertenece a la cultura, al pensar como conciencia del individuo en la forma de la universalidad, que yo sea aprehendido como persona universal, en lo cual todos somos idénticos. El hombre vale porque es hombre y no porque sea judío, católico, protestante, alemán o italiano. La conciencia de este valor del pensamiento es de una infinita importancia". Hegel, G. W. F., Grundlinien der Philosophie des Rechts oder Naturrecht und Staatswissenschaft im Grundrisse, Hamburg, Feliz Meiner Verlag, 2013, p. 200.

189 Cfr., Nooke, Günter, "Universalität der Menschenrechte - Zur Rettung einer Idee", en, Nooke, Günter, Lohmann, Georg y Wahlers, Gerhard (Eds.), Gelten Menschenrechte Universal? Begründungen und Infragestellungen, Friburgo, Herder, 2008, p. 16.

${ }^{190}$ Alexy, Robert, TDF, p. 5.
} 
los ordenamientos jurídicos, sin recurrir a presupuestos de corte metafísico o tradicional. Como ejemplos tenemos a Rawls, que considera que los derechos tienen prioridad sobre lo bueno en un sentido normativo fuerte, ya que en la Justicia como equidad los conceptos de lo justo y de lo bueno tienen rasgos marcadamente distintos que dan como resultado la prioridad del derecho y de la justicia; ${ }^{191}$ a Höffe, cuya idea de intercambio trascendental sirve para justificar, con base en intereses antropológicos, las correspondientes tres generaciones de derechos humanos, que aspiran a una pretensión de validez transcultural; ${ }^{192}$ y finalmente, a Habermas, quien concibe a los derechos como un sistema de "barreras cortafuegos" (Brandmauer) con carácter deontológico, los cuales proveen de protecciones fuertes contra reclamos hechos por la comunidad política. ${ }^{193}$

Ahora bien, por parte de los juristas el tema de los derechos humanos ha ocupado un lugar central de sus reflexiones, como es el caso de tres de los más importantes filósofos del derecho en la actualidad. Para Dworkin los derechos individuales son triunfos políticos en manos de los individuos frente a la mayoría, ${ }^{194}$ ya que ninguna directriz política ni objetivo social colectivo puede triunfar frente a un auténtico derecho; en el caso de Ferrajoli los derechos fundamentales se afirman siempre como leyes del más débil en alternativa a la ley del más fuerte que regía y regiría en su ausencia; ${ }^{195}$ y finalmente, en el caso de Alexy, los derechos fundamentales son normas que pueden ser ponderadas en caso de un conflicto normativo. ${ }^{196}$

Estas reflexiones filosóficas, políticas y jurídicas sobre los derechos han mostrado la importancia de que determinados principios políticos y filosóficos puedan incorporarse en el discurso jurídico moderno; pero, ¿por qué es importante esta inclusión en el discurso jurídico? La institucionalización de principios morales universales es para Alexy tan necesaria como lo es en general la existencia del derecho, debido a que algunas exigencias morales no ofrecen procedimientos institucionalizados para resolver los conflictos por vías

\footnotetext{
${ }^{191}$ Rawls, John, Teoría de la justicia, México, D. F., FCE, 2010, p. 408 ss. Sobre este planteamiento de Rawls también puede consultarse el tema que dedica a la prioridad de lo correcto sobre lo bueno en Political Liberalism, Nueva York, Columbia University Press, 1993, pp. 173-211.

192 Höffe, Otfried, Demokratie im Zeitalter der Globalizierung, Múnich, Verlag C. H. Beck, 1999, p. 54.

193 Habermas, Jürgen Faktizität und Geltung. Beiträge zur Diskurstheorie des Rechts und des demokratischen Rechtstaats, Fráncfort del Meno, Suhrkamp 1992, p. 315.

194 Dworkin, Ronald, Los derechos en serio, Barcelona, Planeta-Agostini, 1993, p. 37.

195 Ferrajoli, Luigi, Derechos y garantías. La ley del más débil, Madrid, Trotta, 2004, p. 54.

${ }^{196}$ Alexy, Robert, TDF, p. 67.
} 
pacíficas, ya que el reconocimiento de la validez de una norma es distinto a cumplirla, ${ }^{197} y$ porque diversos fines valiosos para una comunidad no pueden alcanzarse a través de acciones individuales o mediante una cooperación espontánea. Esta reflexión sobre la necesidad del derecho explica que las filosofías morales y políticas contemporáneas necesitan reconocer la importancia del derecho para poder hacer una filosofía de los derechos humanos en serio; "en este sentido, la pregunta no solamente debe ser ¿qué es el derecho sin la ética?, sino ¿qué es la ética sin el derecho?". 198 A continuación, expondremos la concepción de los derechos humanos y fundamentales según Alexy.

\subsubsection{Los modelos de fundamentación de los derechos según Alexy}

¿Qué son los derechos humanos y fundamentales? Para Alexy, esta pregunta ha sido respondida de diversas maneras por autores que pertenecen a la tradición moderna de la filosofía; no obstante, en un punto parece diferir radicalmente de ellos: los derechos contienen necesariamente elementos metafísicos, racionales y universales. Autores como Patzig, Rawls y Habermas han hecho reflexiones sobre la moral, la justicia y la sociedad al margen de una concepción negativa de metafísica, de ahí los títulos de algunas de sus obras respectivas: Ética sin metafísica de Patzig, ${ }^{199}$ Justicia como equidad: política, no metafísica de Rawls ${ }^{200}$ y Pensamiento posmetafísico de Habermas, ${ }^{201}$ respectivamente.

Alexy, no obstante, se adherirá a una concepción positiva de metafísica, si bien una metafísica constructiva, racional y universal que le permitirá fundamentar su teoría de los derechos fundamentales. No obstante, antes de presentar el modelo de fundamentación alexyano sería conveniente exponer qué es lo que entiende Alexy por derechos humanos. Alexy ha definido cinco propiedades que todo derecho humano posee. De acuerdo con estas propiedades los derechos son (1) universales, (2) fundamentales, (3) abstractos, (4) morales y (5) prioritarios. Los derechos humanos son universales porque el portador de los

\footnotetext{
${ }^{197}$ Y también porque, como lo ha señalado Klaus Günther, es muy distinto un discurso de fundamentación que uno de aplicación en los ámbitos de la ética y del derecho, es decir, la justificación de un principio ético o jurídico no siempre justifica su aplicación en casos concretos, o, como lo señala Kant, algo que es bueno en teoría puede no serlo en la práctica.

${ }^{198}$ Véase, Kirste, Stephan, "Recht als Tranformation", en Brugger, Winfried, Neumann, Ulfrid, y Kirste, Stephan (Eds.) Rechtsphilosophie im 21. Jahrhundert, Fráncfort del Meno, Suhrkamp, 2008, pp. 134 y 135.

${ }^{199}$ Cfr., Patzig, Gunther, Ethik ohne Metaphysik, Gotinga, Vandenhoeck-Reihe, 1983

200 Cfr., Rawls, John, "Justice as Fairness: Political not Metaphysical", en Freeman, Samuel (Ed.) John Rawls. Collected Papers, Massachusetts, Harvard University Press, 1999, p. 388 ss.

${ }^{201}$ Cfr., Habermas, Jürgen, Postmetaphysical Thinking. Philosophical Essays, Cambridge, MIT Press, 1994
} 
derechos humanos es todo ser humano en cuanto ser humano; fundamentales porque protegen intereses y necesidades esenciales; abstractos, porque el objeto concreto de los derechos humanos puede ser objeto de una discusión; morales, porque puede fundamentarse frente a cada participante de un discurso racional; finalmente, prioritarios, porque estos derechos no pueden derogarse por normas de derecho positivo, sino que estos derechos son las normas a las que debe adecuarse toda interpretación de derecho positivo. ${ }^{202}$ Ahora expondremos la fundamentación de los derechos humanos en Alexy.

Para Alexy, la fundamentación de los derechos fundamentales es posible tal y como lo es la fundamentación de normas morales y criterios racionales sobre su corrección, dando así un paso decisivo frente a las objeciones que podrían hacer teorías escépticas como el emotivismo, decisionismo, relativismo o decontruccionismo frente a posturas puramente objetivistas, como es el caso del no-positivismo excluyente. No obstante, si es posible fundamentar derechos de los sujetos de modo racional, ello no excluye que existan diversos métodos para intentar hacerlo, por lo cual Alexy utilizará premisas de la ética del discurso para explicar sus argumentos en torno a la fundamentación de los derechos.

Aunque existen muchas vertientes sobre la fundamentación de los derechos humanos que podrían exponerse y defenderse, dependiendo de la postura política, antropológica y filosófica escogida, Alexy considera ocho aproximaciones respecto al fundamento filosófico de los derechos humanos, y señala que las primeras seis tienen limitaciones para erigirse en modelos normativos adecuados, es por ello que las veremos de modo breve.

4.2.2.1. El modelo religioso: aunque este modelo puede generar razones convincentes para los creyentes de alguna religión en particular debido a que de este modo los derechos se presentan como dados por una autoridad trascendental e incuestionable, éstas sólo valdrán para los creyentes, por lo que tendrán muy poca efectividad en sociedades en las que el desencantamiento y desdivinización del mundo moderno (Entzauberung und Entgöttlichung der Welt en sentido weberiano) se ha asumido casi como un hecho indiscutible. Tal vez en algunos debates en los que es reivindicada la función positiva de la religión —como el sostenido entre Habermas y Joseph Ratzinger- el

\footnotetext{
202 Alexy, Robert, "Menschenrechte ohne Methaphysik?", en Deutsche Zeitschrift für Philosophie, no. 52 Berlín, 2004, p. 16. En adelante, MOM.
} 
fundamento de los derechos puede ser un tema en el que se conjunten argumentos en favor de reivindicar la solidaridad en las sociedades modernas.

4.2.2.2. El modelo biológico: este modelo parte de formas de comportamiento observables, en las que es posible notar que la moralidad es una especie de altruismo que puede mejorar la subsistencia en general, pero tiene el defecto de que también pueden darse comportamientos hostiles frente a los extraños, comportamientos que, entre otras cosas, son incompatibles con el carácter universalista de la fundamentación de los derechos humanos. Ciertas pautas observables de comportamiento pueden ser inmorales y por ello no pueden servir para fundamentar derechos.

4.2.2.3. El modelo intuicionista: para esta postura los derechos podrán fundamentarse cuando se sostenga que éstos son autoevidentes para todos los sujetos, en todas las sociedades y en tdos los tiempos. Pero la debilidad de esta aproximación reside en saber cómo es posible considerar que los derechos son autoevidentes para todos los participantes en casos de que alguien cuestione esta autoevidencia. Ciertos derechos pueden ser evidentes para unos sujetos, pero no para otros. Es necesario pensar en otros modelos de fundamentación de los derechos, ya que, según Alexy, "las evidencias no pueden presentarse como argumentos". ${ }^{203}$

4.2.2.4. El modelo consensual: el defecto de este modelo radica en que parece una especie de intuicionismo colectivo, cuya fuente de objetividad argumental reside en el hecho de la coincidencia de creencias o pretensiones que no son suficientemente argumentadas. Además, aunque se den acuerdos colectivos, estos pueden no ser siempre correctos, es más, esta crítica al consensualismo será uno de los argumentos fuertes para considerar a los derechos fundamentales como base y límite de la democracia. Si fuera suficiente el modelo consensual, entonces deberíamos aceptar todas las consecuencias del intuicionismo colectivo, entre las que podrían incluirse, la supresión de derechos individuales, el linchamiento u otro tipo de penas desmesuradas.

4.2.2.5. El modelo instrumentalista: sin duda, este modelo es bastante efectivo en ciertas prácticas políticas. Para esta aproximación, basta que los sujetos mismos acepten la fundamentación de ciertos derechos en función de la utilidad individual o colectiva o de las consecuencias económicas. El problema de esta aproximación reside en que, bajo

${ }^{203}$ Alexy, Robert, MOM, p. 18. 
argumentos instrumentalistas, podrían violarse derechos fundamentales bajo la aprobación de la comunidad política, si les conviene esta violación para satisfacer sus intereses. No obstante, en favor de este modelo podemos decir que éste puede contribuir de modo decisivo a fortalecer uno más racional que esté guiado por principios éticos, algo que de ningún modo podría generar por sí solo el modelo instrumentalista.

4.2.2.6. El modelo cultural: para esta aproximación lo importante es que la fundamentación de los derechos se vea como un logro de la historia humana. Pero los derechos no aparecieron en todas las culturas y el hecho de que surja en una en particular no implica que deban ser considerados universales si no hay suficientes razones de por medio, de lo contrario, podríamos justificar un argumento de tipo etnocéntrico y no un argumento con validez intercultural. Esta aproximación es muy importante porque reivindica a la cultura en la fundamentación de los derechos, pero puede caerse en lo que Mario Rojas ha llamado la "falacia culturalista", consistente en sostener que todas las culturas tienen exactamente el mismo valor y por ello son igualmente correctas. A final de cuentas, son los individuos los que importan y "no hay ningún derecho, ni individual ni colectivo, a mantener los elementos más retrógrados, regresivos, de la propia cultura. Por lo contrario, existe el deber de identificarlos, abandonarlos o transformarlos". ${ }^{204}$

4.2.2.7. Aproximación explicativa-discursiva: Este modelo sigue la línea de la filosofía trascendental de Kant al intentar fundamentar los derechos haciendo explícito lo que está implícito en las prácticas humanas, buscando así una fundamentación de los derechos humanos. Este modelo lo desarrolla Alexy en tres pasos, en los que vale la pena detenernos. En el primer paso, Alexy trata de mostrar que lo que Robert Brandom llama "el juego de dar y demandar razones", núcleo definitorio de lo que Brandom considera la praxis discursiva, ${ }^{205}$ debe presuponer reglas necesarias del discurso que expresen ideas de libertad e igualdad conectadas con la idea de razonamiento comunicativo. Estas reglas constitutivas, en cuanto reglas discursivas, no implican derechos humanos, debido a que estos últimos son reglas de acción.

204 Rojas, Mario, La razón ético-objetiva y los problemas morales del presente. Crítica ético-racional del relativismo moral-cultural, México, D. F., Ítaca, 2011, p. 413. Sobre una crítica más amplia al relativismo moralcultural en el ámbito de los derechos humanos, cfr., capítulos XV, XVI, XIX y XX de esta obra.

${ }^{205}$ Cfr., Brandom, Robert, Articulating Reasons, Cambridge, Harvard University Press, 2001, p. 190. 
En el segundo paso, Alexy plantea la necesidad de las prácticas discursivas en la totalidad del mundo de la vida. Según Alexy, no existe otra alternativa al discurso porque quien no haya participado en alguna práctica de este tipo, entonces jamás ha participado en la forma más general de la vida humana. Contra la posibilidad de argumentar que es posible sustituir "el juego de dar y demandar razones" por la de sólo expresar deseos, razones imperativas o un mero ejercicio del poder, señala Alexy que esta posibilidad sólo conduciría a un tipo de aislamiento y autodestrucción porque jamás podría darse interacción alguna en la sociedad, ya que ni el más fuerte y poderoso sería capaz de interactuar con los demás ejerciendo meramente actos comunicativos imperativos.

En el tercer paso, Alexy decide dar el paso decisivo del discurso a la acción utilizando tres premisas adicionales de la misma teoría del discurso porque de las reglas del discurso no es posible fundamentar directamente reglas para la acción. Este argumento lo expone Alexy del siguiente modo:

Una deducción directa de los derechos humanos de las reglas del discurso no es posible. Muchos autores lo han intentado pero todos se han equivocado. Las reglas del discurso son meramente reglas de habla. Atenerse a ellas significa que a los otros en el discurso se da el trato de interlocutores con los mismos derechos. De esto todavía no se desprende que al otro sin más, esto es, también en la esfera de la acción tenga que reconocérsele como persona. De un reconocimiento pragmáticolingüístico no se sigue aún ningún reconocimiento moral o jurídico. Para alcanzar las reglas de la acción de las reglas del discurso son sin embargo necesarias otras premisas. ${ }^{206}$

Estas premisas que conectarán al discurso con los derechos vendrán dadas por los argumentos de la autonomía, del consenso y de la democracia. Estos argumentos serán expuestos ahora debido a las deficiencias que poseen las reglas del discurso.

a) El argumento de la autonomía: según este argumento, para la teoría discursiva de los derechos fundamentales se requiere suponer un concepto de persona vinculado al argumento de la autonomía, es decir, todo aquel que participe seriamente en un discurso para resolver conflictos sociales debe admitir la autonomía de su interlocutor para llegar a soluciones válidas. Alexy considera que la autonomía es la principal base de la dignidad humana. Con este reconocimiento moral y jurídico de la autonomía del otro es transmitida

${ }^{206}$ Alexy, Robert, TDDH, pp. 98 y 99. 
la libertad y la igualdad del discurso a la acción, es decir, se reconoce al otro como persona ${ }^{207}$ con capacidad de autodeterminar los contenidos de sus acciones.

Alexy piensa que es posible participar en discursos sin estar interesado en la autonomía de los interlocutores, como es el caso de un tirano, que puede escuchar a sus súbditos sin reconocerles la autonomía que exigen; sin embargo, con el paso del tiempo "fatigado de discursos o que estime los argumentos improductivos, puede emplear la fuerza desnuda. Pero a largo plazo esto no es ventajoso para él". ${ }^{208}$ El tirano puede continuar ejerciendo violencia de manera explícita, bajo el supuesto de que sus poderes serán siempre ilimitados, o encubrirla con argumentos para maximizar sus ganancias, dando lugar a condiciones de participación autónoma en la toma de decisiones.

Si el argumento de la autonomía se enlaza con la regulación jurídica de los conflictos pueden fundamentarse derechos que tutelen la autonomía. En primer lugar, puede derivarse de este reclamo de la autonomía un derecho general a la libertad de los participantes en el discurso que se formule como un principio que exija, dentro de las posibilidades jurídicas, el derecho que cada uno tiene prima facie de juzgar libremente qué es conveniente o bueno y obrar en consecuencia en beneficio de la autonomía de todos los individuos. En segundo lugar, pueden fundamentarse también derechos que actúen como medios necesarios para poder ejercer la autonomía, es por este camino, el de la libertad, como pueden fundamentarse derechos a la protección del Estado y derechos sociales fundamentales, que no son otra cosa que derechos subjetivos institucionalizados bajo la premisa discursiva de tomar en serio al individuo.

b) El argumento del consenso: según este argumento, para la teoría discursiva de los derechos fundamentales se requiere suponer un concepto de consenso que haga posibles e imposibles ciertos resultados obtenidos de éste. Para Alexy el argumento de la autonomía no es suficiente, sino que el derecho necesita vincularse a una aceptación universal de todos los participantes afectados por la toma de decisiones. Esta vinculación

\footnotetext{
${ }^{207}$ Alexy ha señalado que el concepto de persona es uno de los más difíciles de definir, no obstante, ha indicado tres elementos que debe poseer toda persona para ser tal: inteligencia, sentimientos y conciencia. Esto lo ha llevado a debatir si el personaje de Data de la serie televisiva Star Trek 1. es persona y, por tanto, 2. titular de derechos. Al respecto, cfr., "Data und die Menschenrechte - Positronisches Gehirn und doppeltriadischer Personenbegriff", conferencia dictada en el marco del "Ringvorlesung des Instituts für Neuere Deutsche Literatur und Medien zur Erforschung von Populärkultur am Beispiel von STAR TREK" el día 8.2.2000 en la Universidad de Kiel, p. 10. ss. En adelante, DMR.
}

${ }^{208}$ Alexy, Robert, TDDH, p. 109. 
es posible al introducir los criterios de imparcialidad y de igualdad de los participantes, de manera que la autonomía se complemente con la universalidad en forma de igualdad de derechos e imparcialidad en la toma de decisiones, la cual es vista como un resultado necesario del discurso e imposible de suprimir mediante consenso alguno.

Este argumento permite excluir a todos aquellos que pueden cumplir las reglas del discurso y seguir empeñados en desconocer la igualdad de derechos. Como ejemplo de este tipo de actitudes Alexy menciona a sujetos que se apoyan en criterios racistas, religiosos y mágicos para negar la igualdad de derechos, y concluye así que sus argumentos no podrían ser válidos en un consenso racional, por lo cual serían privados de su carácter de participantes en un discurso ideal. De este modo el argumento del consenso debe guiar, por un lado, al postulado de igualdad de derecho y a una validez motivacional para quienes creen en el consenso y, por otro lado, a una validez objetiva o institucional para quienes no creen en él, pero que no les queda otra opción más que la de entrar en éste.

c) El argumento de la democracia: según este argumento, para la teoría discursiva de los derechos fundamentales se requiere suponer un concepto de democracia discursiva que, sin caer en posturas ingenuas, dé cuenta de la tensión existente entre la vigencia y la validez de los derechos fundamentales dentro de un Estado constitucional democrático. El argumento de la democracia está compuesto de tres partes. La primera sostiene que el discurso sólo puede llevarse a cabo a través de la institucionalización de procedimientos democráticos; la segunda parte sostiene que sólo en un régimen democrático pueden ejercerse con igualdad de oportunidades los derechos políticos; la tercera parte sostiene que el ejercicio de los derechos políticos debe suponer el ejercicio de derechos sociales. En caso de que se cumplan estas exigencias será correcta la siguiente proposición:

[Q]uien está interesado en corrección y legitimidad, tiene que estar interesado también en democracia e igualmente tendrá que estarlo en derechos fundamentales y derechos humanos. ${ }^{209}$

Una vez que han sido establecidas estas premisas discursivas para fundamentar los derechos humanos es posible institucionalizar derechos humanos, llevándonos al último

${ }^{209}$ Alexy, Robert, TDDH, p. 130. 
modelo de fundamentación de los derechos, el modelo existencial. Este modelo será el último en ser expuesto.

4.2.2.8. El modelo existencial: Ahora será conectado el modelo explicativo con el existencial, vinculado a la naturaleza discursiva de los seres humanos. En este modelo es asumido que para fundamentar los derechos humanos mediante la ética del discurso es suficiente el criterio de reconocimiento de nosotros mismos como seres discursivos que deciden vivir en una comunidad política democrática. Esto es así porque se requieren institucionalizar discursivamente derechos que le aseguren a los sujetos de la comunidad política la capacidad de autodeterminarse, ser tratados con igual consideración, encontrar satisfechas un mínimo de condiciones existenciales, y de que la dignidad humana que poseen no les sea violentada. Este modelo basado en la naturaleza discursiva de los seres humanos acepta que los derechos fundamentales son un tipo especial de normas capaces de asegurar las condiciones mínimas de existencia de los individuos en una sociedad.

Este modelo de fundamentación existencial ha sido empleado por Alexy para refutar el argumento del relativismo kelseniano, específicamente en el artículo "Derecho, moral y la existencia de los derechos humanos". Para Alexy, la existencia de los derechos humanos implica la existencia de principios de justicia fundamentables racionalmente, y esto apunta a una conexión necesaria entre derecho y moral. Ahora bien, este tipo de fundamentación de los derechos humanos hace explícita una dialéctica de lo objetivo con lo subjetivo, debido a que la objetividad conectada con la subjetividad es menos que "objetividad pura", pero es, de hecho, más que "subjetividad pura". Es por ello que el agumento explicativoexistencial puede servir como fundamento de los derechos humanos, a pesar de que no sea una fundamentación puramente objetiva. Según Alexy, si los derechos humanos existen entonces pueden ser violados. ¿Esto qué consecuencias tendría para refutar al relativismo propuesto por Kelsen?

Cuando los derechos humanos pueden ser violados, ellos pueden, qua derechos abstractos, ser violados tanto en un grado extremo como en un grado menor. Que los derechos violados puedan ser violados en un grado extremo significa que la Fórmula de Radbruch es aplicable. Si todo esto es cierto, el argumento del relativismo es refutado. ${ }^{210}$

\footnotetext{
${ }^{210}$ Alexy, Robert, "Derecho, moral y la existencia de los derechos humanos", en Signos Filosóficos. vol. 15 No. 30, Júlio-diciembre, 2013, p. 169. En adelante, DMEDH
} 
A partir de esta postura existencial-discursiva Alexy fundamentará ciertos derechos universales, es decir, derechos constitutivos de un Estado democrático y social de derecho. No obstante, este argumento es problemático, ya que Alexy sostiene, por una parte, que los derechos humanos existen, pero, por otra parte, que son entidades metafísicas del tercer reino, como los números y las proposiciones, en el sentido de Gottlob Frege, quien indica que los pensamientos no son ni cosas en el mundo externo ni ideas, y que, por lo tanto, un tercer reino debe ser reconocido. ${ }^{211}$ ¿Acaso estamos ante un fundamento metafísico de los derechos humanos? Según Alexy se trata de un discurso metafísico, pero no uno de corte negativo.

Evitar un discurso metafísico de corte negativo es posible, según Alexy, si se reconoce que la metafísica es una cualidad necesaria de los derechos humanos. Esta cualidad es necesaria porque "los derechos humanos sin metafísica sólo serían posibles si fueran susceptibles de una interpretación puramente naturalista, es decir, si pudieran reducirse a datos observables del mundo exterior, interno o social". ${ }^{212}$ Es por ello que los derechos humanos no son posibles sin una metafísica racional y universal, a pesar de que esta tesis en torno a la metafísica de los derechos humanos y su existencia en el tercer reino sea objeto de una polémica respecto al pensamiento del "segundo Alexy". ${ }^{213}$ Ahora señalaremos en qué aspectos jurídicos y sustanciales reside la fundamentalidad de estos derechos, y luego expondremos la distinción entre reglas y principios hecha primero por Dworkin y posteriormente refinada por Alexy.

\subsubsection{El concepto de derecho fundamental y sus cualidades}

Ahora serán reconstruidas las cualidades jurídicas de los derechos fundamentales. Como lo señala Carlos Bernal Pulido, "los derechos fundamentales son un tipo de derecho subjetivo cuya differentia specifica reside en su fundamentalidad", de ahí que una indagación sobre el concepto de derechos fundamentales necesite aclarar tanto el concepto

\footnotetext{
${ }^{211}$ Cfr., Frege, Gottlob, "The Thought: A Logical Inquiry", en, Mind, vol. 65, n. 259, 1956, p. 302. Para Frege el pensamiento no forma parte del mundo físico (physische Welt) ni del mundo psíquico (psychische Welt), sino del mundo espiritual (geistige Welt), en el cual el pensamiento encuentra su realidad efectiva.

${ }^{212}$ Alexy, Robert, MOM, p. 23.

${ }^{213}$ Recientemente John Searle ha sostenido que en la búsqueda a la respuesta en torno a la comprensión de la existencia de nuestra existencia mental y social en un mundo de hechos brutos debemos evitar postular "diferentes reinos ontológicos, uno mental y otro social, o peor aún, un reino mental, uno físico y otro social", en referencia a Popper. Al respecto, cfr., Searle, John, Making the Social World. The Structure of Human Civilization, Nueva York, Oxford University Press, 2011, ix (prefacio).
} 
de derecho subjetivo como el de fundamental. ${ }^{214}$ Para hacer una teoría apropiada de los derechos fundamentales, es necesario aclarar primero el concepto de derecho subjetivo y posteriormente la idea de fundamentalidad.

El concepto de derecho subjetivo. El concepto de derecho subjetivo no está exento de polémica en la teoría del derecho. A diferencia del idioma inglés en el que puede distinguirse al derecho objetivo (Law) del derecho subjetivo (Right) sin gran dificultad, ${ }^{215}$ distinción que Hobbes ${ }^{216}$ y Austin $^{217}$ llevaron a cabo, en el idioma español es preciso agregar el adjetivo de "subjetivo" a todas aquellas normas jurídicas que le otorgan a los sujetos derechos a algo, libertades y competencias, para diferenciarlas así del concepto de derecho objetivo. De este modo pueden comprenderse los derechos subjetivos como "el poder legal reconocido a un sujeto por medio de una norma legal para la persecución de sus propios intereses mediante la exigencia a otro de hacer, permitir u omitir algo". ${ }^{218}$ Para Rodolfo Arango encontramos en la anterior definición las tres características del derecho subjetivo, que consisten en que el derecho subjetivo se compone de una norma, una obligación y una posición jurídicas, que serán descritas sintéticamente. ${ }^{219}$

\footnotetext{
${ }^{214}$ Bernal, Carlos, "Die Fundamentalität der Grundrechte", en, Clérico, Laura y Sieckmann, Jan-Reinard (Eds.), Grundrechte, Prinzipien und Argumentation. Studien zur Rechstheorie Robert Alexys, Baden-Baden, Nomos Verlagsgesellschaft, 2009, p. 83.

215 Para ver más clara esta diferencia, podemos ver cómo se encuentran titulados en lengua inglesa las tres obras fundacionales del positivismo jurídico, como son, respectivamente, la Teoría pura del derecho de Kelsen (Pure Theory of Law), Sobre el derecho y la justicia de Ross (On Law and Justice) y El Concepto de derecho de Hart (The Concept of Law). En éstas "derecho" es traducido como "Law" y no como "Right".

${ }^{216}$ Hobbes señala que quienes se ocupan de cuestiones relacionadas con los conceptos de Derecho y Ley de naturaleza confunden jus y lex, derecho y ley, y que por ello es preciso distinguir esos términos, "porque el DERECHO consiste en la libertad de hacer o de omitir, mientras que la LEY determina y obliga a una de esas dos cosas. Así, la ley y el derecho difieren tanto como la obligación y la libertad, que son incompatibles cuando se refieren a una misma materia" (Hobbes, Thomas, El Leviatán o la materia, forma y poder de una república eclesiástica y civil, México, D. F., FCE, 1987, p. 106.).

${ }^{217}$ Austin, por su parte, define el concepto de ley o regla como una "orden" vinculada a una sanción en caso de que no se obedezca y luego el de derecho como un sustantivo que designa una "facultad" y como un adjetivo equivalente a "justo", términos que Austin considera ampliamente diferentes y vinculados entre sí. Finalmente, Austin reconoce que en el idioma alemán la palabra "Recht" se puede referir tanto al derecho en sentido objetivo, como en el sentido subjetivo, confusión que los escritores ingleses evitan al distinguir entre "Law y "Right". (Cfr., Austin, John, The Province of Jurisprudence Determined, Nueva York, Prometheus Books, 2001, pp. 285-288. Consideramos que la cita 26 contenida en las páginas referidas es bastante explicativa en cuanto a la diferencia decisiva entre Lex y Jus y bastante clara para poder distinguir entre derecho objetivo y subjetivo.

${ }^{218}$ Arango, Rodolfo, El concepto de derechos sociales fundamentales, Bogotá, Legis, 2005, p. 8 y 9.

${ }^{219}$ En este aspecto somos deudores del notable análisis conceptual que hace Arango tanto del concepto de derecho subjetivo, como de su teorización acerca de los derechos sociales fundamentales.
} 
Sobre la característica de norma jurídica, es necesario que todo derecho subjetivo deba presuponer una norma jurídica vigente en el ordenamiento legal. Esta característica resulta de la necesidad de que el cumplimiento del ejercicio derecho subjetivo pueda ser forzado en caso de que sea impedido. Respecto a la característica de obligación jurídica podemos decir que es condición necesaria de un derecho subjetivo la correspondiente obligación jurídica que obliga a un otro a hacer o dejar de hacer algo, aunque no de toda obligación jurídica corresponde un derecho subjetivo. Finalmente, la característica de posición jurídica consiste en el estatus que posee un sujeto dentro de un orden institucional normativo para que se le reconozcan y tutelen ciertas exigencias básicas que han sido positivizadas en un sistema de derecho vigente para que éste pueda perseguir los intereses lícitos que desea. De este modo, un derecho fundamental será un derecho subjetivo estructurado bajo la forma de un derecho a algo. Esta estructura consiste en la estructura de una relación tripartita $D a b G$, en la cual a simboliza al portador de derecho, $b$ al obligado y $G$ al objeto del derecho, simbolizado por $D$.

Esto también implica que "todos los derechos individuales son derechos subjetivos, pero no todos los derechos subjetivos son derechos individuales. Los titulares de derechos subjetivos pueden, pero no tienen que ser individuos". ${ }^{220}$ Este tipo de casos los vemos al referirnos a personas jurídicas, como es el caso de empresas u organismos privados con capacidad jurídica para que se les imputen derechos o deberes. Si bien es cierto que los derechos fundamentales son derechos subjetivos, falta por ver en qué reside la propiedad de "fundamentales". Ésta será analizada ahora.

La idea de fundamentalidad. Anteriormente vimos la primera característica que poseen los derechos fundamentales, la de ser derechos subjetivos, y por ello fue llevado a cabo un análisis de sus características; sin embargo, no todos los derechos subjetivos del sistema jurídico son derechos fundamentales o pueden serlo, sino que son una clase de derechos subjetivos, es decir, son derechos que poseen un estatus especial. Sobre la idea de fundamentalidad es fácil apelar a algún tipo de fundamentalidad de corte metajurídica. Para evitar este tipo de argumentación será presentada la característica fundamental de los derechos: la total indisponibilidad de los derechos fundamentales por el legislador. Esta característica podría sonar, a primera vista, como algo que podría entrar en contradicción con la idea que se tiene de la democracia como un poder constituyente capaz de cambiar

\footnotetext{
${ }^{220}$ Arango, Rodolfo, op. cit., p. 72.
} 
cualquier forma de gobierno en beneficio del pueblo, por lo cual es necesario precisar la concepción de indisponibilidad. Ciertamente, el argumento a favor de la indisponibilidad de los derechos fundamentales por los legisladores tiene un carácter doble en las democracias modernas: por una parte es la base de la democracia y por la otra es el límite de ésta.

Estas características se explican en virtud de que no son normas comunes que regulan la estructura y funcionamiento de los Estados de derecho, sino normas constitutivas. A diferencia de las reglas regulativas que pueden cambiar los legisladores, reglas tales como la forma en la que deben pagarse los impuestos, o deben repartirse las funciones del poder administrativo, las reglas constitutivas son las que hacen que un modelo de Estado sea tal y no otro, esto es, los derechos fundamentales son los criterios constitutivos de un tipo específico de Estado y su indisponibilidad permite considerarlos como tales. Este uso de los derechos fundamentales puede explicarse haciendo una analogía con las reglas del juego de ajedrez. Si encontramos a un sujeto que observa por vez primera el funcionamiento de una partida de ajedrez, notará que, al igual que con otros juegos de mesa, existen ciertas reglas que los participantes siguen; sin embargo, para que el juego de ajedrez sea tal, se requiere que ciertas reglas sean exclusivas de éste, es decir, que sean constitutivas y no meramente otro tipo de reglas que podrían hacer que este tipo de juego de mesa pudiera confundirse con otro. A diferencia de todas aquellas normas que pueden crearse, modificarse o extinguirse bajo la libre decisión de los legisladores, los derechos fundamentales son una clase exclusiva de derechos subjetivos que escapan del arbitrio de éstos, precisamente, para poder hacer que las instituciones y normas de una democracia funcionen. Si le quitáramos ese carácter de indisponibilidad a los derechos fundamentales, la estructura institucional democrática no podría funcionar como tal.

La segunda característica esencial, relacionada con la primera, es la potencial disponibilidad inmediata por sus titulares. Esta característica hace énfasis en que todo derecho fundamental es un derecho que los sujetos pueden ejercer en el momento en que lo deseen, siempre y cuando no contravenga otros derechos de igual o mayor jerarquía. La capacidad que tienen los titulares de estos derechos para ejercerlos reside en que el Estado debe tutelar del goce de este sistema de libertades, competencias y derechos a algo, aun y cuando pudiera estar en oposición a sus intereses.

En casos en los que el titular de estos derechos fundamentales es privado de esta disponibilidad, el Estado debe velar en todo momento por el ejercicio de estos derechos y 
reparar el daño derivado de esta privación, ya que el grado de importancia de éstos es de máxima jerarquía constitucional. La indisponibilidad total de los derechos por el legislador y la disponibilidad inmediata para sus titulares son características exclusivas de los derechos fundamentales, mediante las cuales Alexy considera a los derechos fundamentales "posiciones que, desde el punto de vista constitucional, son tan importantes que su atribución o denegación a un individuo, no pueden quedar en manos de la mayoría parlamentaria simple". ${ }^{221}$

La definición de Alexy indica la exigencia normativa de que los derechos fundamentales alcancen una importancia esencial en todo ordenamiento jurídico, pero también deja ver que los derechos requieren de propiedades materiales, vinculadas a las dimensiones liberales, democráticas y sociales del concepto de persona, ${ }^{222}$ las cuales se referirán al contenido sustancial de los derechos fundamentales. ${ }^{223}$ Estas propiedades tendrán un papel muy importante para fundamentar un sistema de derechos sólido e incluyente.

Efectivamente, el constitucionalismo discursivo parte no sólo de propiedades formales, sino de propiedades sustanciales. La fundamentalidad material de los derechos reside en la inclusión de posturas filosóficas y políticas del concepto de persona. Éstas derivan de diversas concepciones del Estado. De esta manera, la fundamentalidad material de los derechos fundamentales deriva de la comprensión del Estado que se tenga. Por esta razón, el concepto de persona del constitucionalismo discursivo está anclado a una cierta visión del Estado. No obstante, para este programa constitucionalista esta visión debe ser plural, es decir, no debe reducirse a una comprensión unidimensional de los derechos.

Las dimensiones liberales, democráticas y sociales han determinado sus respectivas concepciones de los derechos fundamentales. La fundamentalidad ha estado

\footnotetext{
${ }^{221}$ Alexy, Robert, TDF, p. 395.

${ }^{222}$ Al respecto, cfr., Bernal, Carlos, op. cit., pp. 93-96.

223 En un sentido parecido, Martin Borowski ha indicado la existencia de tres conceptos de derecho fundamental: formal, material y procedimental: lo decisivo, según Borowski, para que los derechos sean considerados como fundamentales radica en que los derechos positivos deben ser tan importantes como para que la opción entre garantizarlos o no garantizarlos pueda ser confiada a las mayorías parlamentarias ordinarias. En otras palabras, quién puede decidir acerca del contenido de los derechos: el constituyente o el legislador parlamentario ordinario (Cfr., Borowski, Martin, La estructura de los derechos fundamentales, Bogotá, UEC, 2003, pp. 36 y 37).
} 
asociada a darle prioridad a alguna de estas dimensiones, dependiendo de la visión estatal preferida. Pero acaso el problema de la fundamentalidad material reside en darle prioridad estricta a una dimensión sobre las demás, de manera que las otras dimensiones suelen considerarse inferiores o contrapuestas a la que se le otorga mayor peso. Esta situación puede solucionarse al conferirse el estatus de "fundamentales" a derechos reivindicados por las distintas dimensiones, siempre y cuando estos derechos tengan un peso normativo considerable para darles tal estatus. De esta manera, las dimensiones liberales, democráticas y sociales, las cuales han dado lugar a los respectivos derechos individuales, políticos y sociales, pueden mostrar la importancia de institucionalizarse en beneficio de los ciudadanos; en otras palabras, estas dimensiones pueden aspirar a explicar la fundamentalidad de este tipo de derechos, en tanto su importancia es decisiva en la conformación de un sistema racional de derechos fundamentales. Por esta razón la fudamentalidad de los derechos fundamentales suele ser también un tema discutido en el terreno filosófico y político. Ahora será analizada la estructura de los derechos fundamentales, expresada mediante la distinción entre reglas y principios.

\subsection{La estructura de derecho fundamental: reglas y principios}

Ahora será reconstruida la diferenciación entre normas categorizadas como reglas y principios. Las normas que expresan derechos fundamentales poseen una estructura doble: por un lado algunas normas pueden concebirse como reglas categóricas o definitivas que pueden aplicarse o no al caso concreto. Por otro lado hay normas que pueden concebirse como principios u objetos de ponderación, los cuales pueden colisionar en una determinada situación, siendo el caso de que sólo uno debe valer para el caso concreto, pero no ambos al mismo tiempo. Para explicar esta diferenciación analizaremos algunos aspectos determinantes de la obra de Dworkin y después desarrollaremos la distinción entre reglas y principios hecha por Alexy, la cual es más refinada que la de Dworkin.

\subsubsection{Reglas y principios según el modelo dworkiniano}

Aunque es usual decir que Dworkin fue quien primero comprendió el derecho como un sistema o modelo de reglas y principios, ${ }^{224}$ en referencia a la obra Los derechos en serio, esta distinción ya había sido tratada primero por Walter Wilburg en 1950 en la obra El

\footnotetext{
${ }^{224} \mathrm{Cfr}$., Sobrevilla, David, La filosofía del derecho alemana actual de orientación racionalista. Estudio sobre $R$. Alexy, K. Günther, J. Habermas y O. Höffe, México, D. F., Fontamara, 2008, p. 88.
} 
desarrollo de un sistema flexible en el derecho privado ${ }^{225}$ y después en 1956 por Josef Esser en la obra Principio y norma en el desarrollo jurísprudencial del derecho privado, ${ }^{226}$ así como otras obras, ${ }^{227}$ sólo que éstas no tuvieron el impacto que tuvo la obra de Dworkin, la cual marcó un antes y un después en la filosofía del derecho en las décadas posteriores a la recepción de esta distinción.

Los derechos en serio fue un libro que tuvo el mérito de definir y defender una teoría liberal del derecho en tiempos en los que "[L]os adultos reprochaban al liberalismo su tolerancia, en tanto que los jóvenes lo culpaban de rigidez, de injusticia económica y de la guerra de Vietnam". ${ }^{228}$ Para formular esta teoría, famosa por hacer célebre la tesis de "los derechos en serio", Dworkin, basándose en Rawls, criticó las debilidades de la teoría dominante, compuesta por el utilitarismo, según la cual el derecho y sus instituciones deben servir al bienestar general y nada más, y, por otra parte, criticó al positivismo jurídico hartiano.

Según Dworkin, el positivismo jurídico en la versión hartiana comete un error en el campo de la aplicación del derecho al no tomar en cuenta el hecho de que cuando los jueces no disponen de una regla apropiada para resolver un caso difícil toman decisiones

\footnotetext{
${ }^{225}$ Cfr., Wilburg, Walter, Entwicklung eines beweglichen Systems im bürgerlichen Recht, Graz, Kienreich, 1950. ${ }^{226}$ Nos referimos a la obra Grundzatz und Norm in der richterlichen fortbildung des Privatrechts, de Esser, poco conocida en el ámbito hispanoparlante, a pesar de encontrarse traducida al español. Al respecto, cfr., Esser, Josef, Principio y norma en la elaboración jurisprudencial del derecho privado, Barcelona, José María Bosch Editor 1961.

${ }^{227}$ Arthur Kaufmann sostiene que otros autores del ámbito alemán elaboraron sistemas de principios jurídicos, reglas de derecho (normas de derecho) y decisiones jurídicas, tales como Kaufmann, Arthur, "Gesetz und Recht", en Existenz und Ordnung; Festschrift für Erik Wolf, 1962; A. Troller, Überall gültige Prinzipien der Rechtswissenschaft, 1965; Werner Lorenz, "General Principles of Law: Their Elaboration in the Court of Justice of the European Communities", en American Journal ofEssf Comparative Law 13 (1964) y la mencionada obra de Esser. Respeto a esta última, Kelsen elaboró una interesante crítica en el capítulo veintiocho de Teoría general de las normas. Posteriores reflexiones a la obra de Dworkin: W. Fikentscher, Methoden des Rechts in vergleichender Darstellung, Tomo 2: Anglo-amerikanischer Rechtskreis, 1975, p. 82; Neil MacCormick, "Principles of Law", en Juridical Review 19 (1974); A. Peczenik, Principles of Law, en Rechtstheorie 2 (1971); Benditt, Law as Rule and Principle, 1978; F. Schauer, Playing by the Rules, 1991; U. Penski, "Rechtsgrundsätze und Rechtsregeln", en Juristische Zeitung, 1985; D. Horster, "Die aktuelle Diskussion über die Funktion von Rechtsprinzipien", en: Archiv für Rechts und Sozial Philosophie 77 (1991), 257 ff., F. Bydlinski, "Fundamentale Rechtsgrundsätze in der Löwengrube", en Rechtstheorie 22 (1991); I. Ilompart, Die Geschichlichkeit der Rechtsprinzipien, 1976 y K. Larenz, Richtiges Recht: Grunzüge einer Rechtsethik, 1979. Citamos las siguientes obras sin contar las de Alexy y diversos miembros de la "Escuela Moderna de Kiel" para mostrar muchas concepciones respecto a qué se entiende por "principios jurídicos". Sobre estas obras citadas, cfr., Kaufmann/Hassemer/Neumann (Eds.), Einführung in die Rechtsphilosophie und Rechtstheorie der Gegenwart, Heidelberg, C.F. Müller, 2011, pp. 106 a 108.
}

${ }^{228}$ Dworkin, Ronald, op. cit., p. 31. 
discrecionales. Según Dworkin, para el positivismo los sistemas normativos consisten sólo en reglas que se identifican en razón de su origen (test of pedegree), las cuales poseen una "textura abierta", ${ }^{229}$ y, con ello, al no poder fijar una decisión judicial en un caso difícil, permiten que los jueces ejerzan su discrecionalidad, ya que las reglas sólo se aplican con los criterios de todo o nada (all or nothing fashion).

En oposición al modelo positivista de Hart, Dworkin, veinte años después de la publicación de la obra de Esser, y sin referencia y ciertamente sin conocimiento alguno de la obra de éste, ${ }^{230}$ ofreció un modelo de derecho en el que además de reglas existen principios, diferentes a las primeras en la medida en que, en primer lugar, mientras las reglas se aplican en la forma "todo o nada", los principios, en cambio, sólo proporcionan razones a favor de una decisión determinada. En segundo lugar, los principios muestran una dimensión de vigencia distinta a la de las reglas, ya que poseen una dimensión de peso, la cual tiene una importancia crucial cuando se da una colisión entre principios; esto quiere decir que en caso de colisiones entre normas se le dará prioridad al principio que tenga mayor peso, sin que por ello el otro principio caiga en desuso; esto implica que en un momento determinado un principio puede ceder ante el mayor peso del otro. En tercer lugar, si las reglas se presentan como finitas, los principios, en cambio, son innumerables y en constante modificación, por lo que intentar enunciar todos los principios conduciría a un fracaso.

Para ejemplificar estos déficits de la teoría positivista, Dworkin acude al famoso caso Riggs v. Palmer. En este caso, un heredero asesina a su abuelo intentando obtener prematuramente la herencia en el testamento y descubre que el razonamiento del tribunal fue guiado, en última instancia, por una máxima general del derecho consuetudinario que no era para Dworkin reconocible por la regla de reconocimiento y que sostenía a manera de conclusión que "a nadie se le permitirá aprovecharse de su propio fraude o sacar partido de su propia injusticia, o fundar demanda alguna sobre su propia iniquidad o adquirir propiedad por su propio crimen", ${ }^{231}$ y en virtud de este razonamiento, el nieto asesino no recibió la herencia.

\footnotetext{
${ }^{229}$ Hart, Hart, H. L. A., The Concept of Law, Nueva York, Oxford University Press, 1994, p. 121.

230 Cfr., Poscher, Ralf, "Principles: How Many Theories? What Merit?", en, Klatt, Matthias (Ed.), Institutionalized Reason. The Jurisprudence of Robert Alexy, Nueva York, Oxford University Press, 2012, p. 221. ${ }^{231}$ Dworkin, Ronald, op. cit., p. 73.
} 
En este ejemplo era claro que el uso de principios le permitió al juez llenar los vacíos legales provocados por la vaguedad del lenguaje jurídico y las reglas y así aproximar las decisiones jurídicas a la idea regulativa de una única respuesta correcta. La postura de Dworkin no tardó en cobrar gran popularidad por mostrar una conexión entre el derecho y la moral -entendida en este contexto como un sistema de valoraciones críticas del juez acerca del derecho- que ponía al positivismo jurídico al borde de una crisis. Según Alfonso García:

Si existen principios en el derecho, entonces existe una relación conceptual necesaria entre derecho y moral.

Es decir, metateóricamente:

Si existen principios en el derecho el positivismo jurídico es una teoría equivocada. ${ }^{232}$

Sin embargo, cabe preguntarse ¿esto es así realmente?, ¿los argumentos de Dworkin son incompatibles con el positivismo jurídico? Antes de pasar al modelo alexyano vale la pena analizar los razonamientos de Dworkin para ver que sus argumentos no podrían de ninguna manera refutar al positivismo jurídico hartiano, por la sencilla razón de que el positivismo jurídico y el derecho positivo han incorporado y tomado en cuenta a los principios desde mucho tiempo antes de la formulación de esta teoría, por lo que necesitará partirse del modelo alexyano para dar cuenta de la estructura, contenido y aplicación de las normas de derecho fundamental. Para realizar esta crítica a la teoría de Dworkin, primero veremos el argumento de los principios aplicado al positivismo jurídico, y, después, aplicado al derecho positivo, para mostrar que esta teoría no refuta al positivismo jurídico como tal.

Los principios como crítica al positivismo jurídico: respecto a los problemas vinculados a la crítica del positivismo jurídico, la postura de Dworkin no descubrió nada nuevo. Al menos no para refutar al positivismo jurídico kelseniano, como bien lo ha indicado Alexandre Trivisonno. ${ }^{233}$ La distinción entre reglas y principios fue usada antes por Josef

${ }^{232}$ García, Alfonso, "¿Existen diferencias entre reglas y principios en el Estado constitucional? Algunas notas sobre la teoría de los principios de Robert Alexy?", en Alexy, Robert, Derechos sociales y ponderación, Madrid, Fundación Coloquio Jurídico Europeo, 2007, p. 336. Consideramos que el razonamiento de García Figueroa es incorrecto porque de la existencia de principios -el concepto de principios usado por él no nos parece clarono se sigue que exista una conexión conceptual y necesaria entre derecho y moral.

${ }^{233}$ En este punto, nuestras objeciones a la crítica de Dworkin al positivismo jurídico mediante la distinción entre reglas y principios son compartidas por Trivisonno, quien ha llevado a cabo un minucioso análisis de la obra de Esser para mostrar que Kelsen conocía esta distinción. Al respecto, cfr., Trivisonno, Alexandre T. G.,"Princípios jurídicos e poisitivismo jurídico: as críticas de Dworkin a Hart se aplicam a Kelsen?", en, Aguiar 
Esser para designar una diferencia en los sistemas de Civil law existente entre principios y normas y en los sistemas de Common law entre reglas y principios, pero esta distinción tampoco era nueva para los positivistas y mucho menos cuando los mencionados principios se refieren al uso de máximas latinas y principios generales del derecho usados con frecuencia en la práctica jurídica de los sistemas consuetudinarios.

En el caso Riggs v. Palmer, Dworkin hace énfasis en que el jurado apeló en la sentencia definitiva al principio jurídico siguiente: "[A] nadie debe aprovechar su propio dolo" (Nemini dolus suus prodesse debet) ${ }^{234}$ para otorgarle la pena estatal correspondiente a este "cariñoso nieto". El uso de este principio por parte de los jueces sólo confirma el uso de una "fuente jurídica permisiva" que Hart, entre otras cosas, conocía bien ${ }^{235}$ y que de ningún modo descubre nada nuevo para un positivista que conoce la distinción entre las fuentes jurídicas obligatorias y las permisivas. El mismo Dworkin reconoce que el juez está facultado para usar los principios en casos difíciles, pero Hart en El concepto de derecho también acepta el uso de los principios jurídicos para determinar la decisión final, y Kelsen en Teoría general de las normas afirma que los principios poseen el carácter de normas que deben ser aplicadas cuando se le autoriza a una corte para usarlos. ${ }^{236}$ Estos argumentos expresan claramente que ni el positivismo hartiano o kelseniano entrarían en contradicción con el uso de los principios al aceptarlos como normas que pueden contribuir a decidir un caso, desechando así la idea de que su mera existencia comprueba el error de la teoría positivista.

de Oliveira, Júlio y Trivisonno, Alexandre, T. G. (Eds.), Hans Kelsen, Teoría jurídica e política, Forense Universitaria, Río de Janeiro, 2013, pp. 197-199.

234 Cabanellas, Guillermo, Repertorio jurídico de principios generales del derecho, locuciones, máximas y aforismos latinos y castellanos, Buenos Aires, Editorial Heliasta, 2003, aforismo 3.736, p. 169.

235 Dice Hart: “[P]ero a veces el juez tiene mucho más que libertad de interpretación. Cuando él considera que ninguna ley u otra fuente formal de derecho determina el caso a decidir, puede fundar su fallo, p. ej., en un texto del Digesto, o en la obra de algún jurista francés. El sistema jurídico no lo obliga a usar estas fuentes, pero está aceptado como cosa perfectamente correcta que lo haga. Ellas son, por lo tanto, más que meras influencias históricas o causales pues tales textos son reconocidos como «buenas razones» para los fallos. Quizás podríamos llamar a tales fuentes, fuentes jurídicas «permisivas» para distinguirlas tanto de las "obligatorias» o formales, como la ley, como de las históricas o materiales" (Hart, Herbert, The Concept of Law, Nueva York, Oxford University Press, 1994, p. 294).

236 Dice Kelsen: "[U]n caso particular lo constituyen «los principios jurídicos generales reconocidos por los Estados civilizados», que la corte de justicia debe aplicar conforme al artículo 38 parágrafo $c$ el Estatuto de la Corte Internacional de Justicia [...] el hecho de ser mencionados expresamente en el derecho consuetudinario internacional (lit. b) junto al acuerdo internacional (lit. $a$ ), reafirma que se trata de normas que se convierten en derecho internacional que debe aplicarse por parte de la corte Internacional de Justicia, porque el artículo 38 parágrafo $c$ autoriza a dicha corte a aplicarlas" (Kelsen, Hans, Allgemeine Theorie der Normen, Viena, Manzche Verlags- und Universitätsbuchhandlung, 1979, p. 99). 
Los principios como crítica al derecho positivo: si el planteamiento de Dworkin no realizó una distinción nueva en el ámbito teórico, al menos podría considerarse que éste puede incluir en el derecho positivo principios jurídicos, o permitir legalmente su aplicación en casos difíciles, lo cual sería de utilidad para la resolución de problemas jurídicos. Sin embargo, el uso de los principios en el derecho positivo no requiere del planteamiento de Dworkin, ya que existen sistemas de derecho que ya han positivizado en la forma de reglas ciertos principios jurídicos, y también han permitido su uso para dictar sentencias definitivas. Veamos a continuación los siguientes párrafos del artículo catorceavo de la Constitución Política de los Estados Unidos Mexicanos:

En los juicios del orden criminal queda prohibido imponer, por simple analogía, y aún por mayoría de razón, pena alguna que no esté decretada por una ley exactamente aplicable al delito [de] que se trata.

En los juicios del orden civil, la sentencia definitiva deberá ser conforme a la letra o a la interpretación de la ley, y a falta de ésta se fundará en los principios generales del derecho. ${ }^{237}$

En el primer párrafo encontramos expresada en una regla de derecho un principio jurídico básico de la legitimidad de los Estados constitucionales modernos, el principio de estricta legalidad o de legalidad formal, formulado primero por Hobbes ${ }^{238}$ y precisado en el ámbito penal por Anselm von Feuerbach bajo la formulación latina: Nullum crimen sine lege, nulla poena sine lege, nullum crimen sine poena legale. ${ }^{239}$ Este principio jurídico, también considerado un axioma del garantismo penal, o de estricta legalidad, ${ }^{240}$ confirma un argumento que no consideró Dworkin por caer en un dilema "todo o nada", esto es, en el que una norma o es regla o es principio: siempre es posible hablar de principios

\footnotetext{
${ }^{237}$ Constitución Política de los Estados Unidos Mexicanos, Art. 14.

${ }^{238}$ Hobbes, Thomas, op. cit., p. 239.

${ }^{239}$ Aunque Anselm Feuerbach, padre de Ludwig Feuerbach, representante de la teoría de la prevención general negativa y autor del Anti-Hobbes, es considerado el padre de la ciencia penal moderna por la creación de este principio jurídico, tal principio es una expresión genuina del pensamiento hobbesiano, como lo señala Schmitt al afirmar que este principio jurídico fue un caso de aplicación del concepto jurídico creado por Hobbes en el capítulo XXVII del Leviatán, en el que se lee: "Ubi lex non est, Peccatum non est. Cessantibus Legibus Civilibus cessant Crimina. Ubi vero Lege vel consuetudine poena limitatur, ibi majoris poenae inflictio iniqua est". Al respecto, cfr., Schmitt, Carl, El Leviatán en la doctrina del Estado de Thomas Hobbes, México, D. F., UAM, 1997, pp. 134 a 139. Para comprender algunos detalles de la filosofía penal de Hobbes, tales como los fundamentos filosóficos de la omisión o la distinción hobbesiana entre forum internum y forum externum, o entre moral y derecho, cfr., Del Valle, Carlos, Estudios de filosofía política y del derecho penal, Bogotá, UEC, 2004, pp. 17 a 50.

${ }^{240}$ Ferrajoli, op. cit., p. 93.
} 
regularizados o de reglas principializadas ${ }^{241}$ y esto es comprobable si le damos un vistazo a las normas fundamentales de muchas constituciones.

Respecto al segundo párrafo, encontramos expresado en él la permisión jurídica para que los jueces hagan uso de los principios generales del derecho, en el supuesto de que no encuentren leyes aplicables para un problema jurídico en específico. En este caso, el artículo decimocuarto de la Constitución Mexicana, el cual reconoce la existencia y aplicación de los principios jurídicos, fue instituido en 1917, cincuenta años antes de que Dworkin publicara el artículo El modelo de las reglas I, lo cual confirma la existencia de los principios.

Indudablemente, alguien podría señalar que los principios enlazan al derecho con la moral, pero este argumento es deficiente, porque el hecho de que sean usados principios en del discurso jurídico no implica que se enlace lógicamente al derecho con la moral, ya que el argumento de Dworkin sería redundante a la luz del previo reconocimiento y permiso que poseen los jueces de recurrir a los principios, es decir, ¿qué sentido alguno tendría decirle al juez que debe aplicar en ciertos casos lo que, efectivamente, debe aplicar en ciertos casos?

Si una una norma admite el uso de los principios por parte de los jueces, y un positivista los admite como parte de las fuentes del derecho, ${ }^{242}$ entonces decir que al reconocer y usar los principios se comprueba el error de la teoría positivista y se vincula al derecho con la moral es erróneo. Este tipo de críticas revelan que la inclusión de principios en el razonamiento jurídico es una cuestión de derecho positivo, y que por tanto la teoría del positivismo jurídico puede incorporarlos sin aceptar por ello una vinculación entre derecho y moral. Finalmente, si Dworkin criticaba con dureza la discrecionalidad judicial y sostenía que con los principios podían asegurarse los derechos en la decisión final del juez, con la inclusión de criterios morales y políticos podría promoverse un peligroso activismo

\footnotetext{
241 Este argumento es parecido al que formula García Figueroa en Principios y positivismo jurídico respecto a la posibilidad de que se puedan "principializar las reglas" y "regularizar los principios", para buscar así un punto intermedio en su reconocimiento como normas, dándole en este sentido mayor importancia a la diferenciación que hace Alexy que a la de Dworkin, debido a que este último no toma en cuenta a las normas que poseen este carácter dual.

${ }^{242}$ Bobbio sostiene que los principios cumplen una función muy importante en cuanto le permiten a los jueces usarlos para llenar las lagunas del derecho, con base en los materiales que éstos mismos ofrecen, cuando no existe una norma específica para el caso concreto y no es posible recurrir a la analogía. Al respecto, cfr., Bobbio, Norberto, Teoría general del derecho, Madrid, Debate, 1995, p. 249.
} 
judicial. Es por ello que no se ve por dónde pueda escapar la postura de Dworkin del peligro de que el juez interprete al derecho acorde a criterios políticos y morales discrecionales, o hasta conservadores. ${ }^{243}$

En el debate que sostuvo con Dworkin, Hart le reconocía los méritos a esta teoría del derecho siempre y cuando se le viera con más humildad. ${ }^{244}$ En este caso, el mérito de esta teoría será el de abrirle paso a Alexy a la formulación de una distinción que afinará, pulirá e incorporará en Teoría de los derechos fundamentales, ya que, de acuerdo con Alexy, Dworkin introdujo en el razonamiento jurídico la dimensión del peso y la reflexión en torno a la discrecionalidad, mas no así la teoría principialista.

\subsubsection{Reglas y principios según el modelo alexyano}

Ahora será analizada la propuesta hecha por Alexy, la cual nos servirá para comprender la estructura, contenido y aplicación de los derechos fundamentales, la cual partirá del modelo de Dworkin respecto a la inclusión de la dimensión del peso, aunque con algunas variantes que pulirán la diferencia entre reglas y principios en muchos aspectos, hasta hacerla prácticamente distinta. La teoría de los principios tiene un peso considerable en la filosofía del derecho de Alexy, ya que sin ella:

[N]o puede existir una teoría adecuada de los límites a los derechos fundamentales, ni una teoría satisfactoria de la colisión entre derechos fundamentales y tampoco una teoría suficiente acerca del papel que juegan estos derechos en el sistema jurídico. Es un elemento básico no sólo de la dogmática de los derechos de libertad e igualdad, sino también de los derechos de protección, los derechos de organización y procedimiento y prestaciones en sentido estricto. Con su ayuda, es posible hacer más transparentes problemas tales como el efecto horizontal de los derechos fundamentales y la división de competencias entre el Tribunal Constitucional y el Parlamento [...] Por todo esto, la distinción entre reglas y principios es uno de los pilares fundamentales del edificio de la teoría de los derechos fundamentales. ${ }^{245}$

No obstante, antes de exponer la diferencia entre reglas y principios en Alexy, aclararemos el concepto de "principios" empleado por Alexy. Esto también ha provocado confusiones conceptuales que persisten hasta nuestros días. El concepto de "principios" es

\footnotetext{
${ }^{243}$ Al menos una de las agudas críticas que Joseph Raz le ha formulado a Dworkin reside en reprocharle el conservadurismo político y jurídico en el que cae este último al sostener que "la interpretación de los jueces debe residir en perpetuar y extender la ideología jurídica existente". Al respecto, cfr., "Professor Dworkin's Theory of Rights", en Political Studies, 1978, pp. 123 ss.

${ }^{244}$ Hart, H. L. A. y Dworkin, Ronald, El debate Hart-Dworkin, Bogotá, Siglo del hombre Editores, 2003, p. 128.

${ }^{245}$ Alexy, Robert, TDF, p. 63.
} 
una especie de cajón de sastre, y al igual que conceptos como el de "moral" o el de "validez", posee una textura ambigua (Mehrdeutigkeit). Como sostiene Bernal, es común comprender los principios como un conjunto de axiomas o postulados éticos que deben inspirar todo el orden jurídico (sentido axiológico), fuentes generadoras del derecho (sentido ontológico), o reglas orientadoras para el conocimiento, interpretación y aplicación de las restantes normas jurídicas (sentido metodológico). ${ }^{246}$ En estas diferentes concepciones, el único elemento común consiste en una confusión en cuanto a lo que quiere decirse cuando se refiere a ellos, y en el caso de la teoría de Alexy, este tipo de confusiones pueden llevar a malos entendidos sobre el uso que le atribuye a esta expresión. Como lo notó Genaro Carrió, el concepto de "principio jurídico" ha provocado muchos problemas, y una aclaración de éste nos llevaría a elaborar una lista amplia si intentáramos explicar este concepto a partir de las diversas escuelas y tradiciones filosófico-jurídicas. ${ }^{247}$

Para Alexy, la distinción que hizo Dworkin será de gran importancia para comprender la estructura, contenido y aplicación de las normas fundamentales, sólo que la afinará y complementará en aspectos importantes. De entrada, el concepto de principio jurídico en ambos es diferente. En la teoría principialista de Alexy los principios tendrán el carácter tradicional de mandatos de optimización y los bienes colectivos también podrán ser principios, a diferencia de la rígida postura liberal de Dworkin, para quien sólo los principios serán los derechos individuales concebidos como triunfos políticos, oponibles frente a la mayoría. También, Alexy va a diferir de la visión de Dworkin de reivindicar a la igualdad como virtud suprema de la comunidad política, y sostendrá, en cambio, que la libertad y la igualdad serán principios del mismo rango, subordinados a la idea regulativa de corrección. ${ }^{248}$ Finalmente, Dworkin no alcanzó a ver los alcances de la distinción entre reglas y principios en el ámbito constitucional, ya que el principio de proporcionalidad no había sido formulado y mucho menos aceptado por las cortes americanas de su tiempo. Como bien afirma Borowski, la conexión entre el principio de proporcionalidad con los principios a ponderar "fue hecha en Alemania, donde emergió la idea del principio de

\footnotetext{
${ }^{246}$ Bernal, Carlos, El principio de proporcionalidad y los derechos fundamentales, Madrid, CEPC, 2005, pp. 510517.

${ }^{247}$ Carrió elaboró una lista de usos que tiene la expresión "principio jurídico", con la pretensión de abarcar todos los usos que tienen estos principios en los contextos jurídicos en los que suelen mencionarse. De este modo, proporcionó once definiciones de "principio jurídico", en las cuales, sin embargo, no aparece la concepción de Alexy. Al respecto, cfr., Carrió, Genaro, Notas sobre derecho y lenguaje, Buenos Aires, AbeledoPerrot, 1994, pp. 210 a 212.

${ }^{248}$ Atienza, Manuel, "Entrevista a Robert Alexy", incluida en la TAJ, p. 500.
} 
proporcionalidad. Con Robert Alexy, los principios jurídicos hicieron su camino del ámbito de la filosofía jurídica al derecho constitucional". ${ }^{249}$ Sobre este tema volveremos en el capítulo sexto.

\subsubsection{Reglas y principios}

De acuerdo con Alexy tanto las reglas como los principios son normas debido a que pueden plantearse mediante las expresiones básicas del mandato, lo que debemos hacer, el permiso, lo que estamos permitidos a hacer y la prohibición, lo que no tenemos que hacer, expresiones desarrolladas por Henrik von Wright en sus trabajos sobre lógica deóntica. Alexy confiere a las reglas y principios el carácter de normas, sólo que con una dimensión diferente para la resolución de conflictos normativos: los conflictos normativos entre reglas serán resueltos mediante la dimensión de la validez, mientras que los conflictos normativos entre principios serán resueltos mediante la dimensión del peso.

Antes de distinguir entre reglas y principios, Alexy se centrará en los criterios que Dworkin propone para hacer esta distinción. Según Alexy, el criterio dworkiniano que sostiene que las reglas se aplican "todo o nada" no es aceptable, ya que es poco factible que puedan conocerse previamente todas las excepciones que se le puedan plantear a las reglas. En los sistemas jurídicos modernos no podrían conocerse todas las excepciones a las reglas porque en cada caso concreto pueden aparecer nuevas excepciones, y si fuera posible conocerlas todas, también podrían conocerse todas las excepciones a los principios, por lo que la única diferencia entre ambos tipos de normas residiría en el carácter más general y abstracto de los principios, esto es, una diferencia de grado, ya que tanto los principios y reglas se aplicarían exactamente de la misma manera, como "todo o nada".

Pero el segundo criterio propuesto por Dworkin sí lo aceptará Alexy, y será el punto de arranque para su teoría de los derechos fundamentales. Para plantear una distinción consistente entre reglas y principios, Alexy considera que algunas normas jurídicas fundamentales deben indicar en su descripción limitaciones que les priven del carácter definitivo para la resolución de un conflicto, por lo que, viendo más allá del modelo

249 Borowski, Martin, "La idea de los principios formales. La proporcionalidad en el control de constitucionalidad", conferencia dictada en el Tribunal Electoral del Poder Judicial de la Federación el día 9 de diciembre de 2013 en México, Distrito Federal, p. 11. 
dworkiniano, sostendrá como punto decisivo que los principios son normas que ordenan algo que debe ser realizado en la mayor medida posible, dentro de las posibilidades jurídicas y reales existentes. Por ello los principios serán concebidos en primera instancia como mandatos de optimización, caracterizados por cumplirse en diferente grado y atendiendo a las posibilidades de cumplimiento reales y jurídicas, mientras que las reglas son normas que sólo pueden ser cumplidas categóricamente, ya que contienen determinaciones en el ámbito de lo fáctica y jurídicamente posible. ${ }^{250}$ De este modo, toda norma es una regla o un principio, cuyas diferencias serán cualitativas y no de grado.

La diferencia entre principios y reglas se ve más clara al analizarse los conflictos de reglas y las colisiones de principios. En los conflictos de reglas la solución reside en introducir cláusulas de excepción que declaren la no vigencia de una de las reglas. En el caso de las colisiones de principios la solución es diferente. En una situación concreta en la que dos principios colisionan, uno de los dos debe ceder ante el otro, sin que por ello pierda vigencia definitiva. Esto se explica en virtud de que en circunstancias concretas uno de los principios puede tener un mayor peso y por ello debe preceder al otro. De este modo, puede concluirse respecto a la diferencia entre reglas y principios que " $[L]$ os conflictos de reglas tienen lugar en la dimensión de la vigencia, mientras que las colisiones de principios tienen lugar más allá de la dimensión de la vigencia, en la dimensión del peso". ${ }^{251}$

Esta diferenciación que distingue entre la vigencia de las reglas y el peso de los principios permite dar cuenta de la estructura de las normas de derecho fundamental, a nivel de fundamentación y aplicación, siendo este segundo nivel el que dará lugar a una crítica de Klaus Günther. Para Günther, la descripción que Alexy hace de los conflictos o colisiones de normas hace muy probable que "la distinción entre las normas y principios tenga menos que ver con la estructura de las normas que con la aplicación de las normas en situaciones concretas, donde la aplicación de éstas requiere que todas las situaciones que se presenten sean tomadas en consideración". ${ }^{252}$

\footnotetext{
250 Alexy, Robert, TDF, p. 68.

251 Alexy, Robert, TDF, p. 71.

252 Günther, Klaus, The Sense of Appropriateness. Application Discourses in Morality and Law, Nueva York, Suny, 1993, p. 214. Sobre el artículo de Searle al que Günther se refiere, cfr., Searle, John, "Prima Facie Obligations”, en, Raz, Joseph (Ed.), Practical Reasoning, Oxford, Oxford University Press, 1978.
} 
Según Günther, la propuesta de Searle respecto a una diferenciación entre una validez prima facie y otra absoluta parece más idónea, ya que la distinción alexyana respecto a la estructura de las normas de derecho fundamental puede reconstruirse mejor mediante los presupuestos de la conversación, sobre los cuales tomamos una postura en una situación concreta; esto quiere decir que la diferencia consistiría en tratar a una norma como regla sin tomar en consideración las características de la situación, o en tratar a una norma como principio tomando en cuenta todas las circunstancias jurídicas y fácticas de la situación. Posteriormente Alexy ha dado una respuesta a esta objeción y sostiene que un modelo mixto (de reglas y de principios) que refleje la distinción tanto a nivel de norma como a nivel de aplicación es mucho más rico en contenido. Un modelo mixto "puede explicar por qué tiene lugar un determinado tipo de aplicación. Por lo demás, no puede renunciarse a la distinción entre reglas y principios porque sólo con su ayuda conceptos tales como los de restricción de un derecho pueden ser adecuadamente reconstruidos". 253

\subsubsection{2. ¿Mandatos de optimización o mandatos a optimizar?}

Ahora bien, aunque generalmente los principios son concebidos como "mandatos de optimización", también han sido definidos como "mandatos a ponderar". ¿En qué reside esta diferenciación? La concepción de los principios qua mandatos de optimización ha sido sometida a una crítica severa por Aarnio ${ }^{254}$ y Sieckmann, ${ }^{255}$ quienes han argumentado que los mandatos de optimización tienen la estructura de reglas en tanto que, según esta definición estándar, los principios al ordenar que algo sea realizado en la mayor medida posible de acuerdo con las posibilidades fácticas y jurídicas muestran su carácter definitivo, esto es, se cumple o no se cumple, se optimiza o no se optimiza. Por tanto Alexy hará una distinción en dos niveles para evitar que la teoría de los principios sea refutada: el nivel de los objetos y el metanivel.

Por una parte, en el nivel de los objetos se encuentran los principios y por ello son concebidos como mandatos a ser optimizados. Por otra parte, en el metanivel se encuentran los mandatos de optimización. En este metanivel los mandatos de optimización

\footnotetext{
${ }^{253}$ Alexy, Robert, CVD, 2008, p. 77.

${ }^{254}$ Aarnio, Aulis, "Taking Rules Seriously", en, Archiv für Rechts-und Sozial philosophie Nr. 42, Stuttgart, Franz Steiner Verlag, 1990, p. 187.

255 Sieckmann, Jan-Reinard, Regelmodelle und Prinzipienmodelle des Rechtssystems, Baden-Baden, Nomos Verlagsgesellschaft, 1990, p. 65.
} 
ordenan que sus objetos, los mandatos a optimizar, deban realizarse en la mayor medida posible. En tanto son concebidos como mandatos de optimización no deben optimizarse, sino cumplirse, esta acción consiste en llevar a cabo la optimización. Así, los principios, en tanto objetos de la ponderación son mandatos a optimizar. Por tal motivo los principios contienen un deber ser ideal (ideales Sollen), todavía no poseen un deber ser relativo a las posibilidades fácticas y jurídicas; no obstante, una vez que han sido optimizados se transforman en un deber ser definitivo (reales Sollen). De esta manera el deber ser ideal es definido por Alexy como un "deber ser abstracto que no se encuentra limitado por las posibilidades fácticas y normativas disponibles". ${ }^{256}$ Así el deber ser ideal implica al mandato de optimización y viceversa. Sin embargo, Alexy afirma que tanto en aspectos prácticos y teóricos "todo aconseja entonces mantener la caracterización de los principios como «mandatos de optimización», y sólo cuando el análisis lo exija, llevar a cabo diferenciaciones más refinadas". 257

El que las normas de derecho fundamental posean un estatus de principios y por ello tengan sean concebidos como mandatos de optimización implica determinar con mayor precisión la concepción de principios que usa Alexy en su filosofía jurídica. Alexy entenderá los principios como normas de derecho fundamental que pueden optimizarse al entrar en colisión con otras normas de este tipo. La idea de que las normas de derecho fundamental deben aplicarse como mandatos a optimizar en virtud de su contenido es de gran importancia para todos los Estados democráticos y sociales de derecho, ya que son normas que todo Estado de derecho debe poseer para tener tal estatus. Esta idea es todavía más clara cuando Alexy reconoce que este tipo de normas han sido incorporadas en la Ley Fundamental de Alemania:

Donde esto es más claro es en los principios constitucionales, como los de dignidad humana, libertad, igualdad, democracia, Estado de derecho y Estado social. Si una constitución contiene estos seis principios, ello significa que se han incorporado a ella las formas principales del Derecho racional de la modernidad. El carácter de los principios significa que no se trata simplemente de normas vagas, sino que con ellas se plantea una tarea de optimización. ${ }^{258}$

\footnotetext{
${ }^{256}$ Alexy, Robert, "Ideales Sollen", en, Clérico, Laura y Sieckmann, Jan-Reinard (Eds.), Grundrechte, Prinzipien und Argumentation. Studien zur Rechstheorie Robert Alexys, Baden-Baden, Nomos Verlagsgesellschaft, 2009, p. 21-38. En adelante, IS.

257 Alexy, Robert, TEDF, p. 110.

${ }^{258}$ Alexy, Robert, DRP, p. 14.
} 
En la cita anterior pueden verse los seis principios constitucionales que Alexy considera necesarios para todo ordenamiento jurídico racional. Por último, Alexy menciona en diversas partes de su obra la necesidad de establecer un orden débil de prioridad entre los principios para reducir los márgenes discrecionales que han llevado a criticar la idea de ponderación como una idea irracional; este orden es muy importante, ya que es imprescindible para darles a los derechos fundamentales una base racional a nivel de la fundamentación filosófica, institucionalización política e interpretación y aplicación jurídicas.

Para hacerle frente a las críticas contra la conceptualización de los derechos fundamentales como principios, Alexy propone, en primer lugar, un orden débil de precedencia de los principios, esto es, un sistema de prioridades o precedencias conceptualizadas bajo la etiqueta prima facie - concepto que, de acuerdo con Bernard Williams, fue acuñado por primera vez por David Ross_- ${ }^{259}$ en caso de conflictos normativos en situaciones en las que dos derechos fundamentales colisionan y sólo uno debe prevalecer en un caso concreto. En este tipo de casos debe plantearse una prioridad prima facie en favor de un principio y luego tomar en consideración las situaciones concretas en las que estos principios deberán ponderarse para alcanzar una decisión jurídica más justa, de acuerdo con las posibilidades fácticas y jurídicas. Es importante saber que debe haber un orden de precedencia prima facie; sin embargo, esto no nos dice nada acerca de la determinación de un principio por otro, tomando en consideración el orden de precedencia y las circunstancias particulares de cada caso particular.

En segundo lugar, al considerar Alexy a los principios como mandatos a optimizar de acuerdo con las posibilidades fácticas y jurídicas, formulará estructuras de ponderación de los principios para resolver las colisiones entre principios jurídicos. En otras palabras: mientras que para los conflictos de reglas se aplicará el método jurídico de la subsunción, en virtud de que contienen mandatos definitivos y categóricos, en el caso de los principios el método jurídico consistirá en sopesar las razones en favor y en contra de los principios en conflicto para dictar un fallo lo más racional posible, haciéndose así explícita la conexión

\footnotetext{
${ }^{259}$ Según Bernard Williams, en la obra Lo correcto y lo bueno Ross inventó la terminología prima facie para discutir, sin mucho éxito, los conflictos de obligaciones o de deberes que distinguen entre obligaciones actuales y prima facie. Sobre esta apreciación, cfr., Williams, Bernard, Ethics and the Limits of Philosophy, Massachusetts, Harvard University press, 1985, p. 176 ss y, Ross, David, The Right and the Good, Oxford, Oxford Clarendon Press, 1930, p. 21 ss. También en el sentido de indicar la falta de claridad de Ross, cfr. Alexy, Robert, TDF, p. 79.
} 
entre la teoría de los principios y el principio de proporcionalidad (Grundsatz der Verhältnismäßigkeit), principio básico de aplicación de normas de derecho fundamental en los Estados sociales de derecho.

No obstante, antes de desarrollar este modelo de aplicación de las normas de derecho fundamental y enfrentarlo a las objeciones que se le han planteado, consideramos, por razones sistemáticas, reconstruir primero el sistema de derechos fundamentales de Alexy, para comprender mejor la idea, estructura y críticas a la ponderación. Las razones para esto son sencillas: si ya fue desarrollada la fundamentación filosófica de los derechos fundamentales, es mejor pasar al contenido político de los derechos fundamentales para saber con mayor exactitud qué es lo que posteriormente deberá aplicarse jurídicamente.

Para terminar este capítulo quisiéramos expresar una idea en torno a buscar una mediación entre los extremos opuestos en torno a ponderar o no ponderar derechos. Hare ha sintetizado con un curioso ejemplo esta idea, según la cual, por una parte, seguir reglas fijas, y, por otra parte, ejercer la capacidad de decisión sin apegarse a las reglas, no deben verse como acciones contrapuestas, sino complementarias:

Sería tonto si al enseñarle a alguien a conducir se tratara de inculcarle principios tan fijos y comprensivos que hicieran que el alumno nunca tuviera que tomar una decisión independiente. Sería igualmente tonto pasarse al otro extremo y dejar que él descubriera la manera de conducir. Lo que hacemos, si somos sensatos, es darle una sólida base de principios y, al mismo tiempo, amplia oportunidad para que tome las decisiones en las que se basan tales principios y mediante las cuales éstos son modificados, mejorados, adoptados a las circunstancias cambiantes o aun abandonados si se tornan totalmente inadecuados al nuevo medio. Enseñar sólo los principios sin dar oportunidad de someterlos a las decisiones de principio del alumno, es como enseñar ciencia exclusivamente con un libro de texto sin entrar nunca en el laboratorio. Por otra parte, abandonar a nuestro hijo o a nuestro aprendiz de conductor a sus fuerzas es como llevar a un niño a un laboratorio y decirle «Arréglatelas». El niño puede divertirse o matarse, pero probablemente no aprenderá mucha ciencia. ${ }^{260}$

Es indispensable comprender la distinción entre reglas y principios, qué clase de derechos deben poseer una prioridad prima facie frente a otros y qué teoria aplicarán para resolver un conflicto entre derechos fundamentales. Todo esto implicará que el juez deba complementar sus conocimientos en derecho público y constitucional con sus capacidades de decisión para resolver un conflicto normativo de modo racional, e, independientemente de si existe o no una única respuesta correcta para éste, elevar la pretensión de que su

\footnotetext{
${ }^{260}$ Hare, Richard, El lenguaje de la moral, México, D. F., UNAM, 1975, pp. 78 y 79.
} 
respuesta debe ser la correcta. Ahora será reconstruido el sistema de derechos fundamentales de Alexy, es decir, la institucionalización o positivización política de los derechos fundamentales. 


\section{Capítulo quinto. La institucionalización política de los derechos fundamentales}

\section{Introducción}

En este capítulo será llevado a cabo el tránsito de la fundamentación filosófica a la positivización o institucionalización política de los derechos fundamentales, ya que es otro momento muy importante en el desarrollo de la teoría de los derechos fundamentales. Las razones por las que debemos pasar a este segundo nivel están justificadas por el carácter debatible en torno a la forma en como el contenido de los derechos fundamentales será institucionalizada y la forma en como deben sistematizarse estos derechos. El análisis de la institucionalización de los derechos fundamentales seráde gran ayuda para comprender mejor las razones por las que será necesario el principio de proporcionalidad.

\subsection{La lucha política y social por el derecho}

En 1966 el Pacto Internacional sobre Derechos Económicos, Sociales y Culturales y el Pacto Internacional sobre Derechos Civiles y Políticos contribuyeron a consolidar en el contexto de la Guerra Fría la división de los derechos humanos en dos categorías, la de los derechos civiles y políticos y la de los derechos económicos, sociales y culturales respectivamente. Como lo señala Liborio Hierro, la distinción entre estas dos categorías en ese contexto histórico contribuyó a que las dos posturas filosóficas y políticas que luchaban por la hegemonía defendieran sus respectivas concepciones del derecho. ${ }^{261}$

Para el pensamiento liberal, los derechos universales y verdaderos eran los derechos civiles y políticos, institucionalizados como un freno frente a los posibles abusos de poder de la autoridad estatal y requeridos para que los ciudadanos ejerzan la libertad, por lo tanto, eran opuestos a los derechos sociales que limitan la autonomía de los ciudadanos al convertirlos en sujetos pasivos. Del mismo modo, para el pensamiento socialista los derechos universales y verdaderos debían incluir los derechos sociales,

\footnotetext{
${ }^{261}$ Cfr., Hierro, Liborio, "Los derechos económico-sociales y el principio de igualdad en la teoría de los derechos de Robert Alexy", en, Alexy, Robert, Derechos sociales y ponderación, Madrid, Fundación Coloquio Jurídico Europeo, 2007, pp. 164 y ss.
} 
institucionalizados como un freno frente a los abusos de poder del capitalismo salvaje y requeridos para que los ciudadanos pudieran alcanzar la igualdad, por lo tanto, son opuestos a los abstractos derechos liberales que privilegian a una clase social y crean una concepción falsa del ser humano. Para ambos pensamientos, los derechos de la parte contraria no eran perversamente "abstractos" o "materiales", sino que eran indispensables una vez que primero se resolvieran los problemas de explotación (para el socialismo) o de escasez (para el liberalismo) de las sociedades modernas; sólo que con el "desenlace de la guerra fría, el problema parece haberse reducido a la visión de si los derechos sociales son o no son auténticos derechos". ${ }^{262}$

En este contexto político también suele hablarse del modelo de tres generaciones de derechos propuesta por Theodor Marshall en 1950 en Ciudadanía y clase social. Mediante esta propuesta tríadica son planteados tres tipos de derechos fundamentales distintos según tres tipos de Estado de derecho: el liberal, el democrático y el social de derecho. Para algunos constitucionalistas el primero, el Estado liberal de derecho, representa los derechos individuales y civiles bajo la forma de una libertad protectora, el segundo, el Estado democrático de derecho, representa los derechos políticos bajo la forma de una libertad participativa y el tercero, el Estado social de derecho, representa los derechos sociales bajo la forma de una libertad promocional. Sin embargo, consideramos mejor mantener la primera distinción porque nos permitirá hacer una aproximación más precisa respecto a los problemas provocados por la tensión constante entre los diferentes contenidos de los derechos.

Precisamente, los ideales filosóficos de los más diversos pensamientos políticos, así como las luchas sociales pasadas y presentes, han contribuido a darle un contenido tanto absoluto y relativo ${ }^{263}$ a los sistemas de derechos fundamentales, lo cual provocará que el conflicto entre diversas concepciones morales, políticas y sociales haga acto de presencia en el derecho.

En la lucha por el contenido de los derechos fundamentales puede percibirse la materialización de los conflictos sociales que han existido, y, también, de las ideas

\footnotetext{
262 Hierro, Liborio, op. cit., p. 169.

${ }^{263}$ Sobre las diversas formas de concebir al contenido esencial absoluto y relativo de los derechos fundamentales, cfr., Da Silva, Virgilio Afonso, Direitos Fundamentais. Conteúdo essencial, restrições e eficacia, Sao Paulo, Malheiros Editores, 2009, p. 183 ss.
} 
filosóficas y políticas que han estado detrás de diversos movimientos sociales. En ocasiones suele pensarse que la institucionalización de los derechos ha sido posible gracias a consensos políticos y debates legislativos en los que el poder de la razón ha triunfado sobre las razones del poder. De la misma manera, suele pensarse que los consensos surgidos en la esfera pública han sido tomados en cuenta por las autoridades gubernamentales, dándose así una situación ideal en la cual los derechos son aquellos que los ciudadanos han sido capaces de darse a sí mismos. Si bien no descartamos que en muchas ocasiones los legisladores y la sociedad civil han institucionalizado derechos por vías consensuales, en otras la situación ha sido distinta, como lo sostiene Ferrajoli:

[P]uede afirmarse tranquilamente que, en la historia del hombre, no ha habido ningún derecho fundamental que haya descendido del cielo o nacido en una mesa de despacho, ya escrito y redactado en los textos constitucionales. Todos son fruto de conflictos, a veces seculares, y han sido conquistados con revoluciones y rupturas, al precio de transgresiones, represiones, sacrificios y sufrimientos: primero el derecho a la vida y a la garantía del habeas corpus, después la libertad de conciencia y de religión, sucesivamente la libertad de opinión y de prensa, más recientemente, la libertad de asociación y de reunión y más tarde el derecho de huelga y los derechos sociales. ${ }^{264}$

Este pasaje confirma el carácter conflictivo de la institucionalización de los derechos fundamentales y apunta a comprender las razones por las que se ha tenido que luchar por el reconocimiento de los derechos. Hablar de luchar por el reconocimiento de los derechos es hablar de las luchas históricas por la expansión de sus alcances en las diferentes esferas para tutelar a los más débiles de los más fuertes; esta lucha por los derechos sigue latente en nuestras sociedades contemporáneas.

Actualmente, el discurso liberal le da prioridad a los derechos individuales y políticos, si bien existen corrientes dentro del liberalismo que abogan por un liberalismo más igualitario. Tiene razón Ferrajoli cuando hace énfasis en que, por desgracia, los prejuicios ideológicos de quienes profesan la idea paleo-liberal del Estado mínimo y vigilante del orden público interior y defensa exterior, han influido en que todavía no se elabore un sistema de garantías sociales parangonable al garantismo liberal dispuesto para los derechos de propiedad y de libertad, así como tampoco lo ha hecho la tradición jurídica marxista y

${ }^{264}$ Ferrajoli, Luigi, Derecho y razón. Teoría del garantismo penal, Madrid, Trotta, 2006, p. 945. 
socialista, debido al desprecio por la legalidad y el Estado de derecho ${ }^{265}$ concebido, tout court, como instrumento de dominación de la clase en el poder.

Por estas razones es indispensable institucionalizar un sistema de derechos fundamentales que vaya más allá de las tendencias ideológicas que, en sus respectivos extremos, amenazan toda reflexión crítica sobre los derechos fundamentales. El sistema de derechos fundamentales, propuesto por Alexy, buscará institucionalizar ciertos derechos como fundamentales, con el objetivo de establecer las condiciones institucionales para el ejercicio y respeto de la libertad, igualdad y dignidad humanas. De igual manera, también esta teoría de los derechos fundamentales contribuirá a presentar una visión crítica de la institucionalización de los derechos, opuesta diametralmente a las posturas posmodernas que los desvalorizan en términos morales y fácticos. Es por ello que el sistema de posiciones fudamentales de Alexy será reconstruido y analizado.

\subsection{El sistema de posiciones fundamentales de Robert Alexy}

Bobbio solía recordar lo que "uno de los más sagaces filósofos del derecho" escribió: "«es indudable que los derechos humanos son uno de los más grandes inventos de nuestra civilización»" ${ }^{266}$ En consonancia con esta comprensión de los derechos como un fruto de la modernidad y modo de evitarle a la humanidad un futuro orwelliano, Luhmann sostenía que la autonomización del derecho de representaciones y contextos de fundamentación religiosos, morales y científicos, así como su institucionalización son una conquista moderna porque no permiten volver atrás. ${ }^{267}$ Este tipo de concepciones acerca de los derechos fundamentales apuntan a que este "invento" sea institucionalizado en el orden social.

Para ello, este invento o logro de la modernidad debe retomar los mejores postulados normativos del Estado liberal, del Estado democrático y del Estado social de derecho para institucionalizar un sistema de derechos fundamentales que pueda reconciliar, en cierto grado, las posturas filosóficas, políticas y sociales que suelen converger y entrar

\footnotetext{
265 Cfr., Ferrajoli, Luigi, El garantismo y la filosofía del derecho, Bogotá, UEC, 2000, p. 189.

${ }^{266}$ Bobbio, Norberto, Norberto Bobbio: el filósofo y la política, México, FCE, 2004, p. 512. En esta cita Bobbio se refería a Carlos Santiago Nino. Sobre esta frase, cfr., Nino, Carlos, Ética y derechos humanos, Buenos Aires, Paidós, 1984, p. 13.

${ }^{267}$ Véase, Luhmann, Niklas, Los derechos sociales como institución. Aportación a la sociología crítica, México, D. F., Universidad Iberoamericana, 2010, pp. 120 y 121.
} 
en conflicto respecto al contenido de los derechos. Para Alexy el Estado es necesario para institucionalizar los derechos, cumplir sus mandatos y reparar sus violaciones. Sólo de este modo Alexy puede sostener que antes que todo derecho fundamental, debe existir un derecho humano al Estado:

Cuando hay un derecho moral, por tanto, un derecho fundamentable frente a todos, como el derecho a la vida por ejemplo, entonces debe haber también un derecho fundamentable frente a todos a la creación de una instancia común para hacer cumplir aquel derecho. De otro modo, el reconocimiento de derechos morales no sería un reconocimiento serio, lo que sería contrario a su carácter fundamental y prioritario. La instancia común que ha de establecerse para el cumplimiento de los derechos humanos es el Estado. Por lo tanto, existe un derecho humano al Estado. Con el establecimiento de un Estado como instancia de cumplimiento, los derechos morales que tienen los individuos frente a otros se transforman en derechos del derecho positivo con contenidos iguales. Adicionalmente, surgen los derechos de los individuos a defensa, protección y procedimiento frente al Estado como derechos nuevos. ${ }^{268}$

Esta exigencia moral y jurídica de tener un derecho al Estado está basada en el deber de que el Estado reconozca como fundamentales ciertos derechos en beneficio de los ciudadanos. Como lo mencionamos previamente, los derechos fundamentales son derechos subjetivos con un alto grado de importancia, de ahí que tengan propiedades formales y sustanciales exclusivas que les otorgan tal differentia specifica. ${ }^{269}$ Sin embargo, la calidad específica de fundamentales no los libra de ciertas dificultades conceptuales que deben analizarse. Alexy ha indicado diversos tipos de problemas normativos, empíricos y analíticos en torno a los derechos fundamentales.

Respecto a los problemas normativos, Alexy los divide en ético-filosóficos y dogmático-jurídicos; por una parte, Alexy señala que estamos ante un problema éticofilosófico cuando se pregunta por qué los sujetos tienen derechos y cuáles son, con

\footnotetext{
${ }^{268}$ Alexy, Robert, "La institucionalización de los derechos humanos en el Estado constitucional democrático", en, Derechos y libertades: Revista del instituto Bartolomé de las Casas, no. 8, Madrid, 2000 p. 32. En adelante, IDHE. Sobre este comentario de Alexy, Ferrajoli ha dicho que "es una tesis poco más que tautológica, dado que es objeto de derecho precisamente la omisión de la lesión que lo viola o la comisión de la prestación que lo satisface, las cuáles son simultáneamente objeto de la prohibición correlativa o de la obligación correlativa en la que consiste su garantía". García, Alfonso, "Entrevista a Luigi Ferrajoli", en, Carbonell, Miguel y Salazar, Pedro (Eds.), Garantismo. Estudios sobre el pensamiento jurídico de Luigi Ferrajoli, Madrid, Trotta, 2003, p. 522.

${ }^{269}$ Bernal, Carlos, "Die Fundamentalität der Grundrechte", en, Clérico, Laura y Sieckmann, Jan-Reinard (Eds.), Grundrechte, Prinzipien und Argumentation. Studien zur Rechstheorie Robert Alexys, Baden-Baden, Nomos Verlagsgesellschaft, 2009, p. 83.
} 
independencia de la vigencia de un ordenamiento jurídico, mientras que estamos ante un problema dogmático-jurídico cuando se pregunta si un sujeto jurídico posee un determinado derecho subjetivo en un sistema jurídico. Sobre los problemas empíricos, Alexy indica que pueden distinguirse enunciados acerca del surgimiento de derechos subjetivos, sobre la historia del concepto de derecho subjetivo y la función social de los derechos subjetivos, problemas que están vinculados con enunciados normativos para relacionarse con los problemas dogmático-jurídicos. Finalmente, desde el punto de vista de los problemas analíticos, que son los que más importan para una teoría estructural de los derechos fundamentales, tiene una importancia decisiva la distinción entre norma y posición.

Esta distinción entre norma y posición es fundamental para distinguir, en primer lugar, entre a) razones para los derechos subjetivos, b) derechos subjetivos como posiciones y relaciones jurídicas, c) la posibilidad jurídica de hacer efectivos los derechos subjetivos, y, también, y no menos importante, para d) mostrar las diversas clasificaciones existentes de aquellas posiciones jurídicas que suelen recibir el nombre de "derechos subjetivos". Con el concepto de "posición jurídica" Alexy comenzará su análisis de los derechos fundamentales, entendidos como un conjunto de posiciones concretas de diferente contenido y estructura.

Aunque el tema de los derechos fundamentales no fue tratado con profundidad por los filósofos clásicos del derecho y del Estado, es posible encontrar en algunas obras de Jellinek, como Teoría del Estado y Sistema de derechos subjetivos públicos, el primer gran esfuerzo para diferenciar tres tipos de exigencias fundamentales del sujeto de derecho frente al Estado. Para Jellinek, estas exigencias eran comprendidas mediante diversas clases de estatus, siendo el estatus negativus el vinculado a los derechos de libertad (derechos individuales), el estatus activus el referido a los derechos de participación democrática (derechos políticos) y el estatus positivus que nombra a las exigencias que puede plantearle el ciudadano al Estado (derechos sociales y culturales). ${ }^{270}$ Para filósofos como Höffe, la teoría de Jellinek es convincente por su capacidad de diferenciación y

\footnotetext{
${ }^{270}$ Sin embargo, en su primera obra sobre la sistematización de los estatus (Sistema de derechos subjetivos públicos), Jellinek pensaba en un cuarto status, el status subjetionis o passivus, que lo usaba para llamarle a las obligaciones impuestas por el Estado a los ciudadanos, en cuanto súbditos. Esta posición fundamental ya no aparecerá después.
} 
continuidad con el derecho de la antigüedad, a tal grado, que la considera más clara que los principios de la justicia de Rawls. ${ }^{271}$

A pesar de sus numerosas oscuridades y deficiencias, Alexy, reconoce la vigencia de la teoría del estatus de Jellinek en obras importantes como la de Peter Häberle y la considera el "ejemplo más grandioso de una teorización analítica en el ámbito de los derechos fundamentales". ${ }^{272}$ Este punto es importante, porque en las contraposiciones que se presentan en la teoría formalista de Jellinek, Alexy parece encontrar un punto clave para la formulación de los derechos fundamentales, vista como una teoría mixta. Como lo indica Alexy, las objeciones y contraposiciones en torno a los derechos fundamentales pueden expresarse del siguiente modo:

Formalismo, carácter abstracto, carácter espacial, individuo aislado y desfasada. Lo contrario sería: realidad vital, concreción, mediación, comunidad/sociedad, hoy. Esta contraposición pone claramente de manifiesto que, en última instancia, se trata de la vieja oposición entre teorías formales y materiales. ${ }^{273}$

A partir de las virtudes y deficiencias de la teoría de Jellinek, Alexy establecerá una tercera vía, un modelo mixto/procedimental con el que intentará ofrecer una teoría formal/material de los derechos fundamentales, la cual retomará sus propiedades a partir de las exigencias de diversos modelos normativos del Estado. A continuación, mostraremos el Sistema de posiciones fundamentales:

271 “El primer principio de la justicia de Rawls, el de la mayor libertad igual, cubre los dos primeros principios -y nos hace echar de menos la diferencia, sin lugar a dudas fundamental, entre derechos de libertad y derechos de participación. El segundo principio de la justicia de Rawls asume en el principio diferencial las tareas del status positivus" (Höffe, Otfried, Derecho intercultural, Barcelona, Gedisa, 2008, p. 171).

272 Alexy, Robert, TDF, p. 233.

${ }^{273}$ Alexy, Robert, TDF, p. 235. 


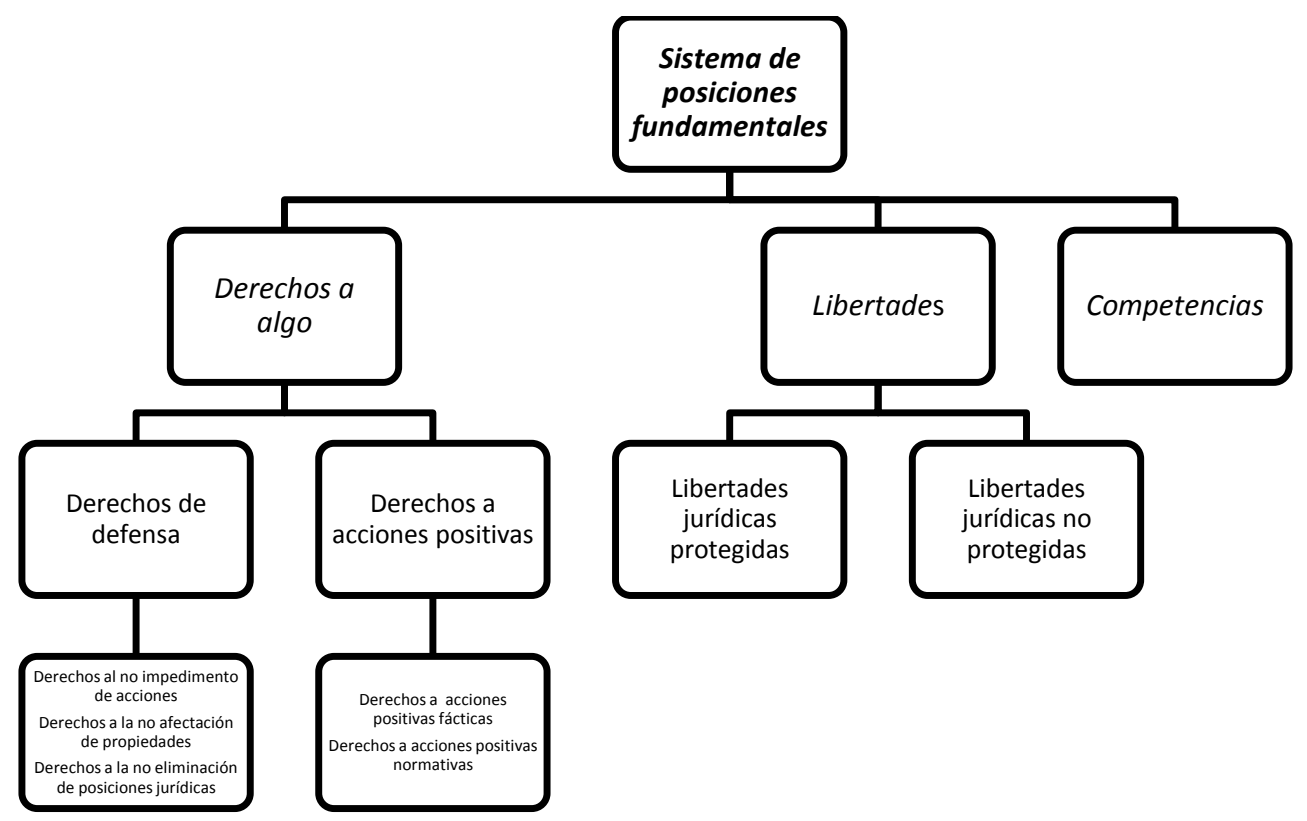

En el sistema de Alexy aparecen inmediatamente dos aspectos en los que vale la pena detenernos. En primer lugar, Alexy no utilizará las distinciones típicas de los derechos fundamentales, y, en segundo lugar, en su sistema aparecerá el concepto de "posiciones" y no de "derechos". Sobre el primer aspecto indicamos que Alexy no recurre a las usuales categorías de derechos fundamentales por razones conceptuales, es decir, no usa las distinciones entre derechos de primera, segunda y tercera generación, o entre derechos individuales y derechos sociales, y en vez de ello se basará en la estructura deóntica que poseen para dar cuenta de la complejidad del contenido de los derechos.

En segundo lugar, al basarse en el concepto de "posiciones jurídicas fundamentales" y no de "derechos fundamentales" encontramos un argumento parecido al anterior. Con el uso del término "posiciones", es posible comprender las determinaciones de los derechos fundamentales en un sentido más amplio, esto es, permite ver a los diferentes tipos de derechos como tres posiciones distintas con un contenido y forma fundamentales, pero diferenciados, lo que implica reconocer que si bien los derechos fundamentales son derechos subjetivos importantes, su contenido material les permitirá agruparse en tres diferentes categorías, entendidas como 1. derechos a algo, 2. libertades y 3. posiciones.

\subsubsection{Derechos a algo}

Los derechos a algo parten de una estructura sencilla con tres elementos, que son el titular del derecho (a), el destinatario del derecho (b) y el objeto (G) de derecho, por lo 
que la forma más general de este enunciado (D) puede expresarse como DabG. Sin embargo, de este esquema sencillo pueden derivarse muchos tipos de "derechos a algo", dependiendo de lo que se ponga en las posiciones de titular, destinatario y objeto. Lo importante será indicar que esta estructura muestra que respecto a los derechos a algo se trata siempre de una acción del destinatario, ya sea esta positiva o negativa, y es así como se derivarán de ellos acciones positivas y negativas.

\subsubsection{Los derechos a acciones negativas o derechos de defensa. Estos} derechos se refieren a los derechos clásicos de libertad que tienen los ciudadanos frente al Estado a acciones negativas por parte de éste. Estos derechos están relacionados con tres tipos prohibitivos, mediante los cuales el Estado no debe obstaculizar o impedir acciones, afectar propiedades o situaciones y eliminar posiciones de los titulares de derecho.

5.2.1.1.1. Derechos al no impedimento de acciones. Entre este tipo de derechos podemos encontrar los que se institucionalizan con el fin de asegurar la libertad de expresión, movimiento, creencias religiosas, educación de los hijos, elección de profesión o de unión. Para asegurarlos, son prohíbidas leyes o actos de autoridad que impidan u obstaculicen estos derechos mediante formas legales que los afecten en ciertos niveles de intensidad. Alexy señala que existen otras formas en las que el Estado puede influir en la realización de estos derechos de libertad, como hacer que ciertas acciones jurídicas se vuelvan jurídicamente imposibles al suprimirse reglas constitutivas de los actos institucionales. Un ejemplo de acciones que vuelven jurídicamente imposibles algunos actos podría ser la desaparición de reglas constitutivas de derecho electoral para hacer imposible el acto jurídico de votar. También están los obstáculos fácticos, que se dan cuando un derecho de libertad no puede ejercerse debido a que no existen las condiciones materiales que lo permitan, como es el caso del voto por correspondencia. Este tipo de derechos pueden expresarse bajo la forma del siguiente enunciado: a tiene frente al Estado un derecho a que éste no le dificulte a a llevar a cabo la acción $h$.

5.2.1.1.2. Derechos a la no afectación de propiedades. Esta segunda categoría de derechos de libertad, o de acciones negativas del Estado, consiste en institucionalizar derechos que impidan que el Estado afecte propiedades y situaciones esenciales de los ciudadanos o personas morales, teniendo como ejemplo típico el de la inviolabilidad del domicilio sin mediar una orden previa. Este tipo de derechos pueden expresarse bajo la 
forma del siguiente enunciado: a tiene frente al Estado un derecho a que éste no afecte la propiedad A o situación B de a.

5.2.1.1.3. Derechos a la no eliminación de posiciones jurídicas. Esta tercera categoría de acciones negativas del Estado consiste en institucionalizar derechos que impidan que el Estado elimine posiciones jurídicas del titular del derecho. Aunque el ejemplo típico de posición jurídica es el del estatus de propietario, también pueden eliminarse posiciones jurídicas al prohíbirse acciones, como es el caso de la manifestación de ideas o de la libertad de profesión en caso de que se deroguen las normas que permiten este tipo de ejercicios. Estos derechos pueden expresarse bajo la forma del siguiente enunciado: $a$ tiene frente al Estado un derecho a que éste no elimine la posición jurídica $P J$ de $a$.

5.2.1.2. Los derechos a acciones positivas o derechos prestacionales. Estos derechos se refieren a la institucionalización de acciones positivas 0 derechos sociales complementarios de libertad que tienen los ciudadanos frente al Estado. Estos derechos pueden dividirse en acciones positivas fácticas y normativas.

5.2.1.2.1. Derechos a acciones positivas fácticas. Estos derechos, también considerados derechos a prestaciones en sentido estricto, se refieren a las exigencias jurídicas de otorgar prestaciones que contribuyan a crear las condiciones mínimas de existencia, sin tomar en consideración las formas mediante las cuales se lleve a cabo la acción positiva requerida. Este tipo de derechos pueden expresarse bajo la forma del siguiente enunciado: a tiene frente al Estado un derecho a que éste lleve a cabo la acción positiva fáctica $h$.

5.2.1.2.2. Derechos a acciones positivas normativas. Estos derechos, también considerados derechos a prestaciones en sentido amplio, se refieren a actos estatales de creación de normas. Se trata, en esencia, de la institucionalización de medidas estatales que aseguren la protección de los diferentes ámbitos de libertad. Este tipo de derechos pueden expresarse bajo la forma del siguiente enunciado: a tiene frente al Estado un derecho a que éste lleve a cabo la acción positiva normativa $h$.

\subsubsection{Libertades}

Antes de comenzar con este segundo tipo de derecho fundamental, Alexy hace algunas aclaraciones pertinentes. Alexy sabe de las dificultades respecto al uso de este 
concepto, debido, entre otras cosas, a los diversos ámbitos de aplicación en los cuales es usado, los grandes debates filosóficos y políticos que ha provocado y la enorme carga emotiva de la palabra libertad, que implica, en muchas ocasiones, que quien la use para describir un fenómeno, al mismo tiempo exprese una valoración positiva de éste. ${ }^{274}$ En virtud de que un análisis del concepto de libertad implicaría desarrollar toda una filosofía moral, política, jurídica y social, Alexy optará por hacer solamente un análisis de la libertad jurídica, que consistirá en una relación triádica entre el titular de una libertad (o de una nolibertad), un impedimento de la libertad y el objeto de la libertad para distinguir entre dos objetos de la libertad, divididos en una alternativa de acción o sólo una acción.

En el caso de la libertad jurídica estamos siempre ante alternativas de acción, y, por ello, se concebirán las diferentes formas de institucionalización de éstas como «libertades negativas», en el sentido de que a los titulares de derechos fundamentales no le deben estar vedadas alternativas de acción, esto es, el sujeto debe poseer la posibilidad de ser libre respecto a un hacer o un no hacer. Este tipo de derechos pueden expresarse bajo la forma del siguiente enunciado: $x$ es libre (o no libre) con respecto a $y$ para hacer $z$ o no hacer $z$. Es por ello que, de acuerdo a Alexy:

La libertad positiva y la negativa se diferencian, de acuerdo con lo hasta ahora dicho, sólo porque en la libertad positiva el objeto de la libertad es exactamente una acción mientras que en la libertad negativa consiste en una alternativa de acción. Estos conceptos de la libertad positiva y negativa no coinciden, desde todos los puntos de vista, con el uso habitual del lenguaje. El concepto de libertad negativa aquí acuñado es más amplio y el de libertad positiva más restringido que el habitual. ${ }^{275}$

A Alexy le parece importante destacar que la libertad negativa en sentido estricto surge de la relación triádica de la libertad, en la cual las alternativas de acción son siempre el objeto de la libertad y las acciones de obstaculización son el obstáculo de la libertad jurídica. Por ello será analizada la libertad jurídica para distinguir entre libertades jurídicas protegidas y libertades jurídicas no protegidas.

\footnotetext{
${ }^{274}$ Un ejemplo de lo que Alexy quiere decirnos al hablar del concepto de libertad es cuando recurre al relato de Aldous Huxley en Ciego en Gaza: "Libertad es un nombre maravilloso. Esa es la razón por la que tienes tantas ganas de usarlo. Crees que si llamas verdadera libertad a estar preso, la gente se sentirá atraída por la prisión. Y lo malo del caso es que tienes razón." Al respecto, cfr., Alexy, Robert, TDF., p. 186 y también, Stevenson, Charles, Ética y Lenguaje, Buenos Aires, Paidós, 1971, p. 201.

${ }^{275}$ Alexy, Robert, TDF, p. 199.
} 
5.2.2.1. Libertades jurídicas protegidas. Este tipo de derechos de libertad consiste en los permisos de hacer algo u omitirlo y en la vinculación con derechos a algo y normas que aseguren al titular del derecho la posibilidad de ejecutar las acciones permitidas. La estructura de las normas destinadas a asegurar las libertades jurídicas protegidas se hace manifiesta de modo más sencillo en las relaciones entre iguales, en el caso típico en el que los comerciantes $a$ y $b$ son igualmente libres para ganarse al comprador $c$ y tienen el derecho a que el Estado no impida hacer aquello para lo que tienen la libertad de este derecho fundamental.

5.2.2.2. Libertades jurídicas no protegidas. Este tipo de derechos de libertad, reducible sólo a permisos, se define como la conjunción de un permiso jurídico de un hacer algo y un posterior permiso jurídico de omitirlo. Esta definición muestra que la libertad no protegida consiste en la mera vinculación del permiso positivo con el negativo y que tiene existencia cuando una acción u omisión tienen que ser calificadas como permitidas, lo cual implica que una norma con tal calificación puede apoyarse en una norma explícita (normas permisivas explícitas), o bien, que puede fundamentarse porque el sistema jurídico no contiene normas de mandato o prohibición bajo las cuales caiga la acción u omisión que debe calificarse (normas permisivas implícitas).

\subsubsection{Competencias}

Dentro de esta categoría entran posiciones jurídicas importantes para el sistema de derechos fundamentales, relacionadas con los derechos a algo y las libertades. Aunque el concepto a veces es poco claro, se trata de un concepto indispensable para comprender la estructura de los derechos fundamentales. Una competencia es una posición conferida por una norma de competencia para que los ciudadanos lleven a cabo el ejercicio de actos jurídicos en el derecho público y privado para modificar una situación jurídica, teniendo como ejemplos el de un matrimonio o un contrato, respectivamente. Una manera idónea para delimitar este concepto es distinguir entre las acciones que modifican una situación jurídica, sin ser competencias, de las competencias en sí.

Alexy ofrece como criterio de distinción el concepto de acciones institucionales, que presuponen, usando la terminología de Searle, el uso de reglas constitutivas y no 
regulativas. ${ }^{276}$ Para ejemplificarlo en el ámbito jurídico, Alexy considera que quien interpreta el comportamiento de dos sujetos como la celebración de un contrato, debe presuponer reglas constitutivas que conviertan ciertas acciones sociales en acciones jurídicas con el estatus de un contrato. Por estas razones, el legislador podría vulnerar las normas de derecho fundamental si derogara las competencias que tienen los ciudadanos para modificar la posición jurídica de otro sujeto jurídico en ámbitos de derecho público y, sobre todo, de derecho privado, que es en donde tienen una mayor importancia. Un punto muy importante de estas normas de derecho fundamental es que, según Alexy, "[C]uanto más individualista sea una teoría normativa de los derechos fundamentales, tanto más derechos a competencias supondrá. La razón de ello es la relación entre la libertad y la competencia". ${ }^{277}$

Mientras que al otorgar una libertad jurídica de hacer o no hacer algo a sus ciudadanos el Estado asume una actitud pasiva, al otorgarle competencias para que tengan alternativas de acción asume una actitud activa. El ejercicio de estas competencias por parte de los ciudadanos también implica que el Estado, además de conferirlas y no intervenir en su ejercicio, establezca normas penales para impedir que terceros las obstaculicen y prestacionales para asegurar su ejercicio fáctico. Con las competencias hemos terminado la reconstrucción del Sistema de posiciones fundamentales de Alexy. Sin embargo, esta presentación ha sido descriptiva respecto a su contenido y no ha planteado problemas normativos respecto al contenido que poseen los derechos a la libertad e igualdad y los derechos sociales, por lo que ahora veremos los problemas en torno al

${ }^{276}$ Para Searle la realidad está constituida por hechos institucionales y hechos brutos. Los hechos institucionales requieren de instituciones humanas para su existencia, mientras que los hechos brutos son aquellos que existen independientemente de cualquier institución humana. Por supuesto que para describir un hecho bruto requerimos de la institución del lenguaje, pero el hecho indicado necesita distinguirse de la indicación misma. Los hechos institucionales requieren de reglas constitutivas para existir. De este modo, las reglas regulativas serán aquellas que regulan actividades que existen independientemente de las reglas, como es el hecho de manejar de un lado específico del camino, mientras que las reglas constitutivas serán aquellas que hacen posible la forma de actividad que regulan, como es el hecho de que para que un juego de mesa tenga el carácter de ajedrez no dependerá de cualquier tipo de reglas, sino de las que hacen que el ajedrez sea tal y no un simple "acto bruto" de mover piezas de madera sobre un tablero. Al respecto, cfr., Searle, John, Mind, Language and Society. Philosophy in the Real World, Nueva York, Basic Books, 1999, pp. 111123 y Searle, John, Making the Social World. The Structure of Human Civilization, Nueva York, Oxford University Press, 2011, pp. 9-11.

${ }^{277}$ Alexy, Robert, TDF, p. 212. 
contenido de estas posiciones jurídicas fundamentales. Esto nos llevará al análisis de la aplicación jurídica de los derechos fundamentales.

\subsection{Sobre los derechos generales de libertad, igualdad y a acciones positivas}

Ahora será expuesto cómo es que "se han convertido en contenido de derechos positivos dos de los objetos más controvertidos de la filosofía política", ${ }^{278}$ y las implicaciones que lleva este acto jurídico. Como vimos antes, Alexy ha presentado una teoría analítica de los derechos fundamentales de corte individualista, ya que la ética del discurso, base moral del pensamiento alexyano y concebida como una "ética del derecho y del Estado", 279 necesita tomar en serio al individuo a nivel moral, jurídico y político sin caer por ello en irracionales posturas libertarianas. Con este sistema de posiciones fundamentales Alexy busca mediar entre posturas antagónicas en la filosofía práctica, y es por ello que en su sistema de derechos tanto los derechos individuales y sociales pueden ser aceptados dentro de éste:

Un socialista, siempre que no sea un fanático, puede aceptar un derecho general a la libertad como un derecho prima facie. Podemos tener la esperanza de que lo acomode, a través de un proceso de ponderación, dentro de sus ideales políticos. Un liberal, considerando de nuevo que no es un fanático, puede aceptar un derecho social general a la asistencia social como un derecho prima facie. Aquí, también, podemos esperar que lo reduzca a través de un proceso de ponderación de acuerdo a sus ideales políticos, por ejemplo, que lo transforme en un derecho definitivo con un contenido mínimo. ${ }^{280}$

Es preciso reconocer que este intento de hacer compatibles los derechos individuales con los sociales no es fácil, sobre todo, en situaciones concretas en las que una visión del derecho y la sociedad está en juego. Por ello es indispensable analizar por qué las relaciones entre los derechos a la libertad y a la igualdad se tornan problemáticas en el discurso jurídico. No obstante, este esfuerzo de Alexy no ha pasado desapercibido. Según Mattias Kumm, la concepción de los derechos de Alexy, en cuanto reconoce un derecho general a la libertad y un derecho general a la igualdad, entra en la categoría de

\footnotetext{
${ }^{278}$ Cfr. Alexy, Robert, TDF, p. 299.

279 Höffe, Otfried, Kategorische Rechtsprinzipien. Ein Kontrapunkt der Moderne, Fráncfort del Meno, Suhrkamp, 1994, p. 379.

${ }^{280}$ Alexy, Robert, DRP, pp. 32-33.
} 
Paradigma Racionalista de los Derechos Humanos, ${ }^{281}$ lo cual constituye un fundamento normativo del Estado democrático y social de derecho. Comenzaremos, pues, con la presentación alexyana del derecho general de libertad.

\subsubsection{El derecho general de libertad: La concepción formal-material}

Sobre el derecho general de libertad es difícil dar una definición precisa debido a que este concepto tiene muy diversos alcances, dependiendo del ámbito en el que se emplee y la postura filosófica que se tenga sobre éste. Lo que hará Alexy será partir de una concepción material-formal del derecho general de libertad. Esta concepción intentará ir más allá de las críticas usuales que se suelen plantear a este derecho respecto a la supuesta falta de contenido y propondrá un principio de la libertad negativa, que se compondrá de tres subprincipios: el primero es el principio de la libertad negativa de acción, referido también a la situación y a la posición, el segundo es el que exige la mayor medida posible de no afectación de situaciones y el tercero es el que exige la no eliminación de posiciones jurídicas del titular de derecho fundamental.

La vinculación entre principios formales y materiales le permite a Alexy sostener que, en primer lugar, sin la libertad jurídica negativa no existe la dignidad humana en un sentido jurídicamente relevante, por lo cual la libertad negativa puede apoyarse en el principio de la dignidad humana y, en segundo lugar, que la libertad negativa del individuo puede limitarse al colisionar con otros principios con un peso suficiente, como los derechos de terceros e intereses colectivos, lo cual lleva a considerar la vinculación del individuo con la comunidad. Es así como Alexy llega a la siguiente formulación:

La concepción del derecho general de libertad aquí expuesta, puede denominarse «concepción formal-material». Es formal en la medida en que parte de la liberta negativa y la trata como un valor en sí mismo. Es material, porque, en caso de colisiones, determina el peso relativo del principio de la libertad negativa en el caso concreto, también sobre la base de otros principios que, frente al de la libertad negativa, tienen un carácter material. ${ }^{282}$

\footnotetext{
${ }^{281}$ Kumm, Mattias, "Alexy's Theory of Constitutional Rights and the Problem of Judicial Review", en, Klatt, Matthias (Ed.), Institutionalized Reason. The Jurisprudence of Robert Alexy, Nueva York, Oxford University press, 2012, p. 201.

${ }^{282}$ Alexy, Robert, TDF, p. 317.
} 
Esta concepción mixta necesitará, por una parte, de una teoría de las esferas de protección de la libertad y de los derechos de libertad tácitos, y, por otra, responder a las objeciones que se le puedan plantear. Estas objeciones las veremos a continuación.

\subsubsection{Esferas de protección de la libertad y derechos tácitos}

Respecto a las esferas de protección de la libertad, Alexy señala tres esferas tomadas en cuenta por el Tribunal constitucional Federal y que requieren de una respectiva decreciente intensidad de protección. Tales esferas son la esfera más interna, el ámbito interno más íntimo del sujeto, la esfera privada amplia, que comprende el ámbito privado diferenciado de la esfera más interna, y la esfera social, referida a todo lo que está fuera de las esferas anteriores. Con esta conceptualización de las esferas de protección es más fácil señalar en dónde pueden presentarse las lesiones más graves a la libertad y a la dignidad humana de los titulares de derecho fundamental y en dónde deben ser más fuertes las protecciones jurídicas, como, por ejemplo, la protección al derecho a la intimidad de las personas.

En cuanto a los derechos de libertad tácitos, Alexy hace tres distinciones. La primera es si los derechos de libertad tácitos se refieren a acciones o situaciones del titular de derecho fundamental, la segunda entre derechos tácitos abstractos y concretos y la tercera entre posiciones prima facie y definitivas. Este tipo de derechos no son tan diferentes del derecho general de libertad, sino que son otras formas del mismo, cualificadas porque presentan una descripción más precisa del hecho y porque poseen una conformación y reforzamiento vía jurisprudencial. La diferencia específica radica en que si los derechos de libertad expresos son reacciones del constituyente a determinadas amenazas a la libertad, los derechos de libertad tácitos son reacciones de la jurisprudencia constitucional a éstas.

\subsubsection{Las objeciones al derecho general de libertad}

Al derecho general de libertad le han sido planteadas varias y severas objeciones.

Éstas repercuten en el contenido de las normas de derecho fundamental a las que Alexy les pondrá especial atención, debido a las consecuencias que podrían tener en el discurso jurídico, es por eso que las analizará con detalle.

1) La objeción de las garantías puntuales: según esta objeción, que nos recuerda en cierto sentido al Estado de naturaleza descrito por Hobbes, los derechos fundamentales 
nacieron históricamente del deseo de seguridad y de evitar peligros acuciantes en un contexto social determinado, lo que los vuelve incompatibles con la concepción de pensar en un derecho general de libertad. Esta tesis está sujeta a limitaciones históricas y normativas que reivindican el derecho general de libertad como un derecho que va más allá de los argumentos históricos, y, además, no tendría sentido siempre interpretar el catálogo de derechos fundamentales mediante argumentos genéticos, sino que es tarea de la ciencia del derecho fundamentar normas generales en otro tipo de argumentos, como los normativos y funcionales para la sociedad.

2) La objeción de sistematicidad cerrada: esta objeción consiste en vincular al derecho general de libertad con un sistema axiomático cerrado y, por tanto, rechazarlo categóricamente. Esta objeción es refutable por la práctica jurídica, al mostrar que siempre es posible que los derechos de libertad $-\mathrm{y}$ las demás normas de derecho fundamental puedan obtener determinaciones adicionales a través de nuevas interpretaciones constitucionales. El sistema jurídico debe ser cerrado en la medida en que el derecho general de libertad tiene que proteger prima facie la libertad negativa, pero también debe ser abierto en la medida en que la existencia de este derecho permita la posibilidad de que se institucionalicen nuevos derechos definitivos y tácitos.

3) La objeción del "individuo aislado": esta objeción, si bien no es la más fuerte en un sentido jurídico, nos parece que es la que más problemas filosóficos provoca respecto al contenido, porque, de acuerdo con posturas filosóficas y políticas como las socialistas y comunitaristas, este derecho de libertad expresaría una versión errónea del ser humano y de la relación que mantiene con sus prójimos y con el Estado, omitiéndose el hecho de que el Estado social de derecho no sólo está institucionalizado para restringir la libertad, sino que al realizar prestaciones promueve el aseguramiento de la libertad para todos. Estas objeciones van dirigidas contra las temibles consecuencias que traería consigo el abuso de este derecho, en tanto es considerado un derecho de libertad ilimitado.

Según Alexy, no se le debe temer a este derecho por su carácter negativo, ni considerarlo ilimitado en todos sus aspectos. Esto puede ser explicado en virtud de que, a diferencia de los lugares comunes acerca de la infinitud de los alcances de la libertad negativa respecto al discurso jurídico, lo protegido conforme a la idea de derecho es todo menos ilimitado, puesto que lo decisivo serán los pesos relativos que tenga la libertad negativa y lo que puede colisionar contra ella, de "tal forma que, al final, la libertad negativa 
sea muy reducida". ${ }^{283}$ Alexy ha afirmado que el peso de la precedencia prima facie del derecho de libertad en su teoría es tan débil que, seguramente, no satisfaría a un representante de una teoría política individualista, lo cual mostraría que la objeción del individualismo planteada a esta teoría es poco sostenible. ${ }^{284}$

Las intervenciones en la libertad negativa comprueban que este derecho no es ilimitado, siempre y cuando las razones ofrecidas para intervenir en un derecho de libertad sean de mayor peso que las ofrecidas a favor del derecho afectado. Alexy señala que, para hablar de una situación total de libertad es necesario aceptar que ésta debe presuponer la justificación de sacrificios a ella misma, porque si no se institucionalizaran límites a la libertad, de ninguna manera podría hablarse de su justificación. Para que esta situación se cumpla, se requiere de la institucionalización de derechos que protejan a sus titulares de aquellas situaciones que pueden poner en peligro esta situación; esto lleva a Alexy a afirmar lo siguiente:

Así como es seguro que la sola libertad negativa no puede constituir la situación total de libertad, así también lo es que sin ella una situación total no puede nunca llevar el calificativo positivo "de libertad». Ya por razones conceptuales presenta dificultades una situación en la que no existe ninguna libertad negativa, en la que, por lo tanto, toda acción concebible está ordenada o prohibida. En todo caso, una situación semejante no sería una situación de libertad. ${ }^{285}$

Esto lleva a reconocer la importancia de limitar este derecho cuando existan razones de mayor peso que puedan justificarse a la luz de procedimientos racionales, especialmente a través de la ponderación. Por ello también debe aceptarse que el derecho general de libertad debe ser tratado como un principio, porque si se tratara como una regla, tendría que establecerse un orden lexicográfico, lo cual llevaría al peligro del fanatismo que tanto teme Alexy. ${ }^{286}$

\footnotetext{
283 Alexy, Robert, TDF, p. 332.

${ }^{284}$ Cfr., Alexy, Robert, DRD, p. 261.

${ }^{285}$ Alexy Robert, TDF, p. 334.

${ }^{286}$ Alexy menciona un interesante ejemplo acerca de los peligros de tratar a las famosas "normas" de justicia formuladas por Chaim Perelman en De la justicia (De la justice) como reglas y no como principios. Al Respecto, dice Alexy: "Quien las trate como reglas se verá de pronto en el aprieto de tener que establecer entre ellas órdenes jerárquicos fijos, esto es, lo que Rawls denomina «órdenes lexicográficos». Con ello surge el peligro del fanatismo. Quien, por ejemplo, sigue la primera regla «a cada uno lo mismo» al pie de la letra, y le otorga prioridad sobre todas las demás reglas, desemboca en un igualitarismo estricto, frente al que pueden aducirse argumentos extremadamente sólidos. Lo mismo resulta aplicable, si bien en distinta medida, a las restantes reglas". (Alexy, Robert, La Institucionalización de la justicia, Granada, Comares, 2005, p. 66. En adelante, IJ).
} 
De este modo, con la institucionalización del derecho general de libertad puede evitarse que la imagen del individuo aislado termine por convertir al sistema de posiciones fundamentales en una defensa del individualismo posesivo, ya que, por medio de la ponderación de criterios materiales, puede tenerse más en cuenta la referencia del sujeto a la comunidad en condiciones legales que contribuyan a realizar una situación total de libertad, de acuerdo con los fundamentos del discurso jurídico de la modernidad.

4) La objeción de la inaceptable ampliación del recurso de amparo: para Alexy esta es la objeción más fuerte en términos jurídicos, y consiste en que al comprenderse el derecho general de libertad como acciones, situaciones y competencias jurídicas, y al permitirse intervenciones cuando sean formal y materialmente conformes a la Constitución (según lo que indica el artículo segundo, párrafo primero de la Ley Fundamental de Alemania), ${ }^{287}$ podría ampliarse el recurso de amparo a niveles exagerados. En el caso de las normas de competencia formales, el recurso de amparo tiene las funciones de defender los derechos fundamentales de los ciudadanos de leyes o actos de autoridad y de proteger el derecho constitucional objetivo, con el fin de contribuir a su desarrollo e interpretación. Para llevar a cabo esas funciones y admitirse el recurso de amparo se requiere que se haga referencia a un "derecho constitucional subjetivo", porque es lo que hace posible la fundamentalidad de las posiciones formales.

En el caso de las normas de derecho fundamental se puede objetar que toda intervención en la libertad negativa viola el citado artículo, provocando una ampliación exagerada del recurso de amparo. Para evitar que toda violación a la libertad negativa caiga en lo que comprende este artículo, Alexy indica que la vulneración al derecho de un titular de derechos fundamentales debe examinarse dentro del marco del derecho fundamental vulnerado y excluyendo la posibilidad de que se apele a otro artículo (como elartículo segundo, párrafo primero de la Ley Fundamental). De esta manera sólo el derecho fundamental vulnerado y el respectivo titular de éste podrán exigir la admisibilidad del recurso de amparo.

\subsubsection{El derecho general de igualdad: la reformulación de una idea clásica}

287 "Toda persona tiene el derecho al libre desarrollo de su personalidad siempre que no viole derechos de otra ni atente contra el orden constitucional o la ley moral." 
El mandato del derecho general de igualdad lo situará Alexy en dos niveles que abarcarán las respectivas determinaciones de la idea de igualdad. Estos niveles se dividirán en los mandatos de igualdad en la creación del derecho y de igualdad en aplicación del derecho, con el objeto de vincular jurídicamente tanto al legislador como a los órganos aplicadores del derecho. Con esto ha sido definido el alcance jurídico que tiene este mandato respecto al legislador y al órgano aplicador de derecho, pero no sabemos todavía qué significa. Es claro que la idea de igualdad no debe tomarse como una directriz abstracta que exige que todo sea tratado igual, cuando vivimos en una sociedad en la cual las situaciones fácticas de las personas son muy diversas, por lo que se requiere partir de un punto de partida acerca de la igualdad.

Este punto de partida, que constituye la columna vertebral de la jurisprudencia del Tribunal Constitucional Federal sobre la idea de igualdad, será la fórmula clásica aristotélica: «[H]ay que tratar igual a lo igual y desigual a lo desigual». ${ }^{288}$ Esta fórmula clásica, considerada como un postulado esencial de la racionalidad práctica, sin embargo, es insuficiente para contribuir al discurso igualitario si no dice nada acerca de cómo deben ser tratados específicamente individuos con propiedades específicas, es decir, siempre es posible discriminar a alguien si no se ofrecen criterios materiales que especifiquen en qué consiste lo igual y lo desigual. ${ }^{289}$

Por criterios materiales serán consideradas determinadas propiedades que den cuenta acerca de las diferencias existentes en los casos concretos, ya que no existen dos personas o situaciones que sean iguales desde todos los puntos de vista, sino sólo algunos aspectos desde los cuales puedan llevarse a cabo juicios valorativos sobre la posibilidad de fundamentar racionalmente juicios de valor sobre el principio de igualdad. Dicho de otro modo, para que exista un orden jurídico diferenciado, en el cual pueda tratarse racionalmente la igualdad o desigualdad en la creación o aplicación del derecho deberá tomarse en cuenta una igualdad valorativa relativa a igualdades (o desigualdades) fácticas

\footnotetext{
${ }^{288}$ Respecto a la idea de que la justicia debe ser proporcional y no basarse en una estricta igualdad, vale la pena remitirnos al pasaje clásico de Aristóteles: “Por ejemplo, parece que lo igual es lo justo, y lo es, pero no para todos, sino para los iguales; y lo desigual parece que es justo, y ciertamente lo es, pero no para todos, sino para los desiguales." (Aristóteles, Política, Madrid, Tecnos, 2004, 1280x, p. 222).

289 Un racista puede asumir la fundamentación racional del principio universal derivado de esta fórmula y violar principios de justicia al ejercer la aplicación fáctica de este principio si no recurre a criterios materiales. Él puede considerar que el trato discriminatorio a una persona de otra raza está justificado al sostener que ella es desigual.
} 
parciales, relativa a determinados tratos y a un criterio de valoración que contribuya a determinar, sobre la base de valoraciones racionales, qué es lo igual y qué es lo desigual.

Pero antes de analizar el problema de la valoración del contenido de las normas en conflictos normativos, Alexy desarrollará a partir de la fórmula clásica otras fórmulas que contribuirán a reducir la incertidumbre de los juicios de valoración en el examen de los casos concretos. Al igual que en el análisis de la sección pasada respecto a las reglas de razón, estas fórmulas sobre la igualdad no eliminarán la posibilidad de que sean emitidos juicios irracionales, sino que reducirán la posibilidades de llevar a cabo valoraciones irracionales. Para solucionar el problema de la valoración vinculada a este mandato y atender a las propiedades específicas de cada caso concreto, el Tribunal Constitucional Federal de Alemania se refiere a esta la fórmula clásica y a dos fórmulas derivadas de ella, que incluyen las expresiones "esencial" y "arbitraria", con la finalidad de hacerlas más específicas respecto a las situaciones de los casos particulares; de este modo, las primeras tres fórmulas son las siguientes:

\section{Las Fórmulas del Tribunal Constitucional Federal}

(1) Al legislador le está prohibido tratar desigualmente a lo igual.

(2) Al legislador le está prohibido tratar desigualmente a lo esencialmente igual.

(3) Al legislador le está prohibido tratar desigual a lo esencialmente igual.

Estas fórmulas intentan adecuar la aplicación del examen de igualdad a las situaciones específicas, sin embargo, todavía no dicen lo suficiente respecto a todas las propiedades fácticas parciales o relevantes que puedan tener éstos. La interpretación del mandato de igualdad requiere de más determinaciones que le hagan justicia a la idea de igualdad. Por esta razón, Alexy introducirá estas otras variaciones:

(4) Existe una igualdad esencial si y sólo si un trato desigual sería arbitrario.

(5) Lo igual no puede tratarse de una manera arbitrariamente desigual.

(6) Están prohibidos los tratos arbitrariamente desiguales.

Con la introducción de estas fórmulas puede prohíbirse la aplicación de un trato desigual a casos en los que existen igualdades esenciales, es decir, en los que la igualdad no debe tratarse de modo desigual sin razones de por medio y así serán prohíbidos criterios arbitrarios desiguales. No obstante, estas fórmulas no han dicho nada todavía acerca de 
que el principio de igualdad exija tratos iguales o desiguales, por lo cual Alexy introducirá dos mandatos más, uno respecto al trato igual y otros dos respecto al trato desigual:

El mandato de trato igual

(7) Si no hay ninguna razón suficiente para permitir un trato desigual, entonces está ordenado un trato igual.

El mandato de trato desigual

(8) Si no hay ninguna razón suficiente para permitir un trato igual, entonces está ordenado un trato desigual.

(9) Si hay una razón suficiente para ordenar un trato desigual, entonces está ordenado un trato desigual.

Aquí encontramos dos mandatos, uno responde a que la norma de trato desigual (8) no debe tener la misma estructura que la del mandato igual (7), sino que debe poseer una formulación distinta (9) para que sea exijida una fundamentación de este mandato. Esto implica que deba exigirse la carga de la argumentación a favor del trato igual y no al revés.

Con la introducción de estas fórmulas, derivadas de la fórmula clásica de Aristóteles, se han hecho precisiones de gran ayuda para contribuir a que la racionalidad jurídica respecto al derecho general de igualdad se realice en la medida de lo posible, ya que estas fórmulas muestran que el operador jurídico tiene ciertos márgenes de acción respecto a la interpretación de este derecho. Pero estas fórmulas no han respondido qué es una "razón suficiente" para permitir u ordenar una diferenciación entre lo igual y lo desigual. Esta diferenciación puede verse con mayor precisión al introducirse criterios valorativos frente a los cuales deben tomarse decisiones.

Recordemos, de nuevo, las tres preguntas en torno a las cuales gira el objeto de la Teoría de la argumentación jurídica según Alexy: ¿dónde y en qué medida son necesarias las valoraciones?, ¿cómo actúan estas valoraciones en los argumentos jurídicos? y ¿son racionalmente fundamentables estas valoraciones ${ }^{290}$ En este caso, las valoraciones del juez siempre están presentes en el discurso jurídico, y las reglas y formas de razón y servirán para reducir los niveles de discrecionalidad, aunque no podrán eliminarla del todo. Lo importante es que las valoraciones de los tribunales se apeguen a las razones del

\footnotetext{
${ }^{290}$ Alexy, Robert, TAJ, p. 37.
} 
legislador o las complementen. En el caso del derecho general de igualdad, estas valoraciones deberán considerarse respecto a la pregunta acerca de qué es un trato igual o desigual.

Esta pregunta puede comprenderse mejor si distinguimos entre una igualdad o desigualdad referida a los actos y otra referida a las consecuencias. Según la idea de igualdad o desigualdad referida a los actos, tanto a personas con recursos y sin recursos económicos la Ley Fundamental las protegería con el seguro del desempleo, es decir, sin tomar en cuenta sus condiciones fácticas, mientras que la segunda idea, referida a las consecuencias, sí tomaría en consideración las circunstancias concretas de cada caso para otorgar el seguro del desempleo, reconociéndose así la desigualdad fáctica y con ello, el deseo de institucionalizar, en cierta medida, una igualdad fáctica.

Los ejemplos pasados muestran la vigencia de la fórmula clásica de la igualdad, puesto que si quiere crearse una igualdad fáctica, deben aceptarse desigualdades jurídicas. Esta es una afirmación que en abstracto podría sonar arbitraria, pero que en casos concretos ayudaría a materializar la igualdad fáctica. No obstante, que el mandato de igualdad apoye la desigualdad jurídica en favor de la igualdad fáctica no implica que los argumentos de Alexy violenten la igualdad jurídica en beneficio de la igualdad de hecho. Este criterio se basa en que la igualdad jurídica posee una mayor certeza que la igualdad de hecho y esto lo ejemplifica Alexy al ver que una igualdad referida al acto —un padre que le regala a sus dos hijos dos balones iguales - no necesariamente genera una igualdad referida a las consecuencias —un hijo puede sentirse feliz y el otro triste-, ya que no puede crearse una igualdad referida a la felicidad, es decir, a una igualdad fáctica.

La valoración respecto a lo igual y lo desigual —así como la valoración de los demás derechos fundamentales - pone de relieve que la fundamentación y el grado de satisfacción del principio de igualdad está vinculado también a la filosofía moral y política, porque Alexy, siguiendo a Dreier, reconoce que "la interpretación del principio de igualdad que se elija depende de la filosofía del derecho y del Estado que se tenga". ${ }^{291}$ En este caso la filosofía jurídica de Alexy concebirá el derecho general de igualdad como un principio. Esto quiere decir que, al igual que el derecho general de libertad, el derecho de igualdad también será concebido como un principio, precisamente, porque éste no estará

291 Dreier, Ralf, Recht - Moral - Ideologie, Fráncfort del Meno, Suhrkamp, 1981, p. 114. 
fundamentado por razones definitivas institucionalizadas en reglas categóricas, sino que estará fundamentado por razones prima facie, institucionalizadas mediante principios que pueden ser desplazados por otros principios contrapuestos en caso de que sean ofrecidas razones de mayor peso.

El hecho de que los derechos de libertad e igualdad los conciba Alexy como principios no es extraño en el ámbito constitucional. Pero debe considerarse también que el principio general de igualdad jurídica puede contribuir a fundamentar el principio general de igualdad fáctica mediante la institucionalización de derechos destinados a la creación de la igualdad de hecho. Si el derecho prima facie a la igualdad jurídica se formula como un derecho negativo prima facie a la omisión de tratos desiguales, el derecho a la igualdad fáctica se formulará como un derecho positivo prima facie a acciones positivas del Estado. Esta diferenciación nos llevará ahora al análisis de las acciones positivas del Estado en sentido amplio y estricto.

\subsubsection{Los derechos a acciones positivas del Estado: los derechos prestacionales en sentido amplio y estricto}

Finalmente, pasaremos a la conceptualización y problemas de las acciones positivas estatales, las cuales han sido motivo de apasionados debates filosóficos, políticos y jurídicos en los últimos años. Como lo dice Alexy, esta polémica sobre los derechos prestacionales "está caracterizada por diferencias de opinión sobre el carácter y tareas del Estado, del derecho y de la Constitución, con los derechos fundamentales incluidos en ella, así como sobre la evaluación de la situación actual de la sociedad”. ${ }^{292}$ En la polémica sobre los derechos sociales también estamos ante un problema de redistribución económica, problema que aqueja incesantemente a las sociedades modernas.

Es fácil comprobar que en los debates sobre la naturaleza de estos derechos suelen darse concepciones contrapuestas sobre lo que se entiende por Estado, derecho y sociedad civil; esto no debería sorprendernos si se consideran las consecuencias de los derechos a acciones positivas para la sociedad civil, el Estado y la comprensión misma del derecho. Pero, además, también es comprobable en estos debates la falta de claridad acerca de qué son las acciones positivas del Estado y los derechos sociales. De entrada, la clarificación del contenido y concepto de los derechos sociales fundamentales es de gran

${ }^{292}$ Alexy, Robert, TDF, p. 390. 
importancia para defenderlos o criticarlos, ya que, en ocasiones, el concepto de derechos sociales es usado de forma indiscriminada. Es por esto que la teoría de Alexy es de gran utilidad, en tanto permite aclarar este tipo de problemas. Primero comenzaremos con el concepto y división de los derechos prestacionales en sentido amplio y luego analizaremos los derechos prestacionales en sentido estricto.

\subsubsection{Derechos prestacionales en sentido amplio}

Con este concepto, Alexy se referirá a todo derecho a una acción positiva, es decir, a una acción del Estado, que serán la contrapartida de los derechos a una acción negativa, es decir, a una omisión del Estado. Este tipo de acciones positivas del Estado englobarán derechos prestacionales más amplios que los concebidos habitualmente, ya que por tales se comprenderán derechos que van desde la protección del ciudadano frente a otros ciudadanos mediante la institucionalización de normas penales, pasando por normas de organización y procedimiento hasta la prestación en dinero y bienes.

Las razones por las que Alexy ofrece un concepto más amplio residen en que los derechos sociales fundamentales, entendidos como derechos prestacionales, se refieren tanto a prestaciones fácticas, entre las que pueden considerarse el derecho a la educación, a la salud, a la vivienda, como a prestaciones normativas, entre las que pueden considerarse las normas de derecho penal y las respectivas de organización y procedimiento. También, otra razón para ampliar el concepto de derechos prestacionales reside en que estos derechos imponen a los representantes del Estado la obligación de perseguir ciertos fines, como es la protección de la vida, a diferencia de los derechos negativos que imponen límites a los representantes del Estado respecto a los fines que persigue.

De este modo, los derechos prestacionales estarán divididos en (1) derechos de protección, (2) derechos a la organización y al procedimiento y (3) derechos prestacionales en sentido estricto. Estos tres tipos de derecho serán fundamentales debido a sus propiedades formales y materiales, y también porque presentarán relaciones triádicas entre un titular de derecho fundamental, el Estado y una acción positiva del Estado. A continuación, pasaremos al primer tipo de derecho.

5.3.1.1. Los derechos de protección. Este tipo de derechos comprenden aquellos derechos constitucionales que se le otorgan al titular de derecho fundamental para que el 
Estado lo proteja de intervenciones de terceros, así como también son comprendidos aquellos derechos a que el Estado organice y maneje el orden jurídico de una manera específica, en lo que se refiere a la relación entre sujetos de igual jerarquía, institucionalizándose así deberes del Estado de proteger a los individuos mediante normas de derecho penal. Aunque el fundamento filosófico de este tipo de derechos de protección podría encajar en la comprensión liberal clásica de los derechos fundamentales, Alexy considera que estos derechos muestran que las diferencias normativas que separan a los derechos del Estado liberal de los del Estado social no son tan grandes como comúnmente se piensa. Si pensáramos en una diferenciación más clara, podríamos decir que los derechos de defensa son todos aquellos derechos fundamentales que exigen que el Estado omita intervenciones, mientras que los derechos de protección son todos aquellos derechos fundamentales frente al Estado para que éste se encargue de que terceros omitan intervenciones. Esta diferencia es muy importante, porque es la que nos permitiría comprender el deber estatal de proteger a los ciudadanos de otros ciudadanos mediante la institucionalización del derecho penal.

5.3.1.2. Los derechos a la organización y al procedimiento. Este apartado comprende derechos fundamentales que no siempre son vistos así debido a sus características formales, nos referimos a los derechos procedimentales. Como es bien sabido, la idea de procedimiento no se limita al ámbito del derecho y esto es comprobable en los debates acerca de las teorías éticas procedimentales, ya sea para valorar sus cualidades o para criticar sus bases "formalistas". ${ }^{293}$ Como lo indica Alexy, la palabra "procedimiento" permite buscar, en primer lugar, un punto intermedio entre una teoría de los valores amplia y un dejar hacer al legislador; en segundo lugar, responde al "espíritu de los tiempos" $y$, en tercer lugar, conduce a los juristas a un ámbito que parecen dominar mejor que nadie: el ámbito procedimental. ${ }^{294}$

Mediante esta concepción Alexy vinculará dos tipos de derechos independientes para darles a los derechos fundamentales normas procedimentales para que tengan así una tutela jurídica eficaz, es por ello que usará este concepto en un sentido amplio para vincular normas relacionadas con la realización y aseguramiento de los derechos

\footnotetext{
${ }^{293}$ En el ámbito de la filosofía moral las teorías procedimentales han tenido un peso importante en las últimas décadas. En este sentido, Alexy ha afirmado en muchas ocasiones que la teoría del discurso pertenece a la clase de teorías procedimentales (Alexy, Robert, DRD, p. 109).

${ }^{294}$ Cfr., Alexy, Robert, TDF, p. 417.
} 
fundamentales por medio de normas de organización y procedimiento. Las razones de la adscripción de estos derechos procedimentales a derechos fundamentales no se vinculan a pretensiones "formalistas", sino todo lo contrario: si los derechos materiales son derechos subjetivos y fundamentales, entonces los derechos procedimentales también deben serlo. Estos derechos, comprendidos en la categoría del estatus positivo de Jellinek, se dividirán en cuatro tipos.

5.3.1.2.1. Las competencias de derecho privado: estas normas conocidas también como «institutos jurídicos» son derechos frente al Estado para que expida normas constitutivas que permitan realizar acciones jurídicas de derecho privado y para que puedan crearse, modificarse y eliminarse posiciones jurídicas de derecho privado. En tanto se entienden como procedimientos para crear derecho mediante el ejercicio de la autonomía privada, estas normas adquieren el carácter de variaciones del modelo del contrato. E argumento para que estas normas procedimentales se conciban como derechos fundamentales radica en que distintos derechos fundamentales presuponen la existencia de instituciones jurídicas de derecho privado, y porque también contribuyen al respeto del Estado frente a la autonomía privada en las relaciones jurídicas.

5.3.2.1.2. Los procedimientos judiciales y administrativos (procedimientos en sentido estricto). Estas normas son derechos a una «tutela jurídica efectiva». Este es el terreno propio del derecho procesal, el cual tiene la función de que los resultados de las decisiones jurídicas se acerquen lo más posible a la justicia a través de procedimientos institucionalizados con ese fin. En otras palabras, son derechos que aclaran la tesis de Luhmann acerca de lograr la legitimidad mediante procedimiento, aunque, a veces, estas normas procesales son vistas como obstáculos para los mismos derechos materiales que deben garantizar. Debe considerarse que aunque las normas procedimentales no garanticen en todos los casos un resultado correcto, es más, a pesar de que ningún procedimiento legal podría presentarse como infalible, con su seguimiento estricto sí aumentan las probabilidades de obtenerse resultados correctos, por lo que no deben subestimarse sus propiedades formales.

En caso de que estos derechos procesales o formales puedan ayudar a hacer efectivos los derechos sustanciales o materiales, deben exigirse prima facie por los principios de derecho fundamental, y si no hay principios que se contrapongan, debe existir 
un derecho definitivo a su vigencia. Entre estos derechos procedimentales de carácter público y privado hay una diferencia considerable:

Mientras los derechos a las competencias de derecho privado aseguran, sobre todo, la posibilidad de que puedan realizarse determinadas acciones iusfundamentalmente garantizadas, los derechos al procedimiento en sentido estricto sirven, en primer lugar, para la protección de las posiciones jurídicas existentes frente al Estado y frente a terceros. ${ }^{295}$

5.3.1.2.3. La organización en sentido estricto: estas normas de derecho fundamental se refieren a ciertos contenidos jurídicos que al institucionalizarse regulan la cooperación de numerosas personas, orientada a determinados fines. Entre este tipo de normas se encuentran las del derecho universitario, el de radiodifusión o de cogestión. Los derechos a la organización serán aquellos derechos de los ciudadanos, dirigidos al legislador, a que sean vigentes ciertas normas de organización. Estos derechos a una organización son derechos del individuo a que el legislador expida normas de organización conforme al derecho fundamental que se aseguren mediante derechos subjetivos y mandatos y prohibiciones de carácter objetivo.

5.3.1.2.4. La formación de la voluntad estatal: estas normas de derecho fundamental se refieren a los derechos que tienen los ciudadanos frente al Estado a que éste, por las vías de la legislación ordinaria, institucionalice los procedimientos que faciliten una participación en la formación de la voluntad estatal, teniendo como ejemplo la competencia del ciudadano para votar y participar así, de modo indirecto, en la creación de las leyes. Estos derechos son muy importantes porque les permiten a los ciudadanos ejercer una función activa que le establezca límites a las competencias del legislador. Los ciudadanos, al ejercer derechos como los de libertad de expresión, de reunión o de asociación pueden contribuir a formar la voluntad estatal acorde con su razón crítica, lo cual muestra, según Alexy, una confianza en la racionalidad de los procesos legislativos que no es ilimitada y permite llevar a cabo una conexión interna entre el ejercicio de los derechos fundamentales y el principio democrático.

5.3.3. Los derechos prestacionales en sentido amplio o derechos sociales fundamentales. Sobre este grupo de derechos prestacionales fundamentales vale la pena enfatizar en que en la discusión sobre estos derechos suele revelarse la concepción y fines

${ }^{295}$ Alexy, Robert, TDF, p. 435. 
del Estado, la sociedad civil y el derecho, a tal grado, que las posiciones de algunos filósofos políticos acerca de los derechos sociales suelen estar cargadas de prejuicios, debido a la falta de precisión sobre el concepto de derechos fundamentales. ${ }^{296}$ Este es el concepto de derechos prestacionales para Alexy:

Los derechos prestacionales en sentido estricto son derechos del individuo frente al Estado a algo que - si el individuo tuviera los medios financieros suficientes, y si encontrase en el mercado una oferta suficiente- podría obtener también de los particulares. Cuando se habla de derechos sociales fundamentales, por ejemplo, del derecho a la seguridad social, al trabajo, la vivienda y la educación, se hace primariamente referencia a derechos prestacionales en sentido estricto. ${ }^{297}$

Estos derechos, surgidos a partir del reconocimiento de las desigualdades económicas inherentes a la estructura y desarrollo de las sociedades modernas, encuentran sus razones para institucionalizarse en argumentos que apuntan a crear las condiciones por las cuales la libertad fáctica puede ejercerse. Los argumentos que ofrece Alexy a favor de los derechos sociales fundamentales son los siguientes:

El primer argumento a favor es un argumento de la libertad, el cual se basa en dos tesis que serán descritas a continuación:

La primera es: la libertad jurídica para hacer u omitir algo, sin la libertad fáctica (real), es decir, sin la posibilidad fáctica de elegir entre lo permitido, carece de todo valor.

La segunda tesis es: bajo las condiciones de la sociedad industrial moderna, la libertad fáctica de un gran número de titulares de derechos fundamentales no encuentra su sustrato material en un «ámbito vital dominado por ellos», sino que depende esencialmente de actividades estatales. ${ }^{298}$

296 Sobre las ambigüedades o falta de precisión de algunos filósofos políticos sobre los derechos fundamentales, nos llamó la atención la obra de Rodolfo Arango, El concepto de derechos sociales fundamentales. Respecto a este tema, es muy sugerente la crítica a Rawls, en la cual, Arango muestra que a pesar de que Rawls considera el mínimo existencial como parte de los contenidos constitucionales esenciales, su carácter jurídico es bastante oscuro porque el segundo principio de justicia jamás lo formula como un derecho. Además, tampoco cuenta con un concepto de derecho subjetivo desarrollado, lo que comprueba que ni el segundo principio de justicia, la idea de orden lexicográfico o su concepción de contenidos constitucionales esenciales, son adecuados para responder a las exigencias de las sociedades bien ordenadas, a las que dirige su teoría. Respecto a la falta de precisión, propia de filósofos poco familiarizados con la teoría y práctica jurídicas, fue de gran ayuda ver las cuatro críticas que Arango señala a la estrechez del concepto de derecho subjetivo de Habermas para comprender mejor este concepto y su relación con el sistema de posiciones fundamentales de Alexy. Cfr., Arango, Rodolfo, Idem, pp. 237 a 270.

297 Alexy, Robert, TDF, p. 443.

${ }^{298}$ Alexy, Robert, TDF, p. 447. 
Los argumentos a favor son razonables, porque dentro de ellos es reconocida la importancia existencial de la libertad fáctica para el individuo, es decir, que son derechos necesarios, pero no suficientes, para contribuir a la realización plena de la libertad, igualdad y dignidad humana de todos los titulares de derecho fundamental. Pero también es posible dar argumentos en contra de ellos, que Alexy dividirá en formales y materiales.

El argumento formal en contra de los derechos fundamentales parte de la tesis de que los derechos fundamentales son exigibles de forma judicial en modo reducido, ya que su objeto es muy impreciso. Este argumento es comprobable si nos preguntamos por las escalas que definen el derecho a la vivienda simple, la educación mínima, el servicio médico indispensable o el salario justo. Para evitar que estas escalas caigan en el terreno movedizo de la política, Alexy señala que los tribunales pueden resolver estas disputas si sus decisiones se enmarcan dentro del ámbito de lo señalado por los legisladores. Este argumento de Alexy es objetable, ya que podríamos preguntarnos si los argumentos de los jueces escapan en todos los casos del terreno político. Alexy supone la irracionalidad de los argumentos de los operadores políticos, pero también es posible que los jueces basen sus decisiones en argumentos políticos sobre los alcances de los derechos sociales. Es evidente que los derechos sociales son costosos para el Estado - así como también lo son los demás derechos fundamentales-, pero debe aceptarse que sean concebidos como normas no sometidas en todos los casos al control de los tribunales constitucionales, para evitar que la política presupuestaria quede en sus manos.

El argumento material plantea que los derechos sociales fundamentales podrían entrar en colisión con otro tipo de normas constitucionales, específicamente, derechos de libertad, como sucede en diversas ramas del derecho laboral. En una rama como el derecho al trabajo puede verse que si el Estado interviene para otorgar empleos a todos los desempleados, entonces debería limitar o eliminar la disponibilidad de los puestos de trabajo existentes en la economía privada para lograr los fines planteados, lesionando así los derechos fundamentales de otros individuos.

En este punto Alexy nota que pueden ser ofrecidos argumentos razonables a favor y en contra de los derechos sociales fundamentales, pero la solución reside en considerar a los derechos fundamentales como principios, y con ello, otorgarle prioridad prima facie a algunos derechos sobre otros, para así decidir cuestiones controversiales con base en el peso que tengan en situaciones concretas. Estas consideraciones de los derechos sociales 
fundamentales como principios no establecen derechos definitivos, pero sí entienden cuáles podrían tener el carácter de derechos sociales fundamentales mínimos, entre los que considera "el derecho al mínimo vital, a una vivienda simple, la educación escolar, a la formación profesional y a un nivel estándar mínimo de asistencia médica". ${ }^{299}$ Sin embargo, si estos derechos se entendieran como derechos definitivos en tiempos de crisis económicas, su exigibilidad judicial sería imposible, tanto por el número de personas desamparadas por las condiciones de las sociedades modernas, como por los abusos que llevarían a cabo los polizones, quienes aprovecharían la oportunidad de recibir beneficios económicos ilegítimos por parte del Estado. 300

Alexy volverá a introducir el tema de la ponderación entre principios para proponer una solución que blinde mínimamente protecciones fundamentales de las posiciones sociales. En las discusiones sobre los derechos sociales se puede caer en argumentos emotivos para exaltar un tipo especial de derechos fundamentales sobre otro, es decir, "[Q]uien sólo hace valer el principio de la libertad jurídica llega a resultados exagerados, al igual que aquél para quien sólo existe el principio de la libertad fáctica". ${ }^{301}$ Para evitar este tipo de argumentos es indispensable enfocarnos en la teoría de los principios, ya que deberán ponderarse las razones que defiendan la prioridad de ciertos derechos en casos concretos, para tomar así una decisión racional. Esta solución nos llevará a analizar el problema de las valoraciones en las controversias jurídicas.

Con la exposición de los derechos prestacionales en sentido estricto terminamos este capítulo dedicado a la institucionalización de los derechos fundamentales. Como pudo verse, en virtud de su contenido, estos derechos fundamentales no pueden concebirse como reglas definitivas, sino como principios que deben ponderarse en caso de que choquen contra otros principios, es decir, si bien pueden eliminarse ciertos grados de incertidumbre con la introducción de ciertas reglas, para la resolución de colisiones de

\footnotetext{
${ }^{299}$ Alexy, Robert, TDF, p. 455.

${ }^{300}$ Existe una relación incómoda entre los polizones (free riders) y los derechos sociales fundamentales, debido a que los polizones podrían aprovecharse de la justicia social exigida para algunos sectores desprotegidos, provocando así problemas financieros en este tipo de políticas sociales. Sin embargo, con todo y la existencia de los polizones, los derechos sociales fundamentales deben seguir otorgándose, ya que, como afirma Stevenson, "[N]o debemos proscribir a todos los médicos con el objeto de eliminar a los curanderos" (Stevenson, Charles, op. cit., p. 156). Lo que sería deseable es la creación de mecanismos institucionales que le impidan a los polizones aprovecharse de los derechos prestacionales.

${ }^{301}$ Alexy, Robert, TDF, p. 459.
} 
derechos necesitaremos una valoración moral, por lo cual en el siguiente capítulo, dedicado a la aplicación jurídica de los derechos fundamentales será explicada la teoría principialista, en cuyo centro se encuentra el principio de proporcionalidad. 


\section{Capítulo sexto. La aplicación jurídica de los derechos fundamentales}

\section{Introducción}

En el capítulo pasado, dedicado a la institucionalización política de los derechos fundamentales, mostramos aspectos básicos de la Teoría de los derechos fundamentales de Alexy, en tanto fue llevada a cabo una reconstrucción del sistema de posiciones fundamentales de Alexy. No obstante, los dilemas normativos que trae consigo la positivización de los derechos nos llevan a comprenderlos como principios y reglas. Esta comprensión nos llevó a hacer énfasis en la fundamentabilidad de las valoraciones en la aplicación de los derechos fundamentales. Este tipo de dificultades acerca del contenido de los derechos nos llevarán ahora al análisis del principio de proporcionalidad.

\subsection{El principio de proporcionalidad y los derechos fundamentales: las dos leyes de la ponderación}

En los dos capítulos anteriores, dedicados a la fundamentación filosófica y la institucionalización política de los derechos fundamentales, fueron reconstruidos aspectos básicos en torno a la naturaleza, concepto, estructura, sistematización y dilemas normativos de los derechos fundamentales. Un aspecto primordial consiste en la distinción entre reglas y principios, siendo la versión de Alexy más precisa en términos analíticos y normativos que la de Dworkin, cuyos planteamientos cada vez parecen más alejados de los debates actuales. ${ }^{302}$ Efectivamente, según Alexy, existen derechos fundamentales que deben

\footnotetext{
302 Como lo ha indicado Sieckmann, la contraposición entre reglas y principios sigue en cierto modo la terminología de Dworkin, aunque hay que decir también que ésta alude a una concepción de normas de Hart que parece no guardar ninguna relación con el modelo de ponderación de Alexy y ni con sus posteriores desarrollos. Al respecto, cfr., Sieckmann, Jan-Reinard, "Probleme der Prinzipientheorie der Grundrechte”, en, Clérico, Laura y Sieckmann, Jan-Reinard (Eds.), Grundrechte, Prinzipien und Argumentation. Studien zur Rechstheorie Robert Alexys, Baden-Baden, Nomos Verlagsgesellschaft, 2009, p. 41. También, Jestaedt ha indicado que la teoría principialista de Alexy, en tanto caracteriza a los principios como mandatos a optimizar, ha ido más lejos de la teoría de Dworkin. Al respecto, cfr., Jestaedt, Matthias, "The Doctrine of Balancing - its Strengths and Weaknesses", en, Klatt, Matthias (Ed.), Institutionalized Reason. The Jurisprudence of Robert Alexy, Nueva York, Oxford University Press, 2012, p. 154. Finalmente, Poscher coincide con Sieckmann y Jestaedt al afirmar que la teoría principialista de Alexy es muy diferente en naturaleza y contenido a la teoría de Dworkin, la cual estaba enfocada en refutar la tesis positivista de la separación entre derecho y moral. Al
} 
concebirse como principios y por tanto ponderarse en caso de un conflicto de normas, si bien es cierto que, de acuerdo con Carla Huerta, este concepto no es del todo claro a la luz de la lógica jurídica. ${ }^{303}$ Por todo ello, es pertinente considerar la distinción entre reglas y principios.

En un sistema jurídico racional deben existir normas cuyo contenido no puede ser definitivo, ya que tal modalidad advierte la posibilidad de que éstas entren en colisión con otras, de tal modo que lo requerido en este caso es admitir que el contenido de ciertos derechos fundamentales no puede ser absoluto y que, por tanto, la colisión entre derechos fundamentales no puede resolverse apelando a un orden lexicográfico estricto y a sus respectivas reglas de prioridad, sino mediante una ponderación acerca de qué principio prevalecerá en un caso concreto. Aunque hay quienes sostienen órdenes lexicográficos de derechos, como Ferrajoli ${ }^{304}$ o Rawls, ${ }^{305}$ Alexy considera insuficiente la idea de concebir a los derechos fundamentales con el carácter de reglas y su correspondiente "prioridad estricta" o "lexical”, esto debido a que "[E]n la lista de las pérdidas de la construcción como regla rawlsiana habría que poner, por ejemplo, la renuncia al derecho fundamental, cargado de posibilidades de colisión, de la libertad de acción general y a los derechos fundamentales sociales". 306 Por ejemplo, la norma que positiviza la libre manifestación de ideas prohíbe que las autoridades interfieran en el ejercicio de este derecho, pero no le da un carácter absoluto, ya que el derecho a la libre manifestación de ideas, para concebirse como tal, debe ir acompañado del permiso a ser ponderado frente a otros derechos en caso de interferir con éstos.

respecto, cfr., Poscher, Ralf, "Principles: How Many Theories? What Merit?", en, Klatt, Matthias (Ed.), Idem, p. 219.

303 Huerta ha señalado un problema conceptual según el cual conceptos como conflictos, colisiones, derogaciones, contradicciones, etc., son usados como sinónimos; no obstante, estos conceptos tienen un significado distinto y pertenecen a diferentes formas de conflictos normativos. Al respecto, cfr., Huerta, Carla, "Normkonflikte im Lichte der Prinzipientheorie" Clérico, Laura y Sieckmann, Jan-Reinard (Eds.), Grundrechte, Prinzipien und Argumentation. Studien zur Rechstheorie Robert Alexys, Baden-Baden, Nomos Verlagsgesellschaft, 2009, pp. 187-189.

${ }^{304}$ Cfr., Ferrajoli, Luigi, Los fundamentos de los derechos fundamentales, Madrid, Trotta, 2001.

305 En The Basic Liberties and Their Priority (The Tanner Lectures on Human Values), conferencia pronunciada en la Universidad de Michigan el 10 de abril de 1981, Rawls intenta responder a las críticas que le formuló Hart en "Rawls on Liberty and its Priority", las cuales lo llevaron a cambiar su concepción de libertad.

306 Alexy, Robert, "John Rawls' Theorie der Grundfreiheiten", en, Philosophische Gesellschaft Bad Homburg/Hinsch Wilfried (Eds.), Zur Idee des politischen Liberalismus, Fráncfort del Meno, Suhrkamp, 1997, p. 273 ss. En adelante, TG; también cfr., Alexy, Robert, IS, p. 32. 
Esto se vio con mayor claridad en el capítulo quinto, en el cual fue reconstruida la concepción de los derechos generales de libertad, igualdad y prestacionales en sentido amplio y estricto. El sistema de posiciones de Alexy mostró que estos derechos no son absolutos, sino que, por su propia naturaleza deben considerarse como no definitivos, por lo cual es indispensable buscar que la aplicación del derecho a prevalecer erija una pretensión de racionalidad. Al igual que las reglas, los principios son normas jurídicas que pueden formularse con las expresiones deónticas básicas del mandato, el permiso y la prohibición, pero la distinción central radicará en que las reglas serán mandatos definitivos que obligan, prohíben o permiten un derecho fundamental, mientras que los principios son mandatos de optimización que ordenan que algo sea realizado en la mayor medida posible, dentro de las posibilidades fácticas y jurídicas existentes. Como no es aconsejable pensar en sistemas jurídicos puros de reglas o de principios, en tanto existen normas de derecho fundamental que deben ser definitivas y otras que no deben ser definitivas, Alexy pensará en sistemas de derechos mixtos, los cuales admitan la posibilidad de que los conflictos normativos pueden resolverse tanto por la subsunción como por la ponderación.

La necesidad de un sistema mixto de reglas definitivas y de mandatos que deben optimizarse es comprensible en la resolución de conflicto entre derechos fundamentales. Mientras que en un conflicto de reglas la solución radica en introducir una cláusula de excepción en una de las reglas o declarar que una de las reglas en conflicto ya no es vigente mediante la introduccion de máximas tales como ley posterior deroga ley anterior (lex posterior derogat legi priori), en el caso de que dos principios colidan la solución residirá en que uno de los dos deba ceder ante el otro. Es importante indicar que la norma desplazada no pierde su vigencia, sino que, bajo circunstancias específicas, uno de los principios debe preceder frente al otro. Es así como Alexy concluye que la distinción entre estos dos tipos de normas reside en que en el ámbito del razonamiento jurídico los conflictos de reglas tienen lugar en la dimensión de la vigencia, mientras que las colisiones de principios tienen lugar en la dimensión del peso. Esto a su vez implica que si es la dimensión del peso la que permite resolver las colisiones entre normas estructuradas como principios, entonces, "[E]l 
núcleo de la construcción como principio consiste en esta relación necesaria entre derechos fundamentales y proporcionalidad". 307

El principio de proporcionalidad, según el cual las normas de derecho fundamental deben tratarse como mandatos a optimizar de acuerdo con sus posibilidades normativas y fácticas, no fue inventado por la doctrina constitucional alemana de la segunda mitad del Siglo Veinte. No obstante, en las cortes alemanas fue desarrollado. Es más, según Alexy, "[L]a idea de ponderación es de hecho una idea antigua. En numerosas representaciones de la justicia con una balanza en la mano y una espada en la otra, y frecuentemente con una venda en los ojos, representan esta idea". ${ }^{308}$ De acuerdo con Borowski, el principio de proporcionalidad no fue desarrollado como una idea académica puesta posteriormente en práctica, sino que emergió de las decisiones de las cortes supremas y luego clarificado a través de una reconstrucción crítica de éstas. Aunque la constitución alemana de 1949 no contempla la proporcionalidad en alguna disposición legal en particular, el tribunal constitucional federal alemán desarrolló la estructura de la proporcionalidad en decisiones importantes de los años cincuenta, y así la proporcionalidad se volvió un criterio clave para determinar si una ley establecida por el poder legislativo u otro acto estatal es constitucional desde el punto de vista sustantivo. ${ }^{309}$ El principio de proporcionalidad ha tenido tal impacto que Alec Sweet Stone y Jud Matthews han sostenido que, al final de los noventa, con la excepción parcial de los Estados Unidos, virtualmente todo sistema constitucional efectivo en el mundo ha adoptado los principios fundamentales del principio de proporcionalidad. ${ }^{310}$

Este recurso emana de la racionalidad práctica respecto a la resolución de problemas morales en torno a la racionalidad de la acción, y está vinculado con una de las formas básicas de aplicación de la filosofía práctica a nuestros razonamientos morales. ${ }^{311}$

\footnotetext{
${ }^{307}$ Alexy, Robert, "Die Konstruktion der Grundrechte", en Laura y Sieckmann, Jan-Reinard (Eds.), Grundrechte, Prinzipien und Argumentation. Studien zur Rechstheorie Robert Alexys, Baden-Baden, Nomos Verlagsgesellschaft, 2009, p. 32.

${ }^{308}$ Alexy, Robert, EAOTG, p. 363.

309 Borowski, Martin, "La idea de los principios formales. La proporcionalidad en el control de constitucionalidad", conferencia dictada en el Tribunal Electoral del Poder Judicial de la Federación el día 9 de diciembre de 2013 en México, Distrito Federal, p. 2.

${ }^{310}$ Stone Sweet, Alec y Matthews, Jud, "Proportionality Balancing and Global Constitutionalism", Columbia Journal of Transnational Law, No. 47, 2008, pp. 153 ss.

${ }^{311}$ Es por ello que Alexy considera que la ponderación, junto con el principio de universabilidad, expresado de forma insuperable en el imperativo categórico de Kant, constituye uno de los dos principios formales fundamentales de razón práctica.
} 
En este aspecto, coincidimos con Afonso da Silva, quien ha indicado también que el problema en cuestión ahora es ya antiguo en el ámbito de la filosofía moral. ${ }^{312}$ Con frecuencia enfrentamos dilemas morales en los que hay que ponderar algo. Piénsese, por ejemplo, en una situación en la que un sujeto debe escoger entre dos opciones que poseen argumentos de peso, sin embargo, el sujeto debe decidirse por una de las dos. En este caso, el sujeto no puede intentar satisfacer a ambas, sino sólo escoger una opción, tomando en consideración la interferencia en ambas opciones derivada de satisfacer a la otra, el valor abstracto de ambas opciones y otros aspectos relativos a la fiabilidad de sus premisas empíricas y normativas. En este caso la decisión no será fácil de tomar, ya que no se trata de que una alternativa sea correcta y otra incorrecta, sino que, desde el punto de vista moral, una opción tendrá mayor peso. En este caso es deseable que el sujeto escoja una opción lo más racional posible.

Los dilemas morales pueden ayudarnos a comprender una propiedad básica de los principios: su validez prima facie y la posibilidad latente de que entren en colisión determinados principios. A esto se refiere Alexy cuando señala que la colisión de principios consiste en que "[D]os normas, tomadas en sí mismas, concluyen a resultados recíprocamente contradictorios. Ninguna es inválida, ninguna tiene una precedencia absoluta. Lo que aquí tenga validez dependerá de qué decisión deba adoptarse a la luz de las circunstancias del caso concreto". ${ }^{313}$ El hecho de que los principios no tengan validez de manera absoluta, sino dependiendo del caso concreto, llevará a Alexy a vincular el principio de proporcionalidad con normas con validez prima facie, algo que también es común ver en dilemas de filosofía moral.

Como lo indica Günther, la distinción entre normas que prescriben, sólo sobre la base de un supuesto general, que algo debe hacerse, y normas que prescriben absoluta o definitivamente que algo debe hacerse, es un tópico frecuentemente discutido en filosofía moral. ${ }^{314}$ Esta distinción nos puede ayudar a resolver problemas que giran en torno a la preferencia de un principio cuando existen dos principios que podrían ser aplicables. Según Baier, un conflicto de este tipo existe cuando "al menos dos normas, cada una aplicada

\footnotetext{
312 Da Silva, Virgilio, "Principios y reglas: mitos y equívocos acerca de una distinción”, en Beade, Gustavo y Clérico, Laura (Eds.), Desafíos a la ponderación, Bogotá, UEC, 2011, p. 135.

${ }^{313}$ Alexy, Robert, TDF, p. 77.

${ }^{314}$ Günther, Klaus, The Sense of Appropriateness. Application Discourses in Morality and Law, Nueva York, Suny, 1993, p. 207.
} 
independientemente, lleva a resultados incompatibles con la otra, es decir, a dos contradictoriamente concretos [...] juicios morales". ${ }^{315}$ Ante este tipo de problemas es conveniente distinguir entre dos tipos de normas en razón de su validez o vigencia prima facie o definitiva, lo cual, según Searle ${ }^{316}$ daría lugar a admitir que esta distinción radicaría en dos concepciones distintas de validez y no en las propiedades de la obligación de la norma, esto es, en una validez prima facie, que no queda claro hasta qué grado obliga, $y$, por otra parte, en una validez absoluta, que no puede ser limitada.

En el ámbito de la filosofía jurídica, Alexy se basará en la distinción "prima faciedefinitividad" para comprender mejor la estructura de las normas de derecho fundamental racionalizar así el principio de proporcionalidad. El principio de proporcionalidad, tal y como es formulado por Alexy, se compone de tres subprincipios, que son el principio de idoneidad, el principio de necesidad o mandato del medio más benigno y el principio de proporcionalidad en sentido estricto, ${ }^{317}$ y la formulación de éste se sigue a partir de la concepción de los derechos fundamentales como principios. El principio de proporcionalidad ahora será explicado con sus elementos, tomando en consideración las diversas reformulaciones que ha tenido con los años. Como es sabido, desde la publicación de Teoría de los derechos fundamentales en 1985, pasando por el Epílogo a la edición inglesa de esta obra en 2002 hasta el reciente trabajo sobre principios formales, escrito en 2014, el principio de proporcionalidad ha tenido algunos cambios notables, que permiten una mejor comprensión de la meta que Alexy decidió fijarse al pensar las bases, alcances y limitaciones de este principio.

El desarrollo ulterior que ha tenido el principio de proporcionalidad se debe, en buena medida, a algunas aclaraciones pertinentes de Alexy y también como el resultado de considerar las críticas que han sido planteadas a este principio en los últimos años. Es por eso que reconstruiremos el principio de proporcionalidad con las elaboraciones que ha hecho Alexy hasta 2014, año en que ha refinado la fórmula en una conferencia dictada en la ciudad de Minas Gerais, Brasil, para dar así el panorama más completo posible, y así responder a las críticas que ha generado.

\footnotetext{
${ }^{315}$ Baier, Kurt, The Moral Point of View, Nueva York, Ithaca, 1958, p. 92 (nota a pie).

${ }^{316}$ Searle, John, "Prima Facie Obligations", en Raz, Joseph (Ed.), Practical Reasoning, Oxford, Oxford University Press, 1978, pp. 81 a 90.

${ }^{317}$ Alexy, Robert, TDF, pp. 91 y 92.
} 


\subsubsection{La estructura, racionalidad y legitimidad del principio de proporcionalidad}

Alexy indica que existen tres problemas fundamentales, relacionados entre sí, respecto al problema de la ponderación: el de la estructura, el de la racionalidad y el de la legitimidad. ${ }^{318}$ Son problemas relacionados entre sí porque la legitimidad de la ponderación depende de la racionalidad de ésta, y la racionalidad depende de la estructura. Parece que la estructura de la ponderación es una condición sine qua non de la racionalidad de la ponderación, y la racionalidad de la ponderación es una condición sine qua non de la legitimidad de la ponderación. Por ello comenzaremos primero con la estructura de la ponderación para comprender el núcleo de las objeciones posteriores de Böckenförde y Habermas, sinedo estas últimas las más conocidas, si bien no las únicas.

\subsubsection{El problema de la estructura: el principio de proporcionalidad y la fórmula del peso completa refinada}

Según Alexy, los derechos fundamentales pueden concebirse como principios. Estos principios no son otra cosa que mandatos a optimizar, en cuanto exigen que algo deba realizarse de acuerdo con las posibilidades fácticas y jurídicas existentes. Ahora bien, cuando se produce un conflicto entre derechos, la manera de resolver éste es mediante la aplicación del principio de proporcionalidad, el cual está compuesto de tres subprincipios.

Los subprincipios de los que está compuesto el principio de proporcionalidad pueden encontrarse claramente delimitados en la jurisprudencia del Tribunal Constitucional Federal a partir de la década del setenta. ${ }^{319}$ Ahora bien, este principio se compone de tres subprincipios que serán descritos con atención. Primero se describirán los dos primeros subprincipios vinculados con la optimización relativa a las posibilidades fácticas y luego el tercero vinculado a las posibilidades jurídicas.

El subprincipio de idoneidad o de adecuación: éste es posible definirlo como aquel que considera que una intervención en los derechos fundamentales debe ser adecuada para contribuir a la obtención de un fin legítimo constitucionalmente. Según lo antes

\footnotetext{
318 Alexy, Robert, "Die Gewichtsformel“, en Jickeli, Joachim, Kreutz, Peter y Reuter, Dieter (Eds.), Gedächtnisschrift für Jürgen Sonnenschein, Berlín, Walter de Gruyter, 2003, p. 771. En adelante, GF.

319 Cfr., Clérico, Laura, El examen de proporcionalidad en el derecho constitucional, Buenos Aires, Eudeba, 2009, p. 25. Sobre el principio de idoneidad o de adecuación cfr., BVerfGE 55, 159; sobre el principio de necesidad cfr., BVerfGE 53, 135; finalmente, Sobre el principio de proporcionalidad en sentido estricto cfr., BVerfGE 86, 1.
} 
mencionado, este subprincipio impone dos exigencias a toda intervención en los derechos fundamentales: que tenga un fin constitucionalmente legítimo y que sea idónea para favorecer su obtención. ${ }^{320}$ Desde la perspectiva de quien aplica el derecho, se trata de un control posterior a la selección del medio escogido. ${ }^{321}$

El principio de necesidad o mandato del medio más benigno: éste también es posible definirlo como aquel que considera que "toda medida de intervención en los derechos fundamentales debe ser la más benigna con el derecho fundamental intervenido, entre todas aquellas que revisten por lo menos la misma idoneidad para contribuir a alcanzar el objetivo propuesto". ${ }^{322}$ El medio establecido será necesario siempre y cuando el legislador no haya podido elegir otro medio o si el fin no puede ser alcanzado por otro medio que afecte el derecho del individuo de una manera menor. ${ }^{323}$

Estos principios están vinculados con el óptimo de Pareto-y también con las curvas de indiferencia-, consistente en que debe preferirse una constelación $A$ a una constelación $B$ en el caso de que, en el paso de $A$ a $B$, ninguno de los participantes resulte peor situado que antes y al menos uno de los participantes experimente una mejora. Estos dos subprincipios presentan criterios formales de decisión vinculado a las posibilidades fácticas. Vista así, la optimización referente a las posibilidades fácticas conssite en evitar costos evitables. Esta situación, como veremos, no pasará con el siguiente subprincipio, porque en el caso de conflictos normativos entre derechos no es posible que uno de los dos derechos en conflicto obtenga una mejora y otro se mantenga igual, sino que un derecho sí se verá afectado debido a la satisfacción del otro.

El principio de proporcionalidad en sentido estricto: éste también es posible definirlo como aquel que considera que "la importancia de la intervención en el derecho fundamental debe estar justificada por la importancia de la realización del fin perseguido por la intervención legislativa". ${ }^{324}$ Como lo indica con certeza Clérico, "que una medida estatal sea adecuada técnicamente y la menos lesiva son ciertamente argumentos que hablan a favor del fin y que pretenden justificar la limitación del derecho fundamental. Sin embargo, no

\footnotetext{
${ }^{320}$ Cfr., Bernal, Carlos, op. cit., p. 689.

${ }^{321}$ Cfr., Clérico, Laura, op. cit., p. 43.

${ }^{322}$ Cfr., Bernal, Carlos, op. cit., p. 736.

${ }^{323}$ Cfr., Clérico, Laura, op. cit., p. 102.

${ }^{324}$ Cfr., Bernal, Carlos, op. cit., p. 759.
} 
bastan para dar por justificada definitivamente una limitación tal. La exigencia de justificabilidad iusfundamental exige algo más". ${ }^{325}$ Ahora bien, éste consiste en que los argumentos ofrecidos a favor de la intervención en un derecho fundamental deben ser considerados de cara a los argumentos que hablan en contra de ésta. Como puede verse, se trata de un criterio material de decisión vinculado a las posibilidades jurídicas.

La estructura del subprincipio de proporcionalidad en sentido estricto está compuesta de dos leyes de la ponderación, la ahora llamada fórmula refinada del peso y las cargas de la argumentación en caso de empates técnicos, características indispensables para comprender la estructura, racionalidad y legitimidad de la ponderación. Como es sabido, en un comienzo el principio de proporcionalidad contenía una ley material de la ponderación, pero las críticas posteriores llevaron a Alexy a plantear una segunda ley epistémica de la ponderación. Ahora serán analizados estos elementos

\section{A) La primera ley de la ponderación (ley material)}

Esta ley tiene que ver con la relación existente entre la intensidad de una interferencia en un derecho fundamental y el peso sustancial de las razones que justifican la interferencia. Esta ley es enunciada por Alexy del siguiente modo:

Cuanto mayor sea el grado de la falta de satisfacción o de la afectación de un principio, tanto mayor tiene que ser la importancia de la satisfacción del otro.

Esta ley de la ponderación está compuesta de tres pasos: en el primer paso debe definirse el grado de la no satisfacción o de afectación de uno de los principios. En el segundo paso, debe definirse la importancia de la satisfacción del principio que se opone al otro. Finalmente, en el tercer paso debe definirse si la importancia de la satisfacción del principio contrario justifica la restricción o la no satisfacción del otro. ${ }^{326}$ Ahora bien, para explicar cómo podemos establecer racionalmente si la satisfacción de un principio justifica intervenir en la realización de otro principio y cómo puede ilustrarse la estructura de la ponderación, Alexy introducirá la fórmula del peso, la cual representará constelaciones concretas. La fórmula del peso ha sido representada tradicionalmente con tres variables. No obstante, a partir de Princípios formais, conferencia publicada en 2014 en portugués, Alexy ha integrado una cuarta variable, con el fin de refinarla y enfocarse en el análisis de

\footnotetext{
${ }^{325}$ Cfr., Clérico, Laura, op. cit., p. 163.

${ }^{326}$ Cfr., Alexy, Robert, GF., p. 774.
} 
los principios formales ${ }^{327}$ en la determinación de la discrecionalidad legislativa y la función de las cortes constitucionales o supremas como órganos de control de las violaciones a derechos fundamentales. Esta cuarta variable fue introducida en virtud de que algunos autores sugirieron la posibilidad de que esta fórmula fuese refinada todavía más. ${ }^{328} \mathrm{~A}$ continuación, presentaremos la estructura completa y simplificada de esta fórmula.

Estructura de la fórmula del peso completa refinada:

$$
W P_{i, j} C \frac{I P_{i} C \cdot W P_{i} A \cdot R_{i}^{e} P C \cdot R_{i}^{n} P C}{I P_{j} C \cdot W P_{j} A \cdot R_{j}^{e} P C \cdot R_{j}^{n} P C}
$$

Estructura simplificada de la fórmula del peso completa refinada:

$$
W_{i, j} \frac{I_{i} \cdot W_{i} \cdot R_{i}^{e} \cdot R_{i}^{n}}{I_{j} \cdot W_{j} \cdot R_{j}^{e} \cdot R_{j}^{n}}
$$

Con la introducción de la nueva fórmula del peso completa refinada Alexy busca dar cuenta de la cuestión de la discrecionalidad legislativa, así como el papel que los principios formales ejercen en la ponderación, sobre todo el concerniente al principio del legislador democráticamente legitimado, dándole así discrecionalidad a éste para resolver la cuestión. Con este nuevo planteamiento Alexy busca plantear un punto de equilibro entre la necesidad de que una corte constitucional proteja los derechos fundamentales y la necesidad de respetar el principio del legislador democráticamente legitimado. De acuerdo con Trivisonno, el argumento de Alexy para introducir esta nueva formulación consiste, en síntesis, en lo siguiente:

"la falta de certeza tanto de las suposiciones empíricas como de las suposiciones normativas debe ser considerada en la ponderación. Cuanto mayor sea la certeza de las suposiciones empíricas y normativas referentes a la lesión de un derecho fundamental, más debe justificarse la actuación de la corte constitucional. Cuanto menor sea la certeza, más debe

\footnotetext{
${ }^{327}$ La distinción entre principios materiales y formales con frecuencia provoca confusiones. Según Alexy, "la differentia specifica de los principios materiales es que sus objetos de optimización son determinados contenidos, como, por ejemplo, la vida, la libertad de expresión, el mínimo existencial o la protección al medio ambiente. En contraste, los objetos de optimización de los principios formales son decisiones jurídicas, independientemente de sus contenidos". Sobre esto, cfr., Alexy, Robert, "Princípios Formais", en, Trivisonno, Alexandre T. G., Tuffi, Aziz y Sétte, Mónica, (Eds), Princípios formais e outros aspectos da Teoria Discursiva do Direito, Forense Universitaria, Rio de Janeiro, 2014, p. 13 (en adelante, PF).

328 Cfr., Klatt, Mathias y Meister, Moritz, The Constitutional Structure of Proportionality, Oxford, Oxford University press, 2012, p. 132. y, Klatt, Mathias, y Schmidt, Johannes, "Epistemic Discretion in Constitutional Law", en, International Journal of Constitutional Law, No. 12, 2012, p. 91.
} 
justificarse dejar la cuestión sobre el dominio del legislador, atribuyéndole así dfiscrecionalidad para resolver la cuestión".329

A continuación, serán descritas las variables de la fórmula del peso refinada, tanto en su versión completa como en la simplificada. ${ }^{330}$

$\boldsymbol{W}_{\boldsymbol{i} . j}$ o $\boldsymbol{W} \boldsymbol{P}_{i, j} \boldsymbol{C}: \mathbf{W}$ representa el peso concreto del principio $\boldsymbol{P}_{\boldsymbol{i}}$, en las condiciones $\boldsymbol{C}$ (Bedingungen) concretas del asunto a decidir, en relación con el principio en colisión $\boldsymbol{P}_{\boldsymbol{j}}$, lo cual permitirá establecer una relación de precedencia condicionada entre éstos.

$\boldsymbol{I}_{\boldsymbol{i}}$ ○ $\boldsymbol{I} \boldsymbol{P}_{\boldsymbol{i}} \boldsymbol{C}$ representa la intensidad de la interferencia con $P_{i}$ por parte del medio o medida $(\boldsymbol{M})$, cuya proporcionalidad deberá ser examinada. Los valores asignados a las escalas de esta variable pueden representarse mediante la secuencia geométrica $2^{0}, 2^{1}$ y $2^{2}$; esto es, 1,2 y 4 .

$\boldsymbol{I}_{\boldsymbol{j}}$ O $\boldsymbol{I} \boldsymbol{P}_{\boldsymbol{j}} \boldsymbol{C}$ representa la intensidad de los efectos negativos que la omisión de la interferencia con $\boldsymbol{P}_{\boldsymbol{i}}$ tendría para el principio en colisión $\boldsymbol{P}_{\boldsymbol{j}}$. Los valores asignados a las escalas de esta variable pueden representarse mediante la secuencia geométrica $2^{0}, 2^{1}$ y $2^{2}$; esto es, 1,2 y 4 .

$\boldsymbol{W}_{\boldsymbol{i}}$ ○ $\boldsymbol{W} \boldsymbol{P}_{\boldsymbol{i}} \boldsymbol{A}$ y $\boldsymbol{W}_{\boldsymbol{j}}$ ○ $\boldsymbol{W} \boldsymbol{P}_{\boldsymbol{j}} \boldsymbol{A}$ representan los pesos abstractos de $\boldsymbol{P}_{\boldsymbol{i}}$ y $\boldsymbol{P}_{\boldsymbol{j}}$. En muchos casos, los pesos abstractos son iguales, por lo que se neutralizan entre sí. Es por ello que es posible reducirlos. Los valores asignados a las escalas de esta variable pueden representarse mediante la secuencia geométrica $2^{0}, 2^{1}$ y $2^{2}$; esto es, 1,2 y 4 .

$\boldsymbol{R}_{i}^{e} \circ \boldsymbol{R}_{i}^{e} \boldsymbol{P C}$ y $\boldsymbol{R}_{j}^{e} \circ \boldsymbol{R}_{j}^{e} \boldsymbol{P C}$ representan la certeza o fiabilidad de las asunciones empíricas relativas a lo que significa la medida $(\boldsymbol{M})$ en cuestión para la no realización de $\boldsymbol{P}_{\boldsymbol{i}}$ y la realización de $\boldsymbol{P}_{\boldsymbol{j}}$ en las circunstancias del caso concreto. Los valores asignados a las escalas de esta variable pueden representarse mediante la secuencia geométrica $2^{0}, 2^{-1}$ y $2^{-2}$; esto es, $1,1 / 2 y^{1 / 4}$.

\footnotetext{
${ }^{329}$ Trivisonno, Alexandre, T. G., "O problema do conocimento prático na teoria discursiva do direito de Alexy", en, Trivisonno, Alexandre T. G., Tuffi, Aziz y Sétte, Mónica, (Eds.), Princípios formais e outros aspectos da Teoria Discursiva do Direito, Forense Universitaria, Rio de Janeiro, 2014, pp. 55-56.

${ }^{330}$ En un principio, consideramos presentar solamente la fórmula simplificada del peso; sin embargo, como no todos los lectores de la obra de Alexy están acostumbrados al uso de estos términos, serán presentadas ambas fórmulas para evitar confusiones respecto al significado de las variables.
} 
$\boldsymbol{R}_{i}^{n}$ ○ $\boldsymbol{R}_{i}^{n} \boldsymbol{P C}$ y $\boldsymbol{R}_{j}^{n}$ ○ $\boldsymbol{R}_{j}^{n} \boldsymbol{P C}$ representan la certeza o fiabilidad de las asunciones normativas relativas a lo que significa la medida $(\boldsymbol{M})$ en cuestión para la no realización de $\boldsymbol{P}_{\boldsymbol{i}}$ y la realización de $\boldsymbol{P}_{\boldsymbol{j}}$ en las circunstancias del caso concreto. Los valores asignados a las escalas de esta variable pueden representarse mediante la secuencia geométrica $2^{0}$, $2^{-1}$ y $2^{-2}$; esto es, $1,1 / 2$ y $1 / 4$.

Desde 2003 la certeza o fiabilidad fue introducida en la fórmula del peso; no obstante, ésta no encajó bien en el Epílogo de Teoría de los derechos fundamentales ni en la segunda ley de la ponderación (la ley epistémica), ya que si bien en ese momento Alexy llevó a cabo la distinción entre la discrecionalidad epistémica empírica y la discrecionalidad epistémica normativa, ${ }^{331}$ en la fórmula del peso esta distinción no podía verse. La ley de la ponderación epistémica se refiere a premisas que justifican la interferencia, sin distinguir entre premisas justificatorias de corte empírico y normativo. Por esta razón Alexy ha buscado resolver esta insuficiencia en Princípios formales para que $R_{i}$ y $R_{j}$ se refieran a este tipo de premisas, dando lugar a la siguiente ecuación:

$$
R_{i}=R_{i}^{e} \cdot R_{j}^{n}
$$

Esta ecuación puede concebirse a partir de ahora como la "ecuación de la certeza". 332 Según Alexy, existen casos en los que la certeza empírica es un problema, entonces, no cualquier necesidad empírica puede aplicarse de modo explícito a esta ecuación. En estos casos, cuando ambos tipos de certeza entren en cuestión tanto la certeza empírica y la certeza normativa, $R_{i}$ y $R_{j}$ tendrán que ser sustituidas por los respectivos productos empíricos y normativos del lado derecho de la mencionada fórmula del peso refinada completa.

Ahora bien, hay casos en los cuales la decisión del juez depende básica o únicamente de $\boldsymbol{R}_{\boldsymbol{i}}$ y $\boldsymbol{R}_{\boldsymbol{j}}$, pero también hay casos en que serán iguales, por lo que es posible reducir ambos.

\footnotetext{
${ }^{331}$ Cfr. Alexy, Robert, TDF, p. 547 ss. En el Epílogo Alexy que estamos ante un margen de acción epistémico normativo "cuando no se tiene certeza sobre cuál es la manera más apropiada para sopesar los derechos fundamentales que se encuentran en juego, y se reconoce que el Legislador dispone de un determinado marco, dentro del cual puede adoptar una decisión según su propia valoración" (Alexy, Robert, TDF, p. 548).

${ }^{332}$ Alexy, Robert, PF, p. 10.
} 
También, si es posible reducir $\boldsymbol{W}_{\boldsymbol{i}}$ y $\boldsymbol{W}_{\boldsymbol{j}}$, la decisión dependerá exclusivamente de $\boldsymbol{I}_{\boldsymbol{i}}$ y $\boldsymbol{I}_{\boldsymbol{j}}$. De este modo, la fórmula del peso puede sintetizarse del siguiente modo:

$$
W_{i, j}=\frac{I_{i}}{I_{j}}
$$

\subsubsection{El problema de la racionalidad: medir lo aparentemente inconmensurable}

Para ejemplificar la función de la fórmula del peso, Alexy hará uso de ejemplos de sentencias dictadas por el Tribunal Constitucional Federal de Alemania para evaluar la racionalidad de las interferencias en los derechos fundamentales. El primer ejemplo consiste en la sentencia acerca de poner advertencias de salud en los productos derivados del tabaco, ${ }^{333} \sin$ que por ello sea lesionada de modo grave la libertad de profesión y oficio de los productores de tabaco. En este ejemplo, en el cual el tribunal consideró una interferencia relativamente leve en la libertad de profesión al imponer la obligación a los productores de tabaco de poner en sus productos advertencias sobre el peligro para la salud que implica fumar, no es complicado entender el uso de escalas, debido a que en el ámbito económico, vinculado a la libertad de profesión y oficio, la aplicación de escalas se fundamenta en la especulación de costos económicos, mientras que en el ámbito de la salud, vinculado al derecho de proteger la salud de los ciudadanos, la aplicación de escalas se fundamenta en investigaciones empíricas acerca de los beneficios de intervenir en el derecho a la libertad de profesión.

Sin embargo, existen otros ámbitos en los que las interferencias en los derechos fundamentales parten de factores que algunos autores estiman inconmensurables. Es por ello que Alexy analiza el Caso Titanic, ${ }^{334}$ el cual consiste en un conflicto normativo entre el derecho a la libertad de expresión y el derecho al honor. Mediante el análisis de la sentencia de este caso, en el cual la revista Titanic le pagó una indemnización de 12.000 marcos alemanes a un oficial de reserva parapléjico al Ilamarle "asesino nato" y, luego, "tullido", al considerar este tribunal que la descripción del oficial como "tullido" fue una interferencia grave en el derecho al honor, Alexy argumenta que pueden justificarse como racionales las

\footnotetext{
333 BVerfGE 95, 173.

${ }^{334}$ BVerfGE 86, 1.
} 
decisiones jurídicas tomadas a partir de un conflicto de derechos fundamentales que tutelan objetos distintos y, por ello, aparentemente inconmensurables.

Alexy menciona estas dos sentencias como ejemplos de la racionalidad del principio de proporcionalidad y de la fórmula del peso, ya que son frecuentes dos objeciones a la teoría principialista de Alexy, las cuales darán lugar a una escala triádica: en primer lugar, la crítica a una tiranía de los valores y, en segundo lugar, la imposibilidad de ponderar dos derechos que protegen valores inconmensurables. Veamos en qué consisten estas objeciones.

Respecto a la primera objeción, es necesario recordar que la idea de un orden lexicográfico de derechos no es compatible con la teoría principialista, ya que dicho orden jerárquico contradiría el postulado discursivo de que ningún derecho puede tener una precedencia absoluta, ya que esto tendría consecuencias negativas. El supuesto de que un derecho individual preceda en todos los casos a un derecho social implicaría un orden jurídico mediado sólo por reglas categóricas insensibles frente a la configuración de un Estado democrático y social de derecho. De esta manera, se produciría la llamada por Schmitt tiranía de los valores: "desde el punto de vista de la lógica de los valores siempre tiene validez el siguiente enunciado: no es demasiado pagar el precio máximo por el máximo valor y tiene que pagarse". 335

El establecimiento de un orden lexicográfico implica tratar siempre a los derechos fundamentales como reglas y este tipo de trato contradice tanto a la práctica constitucional como a la teoría principialista. De este modo, la temida "tiranía de los órdenes lexicográficos" queda superada si es creada una escala que otorgue, prima facie, valores a los derechos y a las interferencias. Esto, por desgracia, no resuelve el problema, ya que la atribución de valores numéricos y cocientes a las intervenciones en los derechos y a las escalas es debatible, ya que tal atribución implica decidirse por darle prioridad a ciertos derechos, lo cual implica también darle una prioridad respectiva a un cierto modelo de Estado de derecho, ya sea este liberal, democrático o social de derecho.

Si ya es complicado darle prioridad a ciertos derechos, entonces, ¿cómo pensar en darle valores específicos a las interferencias de derechos que entran en conflicto? Esto es, el contenido de los principios podría no valorarse de igual manera, de modo tal que "lo que

${ }^{335}$ Alexy, Robert, TDF, p. 132. 
entra en colisión es inconmensurable". ${ }^{336}$ Ahora bien, ¿qué es lo inconmensurable? Según Raz, la inconmensurabilidad es, tout court, "la ausencia de una medida común", ${ }^{337}$ lo cual, en el discurso jurídico, implica mostrar la incomparabilidad de ciertos tipos de derechos, de modo tal que la ponderación sería, de entrada, irracional. Aunque por ahora no es objeto de esta obra el comprender los problemas de la inconmensurabilidad más allá del discurso jurídico, ${ }^{338}$ nos limitaremos a indicar que el señalamiento de Aleinikoff acerca de la inconmensurabilidad de los bienes tutelados por los derechos fundamentales establece una pregunta difícil, pero útil para que Alexy refine la estructura de la ponderación: ¿cómo ponderar lo aparentemente inconmensurable? La respuesta a esta pregunta nos lleva al desarrollo de la escala triádica.

La estructura de la ponderación requiere de una escala que pueda medir la intensidad de las intervenciones en los derechos fundamentales. La necesidad de contar con un baremo que mida lo que algunos consideran inconmensurable es importante, porque parece imposible evaluar un acto jurisdiccional de ponderación sin contar con una escala. Para llevar a cabo ponderaciones racionales pueden concebirse diversos tipos de escalas; es posible imaginar una escala infinitesimal o una medida de dos grados. La razón por la cual Alexy introduce unidades de medida es para fundamentar las intensidades de las interferencias en los derechos fundamentales. Esto implica que la ponderación de derechos debe ser inteligible para los jueces y así ponderar de modo racional lo aparentemente imponderable.

Aunque Alexy considera viable el uso de una escala infinitesimal, opta mejor por usar la escala de "leve", "moderado" y "severo", sintetizados respectivamente como " ", "m" y " $s$ ". La ventaja de esta escala es que puede refinarse en un baremo triádico doble con nueve grados que pueden representarse de la siguiente forma:

\footnotetext{
${ }^{336}$ Aleinikoff, Alexander, "Constitutional Law in the Age of Balancing", The Yale Law Journal, núm. 96, Yale, 1987, p. 972.

${ }^{337}$ Raz, Joseph, "Incommensurability and Agency", en Chang, Ruth (Ed.), Incommensurability, Incomparability and Practical Reason, Cambridge, Harvard University Press, 1997, p. 110.

${ }^{338}$ Ruth Chang ha indicado, correctamente, que existe un interés creciente entre los filósofos políticos, de la moral y del derecho por la "inconmensurabilidad de los valores", a pesar de que estas investigaciones filosóficas todavía están en una etapa temprana debido a que hasta ahora no hay un acuerdo acerca del significado del concepto de "inconmensurabilidad", un concepto que ganó un terreno propio desde la publicación de los escritos de Thomas Kuhn. Al respecto, cfr., Chang, Ruth, "Introduction", en Chang, Ruth (Ed.), Incommensurability, Incomparability and Practical Reason, Cambridge, Harvard University Press, 1997, p. 1.
} 
(1) "Il" Levemente leve

(2) "Im" Moderadamente leve

(3) "Is" Severamente leve

(4) " $m$ l' Ligeramente moderado

(5) " $m m$ " Medianamente moderado

(6) " $m s$ " Severamente moderado

(7) "sl" ligeramente severo

(8) "sm" Medianamente severo

(9) "ss" Severamente severo

Esta escala debe explicarse. Al incluirse esta escala en la estructura de las ponderaciones, puede hacerse más inteligible la estructura de la ponderación y la valorización que puede asignársele a determinados derechos, al mismo tiempo que la inteligibilidad de la escala debe imponerle límites al refinamiento de ésta. Esto implica, por un lado, que las interferencias en los derechos fundamentales pueden tener un peso abstracto mayor o superior dependiendo del caso concreto, dotando de este modo al procedimiento de ponderación de una certidumbre mayor. El modelo triádico permite trabajar con tres expresiones ("leve", "medio" y "grave") que pueden ser entendidas sin muchas complicaciones, empero, el tránsito de un escalón a otro no siempre podría ser claro y hasta podría pensarse en un modelo de dos rangos ("moderado" y "grave"), sin que por ello sea considerado un modelo de un solo rango, ya que en éste la ponderación sería imposible, pues todo valdría igual.

Por otro lado, al usar una escala triádica de dos grados nos permite hacer más explícito el significado de las escalas en sus extremos, como podrían ser los grados de interferencia en los niveles superiores como medianamente severo $(\mathrm{sm})$ y severamente severo (ss), y en los niveles inferiores como moderadamente leve $(I m)$ y levemente leve (II), aunque podría no ser tan fácilmente determinar cuándo puede considerarse una interferencia como algo ligeramente moderado $(m l)$ o severamente moderado (ms). Alexy, incluso, contempla la posibilidad de usar un modelo de triple tríada, como "sss", en casos extremos, ${ }^{339}$ aunque este tipo de refinamiento provocaría más problemas, ya que sería difícil explicar qué se entiende por una interferencia medianamente severa ligera ( $m s$ ). Mientras más refinada sea la escala, el ámbito de discreción será menor.

La estructura de la escala triádica, requiere la asignación de valores a los distintos grados de la escala. Respecto al valor que podría asignársele a estos grados, existen

\footnotetext{
${ }^{339}$ Alexy, Robert, "Sobre los derechos constitucionales a protección", en, Alexy, Robert, Derechos sociales y ponderación, Madrid, Fundación Coloquio Jurídico Europeo, 2007, p. 63. En adelante, DCP.
} 
posibilidades muy variadas de otorgarlos, y, en este sentido, Alexy opta por tomar la secuencia geométrica $2^{0}, 2^{1}$ y $2^{2}$, esto es, I valdrá $1, m$ valdrá 2 y $g$ valdrá $4 .{ }^{340}$ Sobre esta valorización de la escala, es necesario afirmar que con la introducción de ésta Alexy no busca en modo alguno sustituir a la ponderación por el cálculo, sino introducir un dispositivo formal que exprese la estructura inferencial de los principios. De este modo, el cálculo puede contribuir a racionalizar la estructura de la ponderación, pero no la sustituye; dicho en otras palabras, la escala triádica ayuda a racionalizar el procedimiento discursivo de ponderación, pero no se constituye en la ponderación misma, ya que el criterio último de ésta reside en la valoración del tribunal constitucional o supremo.

La idea de la ponderación, sin embargo, no queda completa todavía. Falta por precisar cómo pueden diferenciarse los empates en la ponderación originados a partir de la estructura normativa de los derechos fundamentales, es decir, de los empates en la ponderación que sólo aparecen como consecuencia de que las posibilidades de conocimiento sean limitadas. Esto llevará a Alexy a plantear en el Epílogo una segunda ley de la ponderación, referida a las cualidades epistémicas de la interferencia.

B) Segunda ley de ponderación (ley epistémica): esta ley se refiere no sólo a la importancia sustancial de las razones que justifican la interferencia, sino a sus cualidades epistémicas.

Cuanto más intensa sea una intervención en un derecho fundamental, tanto mayor debe ser la certeza de las premisas (empíricas y normativas) que sustentan la intervención.

Esta ley la formula Alexy debido a que a veces es incierto nuestro conocimiento acerca de lo que está ordenado, prohibido o confiado a la discrecionalidad del legislador por los derechos fundamentales. Esta incertidumbre puede ser provocada por la falta de certeza de las premisas empíricas o normativas. Esto quiere decir que en ocasiones no se tiene la certeza empírica o normativa sobre cuál es la manera más apropiada para sopesar los derechos fundamentales que se encuentran en conflicto y así se admite que el legislador

\footnotetext{
${ }^{340}$ Así esta secuencia geométrica puede atribuirle valores a las escalas del baremo tríadico citado antes de la siguiente manera:

(1) "Il" Levemente leve valdría 1, (2) " $I m$ " Moderadamente leve valdría 2, (3) "Is" Severamente leve valdría 4,

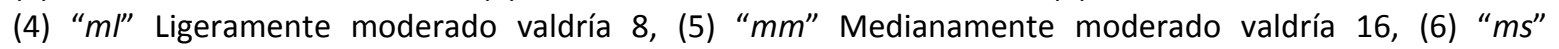
Severamente moderado valdría 32, (7) "sl" ligeramente severo valdría 64, (8) "sm" Medianamente severo valdría 128 y (9) "ss" Severamente severo valdría 256.
} 
dispone de un determinado marco, dentro del cual puede adoptar una decisión según su propia valoración. Los derechos fundamentales tienen dos dimensiones, una es sustantiva o material y la otra es formal o procedimental. Según Alexy,

La dimensión sustancial de un derecho fundamental tiene que ver con las cuestiones de lo que exige el cumplimiento del derecho y la cuestión acerca de las condiciones bajo las cuales el derecho puede limitarse en favor de otros derechos fundamentales o intereses públicos. La dimensión formal de los derechos fundamentales tiene que ver con los problemas institucionales del control de constitucionalidad. Aquí, principios formales como el principio de competencia legislativa para tomar decisiones democráticamente legitimadas tienen un papel muy importante. 341

Ahora bien, cuando se dan casos de conflictos normativos entre principios formales y materiales, es frecuente que sean pensadas dos soluciones extremas: la primera consiste en una primacía absoluta del principio sustancial frente al formal en los casos de falta de certeza empírica o normativa, lo que tendría como consecuencia que, en todos los casos en que sus decisiones afectaran de algún modo a los derechos fundamentales, al legislador sólo le estaría permitido basarse en premisas sobre cuya verdad existiera certeza, solución incompatible con el principio de separación de poderes y del principio democrático. La otra solución extrema consistiría en permitirle al legislador llevar a cabo intervenciones extraordinariamente intensas en los derechos fundamentales, incluso cuando tan sólo estuviesen basadas en pronósticos elevadamente inciertos.

Para evitar caer en estas soluciones extremas, Alexy sugiere que deben existir diferentes grados de certeza para cada intervención en los derechos fundamentales, de manera que la certeza de las premisas empíricas y normativas que fundamentan la intervención sea mayor en cuanto sea más intensa la intervención en el derecho. Esto explica que la segunda ley de la ponderación sostenga que "cuanto más intensa sea una intervención en un derecho fundamental, tanto mayor debe ser la certeza de las premisas (empíricas y normativas) que sustentan la intervención". De este modo, la primera ley hará énfasis en la intensidad de la intervención, mientras que la segunda hará énfasis en el peso de la intervención.

En relación con esta segunda ley de la ponderación, es posible utilizar una escala triádica, justo como con la primera ley de la ponderación. En la sentencia sobre la participación de los trabajadores en la cogestión el Tribunal Constitucional hizo una

\footnotetext{
${ }^{341}$ Alexy, Robert, TR, p. 345.
} 
sugerente distinción entre tres grados de control: "el control material intensivo", "el control de plausibilidad", y "el control de evidencia”. ${ }^{342}$ Estos grados corresponden a los tres grados epistémicos de cierto o seguro $(g)$, plausible $(p)$ o no evidentemente falso $(e)$. Esto dará lugar a que pueda hablarse de seguridad o certeza y de inseguridad o incertidumbre de las premisas empíricas y normativas del legislador y, por tanto, estos modelos epistémicos triádicos pueden incorporarse a la fórmula del peso sin muchos inconvenientes, de modo tal que una nueva fórmula del peso entraría en escena:

$$
W P_{i, j} C=\frac{I P_{i} C \cdot W P_{i} A \cdot \boldsymbol{S} R P_{i}^{e} C \cdot \boldsymbol{S} R P_{i}^{n} C}{I P_{j} C \cdot W P_{j} A \cdot S R P_{j}^{e} C \cdot S R P_{j}^{n} C}
$$

En esta incorporación del modelo epistémico triádico a la fórmula del peso vemos que fue introducida " $\boldsymbol{S}$ ' como símbolo que expresa la certeza o fiabilidad de las apreciaciones empíricas y normativas que versan sobre el significado que tiene la medida examinada para la no realización de $\boldsymbol{P}_{\boldsymbol{i}}$ y para la realización de $\boldsymbol{P}_{\boldsymbol{j}}$ en un caso concreto $(\boldsymbol{C})$, como fue el caso de la sentencia respecto a la cannabis. ${ }^{343}$ Respecto a los tres grados epistémicos de certeza o seguridad seguro $(g)$, plausible $(p)$ o no evidentemente falso $(e)$ pueden asignarse los valores $2^{0}, 2^{-1}$ y $2^{-2}$; esto es, $1,1 / 2$ y $1 / 4$. En caso de que exista un empate entre los principios en conflicto, deberán aplicarse las cargas de la argumentación en favor de otorgarle prioridad a un principio sobre el otro.

Finalmente, las cargas de la argumentación entran en escena cuando el peso de ambos principios es idéntico. Cuando se da esta situación Alexy sugiere que los empates serán decididos en favor del legislador y del principio democrático en que se funda tal competencia del parlamento, es decir, el juez hará valer el principio in dubio pro legislatore, es decir, el juez le concederá al poder legislativo la posibilidad de equilibrar los principios en conflicto mediante un empate entre sus pesos. De esta manera Alexy presenta la versión final de la fórmula del peso:

$$
W_{i, j} \frac{I_{i} \cdot W_{i} \cdot R_{i}^{e} \cdot R_{i}^{n}}{I_{j} \cdot W_{j} \cdot R_{j}^{e} \cdot R_{j}^{n}}
$$

\footnotetext{
342 BverfGE 50, 290 (333).

${ }^{343}$ BverfGE 90, 145 (182).
} 
Esta última versión, desarrollada en 2014, será designada por Alexy como la "Fórmula del peso completa refinada". ${ }^{344}$ Mediante la distinción entre la certeza o fiabilidad de las premisas empiricas y normativas la fórmula adquiere cuatro variables respecto a cada principio. Según esta refinación tendríamos ahora ocho variables en total. Con ocho variables en conjunto basadas en dos escalas triádicas podría obtenerse $3^{8}$, esto es, un amplio número de 6561 constelaciones. Estamos así ante la más completa refinación que ha hecho Alexy hasta ahora. Sin embargo falta analizar todavía el papel del control de constitucionalidad y el principio democrático en la teoría principialista.

\subsubsection{El problema de la legitimidad: el control de constitucionalidad y el principio democrático}

El control de constitucionalidad es definido por Alexy como "la expresión de la prioridad o superioridad de los derechos humanos sobre y contra la legislación parlamentaria". ${ }^{345}$ La ponderación constituye el principal problema metodológico del control de constitucionalidad y su relación con el principio democrático. No obstante, el control de constitucionalidad es legítimo sólo cuando es compatible con la democracia. El problema aquí reside en que los jueces no cuentan con legitimación directa del pueblo. La respuesta de Alexy a esto consiste en afirmar que, según el constitucionalismo discursivo, el control de constitucionalidad es una forma de representación argumentativa del pueblo.

El control de constitucionalidad en sí mismo se ha enfrentado a la objeción democrática en diversas ocasiones, ${ }^{346}$ siendo acaso ésta la objeción más fuerte, ya que los jueces no cuentan con legitimación democrática. Alexy, sin embargo, dará razones para reconciliar el control de constitucionalidad con la democracia. Según Alexy, al igual que el concepto de derecho, el concepto de representación, entendido como la relación entre los repraesentandum y los repraesentans, tiene una dimensión ideal en tanto erige una pretensión de corrección. ${ }^{347}$ Esto es importante ya que la democracia no sólo es un sistema de decisiones, sino también un sistema de argumentación. De acuerdo con esta idea la representación del pueblo es tanto volitiva como argumentativa. Mediante la inclusión de la

\footnotetext{
${ }^{344}$ Alexy, Robert, PF, p. 11.

345 Alexy, Robert, "Balancing, Constitutional Review and Representation", en, International Journal of Constitutional Law, vol. 3, no. 4, 2005, p. 577. En adelante BCRR.

${ }^{346} \mathrm{Cfr}$., Jeremy Waldron, "The Core of the Case against Judicial Review", Yale Law Journal 115, 2006, pp. 13461406.

${ }^{347}$ Alexy, Robert, BCRR, p. 579.
} 
argumentación la democracia se vuelve deliberativa en tanto permite institucionalizar el discurso como medio para la toma de decisiones en la sociedad.

El problema reside en que el control de constitucionalidad puede idealizarse a niveles extremos. Un crítico puede objetar que un tribunal supremo o constitucional puede declarar cualquier argumento como si fuese en representación del pueblo, equiparándose así la dimensión ideal con la real. El control de constitucionalidad podría alejarse de lo que los representados realmente piensan y, no obstante, los jueces podrían afirmar que los representa al declarar la constitucionalidad o inconstitucionalidad de una norma. La pretensión de corrección, por tanto, podría no ser suficiente para defender un control de constitucionalidad que contravendría el principio democrático.

La salida a este problema es posible siempre y cuando pueda establecerse un vínculo entre lo que las cortes llevan a cabo y lo que el pueblo piensa. Alexy llevará a cabo este vínculo mediante dos pasos. En el primer paso, el control de constitucionalidad debe mostrar que no cualquier respuesta puede darse en un procedimiento racional. Tal y como lo vimos respecto al discurso práctico-racional, no cualquier respuesta es posible en un discurso, y existe la posibilidad de distinguir entre argumentos fundamentables, nofundamentables y otros en los que el desacuerdo racional puede permanecer, pero no cualquier argumento puede ser ofrecido en el control de constitucionalidad. En segundo lugar, no sólo es necesario que los argumentos de los tribunales supremos o constitucionales tengan la pretensión de representar al pueblo, sino que, además, un buen número de personas debe estar dispuesto a aceptar la fundamentalidad de los argumentos emitidos por una corte por la mera razón de que estos argumentos son correctos.

De esta manera, Alexy proporciona dos razones fundamentales de una verdadera representación argumentativa, las cuales permiten que el control de constitucionalidad pueda reconciliarse con el principio democrático-representativo: 1. la existencia de argumentos correctos o razonables ofrecidos por la corte suprema o constitucional y 2 . la existencia de personas racionales, dispuestas y capaces de aceptar argumentos correctos y fundamentables. Estas personas, de manera análoga a la "persona liberal" de Rawls, bien pueden llamarse "personas constitucionales". De esta manera, el control de constitucionalidad puede concebirse como un tipo de argumentación representativa, y, con ello, volverse compatible con la democracia. 
No obstante, de acuerdo con Kumm, el problema es que a pesar de que los argumentos de Alexy en favor de fundamentar el control de constitucionalidad son correctos, el desacuerdo racional permanece ${ }^{348}$ en tanto sea discursivamente posible. Respecto a este problema Alexy argumenta que la pretensión de corrección no debe desecharse debido al reconocimiento de la razonabilidad del desacuerdo, ya que la corrección qua idea regulativa posee la consecuencia de que el desacuerdo institucional "debe permanecer abierto para una argumentación futura. Esta es la dimensión ideal de la argumentación jurídica". ${ }^{349}$ Para reconciliar el control de constitucionalidad con la democracia, Alexy ha recurrido a reflexiones de Aristóteles y del Tribunal constitucional Federal de Karlsruhe para sostener que en la relación entre derechos fundamentales y democracia es necesario considerar la tríada "derechos fundamentales, control de constitucionalidad y legislación parlamentaria". ${ }^{350}$

En tiempos recientes, representantes de la teoría principialista han contribuido a rechazar esta objeción hecha a la proporcionalidad. Borowski ha ofrecido tres argumentos para refutar esta objeción. Según Borowski, en primer lugar, el legislador mismo puede usar el análisis de proporcionalidad como guía para llevar a cabo un determinado proyecto de ley en el proceso de legislación, lo cual no tiene nada de antidemocrático. En segundo lugar, el control de constitucionalidad no trata solamente de ponderación, sino que también contiene elementos de la subsunción. En tercer lugar, la reconstrucción de la discrecionalidad en la ponderación por medio de los principios formales puede ofrecer la solución a una parte importante del problema democrático en el control de constitucionalidad. En este sentido contribuye a la solución de este problema. ${ }^{351}$ Estos elementos corroboran la conclusión de Kumm respecto a la teoría de los derechos fundamentales de Alexy y el problema del control de constitucionalidad: "[L]a democracia liberal sin control de constitucionalidad es deficiente". ${ }^{352}$

\footnotetext{
${ }^{348}$ Kumm, Mattias, "Alexy's Theory of Constitutional Rights and the Problem of Judicial Review", en, Klatt, Matthias (Ed.), Institutionalized Reason. The Jurisprudence of Robert Alexy, Nueva York, Oxford University press, 2012, p. 208.

${ }^{349}$ Alexy, Robert, CNPDF, p. 19

350 Alexy, Robert, "Grundrechte im demokratischen Verfassungsstaat", en, Aarnio, Aulis/Alexy, Robert/Bergholtz, Gunnar, Justice, Morality and Society. A Tribute to Aleksander Peczenik on the Occasion of his 60th Birthday, Lund, Juristförlaget i Lund, 1997, p. 36. En adelante, GDV.

${ }^{351}$ Borowski, Martin, op. cit., pp. 8-9.

352 Kumm, Mattias, op, cit., p. 217.
} 
Con la reconstrucción del control de constitucionalidad ha sido desarrollado el problema de la estructura, racionalidad y legitimidad del principio de proporcionalidad. Aunque debería quedar claro que Alexy no busca crear un modelo algorítmico que suprima por completo la discrecionalidad del juez para alcanzar una respuesta única y correcta, las objeciones hacia el principio de proporcionalidad han sido formuladas con una notable intensidad. Ahora analizaremos si éstas refutan este principio o si éste termina erigiéndose como un principio fundamental de un Estado de derecho, indispensable para que una corte suprema o constitucional pueda erigirse realmente como guardiana de la constitución y los derechos fundamentales.

\subsection{Las objeciones planteadas hacia el principio de proporcionalidad}

Hasta ahora sólo fue reconstruido el principio de proporcionalidad, y para ello usamos obras y artículos en los que Alexy ha hecho cambios y adiciones importantes, de cara a las críticas que han recibido los planteamientos esenciales de este principio. Sin embargo, esto es insuficiente para algunos críticos de la ponderación. Por ello plantearemos las objeciones más importantes que se le han formulado al principio de proporcionalidad, a la teoría principialista de Alexy. Previamente a Alexy, la pretensión de establecer racionalmente un orden jerárquico de necesidades humanas $\mathrm{o}$, en este caso, derechos fundamentales, y la solución a una posible colisión entre éstas mediante juicios de valor ya había sido vista por Kelsen:

Pero ¿qué necesidades humanas son dignas de ser satisfechas y, sobre todo, cuál es el orden jerárquico que les corresponde? Estos problemas no pueden ser resueltos por medio de un conocimiento racional. La solución de los mismos implica un juicio de valor determinado por factores emocionales y tiene, por ende, carácter subjetivo, válido únicamente para el sujeto que juzga y, por tanto, relativo sólo a él. La respuesta sería diferente según que proviniese de un creyente cristiano que considera el bien de su alma en el otro mundo más importante que los bienes terrenos, o de un materialista que no cree en otra vida; y sería también diferente si proviniese de quien considera la libertad personal como el bien más alto, en el caso del liberalismo, por ejemplo, o de quien piensa que la seguridad social y la igualdad de todos los hombres es superior a la libertad, como ocurre con el socialismo. ${ }^{353}$

En los últimos años, la teoría principialista ha provocado un número considerable de objeciones. Desde muy variadas perspectivas la teoría de los principios y su método de

${ }^{353}$ Kelsen, Hans, Teoría general del derecho y del Estado, México, D. F., UNAM, 1995, p. 7. 
aplicación han sido criticados, hasta tal punto que han podido sistematizarse las objeciones más importantes a ésta. A continuación mencionaremos las objeciones que se le han planteado a la teoría principialista:

1. Objeciones de teoría de las normas: estas objeciones tratan sobre la existencia y estructura de los principios así como de su diferencia con las reglas.

2. Objeciones de teoría de la argumentación: estas objeciones giran en torno a la pregunta acerca de si la ponderación ofrece una justificación o fundamentación racional.

3. Objeciones de dogmática iusfundamental: estas objeciones ven en la ponderación el peligro de disolución o contracción de los derechos fundamentales.

4. Objeciones institucionales: estas objeciones, por lo contrario, temen a la inflación de los derechos fundamentales, que provocaría que el Estado legislativo parlamentario se transformara en un Estado de justicia constitucional.

5. Objeciones de teoría de la interpretación: estas objeciones cuestionan si es posible justificar que la construcción como principios sea la interpretación correcta de un catálogo jurídicopositivo de derechos fundamentales.

6. Objeciones de teoría de la validez: estas objeciones le reprochan a la teoría de los principios que sea responsable de anular la vinculación a la constitución y a la ley y de disolver la estructura jerárquica del derecho.

7. Objeciones de teoría de las ciencias: estas objeciones sostienen que la teoría de los principios como dogmática de los derechos fundamentales sería insuficiente. ${ }^{354}$

A esta lista pueden sumarse dos nuevas objeciones planteadas en los últimos años, a las que Alexy se ha referido en una conferencia respecto a su concepción no-positivista de derechos fundamentales. ${ }^{355}$ Estas nuevas objeciones, que bien pueden sumarse a las anteriores, son las siguientes:

8. La "objeción de inframoralización": según esta objeción, planteada por Kai Möller, la teoría de los principios es vista como meramente formal porque carece de contenido moral sustancial

\footnotetext{
${ }^{354}$ Alexy, Robert, IS, p. 21. Respecto a esta clasificación de las objeciones, Sieckmann hace una lista similar de críticas, conjuntando a las objeciones de teoría de la interpretación y de teoría de la validez bajo la objeción de inadecuación jurídico-constitucional y dejando de lado a las objeciones de teoría de la ciencia. De este modo, establece cinco objeciones, que son las siguientes: objeciones de inadecuación desde el punto de vista de las normas, objeciones de inadecuación metodológica, objeciones de inadecuación institucional, objeciones de inadecuación jurídico-constitucional y objeciones de inadecuación con respecto a la protección iusfundamental. Al respecto, cfr., Sieckmann, Jan-Reinard, "Probleme der Prinzipientheorie der Grundrechte", en Laura y Sieckmann, Jan-Reinard (Eds.), Grundrechte, Prinzipien und Argumentation. Studien zur Rechstheorie Robert Alexys, Baden-Baden, Nomos Verlagsgesellschaft, 2009, pp. 39-66.

${ }^{355}$ Sobre estas objeciones cfr., Alexy, Robert, "Una concepción no-positivista de derechos fundamentales", conferencia dictada en México el 10 de diciembre de 2013 en el marco del IV Congreso internacional de Argumentación jurídica. En adelante CNPDF. pp. 1-2.
} 
alguno. Por ello, Möller caracteriza su teoría como un "enfoque de moral sustantiva, que, como tal, puede contrastarse con una teoría formal como la de la [...] de Robert Alexy". ${ }^{356}$

9. La "objeción de supramoralización": según esta objeción, planteada por Birgit Reese, "la teoría de los principios está incorporada en una filosofía moral procedimental y en un concepto nopositivista del derecho, y, por esta razón, apunta a una conexión entre derecho y moral". ${ }^{357}$ Esto, sin embargo, conduciría a amenazas inaceptables a la normatividad constitucional, la racionalidad de las decisiones, y a la democracia. ${ }^{358}$

Como puede verse, la lista de objeciones a la teoría principialista es considerable y abarcan puntos específicos e importantes de la teoría de Alexy, tales como la diferencia entre principios y reglas, la interpretación de los derechos, la validez de las normas o la disolución o inflación de los derechos fundamentales. Desde los comienzos de su planteamiento Alexy sabía que el principio de proporcionalidad traería consigo objeciones de peso, y es por ello que en Teoría de los derechos fundamentales señaló cuáles son las más frecuentes objeciones:

Muchas veces se ha objetado en contra del concepto de ponderación que no constituye un método que permita un control racional. Los valores y los principios no regulan por sí mismos su aplicación. Por lo tanto, la ponderación quedaría suelta al arbitrio de quien la realiza. Allí donde comienza la ponderación, cesaría el control que se surte por medio de las normas y el método. Se abriría así un margen para el subjetivismo y decisionismo judiciales. ${ }^{359}$

Estas objeciones a la ponderación persisten hasta ahora. Aunque existen muchas objeciones frente a la postura defendida por Alexy, es posible señalar dos muy importantes; a estas objeciones Alexy se ha referido en el epílogo a la Teoría de los derechos fundamentales con el título de "Demasiado suave y demasiado fuerte" (Too soft and too rigid), aludiendo claramente a las críticas de Habermas y Böckenförde a la idea de que, por una parte, no hay pautas de racionalidad en cuanto los derechos fundamentales son concebidos como principios que deben ponderarse en el caso de que colidan, mientras que, por la otra, los derechos fundamentales provocarían una ampliación del control de constitucionalidad que desembocaría en un Estado jurisdiccional.

Es por ello que ahora desarrollaremos estas dos críticas, ya que son las más fuertes que se le han hecho y en las que está en juego la pretensión de racionalidad, y con ello, la legitimidad de este principio. Estas críticas de Habermas y Böckenförde están relacionadas

\footnotetext{
${ }^{356}$ Kai Möller, The Global Model of Constitutional Rights, Oxford, Oxford University Press, 2012, pp. 1-2.

${ }^{357}$ Birgit Reese, Die Verfassung des Grundgesetzes, Berlín, Duncker \& Humblot, 2013, p. 115.

${ }^{358}$ Alexy, Robert, CNPDF, p. 2.

${ }^{359}$ Alexy, Robert, TDF, p. 135.
} 
respectivamente con las objeciones metodológicas e institucionales, es decir, con las objeciones dos y cuatro antes mencionadas, que serán desarrolladas a continuación. ${ }^{360}$

6.2.1. La objeción de Böckenförde (el "demasiado fuerte"): esta objeción, que puede entrar en la categoría de las objeciones institucionales, reside en exponer que la expansión de los derechos fundamentales altera irremediablemente el carácter de la constitución de forma dramática. Por consiguiente, la constitución deja de ser un orden marco (Rahmenordnung) para el proceso democrático de formación de la voluntad política y se convierte en el orden fundamental (Grundordnung) de la comunidad política. Una constitución que fuera el fundamento de la comunidad ya contendría todo el ordenamiento jurídico in nuce y ab initio (la constitución comprendida como un huevo jurídico originario, en el sentido de Ernst Forsthoff), ${ }^{361}$ razón por la cual el fin del proceso democrático se reduciría a la mera puesta en práctica de lo que ya haya sido previamente establecido por la constitución. Este ejercicio ejercicio del poder sería supervisado por un tribunal constitucional que tendría todo el poder real, atribución incompatible con el principio democrático y la división de poderes.

De acuerdo con Julian Rivers, la crítica de Böckenförde puede entenderse como una exigencia de que el control de constitucionalidad no deba suplantar la contribución de los cuerpos legislativos y ejecutivos en el proceso público de toma de decisiones. ${ }^{362}$ Esto explicaría que para Böckenförde la única forma de evitar un tránsito del Estado legislativo parlamentario al Estado constitucional de jurisdicción sería regresando a la concepción de los derechos constitucionales como derechos subjetivos de libertad dirigidos defensivamente contra el Estado.

Alexy intentará responder a esta objeción mediante una distinción entre orden marco y orden fundamental, la compatibilidad de éstos, y posteriormente, una dogmática de los márgenes de acción, la cual servirá para refutar el efecto sobreconstitucionalizador temido por Böckenförde. Esto será posible si la ponderación y el orden marco son compatibles, refutando así de igual modo el efecto contrario, consistente en una

\footnotetext{
${ }^{360}$ Estas objeciones también se encuentran en la clasificación de Sieckmann, representadas respectivamente por las objeciones de inadecuación metodológica y objeciones de inadecuación institucional.

${ }^{361}$ Forsthoff, Ernst, El Estado de la sociedad industrial, Madrid, Instituto de Estudios Políticos, 1975, p. 242.

362 Rivers, Julian, "Proporcionality, Discretion and the Second Law of Balancing”, en Pavlakos, George (Ed.), Law, Rights and Discourse. The Legal Philosophy of Robert Alexy, Portland, Hart Publishing, 2007, pp. 167-168.
} 
infraconstitucionalización de los derechos fundamentales. A continuación, será analizada la respuesta de Alexy a la objeción del "demasiado fuerte". Según Alexy, la constitución pude ser a la vez un orden fundamental y un orden marco. Veamos con mayor atención la diferencia entre estas dos concepciones de constitución.

La noción de orden marco remite a la idea de que la constitución misma establece un marco dentro del cual las acciones del legislador están claramente delimitadas. Las acciones establecidas mediante este marco pueden establecerse de acuerdo con las modalidades básicas de la lógica deóntica de la siguiente manera: lo prohibido o ilícito puede comprenderse como lo constitucionalmente imposible, lo mandado o debido como lo constitucionalmente necesario y lo permitido o discrecional como lo constitucionalmente posible. Ahora bien, lo prohibido o ilícito y lo mandado o debido conforman el marco, mientras que lo permitido o discrecional es todo aquello que conformará el margen de acción. Aquí se trata de un concepto formal de margen de acción y marco.

La noción de orden fundamental remite a la idea de que la constitución resuelve las preguntas fundamentales para la comunidad política. Esta concepción puede ser cualitativa o cuantitativa. La constitución se comprenderá en un sentido cuantitativo si no establece facultades discrecionales, es decir, que ella sólo manda o prohíbe, pero no da un margen para la discreción. En cambio, el concepto cualitativo no se contrapone al orden marco porque permite que la constitución resuelva aquellas preguntas fundamentales para la comunidad que pueden y deben estar resueltas gracias a ella. Dicho de otro modo el sentido cualitativo de orden fundamental considera que la constitución puede resolver asuntos fundamentales de la comunidad política y, a pesar de ello, también puede dejar muchas preguntas sin responder y por tanto ser un orden marco. El problema al que apunta Böckenförde reside en buscar un equilibrio entre el orden fundamental y el orden marco, lo que puede ser resuelto, según Alexy, con la dogmática de los márgenes de acción.

Estos márgenes de acción son de dos tipos: estructurales y epistémicos. Los primeros se dividen en a) márgenes para la fijación de fines, b) de elección de medios y c) para la ponderación, mientras que los segundos se dividen en a) empíricos y b) normativos. Por un lado, los márgenes de acción estructural expresan el carácter limitado del contenido material de la constitución y son aquellos en los que se encuentra todo lo que la constitución establece definitivamente como discrecional, mientras que por otro lado, los márgenes de acción epistémicos, que permiten traspasar el limitado alcance material de la jurisdicción 
constitucional a la jurisdicción ordinaria, se originan a partir de los límites de la capacidad para conocer lo que la constitución ordena y prohíbe y lo que no ordena ni prohíbe, esto es, el ámbito de lo discrecional. Los márgenes de acción estructural serán descritos ahora.

A) Los márgenes de acción para la fijación de fines son los que tiene el legislador cuando frente a un derecho fundamental se le da capacidad de determinar los fines que justifican las intervenciones en los derechos fundamentales. Piénsese, por ejemplo, en los márgenes que tendría un legislador para determinar los fines sociales que justificarían la intervención en el derecho a la propiedad privada, como el derecho a la protección del medio ambiente.

B) Los márgenes de acción para la fijación de fines son los que tiene el legislador cuando para los fines prescritos mediante deberes positivos la elección del medio adecuado o alternativo se confía a la discrecionalidad del legislador. Piénsese, por ejemplo, en los márgenes que tendría un legislador para determinar los medios que pueden usarse para satisfacer un derecho prestacional, como el derecho a la salud.

C) Los márgenes de acción para la ponderación son los que tiene el legislador cuando no todas las colisiones entre principios pueden resolverse mediante la ponderación, sobre todo, en los casos en los que el peso de los principios se encuentra plenamente equilibrado. En este caso, mediante el análisis del principio de proporcionalidad y la refinación de la escala menos empates existirán. Estos empates en la ponderación llevan a la compatibilidad entre la ponderación y la constitución concebida como orden marco. De este modo, además, el margen para la ponderación se erige como la parte central de la dogmática de la constitución como marco. Piénsese, por ejemplo, en los márgenes para la ponderación que tendría un legislador para determinar el resultado de un conflicto entre dos principios cuyos pesos están casi equilibrados, como es el caso de conflictos entre derechos a la igualdad y a la libertad, en los cuales es exigida una sentencia de acuerdo con las posibilidades fácticas y jurídicas.

Ahora analizaremos los márgenes de acción epistémicos. Estos márgenes de acción aparecen cuando no hay una certeza acerca de lo que la constitución ordena, prohíbe y permite a los poderes públicos. Estos márgenes admiten la posibilidad de que existan afectaciones a los derechos fundamentales que no siempre pueden establecerse y sancionarse por la Corte Constitucional. 
A) Márgenes de acción epistémico-empíricos: estos márgenes afectan sólo indirectamente al contenido material de la constitución y aparecen cuando la incertidumbre empírica afecta a los exámenes de idoneidad y necesidad. Estos límites se establecen mediante una ponderación en la que se pesan los principios en conflicto, junto con el margen de acción que corresponde a los principios formales.

B) Márgenes de acción epistémico-normativos: estos márgenes afectan directamente al contenido material de la constitución y aparecen cuando los poderes vinculados por la constitución poseen la capacidad de decidir sobre el contenido de su vinculación hasta los márgenes de acción. El reconocimiento de estos márgenes de acción implica la transferencia de la jurisdicción constitucional a tribunales ordinarios.

Esta fue la réplica a las objeciones planteadas por Böckenförde. Mediante esta dogmática de los márgenes de acción es muy plausible evitar el riesgo de una sobreconstitucionalización o infraconstitucionalización, situaciones que terminarían por expandir o comprimir a los derechos fundamentales. Después de todo, y haciéndole una ligera variación a cierta expresión de Alexy, ${ }^{363}$ el moloch depredador no tiene por qué devorar a los poderes legislativo y ejecutivo, ni al mismo poder jurisdiccional. Ahora pasaremos a la siguiente objeción, la de Habermas

6.2.2. Las objeciones de Habermas (el "demasiado suave"): estas objeciones, que pueden entrar en las categorías de teoría de la argumentación y dogmática iusfundamental, provienen de un importante representante de la ética del discurso, ${ }^{364}$ filosofía moral que ha tenido una influencia notable en el pensamento de Alexy. Estas objeciones serán presentadas a continuación.

La primera crítica de Habermas al principio de proporcionalidad reside en que priva a las normas de derecho fundamentales de su poder normativo-deontológico, ya que, según Habermas, con la introducción de esta práctica los derechos se reducen al nivel de los objetivos, de las prácticas y de los valores, y con ello se viene abajo la "barrera cortafuegos" con la identifica el carácter deontológico de los derechos, entendidos también, en el sentido

\footnotetext{
${ }^{363}$ Alexy, Robert, TEDF, p. 51.

${ }^{364}$ El núcleo de estas objeciones a la idea de ponderación también las ha planteado Bernhard Schlink en la obra Abwägung im Verfassungsrecht (Berlín, Duncker \& Humblot, 1976), si bien éstas no han resonado en el ámbito latinoamericano como las de Habermas.
} 
de Dworkin, como triunfos políticos frente a la mayoría. De este modo, la ponderación se convierte en un mecanismo decisionista:

Debido a que las normas y principios, en virtud de su carácter deontológico, pueden pretender ser universalmente vinculantes y no sólo especialmente preferidas, poseen una fuerza superior a los valores de justificación [...] Como no hay criterios racionales para esto, la ponderación se lleva a cabo de forma arbitraria o irreflexiva, de acuerdo con las normas consuetudinarias y las jerarquías.

En la medida en que un tribunal constitucional adopta la doctrina de un orden objetivo de valores (objective order of values) y basa su toma de decisiones en una especie de realismo o convencionalismo morales, aumenta el peligro de las decisiones irracionales, porque los argumentos funcionalistas entonces obtienen la ventaja sobre los normativos. ${ }^{365}$

La segunda crítica que Habermas plantea al principio de proporcionalidad fue planteada en un simposio acerca de la teoría discursiva del derecho y la democracia de éste de Habermas. Esta crítica reside en que este principio saca a la decisión del tribunal del ámbito de los conceptos como correcto e incorrecto, corrección e incorrección, y justificación, y los sustituye por nociones como adecuado e inadecuado, y discreción, que terminan por llegar a resultados de la ponderación injustificados por vías racionales. En la contestación a Alexy en este simposio Habermas planteó esta segunda crítica:

La decisión de un tribunal es en sí misma un juicio de valor que refleja, de manera más o menos adecuada, una forma de vida que se articula en el marco de un orden concreto de valores. Pero este juicio ya no se relaciona con las alternativas de una decisión correcta o incorrecta. Por lo tanto, al asimilar las afirmaciones normativas (ought-statements) a evaluaciones (discrecionales), se abre el camino para la legitimación de amplios poderes discrecionales. Las afirmaciones normativas tienen diferentes características gramaticales de las afirmaciones evaluativas. ${ }^{366}$

Es importante indicar que el paradigma procedimental de los derechos fundamentales de Habermas es conocido por Alexy, en cuanto contiene premisas normativas del paradigma de la ética del discurso que van más allá de los defectos de los paradigmas de los Estados liberales y sociales. La autonomía privada es el argumento principal de ambos tipos de paradigmas; no obstante, Habermas trata de señalar un camino intermedio entre los extremos en los que, en ocasiones, caen los defensores de cada paradigma:

El paradigma procedimental del derecho es presentado por Habermas como una reacción a la debilidad de los paradigmas de los Estados liberal y social [...] Se dice que tanto el

\footnotetext{
${ }^{365}$ Habermas, Jürgen, Faktizität und Geltung. Beiträge zur Diskurstheorie des Rechts und des demokratischen Rechtstaats, Fráncfort del Meno, Suhrkamp 1992, pp. 315-316.

366 Habermas, Jürgen, "Reply to Simposium Participants", en Rosenfield, Michel y Arato, Andrew (Eds.), Habermas on Law and Democracy, Massachusetts, MIT, 1998, p. 430.
} 
paradigma liberal y el del Estado social sufren del mismo defecto al final: una concentración exagerada en la autonomía privada. La "cosa" que el paradigma liberal quiere asegurar (secure) y lo que el paradigma de Estado social quiere llevar a la existencia (bring into existence) por medio de los derechos sociales no es más que la autonomía privada. 367

El paradigma procedimental busca evitar los errores tradicionales de aquellos paradigmas que en aras de la libertad y la igualdad terminan por darle una prioridad estricta a un cierto tipo de derechos, mientras que por el otro lado, terminan por hacer a un lado a los demás derechos. Este sistema de derechos propuesto por Habermas parte de una concepción coherentista de los derechos fundamentales, en el sentido de que debe existir una prioridad lexicográfica entre ellos, lo cual evitaría que los derechos fundamentales considerados de menor jerarquía entrasen en conflicto con los de mayor jerarquía, de acuerdo con una cierta concepción del Estado y la sociedad.

Según Habermas, la ponderación eliminaría la barrera cortafuegos de los derechos fundamentales y favorecería juicios irracionales incompatibles con la tradición liberal. Según Arango, en el trasfondo de la polémica entre Alexy y Habermas se encuentra la discusión entre Hilary Putnam y Habermas sobre la separación entre valores y normas expuesta por el segundo. Es obvio cómo en el debate acerca del carácter deontológico o teleológico de los derechos fundamentales se conectan cuestiones filosóficas más generales de problemas propios de los ámbitos de la filosofía política y moral, al mismo tiempo que muestra las limitaciones de intentar trasladar los problemas de fundamentación de normas morales a la esfera de las normas jurídicas. ${ }^{368}$

Pero, ¿realmente es la ponderación un mecanismo jurídico que le daría rienda suelta al decisionismo jurídico?, ¿capitularían los derechos ante los intereses de la comunidad?, ¿acaso la ponderación es una idea que debería desecharse por el bien de los derechos

\footnotetext{
${ }^{367}$ Alexy, Robert, "Basic Rights and Democracy in Jürgen Habermas's Procedural Paradigm of Law", en, Ratio Juris. Vol 7 No. 2 July, 1994, p. 229. En adelante, BRDJH.

${ }^{368}$ Nos parece un acierto de Arango el señalar que en el debate entre Putnam y Habermas respecto a la relación entre normas y valores consiste en que éste "muestra que no puede simplemente trasladarse de manera directa al ámbito de la filosofía del derecho y a la teoría de los derechos fundamentales. En especial esto no debería hacerse cuando Habermas entiende por normas, las normas morales o de validez universal, no las normas de derecho positivo". (Arango, Rodolfo, "Deontologische und teleologische Grundrechtskonzeptionen", en Laura y Sieckmann, Jan-Reinard (Eds.), Grundrechte, Prinzipien und Argumentation. Studien zur Rechstheorie Robert Alexys, Baden-Baden, Nomos Verlagsgesellschaft, 2009, p. 81). La aportación normativa de Habermas a la filosofía del derecho es innegable, aunque sería deseable entenderla como una "filosofía del derecho hecha por filósofos", la cual, en ocasiones, carece de algunas precisiones conceptuales propias de la filosofía del derecho de los juristas.
} 
fundamentales? Si las objeciones de Habermas son correctas, entonces estas preguntas no podrían responderse mediante la teoría principialista.

Según estas objeciones, los jueces tendrían la capacidad de poner en peligro a los derechos fundamentales mediante su discrecionalidad, por lo que la teoría de los principios representaría un tipo de ingenuo "formalismo constitucional". La ceguera normativa frente al probable activismo judicial pondría en riesgo uno de los pilares de un Estado democrático: los derechos fundamentales. Las valoraciones subjetivas de los jueces terminarían imponiéndose así sobre aquel gran invento de nuestra civilización. Para responder a estas objeciones es necesario afirmar que la teoría de los principios no es ciega frente a los prejuicios o discrecionalidad de los jueces.

De hecho, la teoría principialista de Alexy está más cercana a la forma en como deliberan los jueces que la visión habermasiana de los derechos. Es notable que otro crítico de la teoría principialista de los derechos fundamentales, Schlink, le reproche a la teoría habermasiana del derecho que carezca de significación para la práctica de la corte constitucional federal alemana, ${ }^{369}$ y esto tal vez esto se deba, entre otras posibles causas, a la falta de una comprensión acerca del modo mediante el cual ciertos principios de derecho se institucionalizan y aplican en casos concretos.

A veces, quisiéramos evitar que las concepciones morales, políticas y religiosas de los jueces influyeran en sus fallos finales sobre los conflictos jurídicos que deben resolver. Por otra parte, es justo reconocer que la aplicación del método de la ponderación no puede proporcionar siempre una respuesta correcta a todos los conflictos normativos entre derechos. No estamos ante un algoritmo o cálculo matemático, sino ante una forma racional de argumentación práctica, ya que el cálculo no puede suplir a la dimensión argumentativa. Quien sostenga que Alexy ha reducido la argumentación al cálculo seguramente mostrará no haber entendido nada sobre racionalidad práctica. No obstante, estos argumentos suelen repetirse de manera irreflexiva.

La razón por la cual las objeciones de Habermas no refutan al principio de proporcionalidad son sencillas: la discrecionalidad tampoco puede erradicarse de ningún

\footnotetext{
${ }^{369}$ Schlink, Bernhard, "The Dinamics of Constitutional Adjudication", en, Arato, Andrew y Rosenfeld, Michel (Eds.), Habermas on Law and Democracy. Critical Exchanges, California, California University Press, 1998, pp. 317 y 318.
} 
otro ámbito humano en el que llevemos a cabo ponderaciones, como es el ámbito de la razón práctica. Tal y como fue indicado en el análisis de la teoría de la argumentación jurídica de Alexy, la concepción de una racionalidad práctica implica la fundamentación racional de los juicios valorativos en el ámbito del derecho, lo cual es posible, aunque no por ello tengamos una respuesta última para todos los problemas jurídicos.

La teoría principialista de los derechos fundamentales de Alexy no hace a un lado cuestiones empíricas que, en ocasiones, ponen en desventaja a los argumentos normativos frente a las objeciones "realistas"; precisamente, estas últimas consisten en hacer explícito la posible irracionalidad de los jueces y la falta de una certeza última; por ello, el principio de proporcionalidad con sus tres subprincipios, la fórmula refinada del peso y las dos leyes de la ponderación, constituye un notable esfuerzo por defender a los derechos fundamentales de los peligros que los acechan. Consideramos que desde el punto de vista de la ética del discurso y de una teoría de la argumentación práctico-racional, el principio de proporcionalidad pareciera contestarle desde el inicio a las objeciones de Habermas, ya que contribuye a reducir los grados de discrecionalidad en los conflictos normativos.

De hecho, como los jueces no pueden suprimir sus valoraciones emotivas, intuiciones y concepciones morales acerca de los fines del derecho, y, también, como no es posible crear un método práctico-jurídico, conjunto de reglas procedimentales y principios para obtener una respuesta siempre correcta a todos los conflictos que afectan a la sociedad, es que este principio permite reducir la discrecionalidad de quienes interpretan y aplican este tipo de normas fundamentales. En otras palabras, lo que permite el principio de proporcionalidad es darle al juez un modelo para racionalizar la aplicación del derecho de acuerdo con las posibilidades fácticas y jurídicas.La teoría del discurso termina mostrando así una concepción de la racionalidad como optimalidad, expresión acuñada por Bäcker. ${ }^{370}$ La resolución final implica, efectivamente, una decisión, pero, debido al principio de proporcionalidad, ésta tiene un margen de acción delimitado en tanto debe justificarse. De este modo, el Moloch del decisionismo no tiene por qué devorar a los derechos fundamentales.

\footnotetext{
${ }^{370}$ Bäcker, Carsten, "Rationalität ohne Idealität. Grundzüge einer relativistischen Diskurstheorie des Rechts", en, Bäcker, Carsten/Ziemann, Sascha (Eds.), Junge Rechtsphilosophie, Stuttgart, Franz Steiner Verlag/Nomos, 2012, p. 22.
} 
Por otra parte, también plantearemos una crítica a Habermas. La objeción de Habermas a Alexy está dirigida hacia la irracionalidad de la ponderación. Esta crítica posee dos aspectos: por una parte, la crítica metodológica a la ponderación como recurso que resuelve la colisión entre derechos y, por otra parte, la crítica ideológica a la ponderación, entendida como un mecanismo que pondera entre diversos tipos de derechos. Pasaremos al segundo aspecto porque sobre la crítica metodológica ya no hay mucho que decir, esto es, la ponderación no puede ser un recurso que dé una respuesta última y siempre correcta a los problemas de colisiones, pero puede contribuir bastante a la reducción de los niveles de discrecionalidad judicial presentes en todo acto de interpretación y aplicación de los jueces. Sobre este segundo aspecto, puede decirse que la crítica ideológica implica reconocer la existencia de un orden lexicográfico entre los diversos tipos de derechos, lo cual terminaría por imponer una concepción deontológica de los derechos fundamentales.

El problema existente entre la relación entre derechos individuales fundamentales y derechos sociales fundamentales o bienes colectivos ha sido motivo no sólo de la vinculación entre la filosofía política y moral con la filosofía del derecho, sino también es un problema referente al concepto de la estructura básica del Estado y la sociedad. Por ello, Alexy sostiene que "mientras exista disenso en la teoría de la justicia, la ponderación de derechos y bienes colectivos seguirá siendo objeto de polémica". ${ }^{371}$ Frente a esta visión, Habermas parece decidirse por una concepción deontológica de los derechos fundamentales que termina por justificar una visión del Estado y de la sociedad acorde con el triunfo de un lenguaje, tiempo y ámbito de los derechos individuales.

Habermas menciona en Facticidad y validez que "es cierto que no todo derecho (individual) ganará frente a todo bien colectivo en la justificación de decisiones concretas"; 372 no obstante, una concepción como la de Habermas no es compatible con un Estado social de derecho, para el cual los derechos sociales también son derechos fundamentales. Además, los derechos fundamentales tienen en el principio de proporcionalidad un garante básico, tal y como lo sostiene Arango:

Una concepción no estrictamente deontológica es más ventajosa que una estrictamente deontológica, ya que hace justicia al carácter realizativo de los derechos fundamentales. Lo que no sucede con la segunda concepción. La estirpe liberal de la comprensión habermasiana de los derechos como «side constraints»

\footnotetext{
${ }^{371}$ Alexy, Robert, CVD, p. 179.

372 Habermas, op. cit., p. 315.
} 
está más acorde con un Estado de derecho, mientras que la comprensión de los mismos como posiciones iusfundamentales a realizarse según las circunstancias del caso se adecúa más al Estado social de derecho. Los mandatos de optimización garantizan que los derechos fundamentales puedan realizarse sobre una base realista en las circunstancias concretas del caso. Para la determinación de la observancia de estos mandatos el principio de proporcionalidad cumple un papel central. ${ }^{373}$

Efectivamente, buena parte de la tradición liberal todavía no comprende que los derechos fundamentales no pueden reducirse a acciones negativas por parte del Estado, y mucho menos que una prioridad prima facie de los derechos individuales es más que suficiente para tomar en serio al individuo. Dicho de otro modo, si a lo único que aspiramos es a un orden lexicográfico de derechos —con tal de proteger nuestra concepción ideológica de los derechos fundamentales, ya sea meramente liberal o social-, entonces sólo estaríamos defendiendo un orden político unidimensional. En el caso de un orden lexicográfico paleoliberal, las consecuencias serían lamentables, tal y como Alexy lo señala:

Si un orden jerárquico de prelación de todos los derechos fundamentales frente a todos los bienes colectivos tuviese validez, el derecho de propiedad no podría ser restringido para proteger el medio ambiente, así como tampoco podría serlo la libertad de empresa en razón de la protección de los consumidores. La libertad científica permitiría la realización ilimitada de experimentos con animales, se prohibiría la consideración de la función preventiva general de las penas, la lucha contra el desempleo de los jóvenes en la política económica no podría ser una razón admisible para limitar los derechos fundamentales, y no podría prohibirse el funcionamiento de asociaciones, cuando no atiendan la idea de entendimiento entre los pueblos y apelen a la guerra y la dominación. ${ }^{374}$

Un sistema de derechos fundamentales debe integrar características sustanciales propias de un Estado liberal, democrático y social de derecho, aunque esto plantee grandes dificultades para la realización de este ideal. Precisamente, la concepción de los derechos como principios apunta a realizar esta difícil meta. A pesar de sus dificultades, consideramos que los derechos humanos y fundamentales son un logro de la modernidad, acaso el logro por el que más vale la pena luchar, a pesar de no ser siempre apreciado por los críticos del derecho (de izquierda y de derecha). El principio de proporcionalidad y la teoría principialista no proporcionarán una certeza última, pero en el reconocimiento de la racionalidad de esta teoría reside el triunfo de la teoría no-positivista de los derechos fundamentales:

\footnotetext{
${ }^{373}$ Arango, Rodolfo, op. cit., p. 77.

${ }^{374}$ Alexy, Robert, TEDF, p. 133.
} 
De este modo, la divergencia permanece ciertamente como una espina que se clava en el principio iusfundamental material. Sin embargo, esta espina es el imprescindible tributo que los ideales iusfundamentales tienen que pagar a cambio del triunfo, nunca suficientemente apreciado, de su institucionalización en el mundo, tal como es. ${ }^{375}$

\subsection{Teoría de los derechos fundamentales y Estado de Derecho}

Al llegar a esta parte hemos visto que las preguntas y objeciones principales a la teoría de los derechos fundamentales han sido expuestas. No obstante, todavía quedan interrogantes por plantear y que serán las que nos llevarán a la siguiente sección de esta obra. Cuando es analizada la teoría de Alexy, ¿estamos ante concepción tímida de los derechos fundamentales?, ¿acaso ésta satisfaría al fanático liberal?, ¿es posible hablar de la viabilidad de una teoría principialista global?

En primer lugar, puede afimarse que el principio de proporcionalidad es racional, siempre y cuando no se piense que éste es algo así como un algoritmo supresor de la discrecionalidad judicial. El cálculo puede ayudar a racionalizar la argumentación, pero no la sustituye en modo alguno. En segundo lugar, la idea de un procedimiento racional para interpretar y aplicar los derechos fundamentales es de gran importancia si desea tomarse en serio a los derechos y evitar así que se vuelvan parte de una poesía constitucional ${ }^{376} \mathrm{o}$ mera retórica académica en la que está ausente una preocupación legítima por estas normas iusfundamentales. En tercer lugar, una teoría integral de los derechos fundamentales debe responder a la exigencia de un paradigma constitucional basado en la realización de la libertad e igualdad sociales. El universo de significados de las teorías políticas modernas acerca de la mejor forma de gobierno ha tenido un efecto de irradiación en el ámbito de los derechos fundamentales y ello ha provocado que el discurso de los derechos se abra a estos debates para configurarse como un sistema universalista, si bien esto también ha mostrado los límites del derecho en torno a cuestiones de justicia que van más allá de éste. Esto nos lleva a una de las cuestiones centrales que debe afrontar la teoría principialista de Alexy de cara a la posibilidad de un constitucionalismo más allá del Estado nacional, de acuerdo con las posibilidades fácticas y jurídicas existentes.

\footnotetext{
${ }^{375}$ Alexy, Robert, TDF, p. 562.

${ }^{376}$ Alexy, Robert, GDV, p. 29.
} 
Precisamente, un sistema de derechos fundamentales, construido a partir de la teoría del discurso, es congruente con tomar en serio al individuo y sin olvidar que la libertad individual no puede realizarse sin la aseguración de la libertad institucional de los demás. La libertad e igualdad de los ciudadanos va más allá del ámbito del derecho, pero, sin duda, este ámbito es indispensable para institucionalizar estas ideas filosóficas. A pesar de que diversas críticas indican que la concepción alexyana de los derechos sociales es "tímida en exceso" porque no incluye a los derechos sociales dentro del coto vedado indisponible para el legislador, y porque no los fundamenta en el concepto de dignidad humana, sino en el de libertad fáctica, ${ }^{377}$ consideramos que ella es un avance indiscutible dentro del ámbito de las teorías de los derechos fundamentales. Por fortuna, en países como Alemania el Estado social de derecho continúa con el proyecto de consolidar los derechos sociales sin afectar severamente por ello al libre mercado. Como muestra de ello tenemos la decisión del Tribunal Constitucional de Alemania en torno al subsidio social Hartz $I V,{ }^{378}$ la cual fue fundamentada con base en el principio de dignidad humana en combinación con el principio del Estado social de derecho. De esta manera el derecho a un ingreso existencial mínimo se presenta así como un derecho fundamental, reconocido interpretativamente por dicho tribunal.

Al final del capítulo cuarto mencionamos que según Alexy la ética del discurso hará un énfasis normativo en la precedencia prima facie de los derechos individuales tal, que le dará a esta teoría una tendencia individualista "tan débil que no satisfaría a un representante de una teoría política estrictamente individualista". ${ }^{379}$ Pues bien, analizado este argumento en retrospectiva, creemos que esta teoría no puede ser ser del agrado de un partidario del

\footnotetext{
377 Sobre esta crítica, puede consultarse el trabajo de Ernesto Garzón Valdés "Cinco consideraciones acerca de la concepción de los derechos sociales de Robert Alexy", incluido en la compilación Derechos sociales y ponderación. En defensa de la postura de Alexy, indicamos que en el capítulo noveno, apartado segundo de la Teoría de los derechos fundamentales, es mencionada la idea de dignidad humana con las consecuencias lógicas de usar este concepto, que son las de "ampliar extremadamente el concepto de dignidad humana a fin de comprender todo lo digno de ser protegido, lo que implica el peligro, muchas veces aducido, de que la dignidad humana se convierta en dinero de bolsillo o de renunciar a comprender algunas cosas dignas de ser protegidas" (Alexy, Robert, TDF, p. 413). El concepto de dignidad humana no está exento de problemas de interpretación antropológicos, filosóficos, políticos y jurídicos, por lo que al basar los derechos en este concepto tampoco resolvería el problema en torno a qué derechos merecen institucionalizarse.

${ }^{378}$ BVerfGE, 1 BvL 1/09 del 09.02.2010.

${ }^{379}$ Alexy, Robert, DRD, p. 261.
} 
individualismo posesivo, ni tampoco del defensor de una postura colectivista incompatible con el postulado de tomar en serio al individuo.

En este este difícil punto medio, en el cual el constitucionalismo debe enfocarse en institucionalizar exigencias de corte universalista. Para lograr esta exigente pretensión es necesario recurrir a premisas ausentes o no del todo desarrolladas en la teoría de Alexy, vinculadas al proyecto de una ampliación progresiva de posiciones jurídicas fundamentales. Estas premisas consisten en sostener, en primer lugar, que el constitucionalismo debe garantizar todos los derechos fundamentales. El proyecto constitucionalista debe proteger no sólo a los derechos de libertad, sino también a los derechos sociales, para superar así el paradigma del Estado paleoliberal y complementarlo con aportaciones de otros modelos. ${ }^{380}$ En segundo lugar, este constitucionalismo no puede quedarse en la esfera de competencia y controles constitucionales del Estado-nación, sino que debe transitar hacia un constitucionalismo global, para que de este modo los ciudadanos del mundo puedan exigir sus derechos a instituciones globales que los puedan asegurar. Además, en cuarto lugar, agregaríamos que también es deseable que los ciudadanos tengan una conciencia cívica del ejercicio de sus derechos y de sus respectivos deberes para contribuir a la realización de este constitucionalismo integral.

Sin duda, la realización de este constitucionalismo discursivo no debe basarse únicamente en instituciones gubernamentales, normas sustanciales y procedimientos formales para tener realidad, sino en personas constitucionales que reconozcan el deber de ejercer sus derechos con respeto por el derecho de los otros y de no descuidar sus obligaciones hacia las instituciones políticas y los demás ciudadanos de un sistema jurídico democrático. Los procesos de modernización política inscritos en el paradigma de la democracia y el liberalismo "asumen la necesidad de tener un Estado de derecho que imponga límites a la acción de las estructuras de gobierno y que norme las conductas individuales y colectivas", ${ }^{381}$ y en estos procesos es pertinente promover también el ejercicio

\footnotetext{
380 Pensemos, por ejemplo, en los avances del constitucionalismo latinoamericano en materia ecológica, consagrados en las constituciones de Perú y Bolivia. Sin embargo, si estos avances no desean quedarse en la esfera de un "folklorismo jurídico" entonces deben ser efectivos en el momento en que deban aplicarse este tipo de normas. No obstante, estamos ante un avance en materia constitucional, justo como en su tiempo lo fue el constitucionalismo social mexicano respecto a los derechos sociales.

${ }^{381}$ Betanzos, Eber, "Delitos electorales y procuración de justicia electoral", en, Justicia Electoral. Revista del Tribunal Electoral del Poder Judicial de la Federación, Cuarta Época, vol. 1, núm. 10, Júlio-diciembre de 2012, pp. 95-96.
} 
responsable de los derechos fundamentales en un Estado democrático de derecho por parte de sus ciudadanos. Mediante estos complementos, el sistema de derechos fundamentales de Alexy puede contribuir a institucionalizar la razón y la justicia en el ámbito, lenguaje y era de los derechos:

El constitucionalismo discursivo, como un todo, es una empresa para institucionalizar la razón y la corrección. Si existen los argumentos correctos y razonables, así como, también, personas racionales, la razón y la corrección estarán mejor institucionalizadas mediante el control de constitucionalidad que sin dicho control. ${ }^{382}$

Mientras esta institucionalización de la razón llega a realizarse, una cosa es segura: si los gobiernos del mundo no se toman en serio a los derechos, tampoco se estarán tomando con seriedad al derecho, ${ }^{383} \mathrm{ni}$ a ellos mismos. Actualmente, la teoría principialista es aplicada con frecuencia por las cortes latinoamericanas, ${ }^{384}$ aunque falta por analizar con detalle si el principio de proporcionalidad es usado de manera adecuada por dichas cortes. En este sentido, los usos y abusos del principio de proporcionalidad van más allá de la teoría de Alexy; dicho de otro modo, la culpa no puede imputársele a la teoría, sino a sus intérpretes. No obstante, en sintonía con una observación de Jestaedt, ${ }^{385}$ consideramos que el principio de proporcionalidad, aplicado de manera incorrecta y en un contexto incorrecto, podría provocar un daño mayor al beneficio capaz de lograr. Una de las formas de evitar este daño podría consistir en que los argumentos de los jueces estén sujetos al escrutinio de un sector académico actualizado en materia de dogmática constitucional y argumentación jurídica, y objetivo respecto a sus análisis, así como de una opinión pública crítica bien informada, es decir, que las decisiones de las cortes constitucionales estén sujetas al escrutinio de genuinas personas constitucionales.

\footnotetext{
${ }^{382}$ Alexy, Robert, BCRR, p. 581.

${ }^{383}$ Cfr., Dworkin, Ronald, Los derechos en serio, Barcelona, Planeta-De Agostini, 1993, p. 303.

${ }^{384}$ Bernal ha escrito en el Estudio introductorio de la traducción de la Teoría de los derechos fundamentales que en México el Tribunal Electoral del Poder Judicial de la Federación ha citado en diversas sentencias esta obra o diversos artículos de Alexy en sus argumentos conclusivos respecto a conflictos normativos desde 2006, si bien el principio de proporcionalidad fue usado por vez primera durante un amaparo en revisión en 2004 (988/2004). No obstante, habría que analizar con cautela las sentencias para ver si los jueces han llevado a cabo un ejercicio correcto de la teoría principialista. Al respecto, cfr., Bernal, Carlos, "Estudio Introductorio", en, Alexy, Robert, Teoría de los derechos fundamentales, Madrid, Centro de Estudios Políticos y Constitucionales, 2007, p. XXXIII. Sobre los usos del principio de proporcionalidad por parte de la corte mexicana cfr., Díez, Rodrigo, "Principio de proporcionalidad, colisión de principios y el nuevo discurso de la corte", en, Cuestiones constitucionales. Revista mexicana de derecho constitucional, núm. 26, enero-junio 2012, pp. 66-106.

385 Jestaedt, Matthias, op. cit. p. 172.
} 
Todavía faltan problemas de la filosofía del derecho que no han sido mencionados hasta ahora y que, de hecho, están presentes en la filosofía jurídica de Alexy. Cuestionamientos tales como los que giran en torno al concepto y naturaleza del derecho necesitan ser reconstruidos para presentar así a esta filosofía jurídica como una reflexión sistemática en torno al derecho. Estos problemas, que serán la base de la concepción nopositivista del derecho de Alexy, confrontarán al positivismo jurídico en sus diversas variantes. Preguntas permanentes en la filosofía del derecho, tales como las que giran en torno a qué es el derecho, cuál es la relación entre el derecho y la moral, qué sucede cuando una ley vigente es injusta, la posibilidad de considerar a un régimen jurídico como un orden no jurídico o los criterios de validez de las normas jurídicas serán ahora el tema de reflexión de Alexy. La respuesta a estas preguntas también nos llevará a exponer al pensamiento jurídico de Alexy como el sistema de filosofía del derecho más interesante de las últimas décadas. 


\section{Tercera parte}

\section{Capítulo Siete: Moral y derecho. La tragedia conceptual del derecho}

\section{Introducción}

En las dos secciones pasadas hicimos una reconstrucción de las dos primeras obras de Alexy, dedicadas a la teoría de la argumentación jurídica y a la teoría de los derechos fundamentales. Sin duda alguna, estas obras han configurado el paradigma alexyano. Ahora bien, la conexión lógica entre la teoría de la argumentación jurídica y la teoría de los derechos fundamentales se explica por una idea del mismo Alexy según la cual una teoría de la argumentación jurídica supone una teoría de los derechos fundamentales y una teoría de los derechos fundamentales supone una teoría de la argumentación jurídica. La conexión entre ambas obras forma parte de este sistema de filosofía jurídica. No obstante, aunque en ambas obras puede percibirse una visión del derecho opuesta al positivismo jurídico, una réplica directa a las tesis centrales de éste todavía no era explícita.

Es momento de que la filosofía jurídica de Alexy haga una crítica al positivismo jurídico mediante la comprensión de la teoría del concepto, naturaleza y validez del derecho. ${ }^{386}$ Esta conexión será la que hará posible la pretensión de sistematicidad de la obra de Alexy. Esta pretensión de sistematicidad es la que nos permitirá comprender al pensamiento de Alexy como un sistema de filosofía del derecho.

En 1992, después de las publicaciones de sus dos obras mayores, Alexy publica una obra de un tamaño menor al de las dos obras pasadas, titulada, Concepto y validez del derecho. ${ }^{387}$ Según Pavlakos, a pesar de que esta obra estaba planeada más como un libro de texto, "es por mucho el pronunciamiento más maduro de las ideas de Alexy acerca del

\footnotetext{
${ }^{386}$ Si bien es cierto que la obra en la que nos basamos para esta sección está enfocada en el concepto (Begriff) y validez (Geltung) del derecho, también en obras posteriores Alexy se ha referido a la aclaración acerca de la naturaleza (Natur) del derecho. Es por ello que incluimos en esta sección al concepto, naturaleza y validez del derecho, porque nos parece que así quedan más claras las tesis de Alexy, en tanto que la reflexión sobre el concepto y validez del derecho es una reflexión sobre la naturaleza de lo que es y debe ser el derecho.

387 Durante la elaboración de esta obra también revisamos su edición inglesa, la cual lleva por título The Argument from Injustice. A Reply to Legal Positivism, ya que esta traducción contiene precisiones argumentales que contribuyen a aclarar las tesis de Alexy. Como Alexy indica, estas precisiones tienen su origen en las constantes discusiones que tuvo con sus traductores, Stanley Paulson y Bonnie Litschewski Paulson. No obstante, para no confundir al lector sólo citaremos la edición española.
} 
concepto de derecho, al mismo tiempo que sirve como introducción retrospectiva a los problemas filosóficos en respuesta a los cuales él desarrolló en primer lugar la teoría discursiva del derecho". ${ }^{388}$ Tal y como está expresado en la traducción inglesa de esta obra, Alexy desarrollará una crítica al positivismo jurídico mediante una serie de argumentos vinculados a los problemas que siempre suelen aparecer cuando tratamos de definir al derecho como algo más que las órdenes respaldadas por un grupo de ladrones.

Si en las dos secciones pasadas notamos una serie de ideas que incluían un punto de vista moral acerca del derecho, ahora esta obra encarará al positivismo jurídico. El reto de la normatividad del derecho, esto es, el reto de la legitimidad moderna del derecho, reside en renunciar a las formas tradicionales de fundamentación del derecho, pero no al punto de vista moral. En esta sección será presentada la visión del concepto, naturaleza y validez del derecho de Alexy.

\subsection{El problema conceptual de la vinculación entre moral y derecho}

Alexy comienza Concepto y validez del derecho con una aclaración que será el eje rector de esta obra. Ésta parece resumir lo que durante más de dos mil años ha sido discutido en el ámbito de la filosofía práctica con gran pasión y énfasis:

El problema central de la polémica acerca del concepto de derecho es la relación entre derecho y moral. A pesar de una discusión de más de dos mil años, siguen existiendo dos posiciones básicas: la positivista y la no positivista. [...] Todas las teorías positivistas sostienen la tesis de la separación. Esta indica, que el concepto de derecho debe definirse de modo que no debe incorporar elementos morales. [...] Todas las teorías no positivistas sostienen la tesis de la vinculación. Esta indica, que el concepto de derecho debe ser definido de tal manera que contenga elementos morales. ${ }^{389}$

Esta cita sintetiza las posturas básicas de la filosofía jurídica, al mismo tiempo que expresará el objetivo principal de esta obra: buscar aclarar el concepto de derecho, lo cual significa aclarar qué es derecho. Aclarar qué es derecho implica conocer ciertas propiedades que hacen que el derecho sea una cosa específica y no sea otra. Precisamente, intentar buscar una naturaleza del derecho implicará aclarar cuáles son esas

\footnotetext{
388 Pavlakos, George, "Review of The Argument from Injustice from Robert Alexy", en, The Modern Law Review, Vol. 67, No. 2, 2004, p. 342.

${ }^{389}$ Alexy, Robert, CVD, pp. 13-14.
} 
propiedades constitutivas de aquello que deseamos comprender como derecho. De este modo, parece correcto lo que sostiene Ross en el sentido de que, "[D]esprovisto de su formulación metafísica, el problema de la "naturaleza del derecho" es el problema de la filosofía del derecho". 390 Paula Gaido explica el proyecto de Alexy del siguiente modo:

También para Alexy el propósito de la filosofía del derecho es dar una explicación de la naturaleza del derecho. Y, en este contexto, anticipé, una pregunta por la naturaleza del derecho es una pregunta por la naturaleza de sus propiedades esenciales; o, para abundar, por aquello que hace que el derecho sea lo que es, y no otra cosa. Cuando Alexy se refiere a las propiedades esenciales del derecho se está refiriendo a sus propiedades necesarias. ${ }^{391}$

La pretensión alexyana de comprender cuáles son estas propiedades necesarias no es nueva. Esta pretensión ha estado presente en todos los proyectos filosóficos de aquellos pensadores que han reflexionado sobre la filosofía práctica, o, al menos, todos aquellos que han buscado comprender la naturaleza y legitimidad del orden social, y que, por tanto, han intentado elaborar un concepto de derecho adecuado. Efectivamente, como bien lo explicaba Hart, "[P]ocas preguntas referentes a la sociedad humana han sido formuladas con tanta persistencia y respondidas por pensadores serios de maneras tan diversas, extrañas, y aun paradójicas, como la pregunta “¿qué es derecho?”. 392

Estamos ante la pregunta que se devela como la pregunta básica de la teoría y filosofía del derecho. Con base en las innumerables discusiones que podrían citarse para intentarla responder, discusiones que, siglos más, siglos menos, llevan más de dos mil años sin llegar a una respuesta convincente, podríamos plantear tres preguntas acerca de esta búsqueda por dar un concepto de derecho. Estas preguntas son las siguientes:

¿Puede definirse el concepto de derecho por poseer determinadas propiedades morales necesarias?

¿Puede definirse el concepto de derecho de acuerdo con el cumplimiento de ciertos requisitos formales?

\footnotetext{
390 Ross, Alf, On Law and Justice, Nueva York, New Haven Press, 1958, p. 33

${ }^{391}$ Gaido, Paula, Las pretensiones normativas del derecho. Un análisis de las concepciones de Robert Alexy y Joseph Raz, Barcelona, Marcial Pons, 2011, p. 55.

${ }^{392}$ Hart, H. L. A., The Concept of Law, Nueva York, Oxford University Press, 1994, p. 1.
} 
¿Puede definirse el concepto de derecho según las funciones que cumple en la sociedad?

¿O acaso estaremos estas preguntas serán inútiles para comprender el derecho? Puede notarse que el concepto de derecho presenta problemas según respondamos a estas preguntas, lo cual, con frecuencia, provoca que algunos afirmen que es correcto el cuarto cuestionamiento, referido a la inutilidad de preguntarnos acerca de qué es derecho. En efecto, ¿qué es derecho?, ¿un conjunto de principios morales que deben ser obedecidos por la conciencia moral?, ¿un sistema de normas vigentes en una sociedad?, ¿o acaso un conjunto de normas dirigidas a cumplir una función social específica?

¿Por qué es tan difícil definir el concepto de derecho? Tal vez, cierta mezcla de elementos descriptivos, empíricos y normativos es la responsable de hacer problemática la definición del concepto de derecho. El mismo Alexy sabe que esta mezcla vuelve problemática la definición de derecho, pero al mismo tiempo, la considera indispensable para dar un concepto adecuado de derecho.

La cuestión consiste en saber qué concepto de derecho es correcto o adecuado. Quien quiera responder esta pregunta tiene que relacionar tres elementos. El de la legalidad conforme al ordenamiento, el de la efectividad social y el de la corrección del contenido. ${ }^{393}$

Como recordaremos, estos tres elementos están vinculados con la metodología tridimensional que hemos visto en la obra de Alexy. El elemento empírico corresponde a la definición de derecho desde la sociología del derecho, el elemento analítico corresponde a la definición de derecho desde la teoría del derecho y el elemento normativo corresponde a la definición de derecho desde la filosofía jurídica. Ahora bien, las muy variadas tesis positivistas se enfocan en los elementos de la legalidad conforme al ordenamiento y de la efectividad social, dejando de lado el elemento de la corrección del contenido. Pero ¿qué es precisamente eso que entendemos por un contenido correcto del derecho para ser tal?

Para Alexy el grito de guerra del positivismo jurídico kelseniano, "cualquier contenido puede ser derecho", es incorrecto. Esta disputa por un contenido correcto es la que ha hecho que los positivistas, al apelar a una postura no cognitivista, sostengan que no exista un contenido ideal del derecho y por ello basen sus concepciones del derecho en criterios formales o empíricos que sean accesibles para el conocimiento. De este modo el problema

${ }^{393}$ Alexy, Robert, CVD, p. 21. 
del contenido se vuelve un problema concerniente a una concepción que habitualmente es designada como "moral". Esta concepción de moral es la que permite, entonces, crear dos distinciones básicas acerca del concepto y naturaleza del derecho, las cuales serán la tesis de la vinculación y la tesis de la separación respectivamente. ${ }^{394}$ Pero ¿qué es lo que se entiende por vinculación o separación conceptual del derecho con la moral? Hacer una pregunta sobre la vinculación o separación del derecho con la moral implica tener una pretensión de saber cuáles son las propiedades que tiene el derecho para ser tal y no otra cosa, porque lo que indagamos ahora es saber la naturaleza del derecho para comprenderlo en su concepto esencial. Por ello es frecuente considerar que si logramos establecer una vinculación conceptual necesaria con la moral podremos entender qué es derecho.

¿Es en verdad este criterio satisfactorio para saber qué es derecho? Nos parece que no. En la búsqueda por un concepto adecuado de derecho se ha descuidado al otro concepto que nos sirve para comprender qué es derecho y, con ello, ha sido creada una torre de Babel que sigue creciendo hasta ahora. Estamos ante un problema conceptual y normativo. Desde ahora puede verse que la polémica conceptual sobre la vinculación o separación del derecho con la moral no reside en los sofisticados argumentos en favor de una $u$ otra postura, sino en el punto de partida conceptual, que no es precisamente el de derecho, sino en el del otro concepto que sirve para evaluar al derecho mismo, esto es, el del concepto de moral. Si los juristas pensamos que en el ámbito de la filosofía jurídica el concepto de derecho es realmente problemático, lo mismo puede decirse en el ámbito de la filosofía moral acerca del concepto de "moral". A continuación explicaremos que la vaguedad del concepto de moral también ha contribuido a crear malentendidos en torno a este debate.

Si abrimos un libro de filosofía jurídica, de cualquier filósofo del derecho, de cualquier ámbito, veremos que, seguramente, tendrá un capítulo dedicado a la relación entre el derecho y la moral. Desde las obras clásicas de la filosofía del derecho hasta los

\footnotetext{
${ }^{394}$ Alexy ha explicado claramente que los problemas ocasionados por la relación entre derecho y moral han dado lugar a dos tesis básicas, las cuales son la tesis de la vinculación y la de la separación: "[E]n el conflicto sobre el positivismo jurídico existen dos tesis: la tesis de la separación y la tesis de la vinculación". (Alexy, Robert, "Zur Verteidigung eines nichtpositivistischen Rechtsbegriffs", en, Gesang, Bernward und Schälike Julius (Eds.), Die groben Kontroversen der Rechstphilosophie, Paderborn, Mentis, 2011, p. 49. En adelante, VNRB.
} 
nuevos debates es posible leer un capítulo dedicado a este tema. Parece, entonces, que la siguiente frase de Francisco Laporta se ha vuelto una máxima de la filosofía del derecho: "el problema de las relaciones entre derecho y moral no es un tema de la filosofía jurídica, sino que es el lugar donde la filosofía del derecho está". ${ }^{395}$ Esta máxima de la filosofía contemporánea del derecho se ha vuelto un lugar común debido a la falta de claridad conceptual respecto a lo que entendemos por "relaciones entre derecho y moral". Consideramos muy difícil presentar una aproximación de todos los argumentos que han sido ofrecidos a lo largo de la historia respecto a este debate. Lo que sí podemos hacer es un recuento de los más importantes significados que desde la filosofía del derecho se han dado respecto al concepto de moral; de este modo mostraremos a qué tipo de relaciones se refieren los argumentos ofrecidos en favor o en contra de la vinculación y separación entre moral y derecho. Este tipo de distinciones ya han sido desarrolladas por diversos filósofos del derecho.

Filósofos como Arthur Kaufmann y Norbert Brieskorn coinciden en que las relaciones entre derecho y moral son muy diversas, por lo que hablar de una sola tesis de la separación o de la vinculación puede dar lugar a confusiones si no hay una comprensión previa respecto a las relaciones entre derecho y moral, e, inclusive, tales confusiones pueden llevar a los participantes a incurrir en "vértigos argumentales", explicados en el tercer capítulo. Ambos autores coinciden, al igual que otros más, en que el derecho y la moral son dos cosas distintas y por ello sus funciones también lo son, así como en ver que las relaciones entre ambos órdenes normativos son muy variadas.

De este modo, al igual que Kant, estos filósofos entenderán el concepto de moral como "mores", 396 es decir, en el sentido clásico de la época romana, que equipara este concepto con "convenciones", "costumbres" y "usos". De ahí ambos establecerán una serie de relaciones entre derecho y moral distintas entre sí, pero usadas con bastante frecuencia en las distintas tradiciones filosóficas. Por una parte, al referirse Kaufmann a estas relaciones, distinguirá entre autonomía y heteronomía, interioridad y exterioridad, legalidad y moralidad, y luego se referirá a la relación entre reglas de aplicación a la conducta social, para luego mencionar las contradicciones valorativas entre derecho y moral, y terminará

\footnotetext{
395 Laporta, Francisco, Entre el derecho y la moral, México, D. F., Fontamara, 2000, p. 7.

396 Kant, Immanuel, Metaphysische Anfangsgründe der Rechtslehre. Metaphysik der Sitten. Erster Teil, Hamburgo, Felix Meiner Verlag, 2009, p, 12.
} 
con una exposición del principio de subsidiariedad. ${ }^{397}$ Por otra parte, Brieskorn distinguirá entre la mencionada equiparación de moral a las costumbres, convenciones y usos y hábitos, la distinción entre moralidad y legalidad, la idea de moral como un entendimiento "ético" del derecho y la presentación de preguntas clásicas acerca de la relación entre derecho y moral. ${ }^{398}$

\subsection{Los diversos usos del concepto de moral}

Ahora veremos estos cinco tipos distintos de usos del concepto de "moral", los cuales son frecuentes en la filosofía jurídica. Por ahora consideramos que estas cinco distinciones nos permitirán tener una mayor claridad conceptual respecto a lo que entendemos por "moral", y, con ello, también estableceremos, si es que existe, una relación conceptual con el derecho. En otras palabras, buscaremos aclarar en qué relaciones nos parece que la separación es incorrecta, y en qué relaciones ésta es correcta.

7.2.1. Moral como exigencia de justicia. Sin lugar a duda alguna, estamos ante el debate clásico de la filosofía del derecho: la distinción entre el derecho positivo creado por el ser humano y un derecho superior, de corte racional, metafísico o teológico. El debate entre el derecho positivo y el derecho natural es un debate más viejo que el sostenido entre Sócrates y los sofistas. En este debate el objetivo ha sido ver si es posible dar un concepto de derecho de acuerdo a una adecuación a principios de justicia.

Uno de los argumentos básicos del positivismo jurídico para desterrar a la idea de justicia del derecho fue considerarla, una mera expresión emotiva. Alf Ross expresó la pretensión de hacer a un lado la exigencia de justicia del concepto de derecho:

Las palabras «justa» e «injusta» (o «correcta» e «incorrecta») tienen sentido cuando se aplican para caracterizar la decisión hecha por un juez, o por cualquier otra persona que debe aplicar un conjunto de reglas. [...] Pero aplicadas para caracterizar una regla o un orden, las palabras «justo» e «injusto» carecen de significado. La justicia no es una guía para el legislador. [...] Una persona que sostiene que cierta regla o conjunto de reglas - por ejemplo, un sistema impositivo- es injusto, no indica ninguna cualidad discernible en las reglas. No da ninguna razón para su actitud; simplemente se limita a darle una expresión emocional. [...] Invocar a la

\footnotetext{
${ }^{397}$ Kaufmann, Arthur, Rechtsphilosophie, Múnich, C. H. Beck, 1997, p. 212 ss.

${ }^{398}$ Brieskorn, Norbert, Rechtsphilosophie, Colonia, Kohlhammer, 1990, p. 69 ss.
} 
justicia, es como dar un golpe sobre la mesa: una expresión emocional que hace de la propia exigencia un postulado absoluto. ${ }^{399}$

Para el positivismo jurídico de Kelsen el problema principal de la fundamentación del derecho está relacionado con el problema de la justicia. Según Kelsen, la pretensión de que el derecho se separe de la moral, o más bien dicho, de la justicia, tenía tres objetivos concretos y distintos entre sí: separar al derecho de a) las costumbres sociales, b) la conciencia individual de los sujetos y c) la fundamentación metafísica y política del derecho. Los primeros dos incisos serán explicados en los siguientes apartados, mientras que el tercero es vital para entender que, tal y como es indicado por Lars Vinx, la tesis kelseniana de la separación entre derecho y moral "sólo tiene sentido si es interpretada como una exigencia limitada de la independencia de la legitimidad legal de los dictados de la cualidad moral sustantiva del contenido del derecho, y no como una negación general de cualquier relación necesaria entre derecho y moral". 400

Si analizáramos la obra de Kelsen, desde la primera edición de la Teoría Pura del Derecho de 1934 hasta la Teoría General de las Normas de 1973, notaremos que da diversos significados al concepto de "moral", entendiéndola primero y principalmente como una forma de vincular al derecho con la justicia, ${ }^{401}$ también como la autonomía de la conciencia del sujeto, esto es, la conciencia como autoridad moral ${ }^{402}$ y finalmente, como costumbres sociales 0 moral positivizada. ${ }^{403}$ Esta distinción permite ver diversas concepciones de moral en Kelsen. Ahora bien, ¿por qué Kelsen separaba al derecho de la moral? La razón reside en la vinculación del concepto de justicia, por un lado, a especulaciones metafísico-teológicas y, por otro lado, a teorías políticas en conflicto. El problema que tenían estas dos vertientes era su apelación a una idea de validez absoluta, lo cual era incompatible con el relativismo kelseniano. Tenemos, entonces, a un Kelsen que no vinculaba al derecho con la moral porque al hacerlo promovía una postura contraria a la pureza del método positivista, consistente en vincular al derecho con una concepción política, moral o religiosa de justicia. Así, el ideal de justicia podía servir como justificación

\footnotetext{
${ }^{399}$ Ross, Alf, Ross, Alf, On Law and Justice, Nueva York, New Haven Press, 1958, p. 358.

${ }^{400}$ Vinx, Lars, Hans Kelsen's Pure Theory of Law, Nueva York, Oxford University Press, 2007, p. 67.

${ }^{401} \mathrm{Cfr}$., Kelsen, Hans, Reine Rechtslehre. Einleitung in der rechtswissentschaftliche Problematik, Tubinga, Mohr Siebeck, 2008, p. 25.

402 Kelsen, Hans, Allgemeine Theorie der Normen, Viena, Manzche Verlags- und Universitätsbuchhandlung, 1979, p. 65.

${ }^{403}$ Kelsen, Hans, op. cit., p. 15
} 
de cualquier régimen político. Kelsen no dejó de repetir durante toda su obra que siempre ha existido la exigencia de que el derecho corresponda a un ideal de justicia, “¿pero a qué tipo de ideal de justicia? ¿Al ideal de justicia capital-individualista o al socialistacolectivista? ${ }^{404}$

7.2.2. Moral como moral positivizada. Estamos ante una distinción que busca diferenciar al derecho de otro tipo de ordenamientos sociales que también prescriben acciones u omisiones humanas, la distinción entre el derecho como orden institucional y la moral entendida como la positivización de pautas de conducta social, ya sean de carácter social o religioso. La distinción entre derecho positivo y moral positivizada podemos encontrarla en la filosofía de Austin, en la cual hace una aclaración entre las leyes humanas y las leyes divinas, y luego entre dos tipos de leyes humanas: las leyes creadas por el poder político y las que no fueron creadas por el poder político, a las que denominará moral positivizada. De este modo, tenemos tres tipos de ordenamientos de la conducta humana, que obligan de diversas maneras:

De las exposiciones en la parte precedente de mi discurso se desprende que las leyes propiamente dichas son muy similares con respecto a tales leyes inapropiadas, las cuales son de tres tipos de clases: I La ley de Dios. 2. El derecho positivo, o las leyes positivas. 3 . La moral positivizada, las reglas de la moral positivizada o reglas morales positivizadas. 405

Aunque la moral positivizada o la religión han tenido una influencia en la constitución del derecho moderno estos órdenes normativos de la conducta deben diferenciarse. Primero analizaremos la distinción entre las normas jurídicas y las religiosas y luego entre las normas jurídicas y la moral positivizada.

7.2.2.1. La distinción entre derecho y religión: la distinción entre derecho y religión es vista como una aportación básica del proceso de secularización de la modernidad. Al llevar a cabo Hobbes la distinción entre delito y pecado ${ }^{406}$ podremos comprobar que ciertas normas jurídicas no tienen que imponerle al sujeto el obedecimiento a normas religiosas, que obligan en el foro interno, sino sólo aquellas dictadas por la autoridad del Estado. De acuerdo con Hobbes, las prohibiciones del derecho pueden coincidir o no coincidir con la

\footnotetext{
${ }^{404}$ Kelsen, op. cit., p. 98.

${ }^{405}$ Austin, John, The Province of Jurisprudence Determined and The Uses of the Study of Jurisprudence, Nueva York, Prometheus Books, 1998 p. 156 y 157.

${ }^{406}$ Cfr., Hobbes, Thomas, El Leviatán o la materia, forma y poder de una república eclesiástica y civil, México, D. F., FCE, 1987, p. 239.
} 
idea de ciertos pecados, pero no todo pecado debe castigarse como si fuera un delito. En esta concepción podemos advertir el peligro de castigar jurídicamente acciones y omisiones que no están incorporadas en los sistemas modernos de derecho. Si los delitos y pecados fueran equiparados mediante una desdiferenciación de lo que el derecho y los ordenamientos religiosos prohíben, permiten y mandan, el derecho perdería su validez jurídica al ser subsumido por el discurso religioso.

7.2.2.2. La moral como moral positivizada: esta separación conceptual es concebida como la secularización ilustrada del derecho y de la moral, y, según esta tesis, el derecho no reproduce ni tiene la misión de reproducir los dictámenes de la moral o de cualquier otro sistema metajurídico - divino, natural o racional- sino que es sólo producto de convenciones legales no predeterminadas ontológica ni tampoco sistemáticamente. ${ }^{407}$ Para exponer esta concepción de la moral, podemos recordar el debate Hart-Devlin, el cual influyó en la comprensión de Patzig en torno a la separación normativa entre el derecho y la moral, ${ }^{408}$ y que giró en torno a si es posible distinguir entre la moral pública y privada.

El origen de este debate se encuentra en la conclusión a la que llegó la Comisión Wolfenden en torno a la posibilidad de dejar de prohibir jurídicamente la prostitución y la homosexualidad esta comisión, basándose en el Principio del daño de John Stuart Mill, señaló que tiene que existir un reino de moralidad e inmoralidad privadas el cual no es de incumbencia para el Estado". Este argumento no fue convincente para Devlin, ya que consideraba que no hay una distinción entre moral pública y privada. De acuerdo con Devlin, el derecho penal debe reforzar e imponer la moralidad pública compartida de los individuos de una sociedad para evitar la destrucción de ésta.

Desde el punto de vista de un derecho penal liberal, Hart planteó una serie de argumentos contra la postura de Devlin. De acuerdo con Hart, la homosexualidad y la porostitución no dañan a terceros, ni provocan la desintegración de la sociedad o algún otro tipo de daño en el mundo, a menos de que consideremos históricamente válida la afirmación

\footnotetext{
${ }^{407}$ Cfr., Ferrajoli, Luigi, Derecho y razón. Teoría del garantismo penal, Madrid, Trotta, 2006, p. 218.

408 Patzig decidió incursionar en el debate entre moral y derecho a partir del debate entre Hart y Devlin para así defender la tesis de la separación en el campo del derecho penal. De esta manera, Patzig comprende que las reglas jurídicas y morales están vinculadas en cuanto están referidas a conductas humanas y que éste es su terreno común, pero ambas se diferencian en cuanto las jurídicas se aplican institucionalmente en una sociedad y tiempo concretos, mientras que las reglas morales carecen de estas características. (Cfr., Patzig, Günther, Ethik ohne Metaphysik, Gotinga, Vandenhoeck-Reihe, 1983, p. 7 ss)
} 
del emperador Justiniano de que la homosexualidad era la causa de terremotos. ${ }^{409}$ Dicho de otro modo, el derecho no puede permitir que los dictados de una nebulosa concepción de la moral positiva invadan los terrenos del derecho, sino que es necesario que esta incorporación esté sometida a una moral crítica.

7.2.3. Moral como moral crítica. La crítica que suele hacerse a ciertas normas de derecho positivo y al positivismo jurídico, a veces es planteada en nombre de un punto de vista moral. Por esta razón es usual que también se hable de la inclusión de ideas de derecho natural o de una vinculación entre derecho y moral al hablar de la crítica al derecho. En este sentido, el positivismo jurídico suele ser criticado cuando aparece la distinción entre el ser y deber ser del derecho. ¿Acaso el positivismo jurídico carece de una crítica hacia el derecho vigente?

El positivismo jurídico, al sostener una distinción entre el derecho vigente y el derecho correcto, o, entre lo que el derecho es y lo que debe ser, permite la crítica al contenido y praxis del derecho. Es decir, la idea de una moral crítica es compatible con el positivismo jurídico, porque esta brecha entre el derecho vigente y el derecho correcto permite transformar a las normas y sistemas jurídicos. En este sentido Hart ha hecho una defensa de la perspectiva crítica hacia el derecho mediante la tesis de la separación, según la cual ésta es la que nos permite hacer frente al abuso de poder legalmente válido. ${ }^{410}$ Tanto Hart como Kelsen y Ross conciben al positivismo como una doctrina neutral respecto al contenido del derecho y con ello es posible criticarlo, ya que esta postura mantiene la brecha entre lo que el derecho es y lo que debe ser. Esto puede no pasar con los creyentes de doctrinas políticas o religiosas. Pensemos en el caso de un fanático religioso, para quien la expresión "derecho injusto" podría ser impensable, ya que si para él las leyes provienen

\footnotetext{
${ }^{409}$ Cfr., Hart, H. L. A. Law, Liberty and Morality, Cambridge, Oxford University Press, 1963, p. 50.

410 "En tanto que los seres humanos puedan ganar suficiente cooperación de algunos otros para que puedan dominar a los demás, ellos van a utilizar a las formas del derecho como uno de sus instrumentos. Los hombres malvados promulgarán normas perversas que otros cumplirán. Lo que sin duda es más que necesario con el fin de hacer que los hombres lúcidos enfrenten el abuso del poder oficial, es preservar el sentido de que la certificación de algo como legalmente válido no es concluyente sobre la cuestión de la obediencia, y que, por más grande que sea la aura de majestad o autoridad que el sistema oficial podría tener, sus demandas deben al final presentarse bajo el escrutinio moral. Este sentido, que hay algo que está fuera del sistema oficial haciendo referencia a lo que en última instancia el individuo tiene que resolver respecto al problema de la obediencia, seguramente es más probable que se mantenga vivo con quienes estamos acostumbrados a pensar que las normas jurídicas pueden ser injustas, que entre aquellos que piensan que no hay nada injusto en cualquier lugar que pueda tener el estatus de derecho". Hart, H. L. A., The Concept of Law, Nueva York, Oxford University Press, 1997, p. 210.
} 
de Dios, entonces éstas serán siempre perfectas. Un positivista puede estar de acuerdo en considerar a cierto orden como jurídico y al mismo tiempo entender que su deber moral más alto es el de derrocarlo.

7.2.4. Moral como interioridad del sujeto o moralidad. Esta idea de moral como conciencia del sujeto o moralidad está vinculada con la anterior concepción de la moral, si bien tienen características distintas. En esta concepción de moral qua interioridad del sujeto se trata de aquella idea según la cual la moral está vinculada con la capacidad del individuo de examinar y darse sus propias leyes para llevar a cabo una acción u omiión.

Estamos ante la clásica distinción entre legalidad, entendida como un ámbito externo, objeto del derecho, y moralidad, entendida como un ámbito interno, inaccesible para el derecho. El núcleo de esta concepción de la moral está desarrollada en la obra de dos filósofos clásicos de la moral, la política y el derecho: Kant y Hegel. Hablar de esta diferenciación normativa es hacerlo del paradigma de la subjetividad como principio fundamental de la modernidad. ${ }^{411}$ Es bien sabido que Kant sostenía la distinción entre los deberes externos y los deberes internos, propios del terreno de la moral, ${ }^{412}$ con el objetivo de que el individuo orientara sus acciones con base en el bienestar individual. El argumento de fondo de Kant está vinculado con la idea de autonomía de la conciencia del sujeto y de la imposición a sí mismo de normas morales, mientras que las normas jurídicas carecen de esta peculiaridad.

Las así llamadas leyes de la libertad deben distinguirse de las leyes naturales y morales. A menos que se dé sólo la mera acción exterior conforme a la legalidad, será llamada jurídica; si es exigido que las leyes deban ser auto-determinación de las causas de la acción, serán morales. Después se dice: el cumplimiento de las primeras será la legalidad, mientras que el cumplimiento de las segundas será la moralidad. ${ }^{413}$

La distinción kantiana y hegeliana entre legalidad y moralidad está basada en reconocer dos esferas de libertad relacionadas, pero distintas entre sí: la esfera del derecho

\footnotetext{
${ }^{411}$ También este principio puede describirse como filosofía de la subjetividad, el cual significa para la filosofía teórica y práctica la estructura fundamental característica de la modernidad y el cual debe estar asegurado para que el sujeto moral pueda orientar sus acciones autónomamente. Cfr., Schilling, Christof, Moralische Autonomie. Anthropologische und diskurstheoretische Grundstrukturen, Tubinga, Ferdinand Schöningh, 1996, p. 11.

${ }^{412}$ Kant, Immanuel, Rechtslehre. Schriften zur Rechtsphilosophie, Berlín, Akademie-Verlag, 1988, p. 24.

${ }^{413}$ Kant, Immanuel, Metaphysische Anfangsgründe der Rechtslehre. Metaphysik der Sitten. Erster Teil, Hamburgo, Felix Meiner Verlag, 2009, p. 18.
} 
y la esfera de la conciencia. Con esta diferenciación, el individuo posee un ámbito interno de libertad, mientras que al derecho sólo le importarán aquellas acciones que tengan relevancia jurídica. De acuerdo con esto criterios, mientras la moral es autónoma, el derecho es heterónomo; mientras la moral es unilateral, el derecho es bilateral; mientras la moral es interna, el derecho es externo; finalmente, mientras la moral es incoercible, el derecho es coercible. Esta distinción clásica de los diversos modos en que ambos órdenes nos obligan de diversas maneras es difícilmente sostenible. Existen muchos casos en los que las prohibiciones morales y jurídicas coinciden, como el mandato de no lastimar a otro, y otros en los que la moral puede tener una capacidad de coerción, siempre y cuando el tribunal de la conciencia del sujeto esté desarrollado. Sobre lo explicado anteriormente, pensemos, por ejemplo, en el caso de la conciencia de Raskolnikov, personaje de la obra Crimen y castigo de Dostoievski. También, al derecho sí le importan las intenciones y no sólo la exterioridad de las conductas, si esto no fuera así, en el ámbito del derecho penal no podrían distinguirse las acciones u omisiones dolosas de las culposas. Entonces, ¿dónde reside la diferencia entre derecho y moral en este ámbito?

La diferencia decisiva entre el derecho y la moral en este ámbito reside en la institucionalización de los derechos y deberes jurídicos. Esto tiene una explicación. Los deberes morales no requieren de una institucionalización porque pueden ser respetados o no respetados por los sujetos, mientras que lo jurídicos han sido positivizados porque requieren de un respaldo mayor. Del mismo modo, los deberes morales sí pueden ser coercibles, pero el castigo es difuso y sólo funcionan en sujetos con cierto desarrollo moral — como en el caso de la teoría de Kohlberg —, mientras que los castigos institucionalizados permiten crear condiciones estables de la sociedad, y pueden ser racionalizados en beneficio del sujeto que infringió el orden jurídico.

7.2.5. Moral como fundamento de la normatividad del derecho. Esta es la última concepción de moral, entendida como la fundamentación racional del derecho. ¿Acaso esta fundamentación es posible? ¿Es acaso objetiva o subjetiva? Según Hare, todos los filósofos morales del presente, con algunas excepciones honorables, parecen pensar que tienen que tomar una postura acerca de si el "objetivismo" o el "subjetivismo" es el estatus correcto de 
los juicios morales. ${ }^{414}$ La fundamentación de los juicios morales ha sido objeto de innumerables debates en el ámbito del derecho. Tanto la filosofía moral como la filosofía jurídica han lidiado con el problema de la fundamentación racional de las normas; por esta razón ambas filosofías tienen un terreno común que las ha acercado.

Según la ética del discurso, el seguimiento de las reglas y formas de la argumentación práctica y jurídica puede llevarnos a mostrar que ciertos contenidos del derecho son discursivamente imposibles y que, por lo tanto, no pueden incorporarse al derecho, rompiendo así con el paradigma kelseniano de la "neutralidad del contenido" del derecho. Estaríamos, con ello, ante la posibilidad de fundamentar un contenido mínimoracional de derecho, que podríamos designar con la adscripción de ética jurídica universal, en tanto busca institucionalizar un contenido moral aceptable por todas las personas de todas las culturas. Para ello, esta teoría buscará sostener la tesis de la conexión conceptual necesaria entre moral y derecho. La idea de que el derecho posee un contenido moral mínimo la encontramos en la obra de Lon Fuller, La moralidad del derecho.

En esta obra Fuller intentó hacer explícitos los contenidos morales internos que todo sistema jurídico debe poseer para ser tal y así enumeró ocho características morales internas que debe tener todo sistema jurídico, a las cuales llamó moralidad interna del derecho. ${ }^{415}$ Estas características son las siguientes:

1. Generalidad de las leyes

2. Promulgación de las leyes

3. Irretroactividad de las leyes

4. Claridad de las leyes

5. No contradicción de las leyes

6. Leyes que no requieran lo imposible

7. Constancia de las leyes a través del tiempo

8. Congruencia entre la acción oficial y la regla declarada ${ }^{416}$

Las hipotéticamente frustrantes experiencias por las cuáles pasó el rey Rex son las que llevaron a Fuller a proponer estos requisitos morales. Esta pretensión será retomada por Alexy para hacerle frente al reto del positivismo jurídico; para ello, sostendrá una conexión conceptualmente necesaria entre moral y derecho. Esta conexión estará referida

\footnotetext{
${ }^{414}$ Cfr., Hare, Richard, Moral Thinking. Its Levels, Method and Point, Oxford, Clarendon Press, 1988, p. 206. Respecto a este dilema Franz von Kutschera ha hablado en términos de "subjetivismo" y "realismo". Al respecto, cfr. Von Kutschera, Franz, Wert und Wirklichkeit, Paderborn, Mentis, 2010, p. 49 ss.

${ }^{415}$ Fuller, Lon, The Morality of Law, New Haven, Yale University Press, 1964, p, 46.

${ }^{416}$ Fuller, Lon, op. cit., pp. 46-91.
} 
a la pretensión de corrección y la segunda a la institucionalización de un contenido correcto del derecho. Esta conexión entre moral y derecho dará lugar a la tesis de la naturaleza doble. Antes de reconstruir la comprensión del derecho de Alexy, haremos una síntesis en torno a un posible programa de mediación entre moral y derecho.

\subsection{Las relaciones conceptuales y necesarias entre derecho y moral}

Las relaciones entre moral y derecho pueden ser muy distintas, dependiendo de la comprensión que tengamos acerca del concepto de moral. Con frecuencia, pensamos que el concepto de derecho podría comprenderse al vincularse con el concepto de moral; no obstante, el concepto de moral también está cargado de diferentes significados que dificultan el establecimiento de un solo tipo de relaciones entre derecho y moral. El tipo de relaciones entre derecho y moral también suele cambiar dependiendo del tipo de argumentos vinculatorios que establezcamos entre derecho y moral, por lo que ahora analizaremos los criterios de vinculación establecidos por Alexy. En resumen, las cinco distinciones básicas entre derecho moral fueron las siguientes:

a) Moral como exigencia de justicia

b) Moral como moral positiva

c) Moral como moral crítica

d) Moral como interioridad del sujeto o moralidad

e) Moral como fundamento ético del derecho

Estos cinco tipos de relación entre derecho y moral apuntan a muy variados argumentos acerca de si existe o no una conexión necesaria entre derecho y moral, o, mejor dicho, estos cinco tipos de vinculación nos permiten aclarar en qué sentido la teoría de Alexy sugiere una vinculación entre derecho y moral, y si esta es posible. A nuestro parecer, el positivismo jurídico en algunas de sus variantes ha acertado al sostener la separación del derecho de la moral en los puntos "b" y "d", y también comparte con las posturas no positivistas el punto "c", mientras que las posturas "a" y "e" escapan de sus fines.

Frente a esta descripción de la postura positivista y de sus compromisos conceptuales y normativos asumidos respecto a la vinculación entre derecho y moral, podemos concluir que la propuesta alexyana coincidiría en aceptar los argumentos de las posturas "b" y "d", esto es, en separar al derecho de las normas sociales y religiosas, y en 
separar a la legalidad del derecho de la moralidad de la autonomía individual. También, el positivismo jurídico y el pensamiento alexyano coincidirían en mantener una concepción crítica del derecho, esto es, en sostener una moral crítica frente a los mandatos del sistema jurídico. Hasta aquí parece que la separación del derecho de la moral es válida en términos conceptuales y normativos. Pero ahora es conveniente preguntarnos en dónde surgen las posturas en conflicto respecto al debate entre derecho y moral.

Los puntos en los que el positivismo jurídico, en sus variantes incluyentes y excluyentes, y el no-positivismo incluyente de Alexy tomarán posturas contrarias serán en los puntos "a" y "e", es decir, en los puntos vinculados respecto a la relación necesaria entre derecho y la pretensión de justicia y en la fundamentación racional de un contenido moral del derecho. Veamos esto con mayor atención. Mediante la ética del discurso Alexy buscará mostrar que la vinculación necesaria del derecho a la pretensión de corrección es posible en términos racionales. Gustav Radbruch también compartía esta pretensión. En diversos pasajes de su obra encontramos la vinculación de la idea del derecho a valores culturales, los cuales delimitaban la concepción de éste:

El concepto de derecho es un concepto cultural, es decir, un concepto de una realidad basada en valores, una realidad que tiene el sentido de servir a un grupo de valores. El derecho es la realidad que tiene el sentido de adecuarse a los valores para servir a la idea de derecho. El concepto de derecho está vinculado a la idea de derecho. [...] El derecho es la realidad que tiene por finalidad servir a la justicia. ${ }^{417}$

Para Alexy, al igual que lo fue en su momento para Radbruch, vincular al derecho a un contenido correcto es posible en términos racionales. Esta racionalidad proviene de la fundamentación moral del derecho, tanto al nivel de normas individuales como al nivel del sistema jurídico como totalidad. El punto en conflicto con los positivistas no residirá solamente en los argumentos sustanciales acerca de la posibilidad de esta fundamentación, sino en el uso del concepto de moral o, en otras ocasiones, el concepto de ética. ${ }^{418}$ Por

\footnotetext{
${ }^{417}$ Radbruch, Gustav, Rechtsphilosophie, Heidelberg, UTB, 2003, p. 34-37.

418 Si bien podría usarse el concepto de "ética" para referirnos a la relación del derecho con una reflexión racional, también este concepto no está libre de imprecisiones conceptuales. Si quisiéramos refinar los criterios para comprender el concepto de ética y sus correspondientes teorías, podríamos recurrir a las distinciones básicas desarrolladas por Kutschera, quien distingue entre teorías éticas descriptivas y prescriptivas, normativas y metaéticas, cognitivistas y no cognitivistas, naturalistas y no naturalistas, subjetivistas y objetivistas, teleológicas, deontológicas e intencionalistas, monistas y pluralistas. Al respecto, cfr., Kutschera, Franz, Grundlagen der Ethik, Berlín, Walter de Gruyter, 1982, p. 39-86.
} 
ello es necesario aclarar el sentido que alexy le da al concepto de moral, para así comprender la relación que establecerá entre derecho y moral

De esta manera, Alexy sostendrá una relación conceptual necesaria entre derecho y moral. ¿Cómo emprende Alexy esta pretensión de mediar entre los aciertos de las tesis del positivismo jurídico con un punto de vista moral? Primeramente, Alexy sostendrá que él no busca borrar los límites entre la legalidad y la moralidad, sino entre el derecho vigente y el derecho correcto, y la forma de hacerlo será a partir de una serie de conexiones entre derecho y moral que el positivismo jurídico en todas sus variantes no podría sostener. Después, Alexy presentará una reconfiguración del punto del vista interno para indicarnos en qué puntos el positivismo jurídico falla. A continuación, presentaremos esta postura.

Alexy considerará que existen relaciones conceptuales y necesarias entre derecho y moral. Un marco conceptual normativo da origen a cinco relaciones que hacen explícita la relación del derecho con la moral, en términos conceptuales y necesarios. ${ }^{419}$ Estas cinco relaciones son las siguientes:

a) Conceptos de derecho libres de validez y conceptos de derecho no libres de validez: no libre de validez es un concepto de derecho que incluye la validez y libre de validez es aquel concepto de derecho que excluye la validez. La razón de esta distinción es explicada del siguiente modo: alguien puede decir que la norma $N$ tiene vigencia jurídica, pero que no es valida moralmente. No obstante, la incorporación de la idea de validez en el concepto de derecho significa incluir en éste "el contexto institucional de la promulgación, aplicación e imposición del derecho". ${ }^{420}$ Este contexto no es de menor importancia para establecer una conexión entre derecho y moral.

b) Sistemas jurídicos como sistemas de normas y sistemas de procedimientos: cuando se entiende el sistema jurídico como sistema de procedimientos se trata de la comprensión del sistema como un conjunto de acciones basadas y guiadas por reglas, mediante las cuales las normas son fundamentadas, promulgadas, interpretadas, aplicadas e impuestas.

\footnotetext{
${ }^{419}$ En este punto Alexy hace hincapié en distinguir entre necesidad conceptual y necesidad normativa. Según Alexy, "[L]a necesidad normativa debe diferenciarse estrictamente de la necesidad conceptual. Que algo sea normativamente necesario, no significa otra cosa que está ordenado. Pero la validez de un mandato puede negarse sin llevar a cabo una contradicción; esto no puede llevarse a cabo cuando se trata de una necesidad conceptual. Por ello es explicable que la necesidad normativa sólo es una necesidad en sentido amplio" (Alexy, Robert, CVD, p. 42).

${ }^{420}$ Alexy, op. cit., p. 46.
} 
Esta perspectiva estará vinculada a una postura interna. Cuando se entiende el sistema jurídico como sistema de normas se trata de la comprensión del sistema como un conjunto de resultados o producto de procedimientos de creación de normas, sin importar sus características. Esta perspectiva estará vinculada a una postura externa. La diferencia de posturas será de relevancia normativa para comprender las relaciones entre moral y derecho.

c) La perspectiva del observador y del participante: por ahora, esta perspectiva será explicada de manera sucinta. La perspectiva del participante será adoptada por quien en un sistema jurídico participa acerca de lo que en este sistema jurídico está ordenado, prohibido o permitido. En el centro de esta perspectiva está el juez u otras personas que expongan argumentos en pro o en contra de determinados contenidos del sistema jurídico. La perspectiva del observador será adoptada por quien en un determinado sistema jurídico no pregunta cuál es la decisión correcta en éste, sino cómo se decide de hecho en este determinado sistema jurídico. Por ahora es suficiente esta descripción ya que los detalles de esta perspectiva serán explicados en el siguiente capítulo.

d) Conexiones clasificantes y conexiones cualificantes: La conexión clasificante será aquella en la cual las normas o los sistemas de normas que no satisfagan un punto de vista moral no serán consideradas, por razones conceptuales o normativas, normas jurídicas o sistemas jurídicos. La conexión cualificante será aquella en la cual las normas o los sistemas de normas que no satisfagan un punto de vista moral serán normas jurídicas deficientes o sistemas jurídicos deficientes. Para Alexy será de gran importancia indicar que según esta conexión la deficiencia será jurídica y no solamente una deficiencia moral. Esta conexión tendrá la función de indicar que los sistemas jurídicos incluyen una dimensión ideal del derecho que consiste en una pretensión de corrección, la cual será analizada posteriormente.

e) Combinaciones entre las conexiones: a estas combinaciones puede sumarse la distinción entre contextos conceptualmente necesarios y contextos normativamente necesarios. Alexy muestra que las conexiones entre derecho y moral pueden ser muy variadas, y si deseamos combinarlas, podríamos tener treinta y dos combinaciones posibles; si entre estas relaciones es posible la tesis de que en todas ellas puede darse una relación necesaria y otra no necesaria, entonces tendríamos sesenta y cuatro tesis. Según 
Alexy, muchas confusiones y malentendidos entre derecho y moral provienen de la gran cantidad de conexiones posibles entre estos ámbitos:

Una explicación de la esterilidad de esta polémica es probablemente el hecho de que, a menudo, sus participantes no reconocen que la tesis que ellos defienden es de un tipo totalmente distinto al de las tesis que atacan, es decir, que mantienen diálogos paralelos. Esta explicación se vuelve más plausible aún si se considera que, además de las cinco distinciones que aquí han sido consideradas, son concebibles otras de tal modo que el número de las tesis posibles puede ser mucho mayor que sesenta y cuatro. 421

Sin embargo, Alexy dará un giro a esta clasificación. Ante la enorme pluralidad de significados posibles se basará en dos aspectos: el primero consistirá en incluir en el concepto de derecho la validez, y el segundo en ver al derecho desde la perspectiva del observador y del participante. Las otras distinciones permanecerán vigentes, pero subordinadas a estos dos aspectos. Lo importante para Alexy será mostrar la naturaleza doble del derecho, expresada en un concepto de derecho que incluya la validez mediante el desarrollo de la perspectiva de los participantes del sistema jurídico. En el siguiente capítulo será reconstruida la comprensión alexyana del derecho desde la perspectiva del participante.

${ }^{421}$ Alexy, Robert, op. cit., p. 51. 


\section{Capítulo Octavo. Observadores y participantes. La naturaleza del derecho según Alexy}

\section{Introducción}

Si la filosofía del derecho de Alexy aspira a una pretensión de sistematicidad filosófica, entonces debe responder a la pregunta básica de la filosofía jurídica, la quid iuris. Esta pregunta, contestada de modos tan diversos, no puede escapar de las reflexiones de Alexy acerca de la comprensión del derecho en la modernidad. Con cierta frecuencia la búsqueda de un concepto normativo de derecho implica reconocer un dualismo. Esta es la tesis de la doble naturaleza del derecho.

La doble naturaleza del derecho está vinculada con las dos dimensiones en las que buscamos aprehender al derecho: la dimensión del derecho vigente y la dimensión del derecho correcto, o, dicho en términos más comunes, entre lo que el derecho es y lo que debe ser. En muchas ocasiones, para mediar entre ambas posturas muchos filósofos del derecho han recurrido a vincular al derecho con la moral para descubrir la naturaleza del derecho.

No obstante, la vinculación entre el derecho y la moral no resuelve este problema porque a veces se da por supuesto un concepto unívoco de moral, lo cual complica todavía más el debate. Esto es, el concepto de "moral" está cargado de imprecisiones que impiden el esclarecimiento racional de lo que es derecho. De este modo, la vinculación del concepto de derecho al concepto de moral ha terminado por aumentar la confusión. Al tener en consideración este malentendido conceptual, presentamos cinco significados del concepto de moral usados en las variadas tradiciones de la filosofía jurídica, con el propósito de esclarecer el punto de vista de Alexy.

Los resultados anteriores nos permitieron deslindar a Alexy de algunas conexiones que no sostiene y enfatizar en las que sí sostiene. Nos parece que Alexy, después de mostrarnos algunas conexiones entre derecho y moral, reduce los diversos criterios de conexión a dos aspectos esenciales: la formulación de un concepto que incluye la validez y la comprensión del derecho desde el punto de vista del participante. De esta manera, se abren las puertas hacia una comprensión no positivista del derecho y, con ello, toda una 
serie de réplicas a la obra de Alexy. Veamos en qué consisten estas dos maneras de comprender al derecho.

\subsection{La perspectiva del observador y la del participante}

Estamos frente a un punto fundamental de la obra de Alexy en tanto buscará retomar un concepto clave de la obra de Hart para sostener que existe un punto de vista que goza de una comprensión prioritaria en comparación con las posturas positivistas. Este punto de vista ha sido objeto de polémica con filósofos pertenecientes a la corriente del positivismo jurídico. Si en las secciones pasadas la argumentación jurídica y la ponderación fueron objeto de encendidas objeciones en sus ámbitos respectivos, el argumento de la concepción no-positivista del derecho también será objeto de réplicas a Alexy. A continuación expondremos ambas perspectivas.

\subsubsection{La perspectiva del observador}

Como ya vimos antes, Alexy dio una definición acerca de qué se quiere decir cuando hablamos de la perspectiva del observador. La perspectiva del observador será adoptada por todo aquel que en un sistema jurídico no pregunta cuál es la decisión correcta en éste, sino cómo se decide realmente. Según Alexy, esta es la perspectiva adoptada por todos aquellos que se adhieren a las tesis del positivismo jurídico y a sus consecuencias teóricas. Esta perspectiva supuestamente posee el problema de no comprender la conexión clasificante entre derecho y moral, pero, ¿en qué consiste esta conexión clasificante?

La clasificación entre derecho y moral, tal y como fue reconstruida antes, es un problema complejo debido a los múltiples usos del concepto de moral. No obstante, después de la aclaración conceptual que llevamos a cabo, es posible indicar que el desacuerdo entre el positivismo jurídico y la postura de Alexy consiste en las posturas "a" y "e", es decir, en negar la vinculación del derecho a una pretensión de justicia y a una pretensión de incluir un contenido del derecho correcto en términos intersubjetivos. Es por ello que, para los positivistas, el hecho de que una norma o sistema jurídico no tenga la pretensión de ser justa o que no tenga un contenido correcto no le quita la calidad jurídica, pues el mérito o demérito moral no tiene nada que ver con la valdiez jurídica-institucional. Frente a este pensamiento positivista el cuestionamiento de Alexy será el siguiente: 
Se desea saber si una violación de algún criterio moral resta a las normas de un sistema normativo el carácter de normas jurídicas o a todo el sistema normativo el carácter de sistema jurídico. Quien desee dar una respuesta afirmativa a esta pregunta tiene que mostrar que el carácter jurídico de las normas o de los sistemas normativos se pierde si se traspasa un determinado umbral de injusticia, cualquiera que sea la forma como se defina, será llamado el «argumento de la injusticia».422

Es interesante ver que, en este momento, ha aparecido un argumento que será central en contra del positivismo jurídico. A partir de ahora, Alexy buscará mostrar la imposibilidad de plantear esta conexión clasificante desde la perspectiva del observador, en sus dos vertientes: desde el punto de vista de normas aisladas y desde el punto de vista de los sistemas jurídicos. Veamos en qué consisten ambas posturas

Normas aisladas: en el caso de normas aisladas el argumento para sostener una conexión clasificante lo tenemos en la famosa "Fórmula de Radbruch", la cual, tout court, sostiene que una ley extremadamente injusta no es derecho. Este argumento, según Alexy, no es posible desde la perspectiva del observador, ya que éste sólo puede describir el sistema jurídico, sin hacer juicios de valoración. Es por ello que cuando un sujeto, después de analizar la legalidad o efectividad de una norma aislada, se pregunta si es realmente derecho la norma previamente analizada, deja la perspectiva del observador y asume la del participante. Alexy parece decirnos que la perspectiva del participante implica una postura crítica-reflexiva hacia las normas aisladas que va más allá de su mera observación imparcial.

Sistemas jurídicos: lo que vale para una norma aislada no tiene por qué valer respecto al sistema jurídico como totalidad. La exigencia moral de que normas jurídicas aisladas extremadamente injustas dejen de valer como derecho ahora será aplicada a los sistemas jurídicos como un todo desde la perspectiva del observador. Esta exigencia estará dividida en dos partes, una formal y otra material. La exigencia moral formal la ejemplificará Alexy con la teoría de la moral interna del derecho de Fuller, mientras que la exigencia moral material la ejemplificará con algunos postulados morales de la obra Justicia política de Höffe. Estas exigencias tendrán como objetivo saber si es posible decir que los sistemas jurídicos que no cumplen con éstas pueden ser, desde la perspectiva del observador, sistemas jurídicos.

${ }^{422}$ Alexy, Robert, CVD, p. 34. 
Alexy pondrá dos ejemplos de este tipo de ordenamientos jurídicos: el de un orden absurdo y el de un orden depredatorio. El orden absurdo será aquel en el cual una sociedad será gobernada de modo tal que no se conozcan fines consistentes del o los gobernantes, ni tampoco los gobernados puedan perseguir duraderamente sus fines. El orden depredatorio será aquel en el cual el o los gobernantes se transforman en bandidos organizados y, para ello, establecen normas que prohíben la violencia entre éstos y una jerarquización de los mandos. ¿Estos criterios son suficientes para sostener que estos órdenes no pueden ser, conceptualmente, jurídicos? Para sostener esta afirmación, Alexy hablará de un tercer ordenamiento, el cual mostrará la deficiencia de los dos anteriores.

La existencia de un orden depredatorio no es posible a largo plazo. La idea de que los gobernantes de un orden jurídico apelen a la violencia desnuda y al deseo de hacer el mal por el mal mismo como fundamento único de su autoridad es algo que sólo sucede en las series de ficción. Inclusive los gobernantes más crueles se preocupan por su propia legitimación ante los demás. Un sistema jurídico no puede estar basado en la violencia pura como fundamento místico de la autoridad, sino que los gobernantes apelarán a que su orden violento es, al menos para ellos, justo. La dominación y explotación puede seguir, pero jamás la presentarían ante sus súbditos como una dominación injusta y perversa. Además, este orden, por más injusto que sea, si desea mantenerse a largo plazo debe estructurarse mediante reglas generales. De esta manera Alexy indica:

El punto decisivo es más bien que en la praxis del sistema de dominación está enraizada una pretensión de corrección que se hará valer frente a cualquiera. La pretensión de corrección es un elemento necesario del concepto de derecho. [...] Todo sistema jurídico formula una pretensión de corrección. [...] Efectivamente, los sistemas normativos existentes formulan regularmente una pretensión de corrección, por menos justificada que ella esté. [...] Esta pretensión se desplaza del límite al centro cuando se trata de la perspectiva del participante. [...] Por lo tanto, la pretensión de corrección presenta un nexo entre ambas perspectivas. ${ }^{423}$

A diferencia de las normas jurídicas aisladas, la pretensión de corrección es un elemento necesario de los sistemas jurídicos como totalidad, independientemente de si esta pretensión es satisfecha de hecho. Esta pretensión está basada en un tipo de argumento moral, el cual no es desarrollado todavía. No obstante, los límites de la perspectiva del observador han aparecido y ahora se hará el tránsito hacia la perspectiva desde la cual es posible tal pretensión de corrección.

${ }^{423}$ Alexy, Robert, CVD, pp. 40-41. 


\subsubsection{La perspectiva del participante}

El punto de partida de Alexy ha cambiado ahora. En el caso extremo de que existiera un sistema normativo constituido por meras órdenes desnudas de poder, la perspectiva del observador no podría mantenerse en pie. Debido a esta limitación, es necesario pasar a la perspectiva del participante, cuya figura clásica es la perspectiva del juez. Esta perspectiva estará compuesta de tres argumentos conectados entre sí, los cuales tienen la función de hacer explícita la normatividad implícita del derecho.

Para Alexy la perspectiva del participante tiene como fundamento 1. la pretensión de corrección, dentro de la cual dependen los argumentos de 2. la injusticia y de 3. los principios, los cuales formarán el núcleo crítico respecto al positivismo jurídico. Antes de pasar a analizar los tres argumentos que conforman esta perspectiva, consideramos necesario saber cuál es el antecedente de ésta, ya que sólo así sabremos por qué es tan importante esta perspectiva para la comprensión normativa del derecho.

Pocos temas de la filosofía jurídica hartiana han provocado tanta polémica como la famosa diferenciación entre el punto de vista interno y el punto de vista externo. Buena parte de los filósofos del derecho de la tradición angloamericana han dedicado capítulos de libros únicamente a la elucidación de estas dos formas de comprender al derecho. Hay tantas interpretaciones existentes sobre ambos puntos de vista, que cada vez es más difícil saber qué quiso decir Hart mismo.

Una de las cualidades de la obra de Hart es la claridad con la cual elaboró conceptos fundamentales de su pensamiento jurídico. Sin embargo, tal y como lo indicaba el mismo Hart, los conceptos suelen poseer una característica que éste le atribuía con especial énfasis al lenguaje jurídico: la textura abierta. Ahora bien, esta textura abierta es aplicable al caso de un concepto que Hart utilizó para hacer una distinción fundamental entre tener el deber de realizar cierta acción y tener la obligación de realizar cierta acción. ${ }^{424}$ Este concepto es el del punto de vista interno, del cual, según Hart, parece depender la diferenciación del derecho de otro tipo de reglas sociales y hábitos de comportamiento sedimentados en la conciencia de los sujetos. Con esta idea Hart busca introducir la idea de dos puntos de vista distintos para explicar por qué un sujeto acepta como válidas ciertas reglas institucionalizadas en calidad de miembro y no como un mero observador.

\footnotetext{
${ }^{424}$ Hart, H. L. A., The Concept of Law, Nueva York, Oxford University Press, 1994, p. 86.
} 
Precisamente, será la perspectiva interna la que le permitirá a Hart mostrar que la aceptación de las obligaciones jurídicas va más allá de la coerción jurídica externa. No obstante, ambas posturas coexistirán en todas las sociedades, tal y como lo indica Hart:

Es probable que la vida de cualquier sociedad que se guía por reglas jurídicas, jurídicas o no, consiste, en cualquier momento dado, en una tensión entre quienes, por una parte, aceptan las reglas y voluntariamente cooperan en su mantenimiento, y ven por ello su conducta, y la de otras personas, en términos de las reglas, y quienes, por otra parte, rechazan las reglas y las consideran únicamente desde el punto de vista externo, como signos de un probable castigo. Una de las dificultades que enfrenta cualquier teoría jurídica ansiosa de hacer justicia a la complejidad de los hechos, es tener en cuenta la presencia de ambos puntos de vista y no decretar, por vía de definición, que uno de ellos no existe. ${ }^{425}$

El punto de vista interno, que permite asociar la aceptación de la normatividad del derecho sin apelar únicamente al castigo, será el concepto del que arrancará la reflexión de Hart para hacer explícita entre los hábitos y las reglas, a partir de la dimensión interna que poseen las normas jurídicas. Según Gaido, para Hart sólo es explicable la idea de regla si, junto al comportamiento visiblemente repetido - aspecto externo de la regla-, se da cuenta de la actitud de ciertos participantes de la práctica, caracterizada por el hecho de que ven en ella una guía para la propia conducta y un fundamento para la crítica de todo transgresor —aspecto interno de la regla-. ${ }^{426}$ En un primer momento Hart indica que las reglas y los hábitos se caracterizan por la convergencia de los comportamientos sociales en un grupo social determinado, pero después nota que esto no sirve para explicar la differentia specifica entre reglas y hábitos.

Esta diferencia específica reside en el aspecto interno, el cual posee un carácter cognitivo reflejado en la actitud crítico-reflexiva acerca de las razones del sujeto para llevar a cabo cierta acción u omisión. El cumplimiento de este punto de vista interno está respaldado por la pertenencia del sujeto a un grupo social. En otras palabras, será el sentido de pertenencia a un sistema normativo y no la observación imparcial del funcionamiento de éste lo que marcará el interés de Hart. MacCormick ha sintetizado esta distinción, si bien admite una diferenciación más profunda en el punto de vista interno, la concerniente a la perspectiva cognitiva y la volitiva:

Para resumir este punto: hay una distinción genuina tal y como es señalada por Hart entre los puntos de vista "externo" e "interno" en relación con la actividad humana.

\footnotetext{
425 Hart, H. L. A., op. cit., pp. 90-91.

${ }^{426}$ Gaido, Paula, Las pretensiones normativas del derecho. Un análisis de las concepciones de Robert Alexy y Joseph Raz, Madrid, Marcial Pons, 2011, p. 85.
} 
Pero el punto de vista "interno" caracterizado por Hart contiene componentes esencialmente distinguibles, que deberían ser distinguidos. Hay un punto de vista "cognitivamente interno" desde el cual la conducta es apreciada y entendida en términos de los estándares que están siendo utilizados por el agente como guía las normas, esto es suficiente para la comprensión de las normas. Pero es parasitaria respecto a esta porque presupone el punto de vista "volitivamente interno": el punto de vista de un agente, quien en cierto modo y por razones que parecen buenas para él tiene un compromiso volitivo con el cumplimiento de un determinado patrón de comportamiento como un estándar para sí mismo o para otras personas o para ambos su actitud es incluido, pero no está incluido por la actitud "cognitivamente interna". ${ }^{427}$

Aunque Alexy ha señalado que, a pesar de existir similitudes, estas perspectivas y puntos de vista no son idénticos al poseer algunas ambigüedades la postura de Hart, ${ }^{428}$ esta contribución constituye un punto de arranque para la diferenciación entre ambas perspectivas. ¿Pero constituye este punto de vista el acceso más acabado para acceder a la naturaleza del derecho? A continuación, sostendremos que este punto de vista, si bien poseía un desarrollo mucho más precario, no le era del todo ajeno a posturas anteriores al positivismo jurídico de Hart. Para sostener esta pretensión nos basaremos en la postura de Ross.

Según Brian Leiter, Hart introdujo este punto de vista porque filósofos escandinavos como Ross no tenían modo de distinguir entre dos tipos de conducta de masas. Por ejemplo, el caso en el que todos "irreflexivamente" hacen la misma cosa, a diferencia del caso en el cual todos hacen la misma cosa porque sienten que tienen la obligación de hacerlo. Hart notó que el segundo sentido era el distintivo de un sistema jurídico: los oficiales no son como una horda de animales estampándose, como suele suceder, en la misma dirección: ellos "van" en la misma dirección (por ejemplo, aplicando el mismo criterio de vigencia jurídica) porque ellos creen que tienen que hacerlo. Para los escandinavos no había distinción entre ambos casos: todo lo que contaba era lo que hacían los oficiales, ya sea si esta era la consecuencia de una estampida irreflexiva o si era percibida como una acción obligatoria. Esto probó ser, según Leiter, un error fatal en la concepción realista escandinava del derecho. ${ }^{429}$

\footnotetext{
${ }^{427}$ MacCormick, Neil, Legal Reasoning and Legal Theory, Cambridge, Oxford University Press, 1994, p. 292.

${ }^{428}$ Alexy, Robert, CVD, p. 32.

${ }^{429}$ Cfr., Leiter, Brian, Naturalizing Jurisprudence. Essays on American Legal Realism and Naturalism in Legal Philosophy, Nueva York, Oxford University Press, 2007, p. 191
} 
Si entendemos bien a Leiter, Hart introduce esta perspectiva al ver las deficiencias del realismo escandinavo, el cual no distinguía entre acciones reflexivas, imputables a un sujeto consciente, y acciones irreflexivas, motivadas por causas no vinculadas a un proceso cognitivo del sujeto. El aspecto de la reflexión era lo que realmente distinguía al derecho de otro tipo de hábitos sociales. No obstante, Ross sí entendía que el derecho posee una dimensión reflexiva que se devela en la coparticipación en el sistema jurídico.

Ross, al igual que otros filósofos del derecho, compara al sistema jurídico con los juegos, especialmente con el de ajedrez, en cuanto esta metáfora advierte el uso de reglas constitutivas y regulativas. Ross usó esta metáfora para llevar a cabo un análisis del concepto de "derecho vigente" y buscar la comprensión del derecho desde la perspectiva de la coparticipación necesaria. Para ello, Ross nos pide que imaginemos que dos personas juegan ajedrez mientras una tercera las observa. Si la persona no sabe nada de ajedrez no entenderá qué es lo que sucede, pero si sabe algo de juegos, sabrá que se trata de un tipo de juego. Si el sujeto sabe las reglas, entenderá por qué un caballo se mueve de manera diferente a la de un peón, y éste de la de una torre. Puede notarse que estamos ante acciones reflexivas de los sujetos, pero, ¿cómo es que obtienen sentido para éstos?

Cabe señalar que el "entendimiento" que estamos pensando aquí es de un tipo no causal. No estamos operando aquí con las leyes de la causalidad. Los movimientos no están en ninguna relación de causalidad mutua. La conexión entre ellos se establece por la forma de las reglas y la teoría del ajedrez. La conexión es de significado. Además, se puede afirmar que la coparticipación es un factor esencial en una partida de ajedrez. Con esto quiero decir que los objetivos e intereses perseguidos y las acciones condicionadas por éstas sólo pueden ser concebidos como un eslabón en un todo maás grande que incluye las acciones de otra persona. [...] La coparticipación se da también en el carácter intersubjetivo de las reglas del ajedrez. Es esencial que (a las reglas) se les dé la misma interpretación, al menos por los dos jugadores en un juego determinado. De lo contrario, no habría ningún juego, y los movimientos separados se mantendrían aislados, sin significado coherente. Ahora, todo esto demuestra que el juego de ajedrez puede ser tomado como un modelo simple de lo que llamamos un fenómeno social. ${ }^{430}$

De acuerdo con Ross, la participación del sujeto es una clave para tener acceso a la comprensión del juego de ajedrez y, en este caso, del derecho. De otro modo, el juego y el derecho no serían posibles. Estas razones nos permiten sostener que el punto de vista del participante, a diferencia de lo que sostiene Leiter, sí era comprensible para Ross, si

${ }^{430}$ Ross, Alf, On Law and Justice, Nueva York, New Haven Press, 1958, p. 13. 
bien no lo elaboró con el grado de sofisticación de Hart. ${ }^{431}$ Este punto de vista interno o del copartícipe será desarrollado por Alexy mediante tres argumentos que serán la base de su concepción no-positivista del derecho.

\subsubsection{El argumento de la corrección: lo que el derecho pretende}

Tal y como fue señalado previamente, con el paso de los años este argumento ha provocado muy variadas objeciones a Alexy. Este argumento, base para los otros dos, sostiene, grosso modo, que "tanto las normas y las decisiones judiciales individualizadas, así como los sistemas jurídicos como totalidad erigen necesariamente una pretensión de corrección. Los sistemas normativos que no formulan explícita o implícitamente esta pretensión no son sistemas jurídicos". ${ }^{432}$ Ahora bien, saber en qué consiste esta pretensión no es algo sencillo, pues las interpretaciones han variado según los diversos enfoques con los que esta pretensión ha sido estudiada.

Efectivamente, saber a lo que aspira o pretende el derecho se devela como un problema conceptual y normativo. ¿Qué significa tener una pretensión de corrección?, ${ }^{433}$ ¿qué implica que el derecho erija una pretensión de corrección?, ${ }^{434}$ ¿qué es a lo que aspira o pretende el derecho y cómo aspira a conseguir realizarlo?, ${ }^{435}$ ¿ésta es una cuestión

\footnotetext{
431 "Pero para Ross y sus aliados, el naturalismo se entiendía a través de la lente del positivismo lógico, por lo que la ontología, la epistemología, y la semántica de los escandinavos estaba circunscrita en gran parte por las visiones fisicalistas y conductistas que, como las del propio Quine, ahora parecen pobremente motivadas. Hart demolió el programa de investigación escandinavo de derecho medio siglo atrás, y no hay razón para pensar que Hart se equivocó fundamentalmente. Las normas y el "punto de vista interno" son características ineludibles de la estructura causal del mundo social" (Leiter, Brian, Naturalizing Jurisprudence. Essays on American Legal Realism and Naturalism in Legal Philosophy, Nueva York, Oxford University Press, 2007, p. 4). El mismo Leiter sugiere en una nota a pie que, según Brian Berry, la caracterización de Hart puede ser injusta, pero deja injustamente esa cuestión de lado.

432 Alexy, Robert, CVD, p. 41.

${ }^{433}$ La respuesta a esta interrogante escapa del ámbito de la filosofía jurídica y se inserta en el ámbito de la ética del discurso, en las vertientes respectivas de Habermas y Apel, las cuales han estado enfocadas en demostrar las diversas pretensiones de validez inherentes a los actos de habla.

${ }^{434}$ Cfr., Cooke, Maeve, "Law's Claim to Correctness", en, Pavlakos, George (Ed.), Law, Rights and Discourse. The Legal Philosophy of Robert Alexy, Portland, Oxford University Press, 2007, pp. 225-248.

435 Cfr., Gardner, John, "How Law Claims, What Law Claims", en, Klatt, Matthias (Ed.), Institutionalized Reason. The Jurisprudence of Robert Alexy, Nueva York, Oxford University Press, 2012, 29-44.
} 
empírica?, ${ }^{436}$ ¿ésta se refiere a una aplicación del llamado razonamiento práctico?, ${ }^{437}$ ¿0 acaso estamos ante una analogía incorrecta, en tanto el derecho no puede llevar a cabo pretensiones de ningún tipo? ${ }^{438}$ La respuesta a estas preguntas implicaría una revisión integral del argumento de la corrección y de los presupuestos morales de la filosofía jurídica de Alexy, en cuanto es posible rastrear esta pretensión en múltiples partes de la obra alexyana. No obstante, es desde la perspectiva del participante donde puede aclararse la idea de esta pretensión normativa a la cual, según Alexy, aspira todo sistema jurídico como totalidad o norma individualizada.

El argumento de la corrección afirma que tanto las normas aisladas y las decisiones judiciales, así como también los sistemas jurídicos en tanto un todo, formulan necesariamente una pretensión de corrección. Los sistemas normativos que no formulan explícita o implícitamente esta pretensión no son sistemas jurídicos (conexión clasificatoria), mientras que los sistemas normativos que formulan explícita o implícitamente esta pretensión pero no la satisfacen son jurídicamente deficientes (conexión cualificatoria). En el caso de que las normas y decisiones jurídicas individualizadas no formulen esta pretensión la vinculación será únicamente cualificante. Como puede notarse, la pretensión de corrección posee la peculiaridad de incorporar las deficiencias morales de las normas en sus propiedades jurídicas.

Alexy se basará en dos ejemplos para mostrarnos la validez de este argumento. E primer ejemplo consiste en institucionalizar el artículo primero de una constitución del Estado $X$, según el cual la minoría que oprime a la mayoría desea continuar con esta pretensión, pero esta vez la minoría hará explícito lo implícito, es decir, será honesta respecto a sus deseos de dominación. De este modo, la redacción de este artículo quedaría así:

$X$ es una república soberana, federal e injusta.

\footnotetext{
${ }^{436}$ Soper, Philip, “Law's Normative Claims”, en, George, Robert (ed.), The Autonomy of Law. Essays on Legal Positivism, Oxford, Clarendon Press, 1996, p. 217.

437 Cfr., Bongiovanni, Giorgio, Rotolo, Antonino and Roversi, Corrado, "The Claim to Correctness and Inferentialism: Alexy's Theory of Practical Reason Reconsidered", en, Pavlakos, George (Ed.), Law, Rights and Discourse. The Legal Philosophy of Robert Alexy, Portland, Oxford University Press, 2007, pp. 275-300.

${ }^{438}$ Cfr., MacCormick, Neil, "Why Law Makes no Claims", en, Pavlakos, George (Ed.), Law, Rights and Discourse. The Legal Philosophy of Robert Alexy, Portland, Hart Publishing, 2007, pp. 59-68.
} 
Esta cláusula es extraña. Tiene un defecto que impide otorgarle validez en sentido estricto. ¿Pero qué tipo de defecto es el que posee? ¿Estamos ante un defecto técnico, moral o convencional? Saber que existe una falla en este artículo, sin embargo, no nos muestra la respuesta, aunque la respuesta sí nos muestre el error. Tal vez si rescribimos el artículo con una variación al final podamos saber dónde está el error:

$X$ es una república soberana, federal y justa

Alexy aclara que este enunciado es redundante. Ahora bien, ¿por qué el primer artículo posee una falla mientras que el segundo es redundante? La diferencia entre ambos artículos residirá en que el primero posee una falla conceptual en tanto la positivización del primer artículo viola las reglas constitutivas de las expresiones lingüísticas. Podemos ver que en esta parte Alexy introduce la idea de la contradicción performativa, a la que nos habíamos referido en el capítulo segundo de esta obra.

En efecto, el acto de positivización de una norma de esta clase implica necesariamente una pretensión de corrección, la cual, en este contexto, reviste el carácter de ser una pretensión de justicia que fundamenta moral y jurídicamente al derecho. En el caso de esta norma, el legislador constitucional incurre en una contradicción performativa cuando el contenido del acto constituyente niega la pretensión de justicia inherente a la promulgación de ese acto legislativo, a pesar de que con su acto necesariamente debe formularla. Ahora veamos el segundo ejemplo, con el cual podría ser más claro el alcance de esta pretensión.

El acusado será condenado, en virtud de una falsa interpretación del derecho vigente, a prisión perpetua.

En este ejemplo Alexy indica que el juez viola la pretensión de corrección de interpretar correctamente el derecho. Dicho de otro modo, en este ejemplo el juez incurre en una contradicción performativa y con ello en una falla conceptual. La falla conceptual reside en que en el acto de toda sentencia judidicial los jueces erigen una pretensión de corrección, esto es, una pretensión de que el derecho va a ser aplicado correctamente, a pesar de que esta pretensión no pueda ser satisfecha del todo.

Los dos ejemplos anteriores muestran que los participantes del discurso y sistema jurídicos necesariamente erigen una pretensión de corrección, la cual conecta al derecho 
con la moral, pero no con cualquier concepto de moral, sino con la moral entendida como una pretensión de justicia y de un contenido correcto del derecho. Este argumento de la corrección no es suficiente para que un positivista acepte la conexión entre derecho y moral, ya que podría valerse de dos estrategias. La primera consiste en sostener que la no satisfacción de la pretensión de corrección no implica la pérdida de la calidad jurídica, y la segunda en sostener que la pretensión de corrección posee un contenido trivial que de ninguna manera conduce a la vinculación conceptual entre derecho y moral. Estas dos objeciones serán respondidas respectivamente mediante el argumento de la injusticia y el de los principios.

\subsubsection{El argumento de la injusticia: la rehabilitación de la Fórmula de Radbruch}

Ahora veremos el argumento que le dio a Radbruch un lugar privilegiado en la historia del pensamiento filosófico-jurídico, al mismo tiempo que, según Raz, lo convirtió en uno de los "héroes de Alexy". ${ }^{439}$ Este argumento de la injusticiano sólo está conectado con una de las cuestiones más importantes de la filosofía jurídica, sino de la filosofía moral y política. Esta cuestión es la siguiente: ¿las leyes extremadamente injustas siguen siendo derecho? El problema al que nos referimos ha sido sintetizado en la famosa Fórmula de Radbruch. Este argumento consiste en sostener que ciertas normas jurídicas que vayan más allá de un umbral insoportable de injusticia perderán no sólo su legitimidad o fundamento moral, sino su legalidad o estatus jurídico. Este argumento también estará dividido en dos partes: una dedicada a las normas jurídicas individualizadas y otra dirigida a los sistemas jurídicos como totalidad. El núcleo de este argumento se encuentra en la Fórmula de Radbruch, la cual, a partir de la obra de Alexy, ha gozado de una rehabilitación notable en la filosofía jurídica. ${ }^{440}$ Alexy ha sintetizado ocho argumentos que suelen usarse

${ }^{439}$ Raz, Joseph, "The Argument from Justice, or How Not to Reply to Legal Positivism”, en, Pavlakos, George (Ed.), Law, Rights and Discourse. The Legal Philosophy of Robert Alexy, Portland, Oxford University Press, 2007, p. 18.

${ }^{440}$ Esta rehabilitación de la formula Radbruch no es para menos. El uso que Alexy ha hecho del argumento de la injusticia de Radbruch ha contribuido al interés por redescubrir el pensamiento de Radbruch. Un análisis más profundo de la Fórmula de Radbruch va más allá de esta obra. No obstante, sobre esta fórmula pueden consultarse las siguientes obras y artículos: Alexy, Robert, "A Defence of Radbruch's Formula”, en, Dyzenhaus, David (Ed.), Recrafting the Rule of Law: The Limits of Legal Order, Portland, Oxford University Press, 1999, pp. 15-39. Adachi, Hidehiko, Die Radbrusche Formel. Eine Untersuchung der Rechtsphilosophie Gustav Radbruchs, Baden-Baden, Nomos Verlagsgesellschaft, 2005. Sieckmann, Jan-Reinard, "Die «Radbruch'sche Formel» und die Mauerschützen", en, Archiv für Rechts-und Sozial philosophie Nr. 87, Stuttgart, Franz Steiner Verlag, 2001, pp. 496-515. Vassalli, Giuliano, Radbrusche Formel und Strafrecht. Zur Bestrafung der "Staatsverbrechen" im postnazistischen und postkommunistischen Deutschland, Gotinga, Walter de Gruyter GmbH \& Co. KG, 2010. 
al hablar de la Fórmula de Radbruch referida al problema de las normas aisladas. Estos son los argumentos en torno a esta fórmula.

8.1.2.2.1. El argumento lingüístico: según este argumento, puede sostenerse la tesis normativa según la cual la inclusión de elementos morales exigida por el argumento de la injusticia conduce a una estipulación lingüística poco o nada funcional. Este argumento está basado en buena parte en los comentarios de Hoerster acerca del error que podría provocar que un no-positivista no se refiera al concepto de derecho para referirse a leyes extremadamente injustas. Este problema tiene solución, sostiene Alexy, si el juez que evalúa una norma extremadamente injusta — como es el caso de la Onceava Ordenanzasostiene que, prima facie, esta norma es derecho y luego le niega tal carácter. ${ }^{441}$ De hecho, la principal crítica formulada al argumento de Alexy, consistente en sostener que él es un representante de las teorías del derecho natural al negarle validez jurídica a las normas jurídicas, quedaría debilitada si es considerado este argumento; de acuerdo con éste, el juez primero reconocería normas extremadamente injustas como jurídicas y después les negaría tal carácter.

8.1.2.2.2. El argumento de la claridad: según este argumento, se trata de saber si sólo serían incluidos elementos morales en el concepto de derecho. Sobre este aspecto es conocida la tesis de Hart acerca de la necesidad de no negarle la calidad jurídica a las normas jurídicas injustas, ya que se les puede reconocer el carácter jurídico y al mismo tiempo negarles su calidad moral. Tanto Hart como Kelsen, al distinguir entre la vigencia legal y la validez moral negarían la tesis de la legitimación acrítica del derecho, según la cual si las leyes injustas no son derecho, entonces las leyes vigentes son justas. En este

Schreuren-Brandes, Christoph, Der Weg von National-sozialistischen Rechtslehren zur Radbruschen Formel. Untersuchungen zur Geschichte der Idee vom "Unrichtigen Recht", Paderborn, Ferdinand Schöningh, 2006. Sodero, Eduardo, "Reflexiones filosóficas sobre el caso de los guardianes del muro", en, Vigo, Rodolfo, La injusticia extrema no es derecho. De Radbruch a Alexy, México, D. F., Fontamara, 2008, pp. 447-500. Seoane, José, "La doctrina clásica de Lex Iniusta y la fórmula de Radbruch. Un ensayo de comparación", en, Vigo, Rodolfo, La injusticia extrema no es derecho. De Radbruch a Alexy, México, Fontamara, 2008, pp. 393-444. Aguiar de Oliveira, Júlio, "A injustiça extrema e o conceito de direito", en, en, Trivisonno, Alexandre T. G., Tuffi, Aziz y Sétte, Mónica, (Eds.), Princípios formais e outros aspectos da Teoria Discursiva do Direito, Forense Universitaria, Rio de Janeiro, 2014, pp. 139-171. Paulson, Stanley, "Radbruch on Unjust Laws: Competing Earlier and Later Views", en, Oxford Journal of Legal Studies Nr. 15, Oxford, 1995, pp. 489-500 y, del mismo autor, "On the Background and Significance of Gustav Radbruch's Post-War Papers", en Oxford Journal of Legal Studies Nr. 26, Oxford, 2006, pp. 17-40 y “Ein ewiger Mythos: Gustav Radbruch als Rechtspositivist - Teil 1", en Juristen Zeitung, Nr. 3, 2008, Mohr Siebeck, pp. 105-116.

${ }^{441}$ Cfr. Alexy, Robert, CVD, p. 48. 
sentido, son justificables los argumentos de Hart y Kelsen, así como los de Hoerster, en tanto que debe existir cierta brecha entre el ser y debe ser jurídicos. También, no está de más recordar lo que pensaba Castoriadis acerca de las leyes como expresión de la autonomía humana: “[P]or ejemplo, la expresión: «La Ley es injusta» es lingüísticamente imposible, o al menos absurda, para un hebreo clásico, ya que las leyes son dadas por Dios y la justicia es sólo uno de los nombres y atributos de Dios" ${ }^{442}$ Según Alexy, lo que buscará el no-positivista no será la justificación acrítica del orden jurídico, sino de que, en el caso de una injusticia extrema, el postulado moral tenga repercusiones jurídicas.

8.1.2.2.3. El argumento de la efectividad: según este argumento, para los positivistas como Kelsen, Hart y Hoerster es ingenuo suponer que una definición no-positivista de derecho puede tener eficacia alguna en contra de la injusticia legal. Para Hoerster, Radbruch sobrevalora los efectos que el filósofo del derecho tiene en el comportamiento de los sujetos de derecho, quienes van desde los jueces hasta los ciudadanos, ya que, "a través de una mera definición de un concepto no puede modificarse la realidad". ${ }^{443}$ Esta tesis de Hoerster es compatible con la tesis kelseniana de separar los deberes jurídicos de los deberes morales para tener una actitud crítica hacia el derecho. Las objeciones de estos tres positivistas pueden conducirnos a dos objeciones: la primera es que un concepto nopositivista de derecho no puede servirnos en contra de leyes injustas y el segundo es que podría llevarnos a legitimar acríticamente la injusticia legal.

Para responder a la primera objeción, Alexy propondrá una tesis débil de la vinculación entre derecho y moral. El sentido débil permite llevar a cabo una crítica moral del derecho, ya que se admite que normas injustas pueden ser derecho, pero no normas extremadamente injustas. La vinculación débil entre moral y derecho apunta a que ciertas exigencias morales mínimas no puedan ser violadas por ningún tipo de normas jurídicas. Para responder a la segunda objeción, Alexy indica que el defensor de un concepto nopositivista de derecho puede mostrar que sobre la base de éste puede combatir la injusticia legal no menos eficazmente que sobre la base de un concepto positivista. Para Alexy esto es seguro bajo el siguiente cuestionamiento: “¿por qué ha de poder combatirse menos

\footnotetext{
${ }^{442}$ Castoriadis, Cornelius, "Power, Politics, Autonomy", en, Honneth, Axel, McCarthy, Thomas, Offe, Claus y Wellmer, Albrecht (Eds.), Zwischenbetrachtungen Im prozeß der Aufklärung. Jürgen Habermas zum 60 Geburtstag, Fráncfort del Meno, Suhrkamp, 1989, p. 475.

${ }^{443}$ Hoerster, Norbert, "Die rechtsphilosophische Lehre vom Rechtsbegriff", en Juristische Schulung, 3, 1987, p. 186.
} 
eficazmente la injusticia legal cuando no es considerada como derecho que cuando lo es?"444

8.1.2.2.4. El argumento de la seguridad jurídica: según este argumento, la Fórmula de Radbruch pondría en peligro la estabilidad del sistema jurídico, esto es, a la seguridad jurídica, lo cual convertiría a esta fórmula en el argumento del anarquismo. Según Alexy, la Fórmula de Radbruch no pone en riesgo la seguridad jurídica, ya que sólo las normas extremadamente injustas cederán ante la justicia. Para dar certeza de que sólo ciertos tipo de normas pueden ceder ante la justicia, debe vincularse el aspecto material con el epistemológico bajo el enunciado siguiente: "cuanto más extrema sea la injusticia, tanto más seguro su conocimiento". ${ }^{445}$ Sin duda, en el caso de la Onceava Ordenanza existe la justificación para que el Tribunal Constitucional Federal declarara la injusticia extrema como evidente, pero, ¿acaso la injusticia es evidente en todos los casos para todos los mismos sujetos?

La pregunta anterior no es posible responderla en un sentido absolutamente afirmativo. No obstante, la Fórmula de Radbruch no conduce a una pérdida de la seguridad jurídica que lleve al sistema jurídico al borde del derrumbe, sino que se trata de una pérdida mínima de seguridad jurídica y, según nuestro punto de vista, necesaria. Diferentes ejemplos de situaciones cotidianas muestran que el valor de la seguridad jurídica no puede ser un valor absoluto, para bien del derecho mismo. De acuerdo con la teoría principialista de Alexy, las normas de derecho fundamental son mandatos a optimizar no absolutos; en este caso, la seguridad jurídica tiene una prioridad, la cual puede invertirse en el caso de que ésta pueda dar lugar a una injusticia extrema y evidente, la cual, para ser tal, debería de estar ligada a la violación de derechos humanos. Ante el peligro de institucionalizar un orden jurídico en favor absoluto de la seguridad jurídica, Alexy responde que a esto puede oponerse sólo quien considere que la seguridad jurídica es un principio absoluto, argumento que, como toda adhesión a un principio absoluto, contiene una dosis de fanatismo.

8.1.2.2.5. El argumento del relativismo: según este argumento, ningún juicio de justicia es susceptible de fundamentación racional o de cualquier tipo de conocimiento objetivo. En las sociedad modernas es probable que cuestiones morales provoquen un

\footnotetext{
${ }^{444}$ Alexy, Robert, CVD, p. 55.

${ }^{445}$ Alexy, Robert, CVD, p. 57.
} 
desacuerdo en torno a lo que es lo justo e injusto. El mejor ejemplo acerca de un relativista converso es sin duda Radbruch, quien en sus escritos del periodo de posguerra excluyó del escepticismo relativista un conjunto básico de derechos humanos y civiles. En capítulos pasdos ha sido expuesta la fundamentación de la ética del discurso, por lo que basta decir en este momento que, de acuerdo con esta ética, puede refutarse el escepticismo moral mediante la fundamentación discursiva de la moral y el derecho.

8.1.2.2.6. El argumento de la democracia: según este argumento, el concepto nopositivista de derecho puede enfrentar al juez que invoque a la justicia con las decisiones del legislador democráticamente legitimado, lo cual provocaría una violación al principio constitucional de la división de poderes. Esta objeción es refutada por dos razones: la primera es que, tal y como ya lo mencionamos antes, la negación del carácter jurídico de una norma sólo se da en casos de injusticia extrema, esto es, casos minoritarios. La segunda razón es que quien ofrezca este argumento en contra del argumento de la injusticia "tendría que negar toda sujeción judicialmente controlable del legislador a los derechos fundamentales". 446

8.1.2.2.7. El argumento de la inutilidad: según este argumento, es posible tomar en cuenta la injusticia jurídica de otro modo que la negación del estatus jurídico de las normas, lo que volvería inútil al argumento de la injusticia. Para refutar esta objeción Alexy aconseja distinguir entre los casos de derecho penal y los que no lo son para tratar adecuadamente los casos no vinculados a este ámbito. Ante una situación hipotética en la que un juez debe tomar una decisión con la finalidad de evitar que los derechos de un ciudadano sean violados por una ley vigente debido a la falta de acción del legislador, éste puede optar por usar la Fórmula de Radbruch o aplicar la ley injusta para que el legislador haga algo al respecto en los casos futuros. Los dos argumentos en favor de aplicar la Fórmula de Radbruch son los siguientes: proteger los derechos del ciudadano y mantener la pretensión de corrección.

Según la Fórmula de Radbruch sería incorrecto aplicar una ley injusta con el objetivo de indicarle al legislador que debe actuar posteriormente para corregir las leyes. No es correcto valerse de una violación de los derechos fundamentales para modificar una ley, sino de que, según la pretensión de corrección, ninguna injusticia extrema pueda ser

\footnotetext{
${ }^{446}$ Alexy, Robert, CVD, p. 61.
} 
cometida en nombre de ésta. Por todo ello, fuera del ámbito penal hay dos razones que desvirtúan este argumento de la inutilidad, mencionados en el párrafo anterior: "el respeto a los derechos del ciudadano y la pretensión de corrección". ${ }^{447}$

8.1.2.2.8. El argumento de la honestidad: según este argumento, en los casos penales la aplicación de la Fórmula de Radbruch conduciría al abandono del principio Nulla poena sine lege, acaso el principio legitimador más importante del derecho penal. ${ }^{448}$ Para responder al dilema de Hart, ${ }^{449}$ esto es, al problema de la irretroactividad encubierta, Alexy indica que la Fórmula de Radbruch sólo conduce a la punibilidad en casos de injusticia extrema, de modo que el objetivo principal no es el de fundamentar la irretroactividad sino el de eliminar a una injusticia extrema que lleve a excluir la punibilidad. Si el argumento de la injusticia extrema se limita a la tesis débil de la vinculación, entonces no puede hablarse de irretroactividad encubierta y de falta de honestidad. ${ }^{450}$

Ciertamente podríamos afirmar que las ocho objeciones quedan debilitadas en una medida considerable si la Fórmula de Radbruch es vista sólo como la ultima ratio en contra de las leyes extremadamente injustas. Un sistema jurídico puede enarbolar una pretensión de corrección para obtener la calidad de sistema jurídico y, no obstante, ser en la práctica extremadamente injusto. Ahí es en donde entra de modo correctivo la Fórmula de Radbruch. Estas funciones de la pretensión de corrección y de la Fórmula de Radbruch podrían explicarse del siguiente modo: para conectar al sistema jurídico con el ideal de justicia, la pretensión de corrección tendría la función de ser una especie de discurso de fundamentación del concepto y naturaleza del derecho, mientras que la Fórmula de

\footnotetext{
${ }^{447}$ Alexy, Robert, CVD, p. 64.

${ }_{448}$ De todos los ámbitos jurídicos, probablemente el penal es el más complicado para hablar de la aplicación de la Fórmula de Radbruch debido a la posibilidad de dar lugar a una irretroactividad encubierta. Como Alexy lo ha indicado, el objetivo principal de la Fórmula de Radbruch es el de evitar la fundamentación y aplicación de normas extremadamente injustas y no el de fundamentar una punibilidad irretroactiva. Sobre los pros y contras de la aplicación de la Fórmula de Radbruch en el ámbito de la filosofía del derecho, especialmente en los escritos de Alexy, cfr., Vassalli, Giuliano, Radbrusche Formel und Strafrecht. Zur Bestrafung der "Staatsverbrechen" im postnazistischen und postkommunistischen Deutschland, Gotinga, Walter de Gruyter GmbH \& Co. KG, 2010, p. 161 ss.

${ }^{449}$ Este dilema consiste en el análisis del fallo que emitió el Tribunal Superior de Bamberg respecto al juicio emitido contra una mujer que denunció a su marido por formular comentarios despectivos de Hitler ante las autoridades nacionalsocialistas en 1944 para deshacerse de él. La mujer fue considerada culpable a costa de renunciar al principio de irretroactividad. De este modo, el tribunal decidió llevar a cabo un mal para evitar incurrir en otro: en vez de dejar a la mujer sin castigo, optó por castigarla y, con ello, renunció al principio de irretroactividad.

${ }^{450}$ Cfr., Alexy, Robert, CVD, p. 67.
} 
Radbruch tendría la función de ser una especie de discurso de aplicación del derecho por parte de los jueces.

Júlio Aguiar ha explicado esta peculiaridad de la Fórmula de Radbruch, así como las tesis posibles en caso de aceptar sus características. De acuerdo con Aguiar, la Fórmula de Radbruch puede tomarse como una proposición conceptual acerca de la naturaleza del derecho y como una prescripción para la decisión judicial. Esto da lugar a cuatro tesis. Según la primera tesis, representada por Alexy y Radbruch mismo, la Fórmula de Radbruch es admitida como una proposición conceptual acerca de la naturaleza del derecho y también como prescripción para la decisión judicial. Según la segunda tesis, representada por Hart, la Fórmula de Radbruch es rechazada como una proposición conceptual acerca de la naturaleza del derecho e igualmente rechazada como prescripción para la decisión judicial. Según la tercera tesis, representada por Bix, la Fórmula de Radbruch es rechazada como una proposición conceptual acerca de la naturaleza del derecho pero es admitida como prescripción para la decisión judicial. Según la cuarta tesis, representada por Aguiar, la Fórmula de Radbruch es admitida como una proposición conceptual acerca de la naturaleza del derecho pero es rechazada como prescripción para la decisión judicial. ${ }^{451}$

De acuerdo con Aguiar, Alexy concibe a la Fórmula de Radbruch como una proposición conceptual de la naturaleza del derecho (lo que podría concebirse también como un discurso de fundamentación) y como una prescripción para la decisión judicial (lo que podría concebirse también como un discurso de aplicación del derecho). De este modo la Fórmula de Radbruch tendría un efecto de irradiación en la prais jurídica por parte de los jueces, al momento de dictar decisiones jurídicas, así como en el análisis de normas individualizadas. Ahora que hemos visto la función de la Fórmula de Radbruch respecto a las normas y decisiones jurídicas individualizadas, debemos ver qué pasa cuando esta fórmula se erige en contra de sistemas jurídicos. Aquí existen dos posturas: la tesis de la irradiación y la tesis del derrumbe.

\footnotetext{
${ }^{451}$ Cfr., Aguiar de Oliveira, Júlio, "A injustiça extrema e o conceito de direito", en, Trivisonno, Alexandre T. G., Tuffi, Aziz y Sétte, Mónica, (Eds.), Princípios formais e outros aspectos da Teoria Discursiva do Direito, Forense Universitaria, Rio de Janeiro, 2014, pp. 134-140. También puede consultarse el cuadro anexo al final del artículo de Aguiar para una mayor comprensión de las cuatro tesis en torno a la Fórmula de Radbruch.
} 
Según la tesis de la irradiación, la falta de carácter jurídico de normas sustantivas esenciales de todo sistema legal traería consigo un efecto de irradiación que privaría a todas las normas del sistema del carácter jurídico. Esta tesis conduce a un argumento de la totalidad que tendría como consecuencia una pérdida de seguridad jurídica inaceptable, debido a que la Fórmula de Radbruch sólo afectará el valor abstracto de la seguridad jurídica de normas jurídicas extremadamente injustas, pero no tiene por qué irradiar sus efectos a otro tipo de normas. Según la tesis del derrumbe, el sistema jurídico cae como tal cuando debe negársele el carácter jurídico a muchas normas aisladas importantes para el sistema. El derrumbe se distingue de la irradiación por el hecho de que la mayoría de las normas serían injustas y con ello el sistema se derrumbaría al aplicar la Fórmula de Radbruch. El problema aquí sería una cuestión de grado, ya que debería saberse qué porcentaje de leyes son justas, injustas y extremadamente injustas para saber a cuáles se les aplicaría la Fórmula de Radbruch, y con ello saber si el sistema sería derrumbado por completo o no. Esto lleva a Alexy a considerar, acertadamente, que la aplicación de la Fórmula de Radbruch a los sistemas jurídicos no debe ir más allá de las consecuencias de ésta a las normas aisladas. ${ }^{452}$

\subsubsection{El argumento de los principios: el plus del derecho}

Este argumento, a la luz de la Teoría de los derechos fundamentales y de la distinción entre reglas y principios, provoca confusiones al incluirse en Concepto y validez del derecho. Las confusiones que notamos en esta concepción de los principios residen en dos usos que a continuación distinguiremos con mayor claridad. Según Alexy, el argumento de los principios consiste en que en el ámbito del derecho, el juez está obligado a decidir un caso mediante un plus de derecho que crea una vinculación necesaria entre derecho y moral. Para respaldar sus argumentos, Alexy cita la afirmación del Tribunal Constitucional Federal de Alemania respecto al fallo relativo a la creación del derecho:

"El derecho no es idéntico a la totalidad de las leyes escritas. Frente a las disposiciones positivas del poder estatal, puede existir en algunas circunstancias un derecho más grande....". 453

\footnotetext{
452 Alexy, Robert, CVD, p. 73.

453 Alexy, Robert, CVD, p. 75. Respecto a esta cita, preferimos basarnos en la version en inglés (traducida por Bonnie Litschewski Paulson y Stanley Paulson), en la cual usan la expresión "un derecho más grande (a greater law), en vez de traducir un "plus de derecho" (ein Mehr an Recht), tal y como está hecha la traducción en español. Esta traducción nos pareció más correcta para los fines de esta obra, ya que permite entender que
} 
Esta afirmación del Tribunal Constitucional Federal indica dos aspectos que pueden ayudarnos a comprender este argumento, así como a analizar las críticas de Alexy hacia el positivismo jurídico. Estos dos aspectos consisten en indicar que a) el derecho no es idéntico a la totalidad de las leyes escritas, $y$, en segundo lugar, que b) frente a las disposiciones jurídicas puede existir un derecho más grande, o un plus de derecho. Estos argumentos nos provocan dos dudas respecto a la fortaleza de los argumentos de Alexy en contra de la postura que desea criticar: ¿el positivismo jurídico, acaso, identifica el derecho sólo con las leyes escritas?, ¿es verdad que frente a las normas jurídicas existe un derecho extra?

No obstante, quisiéramos aclarar antes en qué consisten nuestras dudas respecto a este argumento. Con base en los argumentos que ofrecimos en el capítulo cuarto de esta obra, creemos que, al menos en lo que respecta a los dos grandes positivistas del Siglo XX, Kelsen y Hart, este argumento carece de validez frente al positivismo jurídico representado por estos autores, ya que la incorporación y aplicación de principios es una cuestión de derecho positivo, no vinculada al positivismo jurídico. No obstante, las citas de Hart y Kelsen, mencionadas previamente confirman que ellos estarían de acuerdo en que estas normas operen en los diversos casos presentados en la praxis jurídica, siempre que estén autorizadas por alguna norma vigente del sistema jurídico. No se trata de un "plus de derecho mas grande", ni tampoco de un derecho que no se identifica con las normas positivizadas, ya que los principios, según el propio Alexy, son un tipo de normas jurídicas concebidas como mandatos a optimizar, las cuales necesitan estar positivizadas para poder entrar en conflicto con otro tipo de normas principializadas.

Un argumento que no había aparecido de modo explícito en la Teoría de los derechos fundamentales, y que ahora aparece en Concepto y validez del derecho, consiste en sostener en que mediante el juicio de ponderación es incorporada la conexión necesaria entre derecho y moral. Si entendemos correctamente a Alexy, ${ }^{454}$ nos dirá que en el argumento de los principios se encuentra una conexión entre derecho y moral de naturaleza conceptual, cualificante y posible sólo desde la perspectiva del participante. Esta triple

en el caso de los principios se trata no sólo de un plus de derecho no legislado, sino, al parecer, de un derecho con mayor jerarquía que no está necesariamente legislado.

${ }^{454}$ Cfr., Alexy, Robert, CVD, p. 75. 
conexión estará basada en las respectivas tesis de la incorporación, tesis moral y tesis de la corrección, las cuales serán analizadas a continuación.

Tesis de la incorporación: según esta tesis, todo sistema jurídico mínimamente desarrollado contiene principios, los cuales no sólo se refieren a normas de derecho fundamental con una estructura definitiva, sino a principios categóricos de derecho, como los positivizados en la Ley Fundamental de Alemania y que ya describimos antes. El problema con esta tesis residirá en que, para Hoerster, un positivista que sigue los pasos de Kelsen y Hart admitirá que la incursión de principios en el sistema jurídico es una cuestión de hecho, y que, por ello, no habrá conexión conceptual entre derecho y moral. Para contestarle a los argumentos de Hoerster, Alexy se valdrá de la comprensión de estos principios desde la perspectiva del participante, esto es, desde la perspectiva del juez que recurre a una ponderación entre principios.

Los siguientes argumentos que nos ofrece Alexy nos parecen un tanto circulares, ya que estos principios no tienen que ser vistos por un positivista jurídico como extrasistémicos, sino que su incorporación fáctica a través del derecho positivo los vuelve un mandato a considerar por el juez. De esta manera, la salida a esta circularidad provocada por el diálogo con un testarudo positivista consiste en indicar que esta incorporación está permeada de una argumentación moral y de una pretensión de corrección, que serán las siguientes dos tesis.

Tesis moral: según esta tesis, entre los principios que deben tomarse en cuenta para resolver casos difíciles siempre se encuentran algunos que pertenecen a alguna moral, lo cual lleva a establecer una versión débil de la conexión entre derecho y moral. Los problemas típicos de una tesis como esta consisten, a grandes rasgos, en saber si es válida en términos intersubjetivos esta moral vinculada con el derecho, especialmente, una moral o ética políticas. El positivismo jurídico defendido por Kelsen y Hart podría ser compatible con esta tesis acerca de la influencia de cuestiones morales o políticas en los criterios de decisión del juez, sólo que ellos indicarían que esta moral no podría fundamentarse en términos universalistas. Por lo tanto veamos cómo fundamenta Alexy la siguiente tesis.

Tesis de la corrección: según esta tesis, el argumento de los principios permite conectar al derecho con una moral correcta, de acuerdo con la perspectiva del participante. Este argumento posee características que lo vuelven en cierto modo problemático, ya que 
"de lo que aquí se trata es de dar una respuesta a una cuestión jurídica que, de acuerdo con su contenido, también es una cuestión de la moral política". 455 Según este argumento, la decisión del juez debe erigir una pretensión de corrección que hace imposible la justificación de cualquier contenido del fallo, sino uno de acuerdo a la moral correcta. La pretensión de corrección es siempre una pretensión de fundamentabilidad. A la pregunta que podría hacer un crítico respecto a quedarnos sólo en el nivel de la pretensión y no en el de la realización de la conexión a la moral correcta, Alexy ha planteado la siguiente respuesta:

Quien apunte a la realización dice demasiado. Sostiene que el derecho, es decir, también cada decisión judicial, cumple necesariamente la pretensión de corrección moral; dicho brevemente: que el derecho es siempre moralmente correcto. Esto último implica que todo lo que no es moralmente correcto no es derecho. El análisis del argumento de la injusticia ha mostrado que no es posible sostener una tesis tan fuerte. Por ello, aquí no puede hablarse de una conexión clasificante, sino tan sólo de una cualificante. ${ }^{456}$

La conexión cualificante apunta a que con la pretensión de corrección ya no cualquier moral puede erigirse como válida para todos los participantes de un discurso, sino que debe cumplir con un mínimo de exigencias morales que la alejen del umbral de la injusticia extrema. De esta manera, la pretensión de corrección nos conecta a una dimensión ideal vinculada necesariamente con el derecho. Ahora es momento de analizar las réplicas de los defensores del positivismo jurídico.

\subsection{Las objeciones a los argumentos de Alexy: la embestida positivista}

La obra El concepto y la validez del derecho no pasó inadvertida para positivistas como Hoerster, Raz y Bulygin. Sobre todo para estos dos últimos, quienes después de una atenta lectura a esta obra decidieron emprender una expedición punitiva hacia los dominios de la filosofía alexyana, con el objetivo de mostrar que el positivismo jurídico no podía ser refutado por los argumentos ofrecidos por Alexy. Lo destacable de esto fue ver el interés de estos distinguidos representantes del positivismo jurídico para refutar la obra de Alexy

\footnotetext{
455 Alexy, Robert, CVD, p. 81.

${ }^{456}$ Alexy, Robert, CVD, p. 83.
} 
en un momento en el cual ésta buscaba poner los últimos clavos en el ataúd de una filosofía que, al final del día, revive como el ave fénix.

O tal vez no es que esta filosofía jurídica reviva constantemente, sino que sus críticos no han sabido cómo refutarla en su propio terreno, ya que no han construido argumentos sólidos en su contra. Después de todo, los críticos del positivismo jurídico han sido quienes más terminan por fortalecerlo. Este destino trágico de los detractores del positivismo jurídico no ha sido el de Alexy; de lo contrario, autores como Raz y Bulygin no se habrían tomado la molestia de responderle con semejante énfasis y rigor. Esta no es la primera vez que Alexy ha entrado en debate con estos filósofos, ${ }^{457}$ ya sea para explicar sus posturas opuestas o para señalar los puntos que tienen en común, como lo ha analizado Rodolfo Gómez. ${ }^{458}$ Comenzaremos primero con la crítica de Bulygin y luego con la de Raz. Después de terminar de exponerlas continuaremos finalmente con la defensa de Alexy.

\subsubsection{La crítica de Bulygin: los tres rounds}

La crítica de Bulygin podría sintetizarse del siguiente modo: los argumentos de Alexy fallan porque la pretensión de corrección, si es que es posible fundamentarla, es insuficiente para mostrar una relación conceptual necesaria entre derecho y moral porque cae en una contradicción. Esta crítica de Bulygin apareció por primera vez en un homenaje al filósofo Werner Krawietz bajo el título Alexy y el argumento de la corrección ${ }^{459}$ y después dio lugar a un intenso debate en torno a sus concepciones del derecho.

\footnotetext{
457 Ya en 2007 la editorial Marcial Pons publicó un libro editado por Hernán Bouvier, Paula Gaido y Rodrigo Sánchez Brigido en torno una discusión entre Raz, Bulygin y Alexy sobre si puede haber una teoría del derecho. Este libro está titulado Una discusión sobre la teoría del derecho.

458 Gómez Alcalá ha llevado a cabo un análisis de la posturas de estos filósofos desarrolladas en la obra publicada por Marcial Pons, Una discusión sobre la teoría del derecho, y ha señalado los puntos en común entre Raz, Bulygin y Alexy, destacando, entre estos puntos, el hecho de que el derecho pueda ser objeto de una verdadera ciencia. Cfr., Gómez, Rodolfo, "Una discusión contemporánea sobre teoría del derecho (Raz, Alexy y Bulygin", en, Revista de investigaciones jurídicas, no. 33, Escuela Libre de Derecho, 2009, pp. $392-394$. 459 Cfr., Bulygin, Eugenio, "Alexy und das Richtigkeitsargument", en, Aarnio, Aulis, Paulson, Stanley, y Weinberger, Ota, (Eds.), Rechtsnorm und Rechtswirklichkeit. Festchrift für Werner Krawietz zum 60 Geburtstag, Duncker \& Humblot, Berlín, 1993, pp. 19-24.
} 
Las objeciones de Bulygin están dirigidas hacia un solo argumento de Alexy, si bien es un argumento del que dependen los otros dos argumentos: el argumento de la corrección. Alexy ha resumido el núcleo de las objeciones de Bulygin del siguiente modo:

Bulygin se opone a todos los aspectos del argumento de la pretensión de corrección. Primero, niega que el derecho formule necesariamente una pretensión de corrección. Segundo, sostiene que aún si el derecho formula tal pretensión, no se sigue respecto de ella una conexión necesaria entre derecho y moral. Tercero, sostiene que el argumento de los antipositivistas basado en la pretensión cae en una contradicción. ${ }^{460}$

Veamos, ahora, cómo plantea Bulygin sus objeciones de cara al proyecto alexyano. Estas críticas han aparecido, hasta ahora, en tres ocasiones, lo cual ha dado lugar a que sean consideradas por Alexy como los "tres rounds". A continuación, presentaremos estas interesantes críticas de Bulygin al proyecto alexyano.

A) El primer round: Bulygin comienza sus críticas recordándonos los aspectos esenciales de la pretensión de corrección, los cuales consisten en que tanto los sistemas jurídicos como un todo y las normas jurídicas y decisiones jurídicas individuales erigen esta pretensión; no obstante, la pretensión de corrección tiene una relevancia distinta en ambas esferas, como ya lo vimos antes. Respecto a los sistemas jurídicos tiene una relevancia clasificatoria, mientras que en las normas y decisiones jurídicas aisladas tiene una pretensión cualificatoria. Esta diferenciación entre una pretensión clasificatoria y una cualificatoria es considerada por Bulygin como contradictoria debido a que la pretensión de corrección es una característica conceptualmente necesaria de los sistemas jurídicos, pero no es una característica definitoria de normas y decisiones jurídicas aisladas y, por tanto, no es una característica conceptualmente necesaria.

Además de esta aparente contradicción entre el trato diferenciado a los sistemas jurídicos como totalidad y a las normas y decisiones jurídicas individualizadas, Bulygin considera carente de solidez la afirmación de Alexy de que todo sistema jurídico erige una pretensión de corrección y, para ello, analiza los dos enunciados en los cuales Alexy intenta mostrarnos una contradicción performativa. Bulygin está de acuerdo con Alexy en que ambos enunciados son deficientes, pero no son contradictorios ni redundantes. Ambos

\footnotetext{
${ }^{460}$ Alexy, Robert y Bulygin, Eugenio, La pretensión de corrección del derecho. La polémica sobre la relación entre derecho y moral, Colombia, UEC, 2001, p. 97. En adelante, PRMD.
} 
enunciados, sostiene Bulygin, son órdenes prescriptivas y no descripciones. Pero como órdenes carecen de sentido, ya que para éste:

No tiene sentido ordenar que una constitución o un Estado sean justos o injustos, como tampoco tiene sentido ordenar que un país sea rico o que los árboles sean verdes. Ciertamente algunas constituciones son justas, algunos países son ricos y los árboles (al menos en verano) suelen ser verdes, pero se trata de estados de cosas que no se pueden prescribir u ordenar. Sólo acciones o aquellos estados de cosas que son el resultado de una acción pueden ser el contenido de una norma. ${ }^{461}$

Según Bulygin, estos enunciados pueden ser interpretados no como órdenes o descripciones, sino como declaraciones políticas. De esta manera, las fallas de estos enunciados serían fallas políticas y no conceptuales, por lo tanto, la contradicción performativa no existiría en los ejemplos aducidos por Alexy. Si la contradicción performativa no existe, entonces el argumento de la pretensión de corrección fracasaría en intentar vincular al derecho con la moral.

B) El segundo round: Este round agudizó más el debate. En la segunda réplica a Alexy publicada en Ratio Juris, ${ }^{462}$ Bulygin arremete contra la idea de una contradicción performativa, al considerarla "bastante oscura" en el contexto de fundamentación de la conexión necesaria entre derecho y moral por dos razones: la primera reside en dudar que todas las autoridades revestidas de la majestad del marco jurídico pretendan que sus normas dictadas sean moral o éticamente justas, como es el caso de los imperios jurídicos de Calígula y Nerón, mientras que la segunda reside en sostener que a pesar de admitir que autoridades como Ghengis Khan, Felipe II de España, Khomeini o Pinochet erijan esta pretensión de corrección, ¿qué garantía podemos tener de que todos ellos entienden por "justicia" y por "moral" lo mismo que todos aspiramos a entender? El argumento de Bulygin apunta a indicar que si Alexy busca demostrar la conexión necesaria entre derecho y moral, debe demostrar también que esta moral universalista es compartida por todos los participantes del discurso, o, en este caso, del sistema jurídico, incluidos quienes hacen el derecho.

Pero además de arremeter contra la idea de una contradicción performativa, Bulygin dirigirá sus críticas contra la distinción entre conexiones clasificantes y cualificantes por parecerle poco clara y efectiva para aclarar el significado de la pretensión de corrección en

\footnotetext{
${ }^{461}$ Alexy, Robert y Bulygin, Eugenio, PRMD, p. 48.

${ }^{462}$ Cfr., Bulygin, Eugenio, "Alexy's Thesis of the Necessary Connections Between Law and Morality", en, Ratio Juris, Vol. 13, Núm. 2, 2000, p. 133-137.
} 
el contexto de la diferenciación entre sistemas jurídicos que necesariamente enarbolan o no esta pretensión, y normas y decisiones jurídicas aisladas que necesariamente satisfacen o no esta pretensión. Después de plantear una analogía acerca de la conexión cualificatoria entre las mujeres y la belleza, a Bulygin le preocupa que Alexy reduzca el significado de "necesidad normativa" a "obligatoriedad", ya que le reprocha a éste el no distinguir apropiadamente entre ambos conceptos. Para recurrir a esta sutil diferenciación, Bulygin indica lo siguiente:

Según la definición estándar de necesidad, una proposición $p$ es necesaria si y sólo si es verdadera en todas las circunstancias en todos los mundos posibles. Pero si $p$ es obligatoria, entonces debe ser falsa por lo menos en algún mundo posible, puesto que si siempre es verdadera, entonces no tiene sentido hacerla obligatoria. Las normas con contenido analítico (por ej.: ¡Cierre la puerta o déjela abierta!) carecen de sentido, porque debe ser posible desobedecer o desatender una norma. [...] Por consiguiente, hablar de "necesidad normativa" es hablar de una metáfora bastante oscura. No es una necesidad lógica, ni una necesidad empírica. Desgraciadamente Alexy no da ninguna explicación acerca del tipo de necesidad para la que usa esta curiosa expresión. 463

C) El tercer round: En un tercer round, Bulygin ha intentado sostener, en oposición a las posturas de Alexy, una curiosa tesis, la tesis del fin del debate. Como lo ha indicado con claridad Alexy, el título del tercer ataque de Bulygin, Alexy entre el positivismo y el no positivismo, parece indicar explícitamente un argumento bastante útil para ir más allá de la postura sostenida por Alexy. Este argumento consiste en sostener, por una parte, la posibilidad de una tercera vía entre el positivismo y el no-positivismo. Lo cual también colocaría al no-positivismo en una posición poco privilegiada.

Según Bulygin, la tesis de la dimensión ideal del derecho no es más que una "invocación metafórica" en la que no es posible encontrar una enorme discrepancia entre el positivismo jurídico de Bentham hasta Raz. Aunque en el caso del positivismo kelseniano no es posible reducir la brecha entre la perspectiva del observador y la perspectiva del participante, este no es el caso del positivismo hartiano, ${ }^{464}$ lo cual lleva a Bulygin a sostener,

\footnotetext{
${ }^{463}$ Alexy, Robert y Bulygin, Eugenio, PRMD, p. 93.

464 Para mostrar que el peso de ambas perspectivas no es tan distinto en la perspectiva de Hart, Bulygin cita el siguiente pasaje del Epílogo del Concepto de derecho: "Pero no hay, de hecho, nada en el proyecto de una teoría descriptiva del derecho como la que está ejemplificada en mi libro para excluir a un observador externo no participante de describir las maneras en como los participantes ven al derecho desde este punto de vista." (Hart, H. L. A., Postscript, en, The Concept of Law, Oxford, Oxford Clarendon Press, 1994, p. 242).
} 
en franca oposición a todas las objeciones de Alexy, que la discrepancia entre ambos es de carácter verbal:

Alexy duda (pero no niega) reconocer un sistema injusto como derecho, mientras que el positivista quiere decir que el derecho, como todo producto de la acción humana, puede ser bueno o malo, justo o injusto. Por ello, mientras nosotros nos neguemos a darle a un régimen jurídico injusto el honorable título de "derecho", las injusticias no serán eliminadas. Seguramente, los regímenes jurídicos injustos ganan las más agudas críticas, pero ¿por qué no verlos como "regímenes jurídicos"? 465

En este punto, las críticas de Bulygin apuntan a terminar el debate entre el positivismo y el no-positivismo, al menos el referido al concepto de derecho, ya que el positivismo jurídico no está interesado en la aplicación del derecho, sino en su identificación. ¿Acaso las agudas críticas de Bulygin han derrumbado al edificio alexyano? Por el momento dejaremos la réplica de Alexy y continuaremos con la crítica de Raz. Una vez que presentemos ambas críticas pasaremos a ver las respuestas de Alexy a los tres embistes de Bulygin.

\subsubsection{La crítica de Raz: el fracaso de criticar a un caballo muerto}

La crítica de Raz bien podría sintetizarse del siguiente modo: los argumentos de Alexy fallan porque han sido dirigidos contra un blanco que tiene múltiples caracterizaciones, dependiendo de sus diversas tradiciones. Esta crítica de Raz apareció publicada en la obra Derecho, derechos y discurso. Temas sobre la filosofía jurídica de Alexy y también fue publicada en la segunda edición de La autoridad del derecho. Ensayos sobre derecho y moral. ${ }^{466}$

El título de esta crítica de Raz está basado en un juego de palabras que hacen referencia a la traducción inglesa de la obra Concepto y validez del derecho, El argumento de la justicia: Una crítica al positivismo jurídico. Con base en este título Raz designa a su crítica El argumento de la injusticia, o cómo no criticar al positivismo jurídico. Si mencionamos esta peculiaridad del título es porque desde éste es evidente el espíritu crítico con el cual Raz analiza esta obra, así como la estructura de su argumentación, la cual

\footnotetext{
465 Bulygin, Eugenio, "Robert Alexy und der Begriff des Rechts", en, Clérico, Laura y Sieckmann, Jan-Reinard (Eds.), Grundrechte, Prinzipien und Argumentation. Studien zur Rechstheorie Robert Alexys, Baden-Baden, Nomos Verlagsgesellschaft, 2009, p. 236.

${ }^{466}$ Crf., Raz, Joseph, The Authority of Law, Essays on Law and Morality, Oxford, Oxford University Press, 2009, p. 313 ss. Durante el citado de esta crítica nos basaremos en la publicación hecha en la antología de Pavlakos y no en la que viene incluida en la segunda edición de La autoridad del derecho.
} 
coincide con la estructura de Concepto y validez del derecho. Estas objeciones están divididas en cinco apartados, en las cuales Raz se encargará de refutar los argumentos que antes vimos desarrollados en la obra de Alexy, dedicados a explicar a) cuál es la tesis que sostiene el positivismo jurídico, b) las perspectivas del observador y del participante, c) el argumento de la corrección, d) el argumento de la injusticia y e) el argumento de los principios.

Las objeciones de Raz desde el inicio parecen indicarnos cuál es su queja principal: ¿para qué ha escrito Alexy un libro cuyo objetivo es el de criticar una teoría que no tiene valor moral alguno?, después de todo, ¿para qué ahogar a un caballo muerto? ${ }^{467}$ No obstante, Raz nos recuerda que años antes y después de la publicación de esta obra ha surgido en el ámbito de la tradición inglesa un número notable de autores que no aparecen mencionados por Alexy, ${ }^{468}$ lo cual le permite sostener que éste, muy probablemente, busca refutar al positivismo jurídico en sus diversas tradiciones existentes, sin considerar que no todas las versiones etiquetadas bajo esta rótula comparten los mismos postulados, como parece sugerirlo Raz, al apelar a las peculiaridades del positivismo jurídico inglés.

Raz comienza la crítica de la postura alexyana con dos premisas que lo llevan a sostener que Alexy no ha logrado aclarar el núcleo del positivismo jurídico. La primera consiste en indicar que para Alexy el núcleo de todas las teorías positivistas reside en separar al derecho de la moral' y la segunda consiste en indicar que esta premisa está basada en el famoso "grito de guerra del positivismo", el cual, según Raz, es erróneo de acuerdo al mismo Kelsen. ${ }^{469}$

${ }^{467}$ Raz, Joseph, "The Argument from Justice, or How Not to Reply to Legal Positivism", en, Pavlakos, George (Ed.), Law, Rights and Discourse. The Legal Philosophy of Robert Alexy, Portland, Hart Publishing, 2007, p. 14. ${ }^{468}$ La lista formulada por Raz es larga, pero significativa, en tanto se refiere a los positivistas contemporáneos: por una parte, Lyons, Coleman, Campbell, Harris, Green, Waluchow, y por la otra, Waldron, Marmor, Gardner, Leiter, Shapiro, Murphy, Himma, Kramer, Endicott, Lamond, Dickson y Bix. Este argumento no es suficiente para refutar los argumentos alexyanos, ya que Alexy intentará refutar al positivismo jurídico como un todo desde la perspectiva de los dos representantes más consecuentes de esta tradición en los respectivos ámbitos alemán e inglés: Kelsen y Hart. Esto no quiere decir que los demás autores citados por Raz no sean importantes, pero sin la comprensión fundamental de estos dos autores no es posible hablar seriamente del positivismo jurídico, ya sea para refutarlo o defenderlo.

${ }^{469}$ Aguiar ha sintetizado dos tesis que últimamente ha sostenido Raz, las cuales se contraponen a las lecturas tradicionales del pensamiento kelseniano. En primer lugar, nos referimos a la tesis según la cual, de acuerdo con la teoría pura del derecho, no cualquier contenido puede ser derecho (la tesis de la falsedad del grito de guerra del positivismo jurídico kelseniano), y, en segundo lugar, la tesis según la cual la teoría pura del derecho contiene una teoría de la normatividad justificada. Cfr., Aguiar, Júlio, "Conteúdo do direito e normatividade 
Raz tiene razón al sostener que existen muchas dificultades que nos impiden delimitar el ámbito de la moral, y más en el ámbito de la filosofía del derecho, ya que podemos atribuirle a los teóricos del positivismo jurídico tesis erróneas acerca de lo que pretendieron con sus construcciones teóricas acerca de su comprensión del derecho. Después de todo, consideramos a Raz no sólo un notable filósofo del derecho, sino un competente filósofo moral, y por ello entendemos la fundamentalidad de esta premisa. En cambio, al sostener Raz que la tesis de la neutralidad del contenido es falsa según el propio Kelsen —esto es, que el grito de guerra del positivismo jurídico nunca lo fue-, creemos que defiende una tesis insostenible de acuerdo con el mismo Kelsen. En cuanto a la crítica de esta premisa no nos detendremos más, puesto que Alexy y Kelsen mismo estarían de acuerdo en indicarle a Raz que no es posible sostener semejante formulación.

Lo que rescatamos de esta primera objeción es que la tesis de la separación es problemática en términos conceptuales, ya que si Alexy y Raz tienen algo en común es que ambos buscan vincular al derecho con una tesis normativa. Según Alexy el derecho erige una pretensión de corrección y según Raz el derecho erige una pretensión de autoridad legítima. Si la tesis de la autoridad legítima es aceptada como una tesis moral, entonces parecería que en Raz hay una paradoja aparente, ya que la pretensión de autoridad legítima tiene un punto en común con el no-positivismo: un tipo especial de vinculación normativa con el derecho.

El siguiente argumento de Raz consiste en cuestionar las diferencias entre el espectador y el participante. Esta diferenciación no le parece a Raz lo suficientemente nítida, y por ello se pregunta si tiene alguna relación con la típica aproximación metodológica de los antropólogos, quienes sugieren que para comprender realmente a una cultura es necesario adoptar la perspectiva de los participantes de ésta. No obstante, Alexy no explica las diferencias metodológicas entre ambas perspectivas, y esto lleva a Raz a asumir que la diferencia entre estas perspectivas reside en el sujeto-objeto de la investigación, lo cual no ofrece razón alguna para esperar que el observador y el participante no compartan los mismos conceptos. Esto significa que ambos no tienen por qué diferir en sus aproximaciones metodológicas y conceptuales hacia el derecho, ya que

justificada na teoría pura do direito: uma crítica ás teses de Joseph Raz", en, Aguiar de Oliveira, Júlio y, Travessoni Gomes, Alexandre (Eds.), Hans Kelsen, Teoría jurídica e política, Forense Universitaria, Río de Janeiro, 2013, p. 105 ss. 
éstas no pertenecen a un ámbito privado e incomprensible para el otro, sino que forman parte del mismo mundo jurídico. Por esta razón, según Raz, el argumento alexyano que pretende sostener la tesis de la separación entre derecho y moral desde la perspectiva del participante es incorrecto.

El tercer argumento va dirigido hacia el argumento de la corrección. En un principio, basándonos en la idea de Raz de que el derecho aspira a tener una pretensión de autoridad legítima, no veríamos problema alguno en compararlo con el proyecto alexyano, pero esto no es así. Raz entiende esta pretensión dentro de un panorama más general de la filosofía del lenguaje aplicable a todas las acciones reflexivas de un sujeto mediadas por actos de habla. En este sentido Raz admite que "el derecho no es una acción, sino producto de una acción, y es común atribuirle al producto de la acción algunas de las propiedades de la acción". ${ }^{470}$ Esta tesis lo llevará a plantear dos objeciones a la tesis de la pretensión de corrección.

La primera objeción consiste en señalarle a Alexy que no admita esta tesis dentro de un contexto más amplio del derecho, lo cual le impide ver esta pretensión corporeizada en el discurso de una banda de ladrones. Para Alexy esta pretensión no puede ser erigida por una banda de ladrones. No obstante, Raz considera que, seguramente, si los bandidos actúan intencionalmente qua bandidos, entonces sus acciones manifiestan esta pretensión: los bandidos están comprometidos con la pretensión de que sus acciones son correctas, independientemente de las razones que pudieran ofrecer ante el otro. Desde luego, bajo los presupuestos de la ética del discurso este punto podría no presentar mayor problema para ser refutado. Pero más interesante podría parecernos la posibilidad de que los bandidos no piensen en sus acciones tal y como las describe Alexy. El ejemplo de Raz acerca de los "buenos bandidos" es el siguiente.

Ellos podrían pensar en ellas (sus acciones) como acciones cristianas, ellos podrían actuar pretendiendo que actúan de un modo cristiano (probablemente así es como Robin Hood y su banda pretendían ver sus acciones). En este caso ellos pretenden corrección para ese estándar, es decir, el estándar del cristianismo. Sus acciones no serían intencionales bajo la descripción de "acciones bandidas" y ellas no buscarían tener este tipo de pretensión de corrección bajo esos estándares, si es que los hay. 471

\footnotetext{
${ }^{470}$ Raz, Joseph, op. cit., p. 26.

${ }^{471}$ Raz, Joseph, op. cit., p. 27.
} 
La segunda dificultad u objeción de Raz consiste en reprocharle a Alexy que crea o suponga que la tesis de la corrección suponga una pretensión de que el derecho es moralmente correcto y así sostener que el derecho está conectado a la moral. Por razones morales, la pretensión de corrección es una pretensión formal en el sentido de que no determina qué tipo de estándares deben incluirse. Esto no es posible para Raz debido a que esta pretensión no puede aplicarse a todas las conductas intencionales. Si el derecho está vinculado a estándares de justicia esto se sigue de la naturaleza del derecho, no de la conducta intencional. Por estas razones, Raz indica que la pretensión de corrección, al ser formal, no puede ayudarnos a comprender la naturaleza del derecho.

La cuarta objeción va dirigida hacia el argumento de la injusticia, el argumento Radbruch. Raz considera que el núcleo de este argumento sostiene que el sistema jurídico necesariamente contiene una norma que instruye a los jueces a rehusarse a aplicar leyes que puedan perpetrar injusticias extremas. Raz describe el ejemplo de la Ordenanza onceava de Alexy y concluye que este argumento, asumiendo que fuera válido (arguendo) no muestra que el derecho deba incluir elementos morales. Lo único que muestra esta presuposición, según Raz, es que el concepto de derecho sólo necesita incluir lo que el poder legislativo legisle. Dicho de otro modo, no se necesita de un cambio de perspectiva para entender que el derecho mismo es capaz de regular que en algunos Estados pueda existir una norma jurídica que pueda derogar otra norma o declarar la no vigencia de un fallo judicial al ser demasiado injustos.

Indudablemente, es una crítica fuerte debido a que Raz sostiene que es posible que en algunos Estados esta norma tenga vigencia y en otros Estados no la tenga, por lo cual su existencia es una cuestión de hecho. Para refutar al positivismo jurídico Alexy debe mostrar no sólo que los jueces de todas las cortes deben hacer a un lado a las normas extremadamente injustas, sino que el derecho debe darles esta facultad como facultad jurídica, de modo que este ejercicio facultativo jamás pueda ser una violación al derecho mismo. ${ }^{472}$ Muchos de los argumentos de Alexy desarrollados en El Concepto y la validez del derecho $-\mathrm{y}$ de toda su reflexión sistemática no-positivista del derecho- están vinculados con pretensiones de que el mundo será moralmente mejor si el derecho posee ciertas características: no obstante, Raz no ve cómo estos argumentos pueden contribuir a semejante misión. Un punto decisivo de la crítica de Raz en este punto reside en reprocharle

\footnotetext{
${ }^{472}$ Raz, Joseph, op. cit., p. 31.
} 
a Alexy la invalidez del argumento que sostiene que "a mayor grado de injusticia mayor es el grado de certeza sobre ella". Raz no está seguro de que un acto de injusticia extrema siempre sea así visto por quien lo comete, y de este modo concluye que existen buenas y notorias evidencias que le dan validez a sus objeciones.

Finalmente, la quinta objeción va dirigida en contra del argumento de los principios. Raz objeta a Alexy que ofrece un argumento non sequitur al sostener que el sistema jurídico de todo país desarrollado debe incluir principios a partir de la premisa de que las cortes están obligadas por la ley a aplicar principios, a pesar de que pueda darse el caso de que existan países cuyos jueces estén obligados a aplicar principios que no sean parte de sus sistemas jurídicos, como es el caso de las cortes de Gran Bretaña.

En síntesis, Raz está convencido de que la tesis alexyana de la separación entre derecho y moral atribuida al positivismo de ningún modo es correcta, al menos, en lo que concierne al positivismo jurídico inglés, cuyo teórico más eminente, Bentham, "hizo más que nadie para argumentar que el derecho debería ser moral, y expuso las deficiencias morales del derecho de su tiempo". ${ }^{473}$ Por ello, no debe sorprendernos que Raz termine sus objeciones con un comentario según el cual la obra de Alexy fracasa precisamente por no querer ir más allá de esta disputa milenaria:

Veo el libro de Alexy (El Concepto y la validez del derecho) como una oportunidad perdida, la oportunidad de ir más allá de la disputa acerca del positivismo jurídico. [...] Probablemente sea tiempo no de refutar al positivismo jurídico, sino de olvidar la etiqueta y considerar los puntos de vista de diversos escritores dentro de la tradición a la que pertenecen en sus propios términos. ${ }^{474}$

Tanto las críticas de Bulygin como las de Raz han atacado los puntos centrales de esta obra de Alexy con una intensidad notable. Ahora analizaremos la defensa de los argumentos principales de esta obra frente a las objeciones que acabamos de sintetizar.

\subsection{En defensa del no-positivismo alexyano: la doble naturaleza del derecho}

Ahora presentaremos la defensa de Alexy de las críticas anteriores formuladas a los postulados normativos de esta obra. Si en las secciones dedicadas a la Teoría de la

\footnotetext{
${ }^{473}$ Raz, Joseph, op. cit. p. 35.

${ }^{474}$ Raz, Joseph, "The Argument from Justice, or How Not to Reply to Legal Positivism", en, Pavlakos, George (Ed.), Law, Rights and Discourse. The Legal Philosophy of Robert Alexy, Portland, Hart Publishing, 2007, p. 35.
} 
argumentación jurídica y a la Teoría de los derechos fundamentales formulamos diversas objeciones planteadas hacia sus puntos esenciales, tratándose de esta obra el resultado no podía ser menor. Es por ello que si esta teoría desea desafiar al positivismo jurídico deberá refutar estas objeciones y luego explicar la tesis de la doble naturaleza del derecho.

\subsubsection{La respuesta a Bulygin}

En un primer debate, Alexy se concentrará en las dos objeciones de Bulygin a la pretensión de corrección, las cuales afectan directamente a la comprensión alexyana del derecho. La primera objeción está dirigida hacia la distinción entre una conexión clasificante de una cualificante, mientras la segunda está dirigida hacia una crítica radical de la pretensión de corrección mediante el escepticismo respecto a la idea de una contradicción performativa. Veamos con más detalle el núcleo de las respuestas a ambas objeciones.

Respecto a la distinción entre conexiones clasificantes y cualificantes la objeción de Bulygin consiste en indicar una contradicción existente entre la conexión necesaria referida a la conexión clasificante y la conexión fáctica o contingente de la conexión cualificante. Alexy defiende sus argumentos explicando que el hecho de erigir una pretensión de corrección es distinto al hecho de satisfacerla. La pretensión de corrección es necesaria para que los sistemas jurídicos califiquen como tales. Si un sistema jurídico no satisface esta exigencia, entonces tendrá el carácter de un sistema jurídico deficiente. Aquí no existe contradicción alguna. Ambas conexiones, la clasificatoria y la cualificatoria, son necesarias.

En el ámbito de las normas jurídicas y decisiones individualizadas la situación cambia, ya que en éstas la conexión referida al hecho de formular y satisfacer la pretensión de corrección siempre es cualificatoria. La razón por la cual la pretensión y satisfacción de ella es cualificatoria reside en el carácter institucional del derecho visto como un sistema. Si el sistema jurídico, para ser tal, requiere de la pretensión de corrección como regla constitutiva, entonces las normas y decisiones jurídicas individualizadas establecen una conexión parasitaria con la pretensión enarbolada por éste. El sistema jurídico como totalidad le confiere a sus normas y decisiones jurídicas individualizadas un marco normativo. La vinculación institucional es la que está detrás de estas normas y decisiones, y, como lo hemos indicado, el sistema jurídico siempre erige esta pretensión de corrección, independientemente de la satisfacción de ésta. Si todo lo que Alexy ha argumentado hasta ahora es correcto, entonces la primera objeción de Bulygin ha sido superada. 
La segunda objeción, sin embargo, no será fácil de refutar. Esta objeción está dirigida hacia la oscuridad del concepto de contradicción performativa. Alexy defenderá la validez del uso de los ejemplos de artículos que vimos anteriormente para mostrar que poseen un defecto, pero no cualquier tipo de defecto, sino uno vinculado a la contradicción performativa. En algo están de acuerdo ambos: estos artículos tienen un defecto. Para Bulygin los artículos son órdenes, pero carentes de sentido, ya que la justicia o injusticia de una constitución o un Estado es un estado de cosas que no puede ser prescrito u ordenado, tan carentes de sentido como ordenar "que un país sea rico o que los árboles sean verdes".

Alexy difiere de Bulygin, ya que de acuerdo con su comprensión del derecho, sí existen destinatarios y acciones a los cuales pueden referirse principios tan abstractos como los de la justicia y la injusticia. Es por ello que la introducción de un principio constitucional injusto sería caer en una contradicción performativa que niegue a la idea la justicia, la cual en el pensamiento no-positivista de Alexy subyace en la fundamentación de todo sistema jurídico. En el caso de los enunciados referidos a sentencias y normas jurídicas aisladas es lo mismo: las sentencias y decisiones jurídicas formulan la pretensión de corrección, aun y cuando ésta no pueda satisfacerse. La no formulación de esta conduciría a un absurdo. La presencia de un absurdo en el acto de habla indica la presencia de una posible contradicción performativa, la cual tiene el objetivo de mostrarnos que ciertas reglas son necesariamente válidas.

Respecto a la contestación al segundo round de Bulygin, Alexy indica que la pretensión de corrección es el recurso normativo que le permite al derecho distinguirse de la famosa banda de ladrones que desde los días de Agustin persigue al positivismo jurídico. Dicho en otras palabras, la pretensión de corrección es la llave para acceder al ámbito de la doble naturaleza del derecho y así al establecimiento de la conexión entre moral y derecho. Como lo vimos antes, a Bulygin le parece muy oscura la idea de la contradicción performativa. Para responderle a Bulygin, Alexy establece tres pasos indispensables en el ámbito de la pretensión de corrección: "[C]ualquiera que formule una pretensión de corrección con un acto a, primero, afirma que a es correcto, segundo, garantiza que a puede ser justificado y tercero, espera que todos los destinatarios de la pretensión acepten a”. ${ }^{475}$

${ }^{475}$ Cfr. Alexy, Robert, “Law and Correctness", en, Current Legal Problems 51, 1998, p. 208. En adelante, LC. 
Alexy vuelve a retomar sus ejemplos para explicar la conexión lógica entre el acto de declarar un hecho jurídico y el siguiente de ejecutarlo. La idea de contradicción performativa está basada en el concepto clásico de contradicción, aplicable a los actos de producción y ejecución del derecho (o actos de fundamentación y de aplicación de las normas) en cuanto estos actos expresan e implican necesariamente contenidos asertivos o proposicionales. Una vez que Alexy explica esta cualidad de los actos jurídicos, procede a refutar la objeción de los ejemplos históricos de Bulygin de Calígula y Nerón, los cuales parecen indicar que no siempre los sistemas jurídicos han enarbolado una pretensión de corrección. Para refutar esta objeción, Alexy plantea que ambos tiranos no formularon sus actos con base en sus convicciones personales de dominación y fetichización del poder, sino que las presentaron como si fueran correctas. Esto, sin duda, fue un abuso de la pretensión de corrección, lo cual sólo confirma que esta es necesaria, aun y cuando esta no se lleve a cabo con honestidad.

Pero hay más respecto a esto: los diversos sujetos mencionados por Bulygin poseen concepciones morales distintas, lo cual puede dar lugar a un relativismo moral que irradiaría a los sistemas jurídicos, a tal grado, que el contenido del derecho no podría fundamentarse bajo presupuestos éticos universales mínimos. Este punto es atacado por Alexy mediante el trasfondo de argumentos basados en la ética del discurso, según los cuales existen prácticas argumentativas racionales que pueden ser suficientes para fundamentar un punto de vista moral y jurídico universalista.

Según Alexy, las normas de competencia vigentes que facultan a un juez o parlamento están enraizadas en un discurso oficial que no puede renunciar a la pretensión de corrección, si es que aspiran a considerarse jurídicas. Esto es, la dimensión fáctica de estos sistemas jurídicos, normas y decisiones jurídicas aisladas incluye, si no desea ser reconocida como simples actos de fuerza bruta, una dimensión ideal, que permite, en buena medida, la aceptabilidad de los sujetos. Alexy pone de ejemplo la conversión de los tres famosos iuris praecepta de Ulpiano para dar cuenta de la imposibilidad de que las decisiones de los jueces romanos dejen de lado esta pretensión, aunque en el fondo no crean en ella. La inversión quedaría del siguiente modo:

luris praecepta sunt haec: honeste vivere, alterum non laedere, suum cuique tribuere ${ }^{476}$

\footnotetext{
${ }^{476}$ Los mandatos del derecho son: vive honestamente, no dañes a otros, da a cada uno lo que le corresponde.
} 
luris praecepta sunt haec: vivere del inhoneste, laedere del alterum, el cuique del suum no el tribuere ${ }^{477}$

Definitivamente, un sistema jurídico no podría tener en sus muros este tipo de inscripciones correspondientes al segundo conjunto de preceptos, al menos no si aspira a que sus decisiones sean jurídicas. Ahora pasaremos al tercer y último round.

Respecto a la contestación de la objeción principal de Bulygin en el tercer round, la tesis del fin del debate, Alexy no cree que tal mediación sea posible: "[S]ólo se puede ser un positivista o un no-positivista: tertium non datur". 478 Para evitar la posibilidad de fundamentar una tercera vía entre el positismo y el no positivismo jurídicos, Alexy ofrece tres argumentos para rechazar la tesis bulygiana.

En primer lugar, la afirmación alexyana acerca de la tesis de la separación positivista del derecho de la moral de la perspectiva del participante, no sólo dice que esta separación es, desde este punto de vista, correcta, sino que es "esencialmente correcta", lo cual permite restringir, en cierto modo, el contenido del derecho. No debemos olvidar que siempre será posible que un sistema jurídico enarbole una pretensión de corrección y que, no obstante, no la realice, aunque ésta excluya del concepto de derecho a todos aquellos sistemas de normas que no enarbolan semejante pretensión. ${ }^{479}$

La segunda razón para rechazar la tesis del fin del debate reside en que el concepto de derecho no es una preocupación exclusiva del positivismo jurídico. Los argumentos normativos no sólo influyen en nuestra concepción sobre lo que debería ser derecho, sino

\footnotetext{
477 Los mandatos del derecho son: vivir deshonestamente, dañar a otros, no dar a cada uno lo que le corresponde.

478 Alexy, Robert, Between Positivism and Non-Positivism? A Third Reply to Eugenio Bulygin, Conferencia ofrecida en Girona en mayo de 2010, p. 17. En adelante, BPNP

${ }^{479}$ Sin duda alguna, estamos ante un tema de la filosofía práctica. Alexy está de acuerdo con Bulygin en que la injusticia extrema encubierta hipócritamente es peor que la injusticia extrema explícita, tal y como es peor enterarnos de que una persona que supuestamente enseña alguna doctrina ética virtuosa lleva a cabo conductas deshonestas. En esta situación, no sólo reprobamos la conducta y consecuencias de esta persona, sino que también reprobamos que teóricamente ésta sostenga lo contrario. A esta contradicción entre lo que supuestamente se profesa y lo que realmente se hace por acción u omisión le llamaremos un problema de "doble moral". Lo mismo pasa con los sistemas jurídicos que encubren la injusticia extrema bajo la fachada de pretender ser justos. Este tipo de lamentables hechos normativos sólo confirman la necesidad de enarbolar la pretensión de corrección en todos los ámbitos prácticos, incluido el jurídico. Sobre el tema de la "doble moral" no podemos extendernos más. Basta decir que la ética no es sólo teoría, sino práctica. De poco o nada sirve que un sujeto se erija como juez moral de los otros si él mismo viola los valores, normas, reglas y principios que consideró universalizables para todos.
} 
que están incluidos en él. Esto está vinculado no sólo con la aplicación del derecho, sino con su identificación como tal. La Fórmula de Radbruch no se queda en el terreno crítico respecto a las leyes extremadamente injustas, sino que busca la desinstitucionalización de éstas: "[L]a fórmula no dice que la 'injusticia extrema no debería ser derecho', sino, más bien, que la 'injusticia extrema no es derecho'". 480

La última razón para rechazar el argumento de Bulygin consiste en admitir que el no-positivismo busca transformar un defecto moral en uno jurídico, a diferencia de diversos positivistas críticos, quienes sostienen que es posible reconocer como jurídico al derecho extremadamente injusto, y sin por que ello se le otorgue un deber moral de obediencia. Lo interesante del razonamiento de Alexy es que no considera que la pretensión de corrección pueda sustituir en modo alguno a la eficacia social y a la legalidad conforme al ordenamiento, sino que estos tres aspectos coexisten en lo que Alexy considera una versión de no-positivismo incluyente, ${ }^{481}$ en el cual se expresa mejor la doble naturaleza del derecho. Por estas razones, la discrepancia de Alexy con Bulygin no es verbal, sino que en ella alcanza a afectar a la naturaleza del derecho.

\subsubsection{La respuesta a Raz}

La respuesta de Alexy a Raz será contundente desde el principio. Al igual que como le contestó a Bulygin, Alexy le recriminará a Raz que, precisamente, es importante no olvidar las etiquetas en torno a la distinción entre positivismo y no-positivismo, ya que estas categorías serán iluminadoras mientras exista el derecho. Según Alexy, la relación entre el derecho como hecho y el derecho como ideal es la cuestión más importante para explicar su naturaleza. ${ }^{482}$

Para comenzar la respuesta a Raz, Alexy indica que las objeciones que éste y Marmor plantean a los argumentos de El concepto y la validez del derecho no logran dar en el blanco. Luego arremete contra la tesis polémica de Raz acerca de que el derecho no puede tener cualquier contenido. Esta tesis no la expondremos porque, como lo hemos mencionado, no es correcta a la luz de los planteamientos del mismo Kelsen. En otros

\footnotetext{
${ }^{480}$ Alexy, Robert, BPNP, p. 18.

${ }^{481}$ Alexy, Robert, "On the Concept and the Nature of Law", en, Ratio Juris, n. 21, 2008, 287-288. En adelante, CNL.

${ }^{482}$ Cfr. Alexy, Robert, "An Answer to Joseph Raz", en, Pavlakos, George (Ed.), Law, Rights and Discourse. The Legal Philosophy of Robert Alexy, Portland, Hart Publishing, 2007, p. 37. En adelante, AJR.
} 
polémicos puntos de esta parte, Alexy cuestionará la tesis hartiana acerca de la inutilidad de dar un concepto de derecho y mejor concentrarse en sus características, a lo cual responderá que si deseamos explicar la naturaleza del derecho, no es suficiente con presentar una lista de sus propiedades, sino que estas propiedades deben ajustarse en un sistema. Después, Alexy notará aquel elemento extrañamente moral existente en la teoría de Raz, el cual consiste en proclamar que el derecho pretende una autoridad legítima, esto es, que Raz sostendrá una pretensión de corte moral en el ámbito jurídico, mientras que al mismo tiempo defiende la causa positivista. Alexy cree que esto no es posible desde ninguna perspectiva.

Alexy pasará a discutir las objeciones planteadas por Raz a la distinción entre observadores y participantes, la clave de la teoría no-positivista para acceder a una comprensión de la naturaleza del derecho. Para Alexy, la tesis de la separación entre derecho y moral será correcta sólo desde la perspectiva del participante. Esto no quiere decir, como podría pensarse a veces, que ambos sujetos tengan siempre perspectivas distintas acerca del derecho, sino que existen ocasiones en las que se necesita saber qué respuesta es la correcta y todo aquel que la formule, según Alexy, necesariamente no hace más que adoptar la perspectiva del participante. Para Alexy el contexto del participante está definido por la cuestión ¿cuál es la respuesta correcta en términos jurídicos?, mientras que el contexto del participante está definido por la cuestión ¿cómo se hacen de hecho las decisiones jurídicas? ${ }^{483}$

Alexy está seguro de que tanto el participante como el observador utilizan diferentes conceptos de derecho, ya que el participante al intentar responder a la pregunta acerca de qué es derecho se basa en dimensiones sobre lo que el derecho es y debe ser, mientras que el observador sólo se queda en la dimensión fáctica. Si el observador abandonara la postura fáctica, dejaría de ser observador. Para comprobar que el participante sí incluye dentro de sus reflexiones la dimensión ideal del derecho, entonces debemos ver la función de los argumentos de la corrección, de la injusticia y de los principios. Es por ello que veremos ahora la defensa de Alexy de sus tres argumentos que conectan al derecho con la dimensión ideal.

${ }^{483}$ Cfr. Alexy, Robert, AJR, p. 46. 
a) la defensa del argumento de la corrección: este argumento, que sirve de base para los otros dos, será defendido por Alexy mediante la tesis de que sólo puede valer como una pretensión de corrección legítima aquella capaz de universalizar las intenciones del sujeto. Tiene razón Raz al sostener que un bandido no tiene por qué ver sus acciones como ilegítimas en todo momento (siempre es posible aducir razones para llevar a cabo acciones reprobables). Si esto fuera así, entonces la pretensión de corrección de nada serviría para intentar comprender la naturaleza del derecho. La pretensión de corrección no tiene un carácter individualista, sino que debe justificarse ante todos los participantes del sistema jurídico.

La pretensión de corrección parte de presupuestos morales universalizables para los participantes de una situación ideal de diálogo, o, en este caso, para los participantes de un sistema jurídico ideal. Esta pretensión impide que el discurso jurídico quede reducido a una mera expresión desnuda de poder encubierta bajo el manto de lo jurídico. No creemos que un bandido pueda proclamar como válida ante un auditorio universal o esfera pública la acción de robarles sus pertenencias para beneficio del gremio al que pertenece. Al menos la intención del bandido sería criticada por este tipo de auditorio, independientemente de que en el ámbito privado algunos sujetos coincidieran en hacer lo mismo si estuvieran en la misma posición. Por tanto, la objeción de Raz al argumento de la pretensión de corrección puede ser superada.

b) la defensa del argumento de la injusticia: este segundo argumento, compuesto por la Fórmula de Radbruch, es atacado por Raz al indicar que el ejemplo de la onceava ordenanza usado por Alexy es compatible con el positivismo jurídico, de modo que el argumento de la injusticia extrema falla en el blanco a atacar. Para defender sus argumentos, Alexy presentará la defensa en dos partes: una teórica y otra normativa. La parte teórica, referida a la naturaleza del derecho, sostiene que la pretensión de corrección está vinculada a una dimensión ideal y a otra dimensión crítica. "El valor más abstracto de la dimensión fáctica es la certeza jurídica, mientras que el valor más abstracto de la dimensión ideal es la justicia. Esto implica que es imposible decir qué es el derecho sin decir cómo debería ser. ${ }^{484}$

\footnotetext{
${ }^{484}$ Alexy, Robert, AJR, p. 52.
} 
El derecho es un orden institucional normativo, en el sentido de que está compuesto de hechos institucionales destinados a la regulación de acciones humanas, pero esto lo conecta, precisamente, a una dimensión ideal de la que no puede escapar la comprensión de su naturaleza. Si esta explicación es convincente, entonces la naturaleza del derecho incluye una dimensión normativa. Ahora bien, ¿qué pasa cuando los principios de seguridad jurídica y justicia entran en un conflicto normativo? Cuando ocurren conflictos entre la dimensión fáctica y la dimensión ideal del derecho en muchas ocasiones la seguridad jurídica es considerada superior a la justicia.

Este tema de la prioridad prima facie de la seguridad jurídica no sólo ha aparecido en el ámbito de la filosofía jurídica, sino de la filosofía moral y política. Según Rawls, cuando la estructura de una sociedad es razonablemente justa los ciudadanos tienen el deber de obedecer inclusive a las leyes injustas, siempre que no excedan ciertos límites de injusticia. ${ }^{485}$ Este deber tiene como fundamento la prioridad de la seguridad jurídica, la cual, a su vez, posee prioridad respecto a la justicia debido a que detrás de la seguridad jurídica está el valor de la legitimidad de la autoridad. Esto puede producirnos un problema en las sociedades modernas, ya que si siempre le damos prioridad a la seguridad jurídica en virtud del valor moral de la legitimidad de la autoridad que se encuentra detrás de ella, entonces es posible que las leyes injustas siempre tengan en todo momento el carácter de derecho. Para Alexy esto no es así. A pesar de que Alexy reconoce el peso de la seguridad jurídica, para él, al igual que para Radbruch, ella no puede estar por encima de la justicia en el caso de una injusticia extrema.

La injusticia extrema ocurre cuando los derechos humanos son flagrantemente violados y estas acciones pueden ser entendidas como inmorales por todos los participantes del sistema jurídico, de ahí que Alexy haya conectado recientemente a los derechos humanos con la moral. ${ }^{486}$ Está claro que este es un punto polémico, ya que la diferencia de grado entre la injusticia y la injusticia extrema no siempre será visible para todos y hasta es posible que esto genere tensiones en personas con la misma postura respecto a una decisión jurídica. ${ }^{487}$ Alexy le concede a Raz un punto importante al reconocer

\footnotetext{
${ }^{485}$ Cfr., Rawls, John, Rawls, John, Teoría de la justicia, México, D. F., FCE, 2010, p. 320 ss.

${ }^{486}$ Cfr., Alexy, Robert, DMEDH, pp. 163-164.

${ }^{487}$ Es posible sostener que dos participantes de un sistema jurídico pueden afirmar que una decisión jurídica fue injusta, pero mientras que uno sostiene que debe respetarse el resultado final, el otro podría afirmar que éste no debe respetarse debido a la injusticia extrema provocada. Ambos estarían de acuerdo en que fue una 
que el discurso racional no está conectado de manera lógica a la comprensión de un conocimiento último acerca del grado de injusticia cometido mediante un acto legal. Creemos que, al igual que con las reglas de la argumentación práctica y jurídica y el principio de proporcionalidad, la tesis de la injusticia extrema no puede brindar una certeza absoluta sobre lo que hay que decidir en una decisión jurídica. Sin embargo, sus premisas pueden acercarnos bastante a un objetivo moral universal. En este caso, al conectar la tesis de la injusticia extrema con la violación de los derechos humanos, puede mostrarse la conexión necesaria entre derecho y moral, y, con ello, establecer un límite para el derecho. Esto bastaría para sostener que la objeción de Raz al argumento de la injusticia también ha sido refutada.

c) La defensa del argumento de los principios: Alexy ahora se enfocará en las dos objeciones de los principios. La primera objeción de Raz, dirigida a la tesis de que todos los sistemas jurídicos mínimamente desarrollados incluyen principios, será respondida por Alexy al sostener que del paso a reforzar un deber jurídico de ponderar al de tener una regla que impone deberes de ponderar no implica ningún cambio de un concepto a otro. Ambos argumentos tiene estructuras diferentes, lo cual es notorio por el hecho de que del paso del concepto de ponderación al del concepto de principio es claro sólo si algunas tesis del concepto de ponderación son verdaderas. ${ }^{488}$ La segunda objeción, no obstante, debe tomarse en serio. Ésta reside en la tesis de la incorporación de los principios al sistema jurídico. Según Raz, las diversas teorías acerca de los conflictos normativos muestran que el derecho puede requerir la aplicación de ciertos estándares, sin que por ello estos estándares jurídicos - y otros principios morales - se vuelvan parte del sistema jurídico del país que los aplica. Para Alexy, desde el punto de vista del no-positivismo incluyente, que los jueces puedan aplicar principios porque así lo manda el derecho no significa otra cosa que los jueces puedan aplicar principios ya que así está ordenado por la naturaleza del derecho. Esta naturaleza del derecho, como veremos, conecta a la dimensión fácticainstitucional del derecho con la dimensión ideal-crítica del derecho. De esta manera, según Alexy, la argumentación moral se incorpora a la argumentación jurídica. ${ }^{489}$ También, de paso, queda refutada la objeción de Raz.

decisión injusta, sin embargo, la diferencia de grado podría llevarlos a aceptar o a rechazar las consecuencias de ésta.

${ }^{488}$ Alexy, Robert, AJR, p. 55.

${ }^{489}$ Alexy, Robert, AJR, p. 55. 
Hasta ahora, las objeciones de Bulygin y Raz han sido contestadas por Alexy mediante un escrupuloso análisis normativo y conceptual. Las objeciones han contribuido decisivamente a que Alexy haya replanteado sus argumentos ofrecidos en El concepto y la validez del derecho y después haya dado un giro hacia la tesis de la doble naturaleza del derecho. Es por ello que ahora veremos en qué consiste esta tesis

\subsubsection{La tesis de la doble naturaleza: coerción y corrección}

La réplica de Alexy a las objeciones tanto de Bulygin como de Raz nos ha parecido, en términos generales, convincente. Así, Alexy ha desarrollado una teoría no-positivista del derecho capaz de soportar la embestida de dos grandes exponentes del positivismo jurídico como estos filósofos, quienes durante muchos años han sido magníficos expositores del positivismo jurídico. Ambos intentaron convencer a Alexy de dejar a un lado la distinción entre positivismo y no-positivismo jurídicos. Aunque en un primer momento esta tesis suena razonable - dejar a un lado las etiquetas y enfocarnos en buscar comprender los argumentos de lo que es y debe ser el derecho-, ésta no es posible enarbolarla desde el no-positivismo incluyente de Alexy. Precisamente, la distinción entre positivismo y nopositivismo refleja el carácter dual del derecho, es decir, entre el derecho como hecho y el derecho como ideal.

La distinción entre el derecho como hecho y como ideal es, según Alexy, la distinción entre el ser y deber ser del derecho. También esta distinción es la base de la tesis de la doble naturaleza del derecho, o, dicho de otro modo, "el nuevo estandarte bajo el cual Robert Alexy presenta su teoría del derecho", 490 el cual no sólo lo llevará a debatir con destacados positivistas, sino también con filósofos no-positivistas como John Finnis, representante del no-positivismo súper incluyente. ${ }^{491}$ La tesis de la doble naturaleza del derecho, la cual apareció en artículos posteriores a El concepto y la validez del derecho, ${ }^{492}$

\footnotetext{
490 Sieckmann, Jan-Reinard, "La tesis de la naturaleza dual en la teoría de Robert Alexy", en, Bernal, Carlos (Ed.), La doble dimensión del derecho. Autoridad y razón en la obra de Robert Alexy, Lima, Palestra Editores, 2011, p. 89.

${ }^{491}$ Sobre este reciente debate, cfr., Alexy, Robert, SRIDL, pp. 97-110, así como la respuesta de Finnis a Alexy, titulada, "Law as Fact an as Reason for Action: A Response to Robert Alexy on Law's «Ideal Dimension»" (The American Journal of Jurisprudence, Vol. 59, No. 1, 2014, pp. 85-109)

492 Esta tesis acerca de la doble naturaleza del derecho, Alexy la ha expuesto en artículos como "La naturaleza de la filosofía del derecho" (2004), "Acerca de dos yuxtaposiciones: concepto y naturaleza, derecho y filosofía. Algunos comentarios acerca de ¿Puede haber una teoría del derecho? De Joseph Raz" (2007), "Sobre el concepto y la naturaleza del derecho" (2008) y "La doble naturaleza del derecho" (2010).
} 
consiste en admitir la existencia de dos elementos que existen necesariamente en el derecho. Estos aspectos no pueden ser contingentes, ya que no pueden no ser incluidos en el derecho si deseamos comprender la naturaleza de éste. Alexy ha descrito esta tesis complementaria del siguiente modo: "[P]reguntar por la naturaleza de algo es más que preguntar por las propiedades interesantes e importantes. Las preguntas sobre la naturaleza del derecho son preguntas sobre sus propiedades necesarias. El concepto de necesidad conduce al corazón de la filosofía". ${ }^{493}$ Al igual que Kelsen, que no reducía a las normas a eventos físicos ni a procesos psíquicos, Alexy entenderá últimamente al derecho como entidades semánticas abstractas o ideales pertenecientes a un reino que compete a la filosofía en sus expresiones más profundas. ${ }^{494}$ Por ello, la pregunta por la naturaleza del derecho se devela como una pregunta genuinamente filosófica:

La pregunta, sin embargo, de si existe un mundo semejante, de entidades semánticas abstractas o ideales, es decir, un "tercer reino" en el sentido de Frege, en adición al mundo físico y psíquico, es uno de lo problemas principales de la filosofía. Este problema compete a la filosofía como metaphysica generalis sive ontología. Esto nos muestra que una clase de argumentos acerca de la naturaleza del derecho tiene una naturaleza genuinamente filosófica. ${ }^{495}$

Para que tengamos la posibilidad de hablar de algo así como una naturaleza del derecho, tendremos que mencionar aquellos aspectos que no son contingentes, es decir, que no son aquellos que pueden ser o no ser propiedades del derecho, sino propiedades necesarias, esto es, aquellas que no pueden no ser incluidas en el derecho. Estas dos propiedades necesarias del derecho lo conectarán con dos respectivas dimensiones: la de

\footnotetext{
${ }^{493}$ Alexy, Robert, NRP, 20. En este sentido, Alexy parece usar el concepto de necesidad no en un sentido epistemológico, sino en un sentido metafísico, tal y como lo ha indicado recientemente, y también como lo indicó Kripke respecto a que en el sentido epistemológico este concepto podría tener el significado de a priori, por lo cual usará el concepto de necesidad en sentido metafísico, pero de ninguna manera en un sentido peyorativo. Sobre esta distinción, cfr., Kripke, Saul, Naming and Necessity, Massachusetts, Blackwell Publishers, 2000, p. 35 ss.

${ }^{494}$ Algunos autores consideran que en los últimos años Alexy ha dado un giro metafísico al defender la tesis de la doble naturaleza del derecho. Sobre este giro, que en palabras de García Figueroa lleva a Alexy a buscar la esencia del derecho en la "región de las verdades eternas" (expresión que retoma García Figueroa de Cassirer), cfr., García Figueroa, Alfonso, "Derecho, metafísica y naturaleza. Alexy en la región de las verdades eternas", en, Bernal, Carlos (Ed.), La doble dimensión del derecho. Autoridad y razón en la obra de Robert Alexy, Lima, Palestra Editores, 2011, p. 246. También en la misma obra cfr., Chiassoni, Pierliugi, "Alexy y la doble naturaleza del derecho: comentarios escépticos", pp. 127-142.

${ }^{495}$ Alexy, Robert, "The Nature of the Arguments about the Nature of Law", en, Meyer, Lukas, Paulson, Stanley y Pogge, Thomas, Rights, Culture and the Law. Themes from the Legal and Political Philosophy of Joseph Raz, Oxford, Oxford University Press, 2003, p. 5. En adelante, NANL.
} 
la efectividad social y la de la legitimidad moral. Estas propiedades son la coerción y la corrección.

a) La coerción: aparentemente esta propiedad es la más fácil de comprender. Un sistema de reglas o normas que no contenga premisas sancionatorias no puede ser un sistema jurídico debido a razones basadas en el uso del lenguaje. Incluir a la coerción en el derecho es adecuado a su objeto porque refleja una necesidad práctica vinculada necesariamente con el derecho. La coerción es necesaria para el derecho porque ella es la que permite que éste pueda satisfacer las prácticas sociales para las cuales es institucionalizado. Si el derecho no tuviera el elemento de la coerción institucional la seguridad jurídica $-\mathrm{y}$ con ello la estabilidad social- peligrarían ante el anarquismo provocado por la falta de eficacia social y vinculación jurídica. Los costos sociales y morales serían enormes en sociedades en las cuales la coordinación y cooperación sociales no siempre son posibles, ya que la validez social es indispensable para lograr la cooperación social, sobre todo porque la moral, sin la vinculación a instituciones coercitivas, no es suficiente para resolver los problemas de nuestras sociedades.

b) La corrección: en términos abstractos esta segunda propiedad necesaria del derecho está en oposición a la coerción, pero al estar ambas integradas en el discurso jurídico la relación es de complementación. Ambos conceptos son diferentes, pero conviven en el derecho. Mientras la coerción posee un carácter teleológico, la corrección posee uno deontológico. La corrección es necesaria para el derecho porque ella forma parte de la estructura de los actos jurídicos y del razonamiento jurídico. La corrección incorporada al discurso permite conectar al derecho con la pretensión de justicia.

La estructura de los actos jurídicos y del razonamiento jurídico incorporan a la corrección en todo momento, aunque a veces la corrección se encuentre implícita. Para hacer explícita esta propiedad implícita y fundamentar la doble naturaleza del derecho, Alexy se valdrá de la construcción de contradicciones performativas, las cuales constituyen uno de sus métodos preferidos para refutar las diversas tesis del positivismo jurídico. Si eliminamos esta pretensión de corrección de los actos y razonamientos jurídicos, entonces desvaneceríamos toda contradicción entre lo explícito e implícito en el derecho. Con este hecho, seguramente, la coerción se erigiría como el único elemento y por tanto el sistema jurídico, normas jurídicas y decisiones jurídicas individualizadas, serían reducidos a meros 
mandatos y órdenes de poder. El derecho sólo podría concebirse como un conjunto de normas dictadas por una banda de bandidos.

Estas dos propiedades son necesarias si una sociedad desea constituirse por medio del derecho, concebido este como un sistema en franca oposición al anarquismo y al absolutismo. La postura anarquista considera que es posible vivir en una sociedad sin normas coercitivas, renunciando con ello a la dimensión fáctica de las normas, mientras que la postura absolutista considera que la autoridad puede ejercer sus normas coercitivas sin apelar a criterios de corrección justificables frente al otro. La idea de una pretensión de corrección en el derecho siempre ha estado ahí, sólo que Alexy ha buscado hacerla más explícita para comprender la naturaleza del derecho, sin renunciar por ello a la dimensión coercitiva y fáctica de las normas. En un texto referido a la idea del surgimiento de la autonomía política en la Grecia clásica, Castoriadis nos recuerda una cláusula que si bien no daba certeza última de la corrección de las normas, sí puede contar como una formulación primera y explícita de la pretensión de corrección:

Ahora bien, ¿cuál es la gran ruptura que introduce la democracia griega, y de un modo más amplio y generalizado, las revoluciones de los tiempos modernos y los movimientos democráticos revolucionarios que le siguieron? Es precisamente la conciencia explícita de que nosotros creamos nuestras leyes, y por lo tanto que también podemos cambiarlas [...] Las antiguas leyes griegas comienzan todas con la cláusula edoxe te boule kai to demo, "le ha parecido bien al consejo y al pueblo". Le "ha parecido bien", pero no "está bien".496

Las leyes parecen buenas. Pero no son buenas. Esta reflexión de Castoriadis nos indica un aspecto esencial de la doble naturaleza del derecho: no podemos aspirar a una certeza última de la corrección de los sistemas jurídicos como totalidad, normas y decisiones jurídicas aisladas, pues afirmar que sólo el derecho justo puede ser tal, nos puede llevar a legitimar acríticamente al derecho. Efectivamente, esta pretensión de que el derecho está conectado y aspira a ser justo, asociada con un mínimo de incertidumbre, es la que puede llevarnos a comprender la dimensión ideal del derecho y conectarla con la dimensión fáctica, para dar cuenta de la naturaleza de éste. ¿Sin esta pretensión de corrección sería posible hablar de derecho?, ¿será cierto que la pretensión de justicia es

\footnotetext{
496 Castoriadis, Cornelius, World in Fragments: Writings on Politics, Society, Psychoanalysis, and the
} Imagination, Stanford, Stanford University Press, 1997, p. 92. 
un elemento contingente?, ¿acaso no termina siendo ésta una excusa hipócrita del dominador?

Para responder a estas tres preguntas, basta con pensar en un ejemplo parecido a los que con frecuencia propone Alexy. La Corte Suprema de México lleva como nombre "Suprema Corte de Justicia de la Nación". Este nombre lleva consigo el concepto de justicia, es decir, incorpora la pretensión de corrección en su carácter institucional-autoritativo. Si quisiéramos saber qué pasaría si intentara contradecir esta pretensión, podríamos valernos del uso de la contradicción performativa para cambiarle su nombre por el siguiente:

\section{Suprema Corte de Injusticia de la Nación}

La pretensión de corrección, entendida como una pretensión de que el derecho incluye a la justicia, quedaría excluida con esta formulación y con ello sus fallos emitidos carecerían de autoridad legítima, porque ¿quién respetaría los fallos de semejante tribunal? Pero, antes de pensar en el respeto a este tribunal, ¿podría instaurarse un tribunal con semejante nombre sin que la sociedad no hiciera algo al respecto? Hasta ahora, no hemos sido testigos de que un tribunal apele a la injusticia para dictar sentencia alguna: esto es, aunque los jueces no la consideren en términos subjetivos para emitir un fallo, en términos institucionales deben apelar a ella.

Ahora bien, es cierto que una corte puede llevar el sustantivo "justicia" en su nombre y dictar fallos injustos y extremadamente injustos, pero esto, lejos de mostrar la inutilidad de la pretensión de corrección ante la praxis, sólo confirma la necesidad de ésta, inclusive por parte de jueces y legisladores injustos. Sus leyes y fallos deben parecer justos aunque no lo sean, de lo contrario no podrían ser considerados "derecho". Es cierto que es lamentable saber de injusticias aplicadas en nombre de la justicia y del poder de la razón, y no en nombre de la injusticia desnuda y las razones del poder, pero esta pretensión implica un deber de fundamentación de todos los fallos y normas de un sistema jurídico ante los ciudadanos, lo cual, ciertamente, puede evitar que fallos extremadamente injustos puedan ser dictados.

No es posible tener una certeza última de que la pretensión de corrección esté siempre detrás de cada acto y razonamiento jurídicos, pero esta aspiración no es un recurso que debamos menospreciar por pertenecer al mundo platónico, al menos no si deseamos que la coerción no sea el único elemento necesario del derecho. Por fortuna, la naturaleza 
del derecho requiere necesariamente de ambos elementos. Ciertamente, no se trata de una concepción puramente platónica, sino también de una concepción institucional-crítica. A partir de la tesis de la doble naturaleza del derecho, tesis central del programa alexyano, ahora será analizado el problema de la validez del derecho. 


\section{Capítulo noveno: Efectividad, vigencia y validez del derecho. En búsqueda de la normatividad de lo fáctico}

\section{Introducción}

En la parte final de esta obra hemos reconstruido y analizado los temas principales de la obra de Alexy, la cual ha tenido una recepción extraordinaria en los más diversos ámbitos de la filosofía jurídica contemporánea. En el caso de la validez del derecho, existen planteamientos conceptuales, normativos y empíricos que deben ser analizados en este capítulo. Estos problemas estarán vinculados respectivamente a los tres ámbitos clásicos de validez del derecho.

Al principio parecería fácil definir en qué consiste un concepto como el de validez, sin embargo, después de un análisis de los usos de este concepto y sus alcances teóricos y prácticos, éste se devela como poco claro. De hecho, el mismo Kelsen fue blanco de críticas por Ross y otros debido al uso de este concepto en diversas secciones de su obra. Además del concepto de derecho, el concepto de validez también parece estar plagado de cargas jurídicas, sociológicas y filosóficas que lo vuelven un concepto difícil de definir. Comenzaremos este capítulo con la descripción de los tres ámbitos de validez del derecho.

\subsection{Tres ámbitos de validez de las normas}

Sin duda, estamos ante un concepto que cuando es escuchado y pensado en nuestras sociedades varía entre el escepticismo y la esperanza, entre la realidad y el mundo de las pretensiones. ${ }^{497}$ Bernd Rüthers y Christian Fischer han afirmado que la pregunta sobre el fundamento de validez del derecho es la pregunta central de la ciencia jurídica y de la justicia. ${ }^{498}$ Veamos en qué consisten estos problemas con mayor detalle. Como lo indica Zai-Wang Yoon, la expresión "validez" no sólo tiene múltiples significados, sino que tanto en la filosofía en general como en la filosofía jurídica es usado con frecuencia en un sentido inconsistente y poco claro. ${ }^{499} \mathrm{El}$ concepto de validez es de los más utilizados en la

\footnotetext{
${ }^{497}$ Cfr., Lüderssen, Klaus, Genesis und Geltung in der Jurisprudenz, Fráncfort del Meno, Edition Suhrkamp 1996, p. 125

498 Rüthers, Bernd, y Fischer, Christian, Rechtstheorie, Múnich, Verlag C. H. Beck, 2010, p. 216.

${ }^{499} \mathrm{Cfr}$. Yoon, Zai-Wang, Rechtsgeltung und Anerkennung. Probleme der Anerkennungstheorie am Beispiel von Ernst Rudolf Bierling, Baden-Baden, Nomos Verlagsgesellschaft, 2009, p. 18.
} 
filosofía del derecho y, no obstante, está lejos de ser claro para quienes lo utilizan. concepto de validez en la filosofía jurídica ha tenido históricamente tres diferentes significados, dependiendo de la perspectiva tridimensional del derecho, la cual, como ya lo vimos antes, consiste en un enfoque que considera al derecho desde la teoría, sociología y filosofía jurídicas.

\subsubsection{El concepto de validez}

En el ámbito de la filosofía jurídica alemana el concepto de validez ha sido usado por la mayoría de los grandes filósofos del derecho. Probablemente, es en este ámbito en el cual el concepto de validez ha sido interpretado desde las más variadas perspectivas. Kelsen no fue el único en analizar este concepto. Antes y después de Kelsen otros filósofos del derecho han visto que detrás de este concepto se encuentra una relación muy especial entre la legitimidad de las normas positivizadas y el correspondiente deber de los ciudadanos de respetar las normas del sistema jurídico.

Si buscáramos hacer un análisis de las diversas concepciones de este concepto en la tradición filosófica alemana, antes y después de Kelsen, nos daríamos cuenta de que este concepto está vinculado a tres posturas que no siempre son claras para otros ámbitos filosóficos, tal vez porque el concepto de validez en alemán (Geltung) posee ciertas características que no posee en inglés (validity). Además de Kelsen, Radbruch y otros llevaron a cabo sugerentes reflexiones al respecto.

Desde la primera edición de 1914 de Principios de la filosofía del derecho, hasta la edición de 1929 de la Filosofía del derecho, Radbruch partía de una idea de Jellinek para plantear el tema que ahora nos preocupa: "[L]a pregunta de la validez del derecho es la pregunta de la «normatividad de lo fáctico»". 500 Esta pregunta llevó a Radbruch a plantear la validez del derecho en tres ámbitos desde sus primeras reflexiones:

La pregunta acerca de la validez del derecho, su pretensión de obediencia, su fuerza obligatoria, puede ser planteada y respondida de maneras tan diversas, que no deberían aparecer respuestas tan contradictorias, para lo que corresponden cuestionamientos diferentes, debido a que estas preguntas no se han podido distinguir con claridad suficiente. Los pensamientos relacionados en los que aparece

${ }^{500}$ Radbruch, Gustav, Rechtsphilosophie, Heidelberg, UTB, 2003, p. 78. 
el problema de la validez jurídica pueden ser probablemente tres: La ciencia del derecho, la sociología jurídica y la filosofía del derecho. ${ }^{501}$

Después de la obra de Radbruch, diversas voces en el ámbito de la filosofía jurídica alemana reinvindicarán la multiplicidad de significados del concepto de validez. Karl Larenz afirmaba que existían cuatro conceptos de validez: el psicológico, el sociológico, el normativo y el ontológico, y entendía el problema de la validez como "el problema de la reunificación entre el ser y el deber ser, realidad e idealidad, existencia temporal y pretensión de intemporalidad de la norma" ${ }^{502}$ En el periodo de posguerra Hans Welzel indicaba en un pequeño opúsculo que "después del problema de la efectividad emerge el problema de la legitimidad". 503 Theodor Geiger, en su polémica con los realistas escandinavos, sostenía que la vigencia de la norma jurídica reside en la posibilidad de conseguir sus efectos. ${ }^{504}$

Décadas posteriores no cambiaron el significado múltiple de este concepto: Alf Ross dedicará un ensayo al concepto de validez con el objetivo de retomar estas distinciones y plantear una crítica a Kelsen que veremos más adelante. Pero la diferenciación de este concepto no quedará aquí. Rupert Schreiber continuará con esta distinción tripartita entre la validez fáctica, la validez constitucional y la validez ideal; ${ }^{505}$ Neumann hablará de un renacimiento de las teorías acerca del concepto de validez; ${ }^{506}$ Dreier también hará una distinción tripartita entre conceptos sociológicos, jurídicos y éticos de validez; ${ }^{507}$ Wróblewski distinguirá entre validez sistémica, fáctica y axiológica; ${ }^{508}$ Hoerster también distinguirá entre la validez (Geltung) y vigencia (Gultigkeit) de las normas; ${ }^{509}$ y en aquella obra de Habermas a las que nos hemos referido en varias ocasiones, el concepto de validez poseerá una carga

\footnotetext{
${ }^{501}$ Radbruch, Gustav, Grundzüge der Rechtsphilosophie, Leipzig, Verlag von Quelle \& Meyer en Leipzig, 1914, p. 159.

502 Larenz, Karl, Das Problem der Rechtsgeltung, Berlín, Junker \& Dünnhaupt, 1929, p. 22.

503 Welzel, Hans, An den Grenzen des Rechts. Die Frage nach der Rechtsgeltung, Colonia y Opladen, Westdeutscher Verlag, 1967, p. 21.

504 Geiger, Theodor, Über Moral und Recht. Streitgespräch mit Uppsala, Berlín, Duncker \& Humblodt, 1979, p. 148.

${ }^{505}$ Schreiber, Rupert, Die Geltung von Rechtsnormen, Heildelberg, Springer-Verlag, 1966, p. 58-68.

506 Cfr. Neumann, Ulfrid, "Theorien der Rechtsgeltung", en, Gessner, Volkmar/Hassemer, Winfried (Eds.) Gegenkultur und Recht, Baden-Baden, Nomos Verlagsgesellschaft 1985, p. 21.

507 Dreier, Ralf, Recht - Moral - Ideologie, Fráncfort del Meno, Suhrkamp, 1982, p. 194 ss.

508 Wroblewski, Jerzy, "Three Concepts of Validity of Law", en, Tidskrift utgiven av Juridiska Foreningen $i$ Finland, 5-6, Finlandia, 1982, pp. 406-419.

${ }^{509}$ Hoerster, Norbert, Was ist Recht? Grundfragen der Rechtsphilosophie, Múnich, Verlag, C. H. Beck, 2006, p. 48 ss.
} 
normativa explícita, tanto así, que será usada con el objetivo de distinguir la legitimidad ética de las normas de la mera facticidad jurídica y social, al considerar al derecho como una categoría de mediación oscilante entre la facticidad y validez. ${ }^{510}$

En el ámbito latinoamericano filósofos como García Maynez y Miguel Reale desarrollaron tempranas reflexiones en torno a la validez del derecho. Para Maynez el problema de la validez del derecho fue parte central de sus reflexiones, como ya se veía desde su temprana obra El problema filosófico-jurídico de la validez del derecho, de 1935, hasta su Filosofía del derecho de 1974, en la cual, con base en los diagramas de Venn, elaborará la Teoría de los círculos, vinculando así al llamado derecho justo con el derecho positivo y el derecho efectivo. ${ }^{511}$ Muy probablemente, Radbruch influyó en este planteamiento de Maynez, así como también en la Teoría tridimensional del derecho de Miguel Reale, quien sostenía que la vida del derecho consistía en la interacción dinámica y dialéctica de sus elementos, a saber, los elementos consistentes en los hechos, valores y normas, los cuales coexisten perfectamente, pues no se excluyen, ni se implican. Es decir, son absolutamente inseparables, y por tanto, no hay ninguno que sea más importante que los otros..$^{512}$

Como podemos apreciar, el concepto de validez no es un concepto cualquiera, y mucho menos en el ámbito de la filosofía jurídica alemana: éste posee la peculiaridad de vincular al sistema jurídico con todos sus destinatarios en un sentido que va más allá del reino de lo jurídico. No es un concepto meramente jurídico, es uno con una carga normativa. Al menos podemos coincidir con Ross en que, por ahora, el concepto de validez es pensado, en corto, análogamente al de verdad. ${ }^{513}$ Antes de pasar a definir este concepto, nos enfocaremos en una acusación clásica a Kelsen debido al uso del concepto de validez. Presentar esta crítica nos permitirá explicar con mayor detalle en qué consisten los problemas que subyacen al uso de este concepto.

\footnotetext{
${ }^{510}$ Habermas, Jürgen, Faktizität und Geltung. Beiträge zur Diskurstheorie des Rechts und des demokratischen Rechtstaats, Fráncfort del Meno, Suhrkamp 1992, p. 15.

${ }^{511}$ Cfr., Maynez, Eduardo, Filosofía del derecho, Porrúa, México, 1974, p. 17 ss.

512 Cfr., Reale, Miguel, Introducción al derecho, Madrid, Pirámide, 1989, p. 69. Sobre este planteamiento de Reale, podemos indicar que los hechos corresponderían a la perspectiva empírica, los valores a la perspectiva normativa y las normas a la perspectiva analítica, y estas a su vez corresponderían a la sociología, filosofía y teoría del derecho respectivamente, lo cual confirmaría la influencia del pensamiento de Radbruch en ambos autores.

${ }^{513}$ Cfr., Ross, Alf, Directives and Norms, Londres, Routledge \& Kegan Paul, 1968, p. 64.
} 


\subsubsection{Validez y vigencia: ¿quasipositivismo kelseniano? El problema de la normatividad justificada en Kelsen}

El tema de la normatividad en la obra de Kelsen siempre ha causado polémica en tanto se entiende como una forma de justificar al derecho. Al menos, autores como Walter ${ }^{514}$ y $\mathrm{Raz}^{515}$ han considerado que esta interpretación es posible dentro del programa kelseniano. Una de las razones por las que Kelsen ha sido considerado un cuasipositivista consiste en el uso en su teoría del concepto de validez. El primero en denunciar el pecado naturalista en contra de la causa positivista fue Ross en el pequeño ensayo El concepto de validez $y$ otros ensayos ${ }^{516}$ y luego fue seguido por $\mathrm{Nino}^{517}$ y Bulygin, ${ }^{518}$ quienes notaron la supuesta presencia de una fuerza normativa en la obra kelseniana mediante este concepto.

Según Ross, Kelsen no debió usar el concepto de validez para referirse a la existencia de las normas, sino el de vigencia. Esta distinción, que en el idioma español está claramente delimitada, la retoma Ross a partir del significado de validez en el idioma danés. Para criticar a Kelsen, Ross hará primero una distinción entre tres diferentes funciones y significados de la palabra validez y luego seguirá con su crítica hacia este supuesto defecto de la teoría kelseniana. Ross señala que el concepto de validez cumple con tres funciones: en primer lugar, este término es usado en las corrientes descriptivas del derecho vigente para indicar si un acto jurídico tiene o no los efectos legales deseados; en segundo lugar, este término es usado en la teoría general del derecho para indicar la existencia de una norma o un sistema de normas; en tercer lugar, este término es usado para indicar una cualidad a priori, específicamente moral, llamada también la "fuerza obligatoria". ${ }^{519}$ Ross, indicará dentro de sus reflexiones que en el idioma inglés estas distinciones no siempre

\footnotetext{
${ }^{514}$ Walter, Robert, "Der gegenwärtige Stand der Reinen Rechtslehre", en, Rechtstheorie, 1, 1970, p. 80.

515 Raz, Joseph, "Kelsen's Theory of the Basic Norm", en, Paulson, Stanley, y Paulson, Bonnie Litschewski, Normativity and Norms. Critical Perspectives on Kelsenian Themes, Oxford, Clarendon Press, 1998, p. 58.

${ }^{516}$ Ross, Alf, "Validity and the Conflict between Legal Positivism and Natural Law", en, Paulson, Stanley, y Paulson, Bonnie Litschewski, Normativity and Norms. Critical Perspectives on Kelsenian Themes, Oxford, Clarendon Press, 1998, p. 149.

${ }^{517}$ Nino, Carlos, "Some Confusions Surrounding Kelsen's Concept of Validity", en, Archiv für Rechts- und Sozial Philosophie, 64, Berlín, 1978, p. 357 ss.

${ }^{518}$ Bulygin, Eugenio, "An Antinomy in Kelsen's Pure Theory of Law", Ratio Juris, 3, 1990, p. 29 ss.

${ }^{519}$ Cfr., Ross, Alf, op. cit., p. 159.
} 
serán explícitas debido a la falta de distinción entre validez y vigencia. ${ }^{520}$ La explicación es la siguiente:

Entiendo, sin embargo, que este uso no es corriente en inglés. En dinamarqués, como en alemán, se hace la distinción entre gyldig (gültig) y gœltende (geltend). Se dice que un testamento es gyldig o ugyldig — válido o inválido, nulo-, pero hablamos de gœltende ret para aludir al derecho con vigencia efectiva, efectivamente existente. Es digno de hacer notar que no existe una palabra para la negación de gœltende que corresponda a ugyldig ("inválido"). Como no pude encontrar un equivalente en inglés para "gœeltende", en las versiones inglesas de mis trabajos he usado la palabra "valid" (válido) para expresar también esta función. Ahora comprendo que esta traducción puede generar confusiones. ${ }^{521}$

De este modo, Ross le recriminará a Kelsen que al usar este concepto introduce una carga moral implícita, incompatible con el proyecto positivista. En otras palabras, si el concepto de validez posee una carga normativa, ${ }^{522}$ entonces se duplica la existencia del deber hacia las normas: por una parte, un deber jurídico, y, por otra parte, un deber moral. Esta duplicación del deber es incompatible para el positivismo jurídico, ya que si la norma jurídica exige la adecuación de la conducta del sujeto a una norma, ¿para qué introducir una razón moral para la adecuación de la conducta al derecho? Dicho de otro modo, esta obediencia se vuelve tautológica, ya que ¿qué sentido tiene decir que hay que obedecer (moralmente) lo que hay que obedecer (jurídicamente)? Al menos, para el positivismo jurídico kelseniano esta duplicación no es aceptable.

¿A qué nos lleva la crítica de Ross?, ¿a reconocer la sombra normativa detrás de la silueta del imponente edificio kelseniano o a aclarar este malentendido ${ }^{523}$ Nuestra opinión, siguiendo la de Paulson, es la de aclarar este malentendido conceptual en torno al problema

\footnotetext{
${ }^{520}$ No obstante, en el idioma alemán no parece existir una diferencia entre "Geltung" (validez) y "Gultigkeit" (vigencia). Durante algunas conversaciones con Paulson, Bäcker y Borowski notamos que esta diferenciación rossiana no parece ser aplicable al idioma alemán; por lo tanto, los diversos críticos de Kelsen que siguieron esta línea (Bulygin y Nino) estarían también equivocados en su apreciación.

${ }^{521}$ Ross, Alf, ibid. En este texto Ross cita como ejemplo de confusión a la crítica de Hart a Ross, la cual luego expone en el apartado séptimo de este ensayo. La falta de distinción entre "vigencia" y "validez" en el idioma inglés es señalada como una causa de confusión en las críticas de Hart a Ross.

522 Sobre este tema puede consultarse el excelente trabajo de Svein Eng, "Lost in the System or Lost in Translation? The Exchanges between Hart and Ross" (Ratio Juris, 24, 2011, p. 194 ss.). De hecho, y al igual que como nos lo indicó Castillejos, Eng sostiene que también en Ross existe una comprensión de la perspectiva del participante, que más tarde sostendrá Hart, de modo tal que entre las teorías jurídicas de Ross y Hart no existe una distancia tan grande. Del mismo modo, el trabajo de Eng será un argumento en contra de los malentendidos de Leiter respecto a su concepción del realismo escandinavo.

${ }^{523}$ Aunque con una argumentación distinta, también Raz le ha atribuido a Kelsen usar consistentemente el concepto de normatividad justificada del derecho natural, a pesar de rechazarlo explícitamente. Sobre este tema, cfr., Raz, Joseph, The Authority of Law, Cambridge, Oxford University Press, 2009, p. 144.
} 
de la validez del derecho. El concepto de norma fundamental en Kelsen, según Paulson, tiene diversos significados en la obra kelseniana, lo cual ha dado lugar a diversas interpretaciones, entre las que destaca la de conferirle a la norma fundamental el carácter de justificatoria del sistema jurídico.

Según Paulson, en torno al significado de norma fundamental giran siete grupos de caracterizaciones, las cuales consisten en 1. facultad y validez legal, 2. normatividad. 3. la unidad del sistema jurídico, 4. definiciones del derecho, 5. significado y "consistencia normativa" y, finalmente, caracterizaciones de la norma básica que apuntan a la dimensión kantiana y neokantiana de la filosofía jurídica de Kelsen, incluyendo las que se pretenden explicar 6. el proceso de comprensión cognitivo del derecho y con ese objetivo, 7. establecer, trascendentalmente, la vigencia objetiva del derecho positivo. ${ }^{524}$

Ahora bien, la mayoría de los argumentos a favor de la tesis del quasipositivismo kelseniano reside en vincular al concepto de norma fundamental con el de validez, equiparando, por una parte, a la norma fundamental con un fundamento moral y a la validez con la aceptación de los sujetos del sistema jurídico. Estos malentendidos han oscurecido el significado del concepto de validez del derecho en Kelsen. En primer lugar, la modalidad principal del uso de la norma fundamental en Kelsen está orientada hacia el concepto de facultad, esto es, la facultad de darle a una autoridad legal ciertas capacidades respecto a las conductas de los sujetos. En segundo lugar, Kelsen entendía por validez el concepto español de vigencia, esto es, como el reconocimiento de la existencia de una norma en un sistema jurídico, con sus características de tener vigencia en las esferas temporal, espacial, material y personal.

El proyecto de Kelsen no estaba vinculado con reflexiones normativas. Definitivamente, aunque existen evidencias textuales que fortalecen este tipo de interpretaciones, éstas pueden contrarrestarse con otras que apunten a entender la llamada "fuerza obligatoria" desde el punto de vista de la sanción imputable a los sujetos:

Aquellas ocasionales referencias a la "fuerza obligatoria" - y ellas están allí, ni Raz ni Nino imaginan cosas - pueden ser explicadas, desde mi punto de vista, por medio

\footnotetext{
${ }^{524}$ Cfr., Paulson, Stanley, "A 'Justified Normativity' in Kelsen's Pure Theory?". Rejoinders to Robert Alexy and Joseph Raz", en, Klatt, Matthias (Ed.), Institutionalized Reason. The Jurisprudence of Robert Alexy, Nueva York, Oxford University Press, 2012, p. 86.
} 
de la teoría jurídica de la sanción de Kelsen, una parte de su mayor caso jurídicoteórico en nombre de la facultad. ${ }^{525}$

Indudablemente, la doctrina de la fuerza obligatoria del derecho no puede derivarse de la norma fundamental en Kelsen. También, las objeciones de Ross tampoco son suficientes para considerar a Kelsen un no-positivista, sino que se trata de un malentendido conceptual que no debería tener mayores consecuencias. Entonces, ¿que es lo que podemos esperar que nos diga Kelsen acerca de la validez normativa del derecho, y, con ello, del deber de obedecer y respetar al derecho? La respuesta, coincidimos con Paulson, no estaba dentro de los planes de Kelsen:

Los comentaristas, al tomar sus pistas de la tradición, han interpretado a la doctrina de Kelsen como la respuesta de éste a la pregunta clásica en la filosofía jurídica y política: ¿cómo está justificada nuestra obediencia a la ley? Pero Kelsen tiene en conjunto a un diferente pez para freír (different fish to fry). Él entiende a la normatividad como una alternativa al psicologismo y al naturalismo en el ámbito de la ciencia jurídica. ${ }^{526}$

El problema de la validez o normatividad del derecho no estaba dentro del programa filosófico de Kelsen, por lo que si deseamos comprender este planteamiento moral será necesario hacerlo desde una postura no-positivista. Por tal razón analizaremos la reflexión de quien sí tiene en mente el problema de la validez moral del derecho.

\subsubsection{Las tres esferas de validez del derecho}

Ahora es momento de presentar la teoría de las tres esferas de validez del derecho según el planteamiento alexyano. Alexy comenzará con asociar los tres conceptos de validez a los tres elementos del derecho: la eficacia social, la corrección ética o material y la legalidad procedimental conforme al ordenamiento. Estos elementos están vinculados a las perspectivas analítica, empírica y normativa respectivamente, y por ello a la teoría, sociología y filosofía del derecho. Efectivamente, lo que Alexy intentará ahora será dar una definición de derecho que incluya a los tres elementos del derecho a los que nos referimos antes, de modo tal que desarrollará tres conceptos de validez.

a) El concepto sociológico de validez: el objeto de este concepto de validez reside en la validez social o conforme a la obediencia o sanciones fácticas respectivas. Según este

\footnotetext{
525 Paulson, Stanley, "La reconstrucción radical kelseniana de la norma jurídica”, en, Clérico, Laura y, Sieckmann, Jan-Reinard, La teoría del derecho de Hans Kelsen, Bogotá, UEC, 2011, p. 42.

${ }^{526}$ Paulson, Stanley, op. cit., p. 111.
} 
concepto, una norma vale socialmente si es obedecida o respetada y, en caso contrario, debe aplicarse la sanción legal correspondiente. En este concepto destacan dos elementos: el de la obediencia o el de respeto ${ }^{527}$ y el de sanción. Ambos conceptos dependen de una cuestión de grado.

Esto es así porque existen casos en los cuales una norma puede ser obedecida en el $90 \%$ de los casos de aplicación y sería aplicada la correspondiente sanción en el 80\% de los casos de desobediencia, por lo cual el grado de eficacia es bastante elevado (en este ejemplo, el grado de eficacia sería del 98\%). Otra situación distinta sería la de una norma que sólo es obedecida en el $80 \%$ de los casos de aplicación y sería aplicada la correspondiente sanción en los $10 \%$ de los casos de desobediencia, por lo cual el grado de eficacia es bastante elevado (en este ejemplo, el grado de eficacia sería del 90\%). Entre ambos extremos, dice Alexy, el asunto podría no ser tan claro. Una norma podría ser obedecida en el $30 \%$ de los casos de aplicación y aplicarse la correspondiente sanción en el $50 \%$ de los casos de desobediencia, y, al mismo tiempo, otra norma podría ser obedecida en el $50 \%$ de los casos de aplicación y aplicarse la correspondiente sanción en el 30\% de los casos de desobediencia, por lo cual el grado de eficacia en ambos casos sería el mismo (65\%) y, por ello, la respuesta acerca de qué norma es más eficaz no podría responderse numéricamente.

Por ello el especialista en la validez sociológica del derecho, el sociólogo del derecho, podría preguntarse qué tipo de obediencia es la exigida por el sistema jurídico, si una obediencia meramente externa o una obediencia interna, lo cual lo llevaría a buscar la respuesta a esta reflexión en el ámbito de la filosofía moral. Lo importante a destacar en este concepto de validez son tres postulados básicos.

El primero es que la validez social es una cuestión de grado. El segundo es que la validez social es cognoscible recurriendo a dos criterios: el de la obediencia y el de la sanción en caso de desobediencia. El tercero dice que la aplicación de la sanción en caso de

527 Aunque Alexy no menciona el concepto de respeto al derecho y sólo plantea el de "obediencia", consideramos más apropiado el uso del concepto de respeto para referirnos a la actitud que deberían tener los ciudadanos frente al derecho en caso de que consideren al sistema jurídico, las normas individuales y las decisiones jurídicas como justas. 
desobediencia incluye el ejercicio de la coacción física, la cual está organizada en los sistemas jurídicos estatalmente desarrollados. ${ }^{528}$

b) El concepto ético de validez: el objeto de este concepto de validez reside en la validez moral o validez conforme a ciertos postulados morales. Según el derecho natural, una norma tiene validez cuando está justificada éticamente y no sólo por tener vigencia en un ordenamiento jurídico o por ser socialmente eficaz. En el caso del planteamiento alexyano, la validez ética de una norma depende de su adecuación a principios morales universales que enarbolen una pretensión de corrección ante todos los participantes del discurso.

c) El concepto jurídico de validez: el objeto de este concepto reside en la validez jurídica o vigencia de las normas y decisiones jurídicas conforme al ordenamiento jurídico. Según diversas versiones del positivismo jurídico, una norma vale jurídicamente cuando es dictada por el órgano competente, de acuerdo con el procedimiento legal previsto y que no lesione un derecho de rango superior. Este concepto tiene la característica de que al incluir elementos de la validez sociológica puede convertirse en un concepto positivista de la validez jurídica, mientras que si incluye elementos de la validez ética puede convertirse en un concepto no-positivista de la validez jurídica.

Este concepto jurídico de validez plantea dos problemas. El primero, llamado problema interno, consiste en que la validez jurídica presupone la validez jurídica misma, lo que lleva directamente al problema de la norma fundamental, mientras que el segundo, llamado problema externo, consiste en determinar la relación del concepto jurídico de validez con los otros dos conceptos, lo cual nos lleva a la dicotomía entre el positivismo y el no-positivismo jurídicos. Si entendemos bien esta distinción, entonces veremos que, en primer lugar, existen tres ámbitos de validez del derecho, y, en segundo lugar, que la vinculación del concepto de validez jurídica a otra esfera de validez, ya sea esta esfera la de la validez sociológica o la de la validez ética, le dará al derecho una ubicación dentro de una postura distinta.

La validez jurídica necesita incorporar otros criterios de validez para comprender la naturaleza del derecho de acuerdo con el positivismo y no-positivismo. De esta manera, si la esfera de la validez jurídica está vinculada a la validez ética, entonces estamos frente a

${ }^{528}$ Alexy, Robert, CVD, p. 88. 
una teoría teoría no-positivista del derecho, mientras que si la validez jurídica está vinculada a la validez sociológica, entonces estamos frente a una teoría positivista del derecho. El problema que nos llevará al siguiente apartado consistirá en plantear cómo podríamos integrar estos ámbitos de validez para dar una respuesta satisfactoria al problema de la validez del derecho. Es por ello que analizaremos con mayor precisión en qué consisten estas esferas y cómo podríamos unirlas de acuerdo con la tesis alexyana de la doble naturaleza del derecho.

\subsection{Hacia una integración de las tres esferas de validez}

La diferenciación entre diversos ámbitos de validez del derecho nos ha permitido comprender las áreas en las cuales el derecho aspira a cumplir con sus pretensiones. Lo que interesa ahora es buscar comprender las cualidades específicas de estos ámbitos de valdiez para determinar así la validez integral del derecho. Estas esferas de validez del derecho bien podrían asociarse con los conceptos de legalidad, legitimidad y efectividad. De esta manera, las categorías respectivas de la teoría, sociología y filosofía política serán compatibles con las de la teoría, sociología y filosofía del derecho:

Según este planteamiento es posible equiparar la validez ética del derecho con la legitimidad, la validez jurídica o vigencia del derecho con la legalidad y la validez sociológica del derecho con la efectividad. Ahora explicaremos en qué consisten estas esferas para determinar cómo un sistema jurídico puede poseer una validez integral, de tal modo que la definición del derecho de Alexy incluya estos elementos.

\subsubsection{La validez ética de las normas: la legitimidad del derecho}

En esta esfera, asociada a la filosofía del derecho y a un enfoque normativo, el problema principal reside en el fundamento y contenido del sistema jurídico como totalidad, así como de las normas y decisiones jurídicas individualizadas. Las reflexiones sobre la validez ética del derecho en buena parte dieron lugar a los debates entre los partidarios del positivismo y no-positivismo jurídicos.

El problema de la validez ética suele tratarse con diferentes rótulos asociados al derecho y a la axiología jurídica: moral y derecho, ética y derecho, justicia y derecho, corrección y derecho, valores y derecho, etc. Lo que podemos constatar de estos 
planteamientos es el intento de fundamentar al derecho en algo más que él mismo. Este "algo más" suele consistir en un conjunto de elementos ideales, esto es, valores, normas, reglas y principios, para otorgarle al derecho un contenido correcto. Es precisamente el problema del contenido correcto el que nos lleva al fundamento ético del derecho.

El fundamento ético del derecho consiste en que la legalidad de las normas no contravenga ciertos ideales considerados "legítimos", "morales" o "éticos". A diferencia del grito de guerra del positivismo jurídico y de las exigencias metafísicas de las teorías clásicas del derecho natural, la postura alexyana propone una tesis intermedia entre los extremos objetivistas y subjetivistas, para sostener que cierto contenido del derecho es conceptual y normativamente necesario. Un ejemplo de contenido conceptual y normativamente necesario son los derechos humanos.

Buena parte de la génesis, evolución y validez de los sistemas de filosofía moral ha tenido el propósito de fundamentar racionalmente normas en tanto directivas de las acciones y omisiones humanas, con el objetivo de proveer de valores universalmente válidos para todas las sociedades. Todos aquellos interesados en la normatividad del derecho han recurrido a categorías morales para legitimar al derecho. Según Weinbeger, "los criterios de legitimidad son criterios de valor que dependen de opiniones filosóficas y políticas". ${ }^{529}$

No obstante, el planteamiento alexyano ha intentado evitar caer en los mismos errores de las teorías no-positivistas excluyentes respecto al problema de la validez, y, para ello, ha propuesto criterios de legitimidad mediados por un fundamento discursivo de corte universalista. Las reflexiones de Alexy en torno al problema del contenido del derecho son claras: "junto al problema de la institucionalización se sitúa el problema del contenido. El punto de partida lo constituye el hecho del pluralismo. Las sociedades modernas se caracterizan porque en muchas cuestiones normativas fundamentales se sostienen concepciones muy diferentes". 530 Sobre esta reflexión rawlsiana consideramos que las bases morales propuestas por Alexy pueden legitimar al derecho, en cuanto ofrece un contenido y aplicación correctos del derecho mediante la pretensión de corrección.

\footnotetext{
${ }^{529}$ Weinberger, Ota, "Legal Validity, Acceptance of Law, Legitimacy. Some Critical Comments and Constructive Proposals", en, Ratio Juris, Vol. 12, No. 4, 1999, p. 347.

${ }^{530}$ Alexy, Robert, IJ, 2005, p. 63
} 
La legitimidad del derecho es un requisito necesario de la legitimidad del poder político en las sociedades modernas. Pero la validez integral del derecho no se agota en la legitimidad. El contenido del derecho requiere de ciertas formas legales. Como bien decía Hart, "[L]as leyes, aunque sean impecables en su contenido, pueden ser de poco servicio para los seres humanos y pueden causar miseria e injusticia a menos de que ellas se conformen de modo general a ciertos requisitos que pueden ser llamados en sentido amplio como procedimentales (en contraste con los requisitos sustanciales referidos anteriormente)" ${ }^{531}$ Estos límites de la legitimidad o validez ética del derecho nos llevan a un segundo nivel, el de la institucionalización o positivización del derecho, representado por la legalidad o vigencia del derecho.

\subsubsection{La validez jurídica de las normas: la legalidad del derecho}

En esta esfera, asociada a la teoría del derecho y a un enfoque analítico, el problema principal reside en la sistematicidad y vigencia del sistema jurídico como totalidad, así como de las normas y decisiones jurídicas individualizadas. La corrección de las normas requiere del carácter institucional para poder aplicarse en la sociedad. La legalidad del derecho es un criterio necesario de los sistemas jurídicos modernos, pues es la que proporciona la seguridad jurídica de las leyes y actos de autoridad vigentes. A pesar de que es frecuente el desprecio por el concepto de legalidad - asociado al concepto de legalismo-, este criterio tiene un valor intrínseco, no es mero formalismo: "[C]uando el derecho prevalece, sabes dónde estás, y qué eres capaz de hacer sin que termines embrollado en litigios civiles o en litigios del sistema de justicia criminal". ${ }^{532}$ Esta reflexión de MacCormick explica la función positiva de que un conjunto de normas logren sistematizarse coherentemente en un sistema jurídico y estén delimitadas sus condiciones de vigencia. Si deseamos saber en qué consisten estos criterios de vigencia de las normas, Kelsen podría ser de gran ayuda.

Como sabemos, Kelsen entiende por validez la existencia específica de la norma ${ }^{533}$ y nada más. La eficacia no es el fundamento de la validez, sino una condición de la misma. El esfuerzo de Kelsen por sistematizar los ordenamientos jurídicos lo llevó a elaborar la norma fundamental, mientras que la concepción alexyana de coherencia está basada en

\footnotetext{
${ }^{531}$ Hart, H. L. A., Essays in Jurisprudence and Philosophy, Oxford, Clarendon Press, 1983, p. 114.

532 MacCormick, Neil, Rhetoric and the Rule of Law, Oxford, Cambridge, Oxford University Press, 2005, p. 12.

533 Kelsen, Hans, Reine Rechtslehre. Einleitung in die Rechtswissenschaftliche Problematik, Aalen, Scientia Verlag Aalen, 1985, p. 7.
} 
una concepción de racionalidad discursiva que requiere "que la justificación jurídica esté incorporada en un sistema coherente". ${ }^{534}$ Este ideal de sistematicidad y coherencia de las normas y las decisiones judiciales es una característica necesaria de la legalidad o vigencia de las normas, pero la sistematicidad de los ordenamientos jurídicos no agota el establecimiento de las normas, sino que también es indispensable establecer los criterios de vigencia del derecho. Los criterios de vigencia del derecho podemos establecerlos a partir de Kelsen, quien distingue esferas de vigencia en las modalidades espaciales, temporales, materiales y personales. ${ }^{535}$

La esfera de vigencia temporal indica que una norma puede comenzar a ser vigente para los sujetos de una sociedad en un momento específico y terminar en otro. La esfera de vigencia espacial indica que una norma es vigente no sólo en cierto tiempo, sino en cierto territorio para los sujetos de una sociedad. La esfera de vigencia material indica que una norma puede determinar cuándo y cómo un sujeto de una sociedad debe comportarse, es decir, qué debe o no debe hacer un sujeto. Finalmente, la esfera de vigencia personal indica qué normas merecen observarse por ciertos sujetos, es decir, a quiénes corresponde la obligación de cumplir con el mandato de una norma.

Estos cuatro criterios, en suma, sintetizan la esfera de vigencia de las normas, lo cual, en conjunto con la sistematicidad de los sistemas jurídicos, normas y decisiones individualizadas, pueden darnos una idea de los requisitos de la legalidad del derecho o validez jurídica de las normas. No obstante, la legitimidad y legalidad de las normas no son criterios suficientes para comprender la validez integral del derecho, sino que se requiere de una tercera esfera de validez. Si bien Hart señalaba que normas con un contenido impecable pueden no sernos de suficiente utilidad si no van acompañadas de normas procedimentales, lo mismo podemos decir de la siguiente esfera de validez del derecho: de

\footnotetext{
${ }^{534}$ Alexy, Robert y Peczenik, Aleksander, "Coherence and Discursive Rationality", en Ratio Juris. Vol. 3, No. 1, 1990, p. 143.En adelante, CDR. La idea de un sistema coherente de normas no excluye que Alexy no indique las desventajas de tal sistema. Alexy indica que la primera desventaja radica en el concepto de coherencia, ya que esta es una cuestión de grado. La segunda desventaja consiste en el carácter formal de la coherencia, ya que este criterio no dice nada cerca del contenido de los sistemas normativos. Finalmente, la tercera desventaja consiste en el carácter necesariamente incompleto de todos los sistemas normativos (la "textura abierta" hartiana), el problema acaso más importante en la práctica. Al respecto, cfr., Alexy, Robert y Peczenik, Aleksander, CDR, 145.

${ }^{535}$ Cfr., Kelsen, Hans, Kelsen, Hans, Teoría general del derecho y del Estado, México, D. F., UNAM, 1995, p. 49 ss.
} 
poco sirve que normas con un contenido impecable estén institucionalizadas si no hay una aplicación del derecho. Esto nos lleva al tercer criterio de validez del derecho: el de la validez social del derecho, o el de la efectividad del derecho.

\subsubsection{La validez social de las normas: la efectividad del derecho}

En esta esfera, asociada a la sociología del derecho, y con ello a un enfoque empírico, el problema principal reside en la aplicación y respeto hacia las normas del sistema jurídico como totalidad, así como a las normas y decisiones jurídicas individuales. La efectividad de las normas requiere del conocimiento de los efectos del derecho en la sociedad. Aunque a veces los conceptos de efectividad y de eficacia son usados como sinónimos, es deseable hacer algunas precisiones al respecto. Mientras que la efectividad hace referencia a la capacidad de comprobar que los sujetos producen las acciones $u$ omisiones dictadas por las normas $-y$ en el caso de que los sujetos no produzcan las conductas debidas se aplique la sanción correspondiente-, la eficacia hace alusión a los objetivos políticos de quien produce el discurso, en este caso, el discurso jurídico. ${ }^{536}$ El caso típico de conflicto entre efectividad social de las normas y eficacia política de las normas es comprobable en las normas jurídico-penales de la política criminal dirigidas a combatir al narcotráfico.

La efectividad, tal y como lo hemos señalado, es una cuestión de grado, comprobable en términos empíricos. Pero en la efectividad del derecho se encuentran aspectos que escapan de cuestiones meramente comprobables, los cuales permiten vincular en cierto modo a la validez sociológica con la validez ética del derecho. Si entendemos efectividad como obediencia o respeto al derecho, encontraremos aspectos que van más allá de los aspectos meramente externos de la efectividad de las normas. La efectividad se mantiene en un discurso formal cuando el derecho es respetado externamente, mientras que la efectividad alcanzará un discurso material si el derecho es respetado internamente. Las normas pueden ser respetadas $u$ obedecidas por razones adoptadas por el sujeto moral. Estos tipos de razones están vinculadas al respeto u obediencia al derecho por temor a la sanción, por intereses utilitarios o por razones morales.

Respeto u obediencia al derecho por temor: estamos ante la tesis básica de la teoría imperativista del derecho. La única razón para obedecer al derecho estaría basada en el

${ }^{536}$ Cfr., Correas, Óscar, Introducción a la sociología jurídica, México, D. F., Ediciones Coyoacán, 2009, p. 181. 
temor a la coerción, por lo que es necesario observar la conducta prescrita por las normas. La efectividad de las normas suele ser alta en sociedades con sistemas jurídicos bien estructurados y poco corruptos, pero también en sistemas totalitarios basados en el ejercicio desnudo del poder. El problema de la efectividad del derecho basada en el temor reside en que éste puede constituir una fuerte razón para obedecer al sistema jurídico, pero habrá ocasiones en las cuales los sujetos tendrán más razones morales para rebelarse ante éste. ${ }^{537}$

Respeto u obediencia al derecho por conveniencia: estamos ante la tesis básica del utilitarismo moral. Las razones para obedecer al derecho son variadas, pero todas tendrían en común un cálculo de ganancias del sujeto. Sin necesidad de dar explicaciones innecesarias acerca de los porqués de un sujeto por maximizar sus ganancias o beneficios, ${ }^{538}$ podemos decir que el derecho sería obedecido o respetado sólo por razones basadas en los intereses momentáneos de los sujetos. El problema de este respeto u obediencia al derecho sería que, bajo argumentos utilitaristas, los sujetos podrían desobedecer o no respetar al ordenamiento jurídico si esto les conviene para satisfacer sus intereses egoístas. La efectividad del derecho no puede basarse solamente en función de argumentos utilitaristas, sino en razones de mayor peso.

Respeto u obediencia al derecho por razones morales. Estamos ante la tesis básica de la ética del discurso. Las razones para obedecer o respetar al derecho estarían basadas en que el consenso previo respecto a la fundamentación de una norma y de la efectividad del derecho en la resolución de los conflictos sociales. Este argumento estaría compuesto de dos partes: por una parte, el derecho tendría un alto grado de efectividad si está legitimado y cumple en gran medida con sus funciones, de modo que los sujetos de una sociedad consideren justo obedecer o respetar al derecho y, por otra parte, que los sujetos que no respetan u obedecen al derecho correcto e institucionalizado sean castigados, de modo que los objetivos políticos de la comunidad constituida bajo el régimen del derecho sean respetados por la mayoría de los sujetos, incluidos aquellos que estarían dispuestos a no obedecer o respetar el derecho en pos del beneficio personal.

\footnotetext{
${ }^{537}$ Hart, H. L. A, op. cit., p. 82.

538 Sobre los vínculos entre el derecho y la elección racional, cfr., van Aaken, Anne, "Rational Choice" in der Rechtswissenschaft. Zum Stellenwert der ökonomischen Theorie im Recht, Baden-Baden, Nomos Verlagsgesellschaft, 2003.
} 
Tal y como pudimos ver, las tres esferas de validez del derecho tienen objetivos muy distintos, pero vinculados entre sí, en caso de que intentemos fundamentar la validez integral de todo el sistema jurídico y así ofrecer un concepto integral de derecho. Con la validez social de las normas queda concluida la división tripartita de la validez del derecho. Pero también esta reflexión sistemática acerca de la validez del derecho puede mostrar las deficiencias de los sistemas jurídicos reales. De acuerdo con Alexy, pueden presentarse colisiones de validez, ya sea entre la validez jurídica y la validez social o entre la validez jurídica y la validez moral, pero teniendo más claros los criterios de validez de cada esfera, podríamos determinar con mayor precisión a cuál esfera podríamos darle una prioridad en un caso concreto de colisión. No obstante, por ahora es suficiente indicar que este criterio de validez integral del derecho apunta a un concepto integral de derecho.

Una vez que Alexy expuso las diferencias entre la perspectiva del observador y el participante, la relación entre derecho y moral, la tesis de la doble naturaleza del derecho y sus criterios de validez, ofrecerá un concepto de derecho de acuerdo con todo lo que hemos visto antes. Este concepto es el siguiente:

El derecho es un sistema de normas que (1) eleva una pretensión de corrección, (2) el cual consiste en la totalidad de las normas que pertenecen a una Constitución generalmente eficaz y no son extremadamente injustas, como así también a la totalidad de las normas promulgadas de acuerdo con esta Constitución y que poseen un mínimo de eficacia social o probabilidad de eficacia y no son extremadamente injustas y al que (3) pertenecen los principios y otros argumentos normativos en los que se apoya el procedimiento de la aplicación del derecho y/o tiene que apoyarse a fin de satisfacer la pretensión de corrección. ${ }^{539}$

El concepto de derecho de Alexy requiere de algunas precisiones que nos permitirán comprenderlo mejor. Las características de este concepto que vincula al derecho con la moral son tres: 1. es una definición jurídica, elaborada desde la perspectiva del participante, 2. ésta incluye los tres ámbitos de validez y 3. a ella corresponden los argumentos de la corrección, la injusticia y de los principios.

Este concepto parte de la perspectiva del participante en tanto hace explícita la doble naturaleza del derecho, la cual, según Alexy, sólo puede comprenderse desde esta perspectiva. Al ser una definición del participante, debe incluir los tres elementos descritos en el capítulo pasado, es por ello que Alexy enfatiza en que "[E]l derecho es un sistema de normas que (1) eleva una pretensión de corrección", esto es, que todas las normas y fallos

${ }^{539}$ Alexy, Robert, CVD, p. 123. 
del sistema jurídico deben elevar tal pretensión, independientemente del cumplimiento real de ésta.

El segundo elemento, el de la injusticia extrema, está incluido al indicar Alexy que el derecho es un sistema "[...] (2) el cual consiste en la totalidad de las normas que pertenecen a una Constitución generalmente eficaz y no son extremadamente injustas". Tal y como lo vimos antes, los sistemas jurídicos y las normas y fallos extremadamente injustas para Alexy no sólo contienen fallas sustancialmente morales, sino que también poseen fallas estructuralmente jurídicas. Estas fallas, vistas desde el argumento de la injusticia extrema, privarán a los sistemas jurídicos, normas y fallos de su carácter de derecho, tesis polémica que debe entenderse en el sentido de que la pérdida de la calidad jurídica es un efecto posterior. Esta pérdida de la calidad jurídica a posteriori implica que en un primer momento se reconozca que determinados sistemas jurídicos, normas y fallos poseen carácter jurídico, pero cuya injusticia extrema los hace perder tal carácter con posterioridad. Esto permite superar ciertas críticas hacia el planteamiento alexyano.

También, en este segundo punto encontramos que al derecho pertenecen "la totalidad de las normas promulgadas de acuerdo con esta Constitución y que poseen un mínimo de eficacia social o probabilidad de eficacia y no son extremadamente injustas", lo cual significa que la definición de derecho incluye los tres ámbitos de validez del derecho, esto es, la validez ética, jurídica y sociológica, de manera tal que el derecho debe ser legal, legítimo y efectivo. Finalmente, en el tercer punto encontramos el argumento de los principios, al indicar Alexy que al derecho "[...] (3) pertenecen los principios y otros argumentos normativos en los que se apoya el procedimiento de la aplicación del derecho y/o tiene que apoyarse a fin de satisfacer la pretensión de corrección”. Los principios y otros argumentos normativos tiene la función de contribuir a una más refinada y correcta aplicación del derecho para satisfacer la pretensión de corrección, subsanando así posibles deficiencias legislativas o errores judiciales.

De este modo concluimos con la definición de derecho formulada por Alexy. Es una definición resultado de un largo proceso reflexivo llevado a cabo desde las pretensiones de racionalizar la argumentación jurídica, desarrollar una teoría de los derechos fundamentales apropiada para las sociedades modernas y delinear las bases de una teoría no-positivista del derecho. Estamos ante un concepto de derecho coherente con el programa filosófico y 
jurídico de la institucionalización de la razón, desde el cual "se vuelve posible una crítica de la praxis de las decisiones desde el punto de vista del derecho". ${ }^{540}$

\subsection{Validez integral de las normas y Estado de derecho}

Las reflexiones de este capítulo nos han llevado a establecer una conexión necesaria entre la validez integral de las normas con la idea de Estado de derecho. Si antes planteamos una conexión normativa y necesaria entre la racionalidad de la argumentación jurídica y el Estado de derecho, y entre los derechos fundamentales y el Estado de derecho, ahora será realizado lo mismo entre la validez integral del derecho y el ideal de un Estado democrático y social de derecho.

Esta conexión es igual de importante que las conexiones pasadas, ya que no sólo se trata de que la racionalidad de los actos y razonamientos jurídicos estén asegurados, ni de que las normas de derecho fundamental estén correctamente fundamentadas, institucionalizadas y aplicadas, sino de que también el concepto, naturaleza y validez del derecho sean adecuados a su objeto: la institucionalización de la razón mediante la institucionalización de un Estado democrático y social de derecho. Un Estado de derecho no puede incorporar cualquier tipo de normas y decisiones jurídicas en sus sistemas jurídicos, sino sólo aquellas que pasen ciertos test morales. Precisamente, la filosofía alexyana del derecho se opondrá de modo tajante al grito de guerra del positivismo jurídico mediante la tesis de la conexión conceptual y normativamente necesaria entre derecho y moral.

Pero no se trata de cualquier conexión entre derecho y moral: en el transcurso de la historia de la filosofía del derecho las conexiones han sido muy diferentes, por ello, nos enfocamos en la conexión formulada por Alexy. Según esta postura, existe una conexión entre el derecho y un contenido correcto, es decir, entre el derecho y su pretensión de corrección, la cual es inherente a todo acto y razonamiento jurídico según la tesis de la doble naturaleza del derecho. Esta conexión no sólo muestra como imposible cualquier concepto de derecho, sino que busca adecuarlo a una determinada naturaleza. Una

${ }^{540}$ Alexy, Robert, CVD, p. 126. 
concepción adecuada del derecho debe fundamentar la comprensión de la naturaleza de los argumentos sobre lo que es y debe ser el derecho.

Para describir mejor esta perspectiva reconstruimos los argumentos de la corrección, de la injusticia extrema y de los principios, pues estos argumentos son los que le permiten a Alexy fundamentar la perspectiva del participante para superar a una buena parte de las objeciones de los defensores del positivismo jurídico. Estos argumentos estarán acompañados de la incorporación de la tesis de la doble naturaleza del derecho. Alexy reivindicará el valor de la dimensión fáctica, representada por la coerción, aunque incorporada en un modelo que le dará un peso considerable a la dimensión ideal, representada por la pretensión de corrección. La institucionalización de la razón permite tal reconciliación, si bien la tensión entre ambas dimensiones permanecerá en el núcleo de la naturaleza del derecho.

Pero esto no es suficiente para legitimar al derecho: es necesario comprender por qué el derecho debe ser aceptado por la mayoría de los sujetos que constituyen una comunidad política. Esto explica el análisis de las tres esferas de validez del derecho, asociadas a la legalidad, legitimidad y efectividad, explicando así un criterio óptimo de validez de los sistemas jurídicos, normas y decisiones jurídicas individualizadas. De esta forma, podemos indicar qué niveles de validez poseen determinados sistemas jurídicos, normas y decisiones jurídicas individualizadas. Estas razones parecen ser suficientes para entender la importancia de establecer una conexión entre la validez integral del derecho con el ideal de un Estado de derecho.

Parece que a la luz de la filosofía jurídica el concepto de validez integral del derecho está vinculado con la construcción de un Estado de derecho, pero esto no siempre es visto así. No obstante, el discurso jurídico a veces ha sido desvalorizado por parte de la sociedad, ya que lo concibe en términos formales o represivos, pero muy pocas veces como un discurso que puede contribuir a crear una sociedad más justa. Efectivamente, el discurso jurídico puede quedarse en ámbitos formales o ser usado con fines totalmente represivos, pero esto es una parte contingente de su existencia y no puede explicar su doble naturaleza. Comprender la doble naturaleza del derecho nos permite distinguir entre la vigencia fáctica de las normas de la validez ideal, la cual puede proporcionarnos mejores argumentos para respetar el orden jurídico. 
En la segunda sección de esta obra llevamos a cabo una diferenciación en tres niveles de los derechos humanos y fundamentales. Esta división se basó en un primer nivel filosófico, en un segundo nivel político y en un tercer nivel jurídico. Ahora bien, respecto del concepto de validez del derecho podemos decir lo mismo. La validez del derecho es requerida en tres niveles que apunten a la fundamentación moral, institucionalización jurídica y aplicación social de los sistemas jurídicos y normas y decisiones individualizadas para constituirse así en un garante del Estado democrático de derecho. El Estado de derecho, en términos normativos, es un símbolo ineludible de la legitimidad de la modernidad. La idea de Estado de derecho no es, ni puede ser, una mera tautología en el sentido positivista, sino que es más que eso: es un orden social que debe procurar en todo momento el establecimiento de las condiciones de libertad e igualdad de las personas. El Estado de derecho, en tanto orden social, sólo puede funcionar mediante normas e instituciones. Esto demuestra la importancia del derecho para la plena realización de un Estado democrático y social de derecho, lo cual nos permite comprender el valor del derecho para vivir armónicamente en sociedades con un alto grado de complejidad.

Las normas e instituciones del Estado de derecho deben poseer validez para los sujetos, es decir, deben ser consideradas aceptables para todos los sujetos en tanto participantes de la sociedad en la que viven. La legalidad del derecho es una cualidad muy importante, pero, además, es necesario que la legalidad esté acompañada de la legitimidad para que el grado de aceptación de las normas sea mayor. Apelar a la mera legalidad ha mostrado ser un discurso insuficiente en las sociedades modernas, puesto que en muchas ocasiones apelar sólo a ésta ha conducido a equiparar a los órdenes jurídicos a mero legalismo. Es necesario que también la legalidad y la legitimidad de las normas e instituciones estén acompañadas de un cierto grado de efectividad, para que así la institucionalización de la razón tenga realidad efectiva. Esto implica que las razones del derecho estén sometidas a un proceso de conformación y deliberación crítico-democrática, que lleve a vincular los sistemas jurídicos, normas y fallos jurídicos individualizados con un ideal de democracia deliberativa.

En este sentido, la efectividad del derecho podría vincularse a razones normativas, si pudiéramos establecer que las razones morales de la efectividad del derecho están referidas a que el derecho cumpla no sólo con el requisito de ser legítimo, sino que es parte de la naturaleza del derecho el cumplir con sus funciones sociales para ser considerado 
válido desde la perspectiva del participante. Durante este capítulo buscamos dar razones para afirmar que el derecho debe aspirar a una validez integral para ser aceptado como tal. Pero, ¿qué consecuencias se derivan de considerar al derecho válido como aceptable para todos los sujetos de una sociedad política?, ¿ante qué tipo de obligación estamos?, ¿ante un deber de obedecer o respetar al derecho?, ¿o acaso el derecho no merece obediencia o respeto de los sujetos?

Tenemos la impresión de que al llegar al problema de la validez del derecho y vincularlo con la idea de Estado de derecho debemos establecer ante qué tipo de obligación se encuentran los participantes de un sistema jurídico, esto es, si a un deber de obedecer o respetar al derecho. Definitivamente, estamos ahora no sólo ante una de las preguntas básicas de la filosofía del derecho, sino ante una pregunta básica de la filosofía moral y política: ¿existe un deber de obedecer al derecho? Por su parte, el positivismo kelseniano jamás intentó responder a otra pregunta, pues sus objetivos eran otros. Por otra parte, las diversas corrientes del no-positivismo excluyente tampoco lograron dar una respuesta satisfactoria. ¿Cuál es la postura de Alexy frente a esta interrogante? parece que Alexy sí intenta dar una respuesta afirmativa a esta cuestión, a pesar de que no ha hecho suficientemente explícita esta pretensión. Al menos no en términos prácticos. ${ }^{541}$

Por nuestra parte sostenemos que nuestra postura respecto a esta interrogante está más cercana a Raz que a Alexy. Para Raz no existe una obligación de obedecer al derecho, ni siquiera al derecho justo. Según Raz el derecho aspira a tener una autoridad legítima sobre los ciudadanos, pero esta autoridad está basada en el respeto y no en la obediencia al derecho. En algunas de las principales obras de Raz hemos encontrado este argumento ${ }^{542}$ y nos parece que bien podría complementar los argumentos de Alexy, los cuales son en este aspecto insatisfactorios. Según Raz, la actitud moral idónea hacia el derecho justo debe ser el respeto y no la obediencia, el cual tiene un gran valor en las

\footnotetext{
${ }^{541}$ Cuando se le preguntó a Alexy acerca de si los filósofos del derecho deberían estar más preocupados por los efectos de sus doctrinas en la práctica jurídica, su respuesta fue la siguiente; "sí y no", ya que la filosofía jurídica qua filosofía no debe perseguirse solamente en vista de sus efectos positivos prácticos, porque en tanto investigación básica tiene que ser libre. De cualquier manera, la filosofía del derecho qua reflexión sobre el derecho debe estar ligada a los problemas jurídicos (Cfr., Alexy, Robert, FQ, p. 9).

${ }^{542} \mathrm{Cfr}$. Raz, Joseph, Between Authority and Interpretation. On the Theory of Law and Practical Reason, Nueva York, Oxford University press, 2010, p. 169 ss., Ethics in the Public Domain. Essays in the Morality of Law and Politics, Nueva York, Oxford University press, 2010, p. 325 ss., y The Authority of Law. Essays on Law and Morality, Nueva York, Oxford University press, 2010, p. 233.
} 
sociedades modernas debido a que mediante el respeto al derecho se expresa cierta idea de acuerdo o simpatía racional de los sujetos hacia los sistemas jurídicos, normas y fallos jurídicos individualizados.

Este respeto hacia las normas también debe estar basado en la comprensión de las funciones del derecho. Según Raz, el concepto de las funciones del derecho es de gran importancia para cualquier teoría del derecho que intente ofrecer una explicación de la naturaleza del derecho. ${ }^{543}$ Estas consideraciones sobre las funciones del derecho, no obstante, no aparecen en la obra de Alexy. Por tanto, una explicación completa sobre el deber del participante de obedecer o respetar al derecho es insuficiente desde esta filosofía del derecho. Sin embargo, la filosofía jurídica de Alexy nos proporciona otro tipo de argumentos para respetar al derecho, aunque por sí sólos insuficientes.

La pretensión de vinculación integral de las normas con el Estado de derecho, al igual que las otras pretensiones de vincular la teoría de la argumentación jurídica y la de los derechos fundamentales con el ideal de un Estado de derecho, sin duda alguna es muy difícil de cumplir. Sin embargo, la filosofía jurídica de Alexy ha mostrado que a pesar de la persistencia de una racionalidad desencantada es posible una teoría jurídica de la justicia; por tanto, tales vínculos también son posibles. Definitivamente, después de la aparición de la obra de Alexy la comprensión del derecho no podrá ser pensada de la misma manera. Al menos no mientras el derecho sea pensado no sólo desde la dimensión autoritativa, sino desde la dimensión racional. Esta dimensión, por cierto, no puede no ser parte del derecho, ya que es una parte de su propia naturaleza. Si estos argumentos son correctos, entonces la institucionalización de la razón se devela así como una concepción no-positivista del derecho, cuya sistematización ha dejado las bases de un programa que debe seguir desarrollándose para comprender y fundamentar la legitimidad del derecho moderno.

\footnotetext{
${ }^{543}$ Raz, Joseph, The Authority of Law. Essays on Law and Morality, Nueva York, Oxford University press, 2010, p. 163. En este sentido, consideramos importante el panorama general de las funciones directas e indirectas del derecho ofrecido por Raz, el cual está enfocado en ofrecerlas como argumentos en favor de respetar al derecho. Sobre este panorama, cfr., Raz, Joseph, op. cit., p. 176.
} 


\title{
Conclusiones
}

\section{Entre la utopía y la institucionalización de la razón. Robert Alexy y la legitimidad del derecho moderno}

En una reseña reciente a Razón institucionalizada. La filosofía del derecho de Robert Alexy, obra editada por Klatt, John Adenitire celebra el momento actual por el que pasa la filosofía de Alexy. Según Adenitire:

\begin{abstract}
Es un buen momento para la filosofía del derecho de Robert Alexy en el mundo de habla inglesa. Sus numerosas publicaciones siguen atrayendo una considerable atención en en lo que de otro modo sería un mundo filosófico encarcelado en el canon Hart/Dworkin/Raz. Sin embargo, no es sólo el escape que Alexy ofrece de los teóricos tradicionales de habla inglesa lo que ha llevado a un amplio con la obra del filósofo alemán. Es, en cambio, la fertilidad de sus argumentos, la concisión de expresión y, quizás por encima de todo, su generosidad manifiesta al participar en las discusiones con los demás acerca de su obra. ${ }^{544}$
\end{abstract}

Más de treinta y siete años han pasado desde la publicación de aquella gran obra de Alexy dedicada a la teoría de la argumentación jurídica. Sin duda alguna, si existe una filosofía del derecho que en todos estos años ha provocado un interés sin igual en el ámbito jurídico es la suya. Durante esta obra fue reconstruido un panorama integral de esta filosofía del derecho y de esta manera han sido analizados los tres pilares que han ocupado el centro de las reflexiones de Alexy: la racionalidad práctica y jurídica, los derechos humanos y fundamentales y el concepto y naturaleza del derecho.

Con el objetivo de lograr una exposición integral de este sistema de filosofía del derecho, o, como también la ha llamado Alexy, esta concepción no-positivista del derecho, fue presentado este proyecto de modo sistemático, esto es, de una manera completa y ordenada. Para ello, comenzamos con la obra Teoría de la argumentación jurídica, seguimos con Teoría de los derechos fundamentales y terminamos con El concepto y la validez del derecho. Durante el transcurso de esta obra fue comprobada la coherencia de

\footnotetext{
${ }^{544}$ Adenitire, John, "Between Institutional and Moral Discourse: On Alexy's Legal Philosophy", Jurisprudence 4, 2013, p. 358.
} 
este pensamiento y la inclusión de los grandes problemas de la filosofía del derecho, así como también diversos problemas de la filosofía moral y política. ${ }^{545}$

También fue reconstruida la inclusión de algunos de los grandes problemas de la filosofía del derecho desde el momento en el cual en la Teoría de la argumentación jurídica presentó las premisas fundacionales de su proyecto: la posibilidad de fundamentar racionalmente los argumentos jurídicos mediante diversas reglas y formas de la argumentación práctica y jurídica, la tesis del caso especial y la pretensión de corrección, expuesta en esta obra fundacional, apuntaban a una conexión de la argumentación jurídica con la posibilidad de fundamentar racionalmente la interpretación y aplicación de los derechos fundamentales y una visión no-positivista del derecho.

De acuerdo con Alexy no es posible pensar en una teoría de la argumentación jurídica sin presuponer una teoría de los derechos fundamentales, y del mismo modo, una teoría de los derechos fundamentales debe presuponer una teoría de la argumentación jurídica. Basándose en esta reflexión sistemática, Alexy desarrolló en Teoría de los derechos fundamentales un sistema de derechos universales, fundamentales, abstractos, morales y prioritarios, de acuerdo con los presupuestos de la ética del discurso. La estructura de estos derechos fundamentales subjetivos tendrá la forma peculiar de mandatos de optimización, dando así origen a la teoría de los principios. Pero no sólo desarrolló un sistema de derechos fundamentales y una concepción de estos como principios que deben ser optimizados en caso de conflictos normativos, sino que también desarrolló un mecanismo para resolver las controversias jurídicas surgidas a partir de la colisión de diversos derechos fundamentales. De esta manera, Alexy presentó la relación entre la teoría principialista y el principio de proporcionalidad.

Pero la reflexión sistemática de Alexy acerca del derecho no podía quedarse ahí. Era necesario que esta filosofía del derecho, qua sistema, confrontarse al positivismo jurídico con el objetivo de establecer cuál es el concepto, la naturaleza y la validez del

\footnotetext{
${ }^{545}$ En este sentido, compartimos la visión de Alexy de integrar a la filosofía jurídica con la filosofía moral y política. Alexy lo ha expresado de la siguiente manera: "[E]I tercer problema, vinculado a la cuestión acerca de los derechos y la justicia, apunta a la pregunta filosófica acerca de qué es lo que debe hacerse o es bueno. Esto sugiere, correctamente, que los derechos y la justicia no son sólo temas de la filosofía del derecho, sino también de la filosofía moral y política. No es posible marcar una línea delimitada entre estas disciplinas aquí." (Alexy, Robert, FQ, p. 8). Por nuestra parte, viniendo no sólo del campo de la filosofía del derecho, sino de la filosofía moral y política, no podemos más que compartir esta pretensión de hacer una filosofía práctica que abarque a sus tres esferas principales.
} 
derecho más adecuados. Esto llevó a Alexy a reformular el problema de la pretensión de corrección desde la perspectiva del participante, y con ello vimos cómo aparecieron los problemas en torno a la relación entre derecho y moral, derecho y justicia, y derecho y validez en su pensamiento.

En cada una de estas tres secciones expusimos el pensamiento de Alexy y las diversas objeciones de sus detractores, lo cual nos permitió hacer un examen más crítico de éste. Las respuestas de Alexy a las objeciones de sus críticos contribuyeron a reformular sus planteamientos, si bien, hay muchos aspectos en los que el desacuerdo racional perdurará por siempre, en tanto están referidas a cuestionamientos eternos de la filosofía del derecho. Al final de cada sección fueron vinculados los respectivos temas de la filosofía jurídica de Alexy con la idea de Estado de derecho para establecer así la conexión entre la filosofía jurídica y el Estado de derecho. Ahora que esta obra llega a su fin retomaremos la pregunta en torno a si la filosofía del derecho de Alexy es un sistema. Klatt ha respondido a esta pregunta con especial precisión:

La pregunta permanece: ¿es la filosofía del derecho de Alexy un sistema? De acuerdo al significado del término 'sistema' empleado aquí, la respuesta a esta pregunta es clara. La filosofía del derecho de Alexy cubre un amplio rango de preguntas fundamentales. Ésta tiene un carácter triple, el cual combina análisis estructurales y una teoría orientada al uso de la aplicación del derecho. De hecho, existen fuertes indicadores de que el todo es más que la suma de las partes. Si esto no cuenta como un sistema de filosofía del derecho, sería difícil pensar en qué sí cuenta como tal. ${ }^{546}$

Efectivamente, si este sistema de filosofía del derecho no cuenta como tal, sería difícil encontrar otra reflexión que cuente como un sistema de filosofía del derecho. Las tres obras de Alexy, estudiadas bajo la tríada conceptual razón, derechos y validez, forman una reflexión sistemática acerca de los grandes problemas de la filosofía jurídica. Los ulteriores refinamientos y desarrollos de este sistema de filosofía del derecho, llevados a cabo en sus más de cien artículos, han sido fruto de las múltiples objeciones y diálogos que Alexy ha tenido con sus estudiosos y críticos, lo cual confirma el carácter dialógico y generoso de sus reflexiones, como lo ha afirmado Adenitire. En definitiva, la concepción no-positivista del derecho de Alexy es un sistema bien ordenado y estructurado de filosofía del derecho, pero abierto a sugerencias y críticas que han contribuido a refinarlo. Por tanto, estamos

\footnotetext{
${ }^{546}$ Klatt, Matthias, “Robert Alexy's Philosophy of Law as a System”, en, Klatt, Matthias (Ed.), Institutionalized Reason. The Jurisprudence of Robert Alexy, Nueva York, Oxford University press, 2012, p. 26.
} 
ante una reflexión sistemática sin parangón en el ámbito de la filosofía jurídica contemporánea.

Esto no implica que la reflexión sistemática de Alexy no esté libre de incorporar más elementos, modificar algunas tesis y responder a algunas objeciones que seguirán siendo planteadas que tanto positivistas como no-positivistas han señalado. Según Alexy, cuatro temas de su pensamiento merecen desarrollarse en una medida especial. En primer lugar, respecto a la teoría de la argumentación jurídica, la tensión entre la dimensión fáctica y la dimensión ideal, así como el papel que los derechos humanos y fundamentales desempeñarán en la solución de dicha colisión. En segundo lugar, respecto a la teoría principialista, la determinación del contenido, estructura y función de los principios formales, así como la refinación de la fórmula del peso, la cual ha sido explicada en esta obra. En tercer lugar, respecto a los problemas del concepto y naturaleza del derecho, la distinción entre positivismo y no-positivismo, así como las diversas variantes de cada uno. En cuarto lugar, respecto a la teoría no-positivista como una reflexión sistemática, estos y otros problemas en el contexto de la globalización. ${ }^{547}$

Como puede verse, estos cuatro temas indicados por Alexy, así como otros pertenecientes a su reflexión sistemática, serán parte fundamental de las principales discusiones en el ámbito de la argumentación jurídica, el derecho constitucional y la teoría y filosofía del derecho. No obstante, los caminos que ha recorrido Alexy se han vuelto una ruta obligatoria para quienes deseen adentrarse en el ámbito de la flosofía jurídica, ya sean juristas-filósofos o filósofos-juristas.

Antes de que la más reciente obra de Derek Parfit, Sobre lo que importa (On What Matters), viera la luz en 2011, fue estudiada en algunos círculos filosóficos bajo el título Escalando la montaña (Climbing the Mountain). Este título hacía referencia a un postulado fundamental de Parfit. Según este filósofo, la ética kantiana, el consecuencialismo y el contractualismo, más que diferir en torno a la fundamentación normativa de la moral, poseen puntos normativos en común, sólo que estos esfuerzos han consistido en subir a la montaña por diversos lados de ésta. Del mismo modo podemos afirmar que Alexy, al igual que otros filósofos del derecho, ha intentado subir a la montaña de la legitimidad del derecho moderno, sólo que lo ha hecho del lado de la razón práctica institucionalizada, anclada en

547 Alexy, Robert, EAOTG, pp. 369 y 370. 
la metaética analítica, la ética del discurso y en una visión no-positivista del derecho que procura darle un peso apropiado a la pretensión de corrección, la seguridad jurídica y la eficacia.

En este sentido Alexy ha hecho un esfuerzo notable para mostrar que en el discurso jurídico convergen tanto la dimensión real del derecho, representada por la dimensión institucional, como la dimensión ideal del derecho, representada por la dimensión de la razón. Por ello, la obra de Alexy bien puede contar como el esfuerzo más acabado hasta ahora por hacer del derecho algo distinto a una banda de ladrones. Al menos, como afirma Frederick Schauer, Alexy ha servido a un valioso propósito al mostrar que "el lado no formal del derecho no es el lado irracional del derecho", ${ }^{548}$ como usualmente suele creerse. Esto nos lleva a plantear la pregunta final de esta obra: ¿es la teoría de Alexy una utopía o institucionalización de la razón?

Analizada desde este punto de vista, según el cual no tenemos otra alternativa al principio tertium non datur, la filosofía jurídica de Alexy ha sentado un modelo normativo de derecho tan racional que podría más bien parecer una utopía jurídica, a la que, sin embargo, no es deseable renunciar. Puede decirse, sin problema alguno, que este proyecto ha contribuido a enriquecer la cultura jurídica y democrática de diversos Estados de derecho interesados en fortalecer la democracia y garantizar los derechos humanos y fundamentales de sus ciudadanos mediante la institucionalización de la razón. Por lo tanto, estamos ante lo que Trivisonno considera que toda teoría jurídica correcta debería poseer: "una teoría ideal, que muestra lo que deberíamos hacer si viviéramos en un mundo ideal, y una teoría no ideal, que muestra lo que es posible realizar en el mundo real". ${ }^{549}$

Del mismo modo, esta teoría sobre la institucionalización de la razón debe responder a los grandes retos del derecho moderno en un mundo desencantado, sobre todo, en tiempos en los que la importancia de la legitimidad de los ordenamientos jurídicos va más allá del Estado nacional. Mientras tanto, el derecho seguirá ahí, en peligro siempre latente de volverse un instrumento de represión y dominación por parte de alguna banda de

\footnotetext{
${ }^{548}$ Schauer, Frederick, "Balancing, Subsumption and the Constraining Role of Legal Text", en, Klatt, Matthias (Ed.), Institutionalized Reason. The Jurisprudence of Robert Alexy, Nueva York, Oxford University press, 2012, p. 316.

${ }^{549}$ Trivisonno, Alexandre, T. G., "O problema do conhecimento prático na teoria discursiva de Alexy", en, Trivisonno, Alexandre, T. G., Tuffi, Aziz y Sétte, Mónica, (eds), Princípios formais e outros aspectos da Teoria Discursiva do Direito, Forense Universitaria, Rio de Janeiro, 2014, p. 67.
} 
ladrones. Es por ello que la pretensión alexyana de concebir al derecho como un sistema institucionalizado racional y justo es más importante que nunca. Si no aspiramos a esta pretensión, tal vez en algún momento podrían faltarnos los mejores argumentos para criticar al derecho existente y adecuarlo a su dimensión ideal o crítica. Después de la filosofía jurídica de Alexy, la brecha entre una banda de ladrones y un Estado de derecho ha crecido considerablemente. Seguramente estamos ante una cuestión de grado. Pero de esta cuestión de grado depende la legitimidad del derecho moderno.

Por nuestra parte, han pasado más de cinco años desde que comenzamos esta obra sobre la filosofía del derecho de Alexy. El camino ha sido largo, pero ciertamente ha valido la pena. Durante este tiempo nuestro recorrido filosófico y jurídico nos ha llevado a adentrarnos en algunos de los más importantes problemas de la filosofía jurídica, así como en otros de la filosofía moral y política. Del mismo modo, Alexy ha dejado una notable escuela de pensamiento tanto en Europa como en América Latina, de la cual esta obra es fiel deudora. Ahora bien, si quisiéramos expresar cuál es acaso la lección más importante que la Escuela Moderna de Kiel —la cual incluye tanto a Alexy como a sus estudiantesnos ha dejado, es el convencimiento de que la filosofía del derecho, en cuanto es concebida como una reflexión sistemática acerca de ciertos núcleos básicos universales vinculados al derecho, nos puede ayudar a comprender algunos de los grandes problemas morales, políticos, jurídicos y sociales de nuestro mundo moderno.

Ahora es momento de terminar esta obra sobre la filosofía jurídica discursiva nopositivista de Robert Alexy, acaso el más importante filósofo del derecho de nuestro tiempo. Esperamos que esta obra contribuya a difundir el pensamiento de Alexy, y así, dar cuenta de la legitimidad del derecho mediante la razón práctica, incorporada en los sistemas jurídicos mediante la argumentación jurídica, los derechos fundamentales y la doble naturaleza del derecho, es decir, los elementos esenciales de la institucionalización de la razón. 


\section{Bibliografía}

\section{A) Obras de Alexy}

Alexy, Robert, Teoría de la argumentación jurídica. La teoría del discurso racional como teoría de la fundamentación jurídica, Lima, Palestra, 2007 (TAJ)

Alexy, Robert, Teoría de los derechos fundamentales, Madrid, Centro de Estudios Políticos y Constitucionales, 2008 (TDF)

Alexy, Robert, El concepto y la validez del derecho, Barcelona, Gedisa, 2008 (CVD)

Suhrkamp, 1995 (DRD)

Recht, Vernunft, Diskurs. Studien zur Rechtsphilosophie, Fráncfort del Meno,

\section{B) Artículos de Alexy (citados en orden cronológico)}

Alexy, Robert, "Eine Theorie des praktischen Diskurses", en, OelMüller, Willi (Ed.), Normenbegründung-Normendurchsetzung, Paderborn, UTB Schöningh, 1978 (ETPD)

, "Basic Rights and Democracy in Jürgen Habermas's Procedural Paradigm of Law", en, Ratio Juris. Vol 7 No. 2 July, 1994 (BRDJH)

Teoría del discurso y derechos humanos, Bogotá, UEC, 1995 (TDDH)

, "John Rawls' Theorie der Grundfreiheiten“, en, Philosophische Gesellschaft Bad Homburg/Hinsch Wilfried (Eds.), Zur Idee des politischen Liberalismus, Fráncfort del Meno, Suhrkamp, 1997 (TG)

, "Grundrechte im demokratischen Verfassungsstaat", en, Aarnio, Aulis/Alexy, Robert/Bergholtz, Gunnar, Justice, Morality and Society. A Tribute to Aleksander Peczenik on the Occasion of his 60th Birthday, Lund, Juristförlaget i Lund, 1997 (GDV)

"Law and Correctness", en, Current Legal Problems, 51, 1998 (LC)

, "Data und die Menschenrechte - Positronisches Gehirn und doppeltriadischer Personenbegriff", conferencia dictada en el marco del "Ringvorlesung des Instituts für Neuere Deutsche Literatur und Medien zur Erforschung von Populärkultur am Beispiel von STAR TREK" el día 8.2.2000 en la Universidad de Kiel (DMR)

"Die Gewichtsformel", en Jickeli, Joachim, Kreutz, Peter y Reuter, Dieter (Eds.), Gedächtnisschrift für Jürgen Sonnenschein, Berlín, Walter de Gruyter, 2003 (GF)

, "The Nature of the Arguments about the Nature of Law", en, Meyer, Lukas, Paulson, Stanley y Pogge, Thomas, Rights, Culture and the Law. Themes from the Legal and Political Philosophy of Joseph Raz, Oxford, Oxford University Press, 2003 (NANL)

UEC, 2003 (TEDF)

Tres escritos sobre los derechos fundamentales y la teoría de los principios, Bogotá,

, "Discourse Theory and Constitutional Rights", en, Menéndez, Agustín y Eriksen, Erik, Fundamental Rights through Discourse. On Robert Alexy's Legal Theory. European and Theoretical Perspectives, Oslo, Arena, 2004 (DTHR) 
52 Berlín, 2004 (MOM)

"Menschenrechte ohne Methaphysik?", en Deutsche Zeitschrift für Philosophie, no.

"Arthur Kaufmanns Theorie der Rechtsgewinnung" (en, Neumann, Ulfrid, Hassemer, Winfried, y Schroth, Ulrich, Verantwortetes Recht. Die Rechtsphilosophie Arthur Kaufmanns, ARSPBeiheft 100, Stuttgart, Nomos, 2005 (AKTR)

, La Institucionalización de la justicia, Granada, Comares, 2005 (IJ)

"Balancing, Constitutional Review and Representation", en, International Journal of Constitutional Law, vol. 3, no. 4, 2005 (BCRR)

Derecho y razón práctica, México, D. F., Fontamara, 2006 (DRP)

, "Sobre los derechos constitucionales a protección", en, Alexy, Robert, Derechos sociales y ponderación, Madrid, Fundación Coloquio Jurídico Europeo, 2007 (DCP)

"Thirteen Replies", en, Pavlakos, George (Ed.), Law, Rights and Discourse. The Legal Philosophy of Robert Alexy, Portland, Hart Publishing, 2007 (TR)

, "An Answer to Joseph Raz", en, Pavlakos, George (Ed.), Law, Rights and Discourse. The Legal Philosophy of Robert Alexy, Portland, Hart Publishing, 2007 (AJR)

"Five Questions", en, Ebbe Morten y Nielsen, Juul, Legal Philosophy. Five Questions, Nueva York, Automatic Press, 2007 (FQ)

"On the Concept and the Nature of Law", en, Ratio Juris, Vol. 21, No. 3, 2008 (CNL)

, "Die Natur der Rechtsphilosophie", en, Brugger, Winfried, Neumann, Ulfrid y, Kirste, Stephan, Rechtsphilosophie im 21. Jahrhundert, Fráncfort del Meno, Suhrkamp, 2008 (NRP)

"Ideales Sollen“, en, Clérico, Laura y Sieckmann, Jan-Reinard (Eds.), Grundrechte, Prinzipien und Argumentation. Studien zur Rechstheorie Robert Alexys, Baden-Baden, Nomos Verlagsgesellschaft, 2009 (IS)

"Between Positivism and Non-Positivism? A Third Reply to Eugenio Bulygin," Conferencia ofrecida en Girona en mayo de 2010 (BPNP)

"Two or Three", en Borowski, Martin, On the Nature of Legal Principles, ARSPBeiheft 119, Stuttgart, Nomos Verlagsgesellschaft, 2010 (TOT)

, "Reflections on How My Thinking about Law Has Changed over the Years", conferencia llevada a cabo en el Tampere Club Symposium organizado por Aulis Aarnio, Law, Democracy and Legal Argumentation. A Seminar dedicated to the Thinking of Professor Robert Alexy, Finland, en Febrero 9 de 2010 (RTLY)

, "Zur Verteidigung eines nichtpositivistischen Rechtsbegriffs", en, Gesang, Bernward und Schälike Julius (Eds.), Die großen Kontroversen der Rechstphilosophie, Paderborn, Mentis, 2011 (VNRB)

, "Derecho, moral y la existencia de los derechos humanos", en Signos Filosóficos. vol. 15 No. 30, julio-diciembre, 2013 (DMEDH)

"Una concepción no-positivista de derechos fundamentales", conferencia dictada en México el 10 de diciembre de 2013 en el marco del IV Congreso internacional de Argumentación jurídica (CNPDF) 
, "Some Reflections on the Ideal Dimension of Law an on the Legal Philosophy of

John Finnis, en, The American Journal of Jurisprudence, Vol. 58, No. 2, 2013 (SRIDL)

, "Entrevista a Aguiar de Oliveira e a Travessoni Gomes Trivisonno, en, Alexy, Robert, Teoría discursiva do direito, Forense Universitaria, Rio de Janeiro, 2014 (EAOTG)

"Princípios Formais", en, Trivisonno, Alexandre T. G., Tuffi, Aziz y Sétte, Mónica, (Eds.), Princípios formais e outros aspectos da Teoria Discursiva do Direito, Forense Universitaria, Rio de Janeiro, 2014 (PF)

, "As dimensões real e ideal do direito", en, Princípios formais e outros aspectos da Teoria Discursiva do Direito, Forense Universitaria, Rio de Janeiro, 2014 p.136. Discurso llevado a cabo por Robert Alexy durante la concesión del doctorado Honoris Causa por la UFMG, en la ceremonia realizada en la facultad de derecho, el día 10.02.2014 (DRID)

Alexy, Robert, Aarnio Aulis y Peczenik Aleksander, "The Foundation on Legal Reasoning", en Rechtstheorie 12, Berlín, Duncker \& Humblot, 1981 (FLR)

Alexy, Robert y Peczenik, Aleksander, "Coherence and Discursive Rationality", en Ratio Juris. Vol. 3, No. 1, 1990 (CDR)

Alexy, Robert y Bulygin, Eugenio, La pretensión de corrección del derecho. La polémica sobre la relación entre derecho y moral, Colombia, UEC, 2001 (PRDM)

\section{B) Obras citadas}

Aarnio, Aulis, "Taking Rules Seriously", en, Archiv für Rechts-und Sozial philosophie Nr. 42, Stuttgart, Franz Steiner Verlag, 1990

México, D. F., Fontamara, 2000

Adenitire, John, "Between Institutional and Moral Discourse: On Alexy's Legal Philosophy", Jurisprudence 4, 2013

Albert, Hans, Traktat über kritische Vernunft, Tubinga, J. C. B. Mohr, 1991

Aleinikoff, Alexander, "Constitutional Law in the Age of Balancing", The Yale Law Journal, núm. 96, Yale, 1987

Adachi, Hidehiko, Die Radbrusche Formel. Eine Untersuchung der Rechtsphilosophie Gustav Radbruchs, Baden-Baden, Nomos Verlagsgesellschaft, 2005

Aguiar de Oliveira, Júlio, "Conteúdo do direito e normatividade justificada na teoría pura do direito: uma crítica ás teses de Joseph Raz", en Aguiar de Oliveira, Júlio y, Trivisonno, Alexandre, T. G. (Eds.), Hans Kelsen, Teoría jurídica e política, Forense Universitaria, Río de Janeiro, 2013

, "A Injustiça extrema e o conceito de direito", en, en, Trivisonno, Alexandre T. G., Tuffi, Aziz y Sétte, Mónica, (Eds.), Princípios formais e outros aspectos da Teoria Discursiva do Direito, Forense Universitaria, Rio de Janeiro, 2014

Apel, Karl-Otto, La transformación de la filosofía II, Madrid, Taurus, 1984 
, "Diskursethik vor der Problematik von Recht und Politik: Können due Rationalitätsdifferenzen zwischen Moralität, Recht un Politik selbst noch durch Diskursethik normativrational gerechtfertigt werden", en, Apel, Karl-Otto y Kettner, Matthias, Zur Anwendung der Diskursethik in Politik, Recht und Wissenschaft, Fráncfort del Meno, Suhrkamp, 1992

Arango, Rodolfo, El concepto de derechos sociales fundamentales, Bogotá, Legis, 2005

"Deontologische und teleologische Grundrechtskonzeptionen", en Laura y Sieckmann, Jan-Reinard (Eds.), Grundrechte, Prinzipien und Argumentation. Studien zur Rechstheorie Robert Alexys, Baden-Baden, Nomos Verlagsgesellschaft, 2009

Aristóteles, Política, Madrid, Tecnos, 2004

Atienza, Manuel, "Argumentación jurídica”, en, El derecho y la justicia, Edición de Ernesto Garzón Valdés y Francisco Laporta, Madrid, Trotta, 2000

2006 , Las razones del derecho. Teorías de la argumentación jurídica, Lima, Palestra, , Curso de Argumentación Jurídica, Madrid, Trotta, 2013

Austin, John, The Province of Jurisprudence Determined, Nueva York, Prometheus Books, 2001

Bäcker, Carsten, "Recht als institutionalisierte Vernunft. Zu Robert Alexys diskurstheoretischer Konzeption des Rechts“, en, Archiv für Rechts- und Sozialphilosophie, Vol. 97, Franz Steiner Verlag, 2011

Begründen und Entscheiden. Kritik und Reconstruction der Alexyschen Diskurstheorie des Rechts, Baden-Baden, Nomos Verlagsgesellschaft, 2012

, "Rationalität ohne Idealität. Grundzüge einer relativistischen Diskurstheorie des Rechts“, en, Bäcker, Carsten/Ziemann, Sascha (Eds.), Junge Rechtsphilosophie, Stuttgart, Franz Steiner Verlag/Nomos, 2012

Baier, Kurt, The Moral Point of View, Nueva York, Ithaca, 1958

Bernal, Carlos, El principio de proporcionalidad y los derechos fundamentales, Madrid, CEPC, 2005 Estudio Introductorio a Alexy, Robert, Teoría de los derechos fundamentales, Madrid, Centro de Estudios Políticos y constitucionales, 2008,

, "Die Fundamentalität der Grundrechte”, en, Clérico, Laura y Sieckmann, Jan-Reinard (Eds.), Grundrechte, Prinzipien und Argumentation. Studien zur Rechstheorie Robert Alexys, BadenBaden, Nomos Verlagsgesellschaft, 2009

Betanzos, Eber, "Delitos electorales y procuración de justicia electoral", en, Justicia Electoral.Revista del Tribunal Electoral del Poder Judicial de la Federación, Cuarta Época, vol. 1, núm. 10, Juliodiciembre de 2012

Beyleveld, Deryck y, Brownsword, Roger, Law as Moral Judgement, Sheffield, Sheffield Academic Press, 2001

Bobbio, Norberto, Contribución a la teoría del derecho, Madrid, Debate, 1990, , Teoría general del derecho, Madrid, Debate, 1995 , Norberto Bobbio: el filósofo y la política, México, FCE, 2004 
Bongiovanni, Giorgio, Rotolo, Antonino and Roversi, Corrado, "The Claim to Correctness and Inferentialism: Alexy's Theory of Practical Reason Reconsidered", en, Pavlakos, George (Ed.), Law, Rights and Discourse. The Legal Philosophy of Robert Alexy, Portland, Oxford University Press, 2007

Borowski, Martin, La estructura de los derechos fundamentales, Bogotá, UEC, 2003 Grundrechte als Prinzipien, Baden-Baden, Nomos Verlagsgesellschaft, 2007 , "Discourse, Principles, and the Problem of Law and Morality: Robert Alexy's Three Main Works", en, Jurisprudence, 2 (2), 2011

"La idea de los principios formales. La proporcionalidad en el control de constitucionalidad", conferencia dictada en el Tribunal Electoral del Poder Judicial de la Federación el día 9 de diciembre de 2013 en México, Distrito Federal

Brandom, Robert, Articulating Reasons, Cambridge, Harvard University Press, 2001

Brieskorn, Norbert, Rechtsphilosophie, Colonia, Kohlhammer, 1990

Bubner, Rüdiger, Antike Themen und ihre moderne Verwandlung, Fráncfort del Meno, Suhrkamp, 1992

Bulygin, Eugenio, “An Antinomy in Kelsen's Pure Theory of Law”, Ratio Juris, 3, 1990

"Alexy und das Richtigkeitsargument", en, Aarnio, Aulis, Paulson, Stanley, y Weinberger, Ota, (Eds.), Rechtsnorm und Rechtswirklichkeit. Festchrift für Werner Krawietz zum 60 Geburtstag, Duncker \& Humblot, Berlín, 1993

, "Alexy's Thesis of the Necessary Connections between Law and Morality", en, Ratio Juris, Vol. 13, Núm. 2, 2000

, "Robert Alexy und der Begriff des Rechts", en, Clérico, Laura y Sieckmann, JanReinard (Eds.), Grundrechte, Prinzipien und Argumentation. Studien zur Rechstheorie Robert Alexys, Baden-Baden, Nomos Verlagsgesellschaft, 2009

Cabanellas, Guillermo, Repertorio jurídico de principios generales del derecho, locuciones, máximas y aforismos latinos y castellanos, Buenos Aires, Editorial Heliasta, 2003

Carrió, Genaro, Notas sobre derecho y lenguaje, Buenos Aires, Abeledo-Perrot, 1994

Castoriadis, Cornelius, "Power, Politics, Autonomy", en, Honneth, Axel, McCarthy, Thomas, Offe, Claus y Wellmer, Albrecht (Eds.), Zwischenbetrachtungen Im prozeß der Aufklärung. Jürgen Habermas zum 60 Geburtstag, Fráncfort del Meno, Suhrkamp, 1989

World in Fragments: Writings on Politics, Society, Psychoanalysis, and the Imagination, Stanford, Stanford University Press, 1997

Chang, Ruth, "Introduction", en Chang, Ruth (ed), Incommensurability, Incomparability and Practical Reason, Cambridge, Harvard University Press, 1997

Chiassoni, Pierliugi, "Alexy y la doble naturaleza del derecho: comentarios escépticos", en Bernal, Carlos (Ed.), La doble dimensión del derecho. Autoridad y razón en la obra de Robert Alexy, Lima, Palestra Editores, 2011

Clérico, Laura, El examen de proporcionalidad en el derecho constitucional, Buenos Aires, Eudeba, 2009 
"Los casos en el modelo de la ponderación orientado por reglas. El modelo alexyano de la ponderación en comparación con el modelo "especificionista" de Moreso", en, Bernal, Carlos (Ed.), La doble dimensión del derecho. Autoridad y razón en la obra de Robert Alexy, Lima, Palestra Editores, 2011

Coleman, Jules, "Authority and Reason", en, George, Robert, The Autonomy of Law, Oxford, Clarendon Press, 1996

Correas, Óscar, Introducción a la sociología jurídica, México, D. F., Ediciones Coyoacán, 2009

Cooke, Maeve, "Law's Claim to Correctness", en, Pavlakos, George (Ed.), Law, Rights and Discourse. The Legal Philosophy of Robert Alexy, Portland, Oxford University Press, 2007

Da Silva, Virgilio Afonso, Direitos Fundamentais. Conteúdo essencial, restrições e eficacia, Sao Paulo, Malheiros Editores, 2009

, "Principios y reglas: mitos y equívocos acerca de una distinción", en Beade, Gustavo y Clérico, Laura (Eds.), Desafíos a la ponderación, Bogotá, UEC, 2011

Davidson, Donald, Inquiries into Truth and Interpretation, Oxford, Oxford University Press, 1988

Dávila, Nicolás, Escolios a un texto implícito, Madrid, Ediciones Atalanta, 2009

Douzinas, Costas, El fin de los derechos humanos, Bogotá, Legis, 2008

Dreier, Ralf, Recht - Moral - Ideologie. Studien zur Rechtstheorie, Fráncfort del Meno, Suhrkamp, 1981

Díez, Rodrigo, "Principio de proporcionalidad, colisión de principios y el nuevo discurso de la corte", en, Cuestiones constitucionales. Revista mexicana de derecho constitucional, núm. 26, enero-junio 2012

Dworkin, Ronald, Los derechos en serio, Barcelona, Planeta-Agostini, 1993

Dussel, Enrique, Ética de la globalización en la era de la globalización y de la exclusión, Madrid, Trotta, Madrid, Trotta, 2006

Eckert, Jörn, "Was war die Kieler Schule?", en, Säcker, Franz Jürgen, Recht und Rechtslehre im Nationalsozialismus, Baden-Baden, Nomos Verlagsgesellschaft, 1992

Eng, Svein, "Lost in the System or Lost in Translation? The Exchanges between Hart and Ross", Ratio Juris, 24, 2011

Esser, Josef, Principio y norma en la elaboración jurisprudencial del derecho privado, Barcelona, José María Bosch Editor 1961

Farrali, Carla, La filosofía del derecho contemporánea. Temas y desafíos, Bogotá, UEC, 2007

Ferrajoli, Luigi, El garantismo y la filosofía del derecho, Bogotá, UEC, 2000

, Los fundamentos de los derechos fundamentales, Madrid, Trotta, 2001

, Derecho y razón. Teoría del garantismo penal, Madrid, Trotta, 2006

Derechos y garantías. La ley del más débil, Madrid, Trotta, 2004 
Feteris, Eveline, Fundamentals of Legal Argumentation. A Survey of Theories on the Justification of Judicial Decisions, Dordrecht, Springer, 1999

Finnis, John, "Law as Fact an as Reason for Action: A Response to Robert Alexy on Law's «ldeal Dimension»", en, The American Journal of Jurisprudence, Vol. 59, No. 1, 2014

Forsthoff, Ernst, El Estado de la sociedad industrial, Madrid, Instituto de Estudios Políticos, 1975

Frege, Gottlob, “The Thought: A Logical Inquiry”, en, Mind, vol. 65, n. 259, 1956

Fuller, Lon, The Morality of Law, New Haven, Yale University Press, 1964

Fusfield, Daniel, "Can Jürgen Habermas' «Begründungsprogramm» Escape Hans Albert's Münchhausen-Trilema", en, Jahrbuch Rethorik 8, 1989

Gaido, Paula, Las pretensiones normativas del derecho. Un análisis de las concepciones de Robert Alexy y Joseph Raz, Madrid, Marcial Pons, 2011

García Figueroa, Alfonso, "Entrevista a Luigi Ferrajoli", en, Carbonell, Miguel y Salazar, Pedro (Eds.), Garantismo. Estudios sobre el pensamiento jurídico de Luigi Ferrajoli, Madrid, Trotta, 2003

Constitucionales, Madrid, 2006

(Ed.), Racionalidad y derecho, Centro de Estudios Políticos y

“¿Existen diferencias entre reglas y principios en el Estado constitucional? Algunas notas sobre la teoría de los principios de Robert Alexy?", en Alexy, Robert, Derechos sociales y ponderación, Madrid, Fundación Coloquio Jurídico Europeo, 2007

"¿Existen diferencias entre reglas y principios en el Estado constitucional? Algunas notas sobre la teoría de los principios de Robert Alexy?", en Alexy, Robert, Derechos sociales y ponderación, Madrid, Fundación Coloquio Jurídico Europeo, 2007

"Derecho, metafísica y naturaleza. Alexy en la región de las verdades eternas", en, Bernal, Carlos (Ed.), La doble dimensión del derecho. Autoridad y razón en la obra de Robert Alexy, Lima, Palestra Editores, 2011

García Máynez, Eduardo, Filosofía, del derecho, México, Porrúa, 1974

Gardner, John, "How Law Claims, What Law Claims", en, Klatt, Matthias (Ed.), Institutionalized Reason. The Jurisprudence of Robert Alexy, Nueva York, Oxford University Press, 2012

Geiger, Theodor, Über Moral und Recht. Streitgespräch mit Uppsala, Berlín, Duncker \& Humblodt, 1979

Gorman, Jonathan, "Three Person Justification”, en, Pavlakos, George, Law, Rights and Discourse. The Legal Philosophy of Robert Alexy, Oxford, Hart Publishing 2007

Grice, Paul, "Logic and Conversation", en, Cole, Peter, y Morgan, Jerry (Eds.), Syntax and Semantics, Vol. 3, Speech Acts, Nueva York, Academic Press, 1975

Gunnarsson, Logi, Making Moral Sense: Beyond Habermas and Gauthier, Cambridge, Cambridge University Press, 2003

Günther, Klaus, The Sense of Appropriateness. Application Discourses in Morality and Law, Nueva York, Suny, 1993 
Habermas, Jürgen, Strukturwandel der Öffentlichkeit.Untersuchungen zur einer Kategorie der bürgerlichen Gesellschaft, Fráncfort del Meno, Suhrkamp, 1971

Suhrkamp, 1986

, Der philosophische Diskurs der Moderne. Zwölf Vorlesungen, Fráncfort del Meno,

Habermas, Jürgen, La necesidad de revisión de la izquierda, Madrid, Tecnos, 1991

Habermas, Jürgen, Erläuterungen zur Diskursethik, Fráncfort del Meno, Suhrkamp, 1991

Faktizität und Geltung. Beiträge zur Diskurstheorie des Rechts und des demokratischen Rechtstaats, Fráncfort del Meno, Suhrkamp, 1992

Habermas, Jürgen, Conciencia moral y acción comunicativa, Barcelona, Planeta - De Agostini, 1994

Habermas, Jürgen, Postmetaphysical Thinking. Philosophical Essays, Cambridge, MIT Press, 1994

Habermas, Jürgen, "Reply to Simposium Participants", en Rosenfield, Michel y Arato, Andrew (Eds.), Habermas on Law and Democracy, Massachusetts, MIT, 1998

Hare, Richard, Freedom and Reason, Oxford, Oxford University Press, 1963

The Language of Morals, Oxford, Clarendon Press, 1973

, Moral Thinking. Its Levels, Method and Point, Oxford, Clarendon Press, 1988

Hart, H. L. A., Law, Liberty and Morality, Cambridge, Oxford University Press, 1963

, Essays in Jurisprudence and Philosophy, Oxford, Clarendon Press, 1983

, The Concept of Law, Oxford, Oxford University Press, 1994

Hegel, G. W. F., Grundlinien der Philosophie des Rechts oder Naturrecht und Staatswissenschaft im Grundrisse, Hamburg, Feliz Meiner Verlag, 2013

Heidemann, Carsten "The Concept of Validity in a Theory of Social Action", en, Pavlakos, George (Ed.), Law, Rights and Discourse. The Legal Philosophy of Robert Alexy, Oxford, Hart Publishing, 2007

Hierro, Liborio, "Los derechos económico-sociales y el principio de igualdad en la teoría de los derechos de Robert Alexy", en Alexy, Robert, Derechos sociales y ponderación, Madrid, Fundación Coloquio Jurídico Europeo, 2007

Hobbes, Thomas, El Leviatán o la materia, forma y poder de una república eclesiástica y civil, México, D. F., FCE, 1987

Hoerster, Norbert, "Die rechtsphilosophische Lehre vom Rechtsbegriff", en Juristische Schulung, 3, 1987

2006

, Was ist Recht? Grundfragen der Rechtsphilosophie, Múnich, Verlag, C. H. Beck,

Höffe, Otfried, Politische Gerechtigkeit. Grundlegung einer kritischen Philosophie von Recht und Staat, Fráncfort del Meno, Suhrkamp, 1987

"Vernunft im Recht?", en, Fulda, Hans y Horstmann, Rolf-Peter, Vernunftbegriffe in der Moderne, Stuttgart, Klett-Cotta, 1994 
Suhrkamp, 1995

Kategorische Rechtsprinzipien. Ein Kontrapunkt der Moderne, Fráncfort del Meno,

, Demokratie im Zeitalter der Globalizierung, Múnich, Verlag C. H. Beck, 1999

, Derecho intercultural, Barcelona, Gedisa, 2008

,"Rechtsphilosophie als Politische Philosophie“, en Kühl, Kristian (ed.), Zur Kompetenz der Rechtsphilosophie in Rechtsfragen, Archiv für Rechts-und Sozial philosophie Nr. 126, Stuttgart, Franz Steiner Verlag, 2011

Honneth, Axel, Pathologien der Vernunft. Geschichte und Gegenwart der Kritischen Theorie, Fráncfort del Meno, Suhrkamp, 2007

Huerta, Carla, "Normkonflikte im Lichte der Prinzipientheorie" Clérico, Laura y Sieckmann, JanReinard (Eds.), Grundrechte, Prinzipien und Argumentation. Studien zur Rechstheorie Robert Alexys, Alemania, Baden-Baden, Nomos Verlagsgesellschaft, 2009

Jestaedt, Matthias, "The Doctrine of Balancing -its Strengths and Weaknesses", en, Klatt, Matthias (Ed.), Institutionalized Reason. The Jurisprudence of Robert Alexy, Nueva York, Oxford University Press, 2012

Joerden, Jan-Reinard, Logik im Recht. Grundlagen und Andwendungbeispiele, Heidelberg, Springer, 2010

Kalscheuer, Fiete, Autonomie als Grund und Grenze des Rechts: Das Verhaltnis zwischen dem kategorischen Imperativ und dem allgemeinen Rechtsgesetz Kants, Berlín, Walter de Gruyter, 2014

Kant, Immanuel, Rechtslehre. Schriften zur Rechtsphilosophie, Berlín, Akademie-Verlag, 1988

, Metaphysische Anfangsgründe der Rechtslehre. Metaphysik der Sitten. Erster Teil, Hamburgo, Felix Meiner Verlag, 2009

Kaufmann, Arthur, Rechtsphilosophie, Múnich, C. H. Beck, 1997

Kaufmann, Arthur/Hassemer, Winfried/Neumann, Ulfrid (Eds.), Einführung in die Rechtsphilosophie und Rechtstheorie der Gegenwart, Heidelberg, C.F. Müller, 2011

Kelsen, Hans, Allgemeine Theorie der Normen, Viena, Manzche Verlags- und Universitätsbuchhandlung, 1979

Reine Rechtslehre. Zweite, vollständig neu bearbeitete und erweiterte Auflage 1960, Viena, Österreichische Staatsdruckerei, 1992 , Teoría general del derecho y del Estado, México, D. F., UNAM, 1995

Tubinga, Mohr Siebeck, 2008

Kirste, Stephan, "Recht als Tranformation", en Brugger, Winfried, Neumann, Ulfrid, y Kirste, Stephan (Eds.) Rechtsphilosophie im 21. Jahrhundert, Fráncfort del Meno, Suhrkamp, 2008

Klatt, Mathias, Theorie der Wortlautgrenze. Semantische Normativität in der juristischen Argumentation Baden-Baden, Nomos Verlagsgesellschaft, 2004. 
, "Robert Alexy's Philosophy of Law as a System", en, Klatt, Matthias (Ed.), Institutionalized Reason. The Jurisprudence of Robert Alexy, Nueva York, Oxford University press, 2012

Klatt, Mathias y Meister, Moritz, The Constitutional Structure of Proportionality, Oxford, Oxford University press, 2012

Klatt, Mathias, y Schmidt, Johannes, "Epistemic Discretion in Constitutional Law", en, International Journal of Constitutional Law, No. 12, 2012

Klement, Jan-Reinard, "Vom Nutzen einer Theorie, die alles erklärt", en, Juristen Zeitung, vol. 63, No. 15 , Tubinga

Kripke, Saul, Naming and Necessity, Massachusetts, Blackwell Publishers, 2000

Kumm, Mattias, "Political Liberalism and the Structure of Rights", en, Pavlakos, George (Ed.), Law, Rights and Discourse. The Legal Philosophy of Robert Alexy, Portland, Hart Publishing, 2007

, "Alexy's Theory of Constitutional Rights and the Problem of Judicial Review", en, Klatt, Matthias (Ed.), Institutionalized Reason. The Jurisprudence of Robert Alexy, Nueva York, Oxford University press, 2012

Kunz, Karl-Ludwig y Mona, Martino, Rechtsphilosophie, Rechtstheorie, Rechtssoziologie. Eine Einführung in die theoretischen Grundlagen der Rechtswissenschaft, Berna, UTB, 2006

Laporta, Francisco, Entre el derecho y la moral, México, D. F., Fontamara, 2000

Larenz, Karl, Das Problem der Rechtsgeltung, Berlín, Junker \& Dünnhaupt, 1929

Lehmann, Hartmut, Die Entzauberung der Welt. Studien zu Themen von Max Weber, Gotinga, Wallstein Verlag, 2009

Leiter, Brian, Naturalizing Jurisprudence. Essays on American Legal Realism and Naturalism in Legal Philosophy, Nueva York, Oxford University Press, 2007

Leyva, Gustavo, "Pasado y presente de la teoría crítica. Tres vertientes de reflexión para la crítica en el presente", en, Leyva, Gustavo (ed.) La Teoría Crítica y las tareas actuales de la crítica, Barcelona, Anthropos, 2005

, “Jürgen Habermas: espacio público y democracia”, en, Rendón, Jorge (Ed.), filosofía política: sus clásicos y sus problemas actuales, México, D. F., Casa Juan Pablos y UAM Iztapalapa, 2007

Lüderssen, Klaus, Genesis und Geltung in der Jurisprudenz, Fráncfort del Meno, Edition Suhrkamp 1996

Luhmann, Niklas, Legitimation durch Verfahren, Fráncfort del Meno, Suhrkamp, 1997

, Los derechos sociales como institución. Aportación a la sociología crítica, México, D. F., Universidad Iberoamericana, 2010

MacCormick, Neil, Legal Reasoning and Legal Theory, Oxford, Oxford University Press, 1994 Rhetoric and the Rule of Law, Oxford, Cambridge, Oxford University Press, 2005

Discourse. The Legal Philosophy of Robert Alexy, Portland, Hart Publishing, 2007

"Why Law Makes no Claims", en, Pavlakos, George (Ed.), Law, Rights and 
, "Five Questions, Ebbe Morten y Nielsen, Juul, Legal Philosophy. Five Questions, Nueva York, Automatic Press, 2007

Menéndez, Agustín, "Introduction", en, Menéndez, Agustín y Eriksen, Erik, Fundamental Rights through Discourse. On Robert Alexy's Legal Theory. European and Theoretical Perspectives, Oslo, Arena, 2004

McCarthy, Thomas, La teoría crítica de Jürgen Habermas, Madrid, Tecnos, 2002

Möller, Kai, The Global Model of Constitutional Rights, Oxford, Oxford University Press, 2012

Nino, Carlos, "Some Confusions Surrounding Kelsen's Concept of Validity", en, Archiv für Rechtsund Sozial Philosophie, 64, Berlín, 1978

Ética y derechos humanos, Buenos Aires, Paidós, 1984

Neumann, Ulfrid, "Theorie der juristischen Argumentation“, en, Brugger, Winfried, Neumann, Ulfrid, y Kirste, Stephan (Eds.) Rechtsphilosophie im 21. Jahrhundert, Fráncfort del Meno, Suhrkamp, 2008, p. 233

, "Theorien der Rechtsgeltung", en, Gessner, Volkmar/Hassemer, Winfried (Eds.) Gegenkultur und Recht, Baden-Baden, Nomos Verlagsgesellschaft 1985

Nooke, Günter, "Universalität der Menschenrechte - Zur Rettung einer Idee", en, Nooke, Günter, Lohmann, Georg y Wahlers, Gerhard (Eds.), Gelten Menschenrechte Universal? Begründungen und Infragestellungen, Friburgo, Herder, 2008

Patzig, Günther, Ethik ohne Metaphysik, Gotinga, Vandenhoeck-Reihe, 1983

Paulson, Stanley L., "Radbruch on Unjust Laws: Competing Earlier and Later Views", en, Oxford Journal of Legal Studies Nr. 15, Oxford, 1995

, "Four Phases in Hans Kelsen's Legal Theory? Reflections on a Periodization", en, Oxford Journal of Legal Studies, Vol. 18, Oxford, 1998

, "On the Background and Significance of Gustav Radbruch's Post-War Papers", en Oxford Journal of Legal Studies Nr. 26, Oxford, 2006

, "Ein ewiger Mythos: Gustav Radbruch als Rechtspositivist - Teil 1", en Juristen Zeitung, Nr. 3, Tubinga, Mohr Siebeck, 2008

, "La reconstrucción radical kelseniana de la norma jurídica", en, Clérico, Laura y, Sieckmann, Jan-Reinard, La teoría del derecho de Hans Kelsen, Bogotá, UEC, 2011

,A 'Justified Normativity' in Kelsen's Pure Theory?. Rejoinders to Robert Alexy and Joseph Raz", en, Klatt, Matthias (Ed.), Institutionalized Reason. The Jurisprudence of Robert Alexy, Nueva York, Oxford University Press, 2012

Pavlakos, George, "Review of The Argument from Injustice from Robert Alexy", en, The Modern Law Review, Vol. 67, No. 2, 2004

Peczenik, Aleksander, Derecho y razón, México, Fontamara, 2000

Pereda, Carlos, Vértigos argumentales. Una ética de la disputa, Barcelona, Anthropos, 1994

Perelman, Chaim, Juristische Logik als Argumentationslehre, Friburgo/Múnich, Verlag Karl Alber, 1979 
, La lógica jurídica y la nueva retórica, Madrid, Civitas, 1979

Poscher, Ralf, "Principles: How Many Theories? What Merit?", en, Klatt, Matthias (Ed.), Institutionalized Reason. The Jurisprudence of Robert Alexy, Nueva York, Oxford University Press, 2012

Radbruch, Gustav, Grundzüge der Rechtsphilosophie, Leipzig, Verlag von Quelle \& Meyer en Leipzig, 1914

Rechtsphilosophie, Heidelberg, UTB, 2003

Rawls, John, Political Liberalism, Nueva York, Columbia University Press, 1993

, "Justice as Fairness: Political not Metaphysical", en Freeman, Samuel (Ed.) John

Rawls. Collected Papers, Massachusetts, Harvard University Press, 1999

Teoría de la justicia, México, D. F., FCE, 2010

Raz, Joseph, “Professor Dworkin's Theory of Rights”, en Political Studies, 1978

"Incommensurability and Agency", en Chang, Ruth (Ed.), Incommensurability,

Incomparability and Practical Reason, Cambridge, Harvard University Press, 1997

"Kelsen's Theory of the Basic Norm", en, Paulson, Stanley, y Paulson, Bonnie Litschewski, Normativity and Norms. Critical Perspectives on Kelsenian Themes, Oxford, Clarendon Press, 1998

, "The Argument from Justice, or How Not to Reply to Legal Positivism", en, Pavlakos, George (Ed.), Law, Rights and Discourse. The Legal Philosophy of Robert Alexy, Portland, Hart Publishing, 2007

2009

The Authority of Law, Essays on Law and Morality, Oxford, Oxford University Press,

"Humans Rights without Foundations", en, Besson, Samantha y Tassioulas, John, The Philosophy of International Law, Oxford, Oxford University Press, 2010

, Ethics in the Public Domain. Essays in the Morality of Law and Politics, Nueva York, Oxford University press, 2010

Reale, Miguel, Introducción al derecho, Madrid, Pirámide, 1989

Reese, Birgit, Die Verfassung des Grundgesetzes, Berlín, Duncker \& Humblot, 2013

Rehg, William, Insight and Solidarity. The Discourse Ethics of Jürgen Habermas, California, University of California Press, 1994

Richards, David, "Review: Robert Alexy, A Theory of Legal Argumentation”, en, Ratio Juris No. 2, 1989

Riley, Patrick, Kant's Political Philosophy, Nueva Jersey, Rowman and Littlefield, 1983

Rivers, Julian, "Proporcionality, Discretion and the Second Law of Balancing", en Pavlakos, George (Ed.), Law, Rights and Discourse. The Legal Philosophy of Robert Alexy, Portland, Hart Publishing, 2007 
Rojas, Mario, La razón ético-objetiva y los problemas morales del presente. Crítica ético-racional del relativismo moral-cultural, México, D. F., Ítaca, 2011

Ross, Alf, On Law and Justice, Nueva York, New Haven Press, 1958 , Directives and Norms, Londres, Routledge \& Kegan Paul, 1968

, "Validity and the Conflict between Legal Positivism and Natural Law", en, Paulson, Stanley, y Paulson, Bonnie Litschewski, Normativity and Norms. Critical Perspectives on Kelsenian Themes, Oxford, Clarendon Press, 1998

Ross, David, The Right and the Good, Oxford, Oxford Clarendon Press, 1930

Rüthers, Bernd, y Fischer, Christian, Rechtstheorie, Múnich, Verlag C. H. Beck, 2010

Schauer, Frederick, "Balancing, Subsumption and the Constraining Role of Legal Text", en, Klatt, Matthias (Ed.), Institutionalized Reason. The Jurisprudence of Robert Alexy, Nueva York, Oxford University press, 2012

Schreiber, Rupert, Die Geltung von Rechtsnormen, Heildelberg, Springer-Verlag, 1966

Sieckmann, Jan-Reinard, Regelmodelle und Prinzipienmodelle des Rechtssystems, Baden-Baden, Nomos Verlagsgesellschaft, 1990 , El modelo de los principios del derecho, Bogotá, UEC, 2006

, "Probleme der Prinzipientheorie der Grundrechte", en, Clérico, Laura y Sieckmann, Jan-Reinard (Eds.), Grundrechte, Prinzipien und Argumentation. Studien zur Rechstheorie Robert Alexys, Baden-Baden, Nomos Verlagsgesellschaft, 2009

, "La tesis de la naturaleza dual en la teoría de Robert Alexy", en, Bernal, Carlos (Ed.), La doble dimensión del derecho. Autoridad y razón en la obra de Robert Alexy, Lima, Palestra Editores, 2011

Schilling, Christof, Moralische Autonomie. Anthropologische und diskurstheoretische Grundstrukturen, Tubinga, Ferdinand Schöningh, 1996

Schlink, Bernhard, Abwägung im Verfassungsrecht, Berlín, Duncker \& Humblot, 1976

, "The Dinamics of Constitutional Adjudication", en, Arato, Andrew y Rosenfeld, Michel (Eds.), Habermas on Law and Democracy. Critical Exchanges, California, California University Press, 1998

Schmitt, Carl, El Leviatán en la doctrina del Estado de Thomas Hobbes, México, D. F., UAM, 1997

Schlüchter, Wolfgang, Die Entzauberung der Welt. Sechs Studien zu Max Weber, Tubinga, Mohr Siebeck, 2009

Schaal, Gary (Ed.), Das Staatsverständnis von Jürgen Habermas, Baden-Baden, Nomos Verlagsgesellschaft, 2009

Searle, John, "Prima Facie Obligations", en Raz, Joseph (ed.), Practical Reasoning, Oxford, Oxford University Press, 1978

2004 Mind, Language and Society. Philosophy in the Real World, Nueva York, Basic Books, 
, Making the Social World. The Structure of Human Civilization, Nueva York, Oxford University Press, 2011

Sobrevilla, David, La filosofía del derecho alemana actual de orientación racionalista. Estudios sobre R. Alexy, K. Günther, J. Habermas y O. Höffe, México, D. F., Fontamara, 2008

Soper, Philip, "Law's Normative Claims", en, George, Robert (ed.), The Autonomy of Law. Essays on Legal Positivism, Oxford, Clarendon Press, 1996

Stevenson, Charles, Ética y Lenguaje, Buenos Aires, Paidós, 1971

Stone Sweet, Alec y Matthews, Jud, "Proportionality Balancing and Global Constitutionalism", Columbia Journal of Transnational Law, No. 47, 2008

Trivisonno, Alexandre, T. G.,"Princípios jurídicos e poisitivismo jurídico: as críticas de Dworkin a Hart se aplicam a Kelsen?", en, Aguiar de Oliveira, Júlio y, Trivisonno, Alexandre, T. G. (Eds.), Hans Kelsen, Teoría jurídica e política, Forense Universitaria, Río de Janeiro, 2013, pp. 37-68.

, "O problema do conocimento prático na teoria discursiva do direito de Alexy", en, Trivisonno, Alexandre T. G., Tuffi, Aziz y Sétte, Mónica, (Eds.), Princípios formais e outros aspectos da Teoria Discursiva do Direito, Forense Universitaria, Rio de Janeiro, 2014, pp. 185-212.

Toulmin, Stephen, Los usos de la argumentación, Barcelona, Península, 2007

Turiel, Elliot, "The Multiplicity of Social Norms: The Case for Psychological Constructivism and Social Epistemologies", en, Smith, Leslie, y Vonèche, Jacques, Norms in Human Development, Cambridge, Cambridge University Press, 2009

Vassiloyannis, Philippos, "Discourse Ethics, Legal Positivism and the Law", en Pavlakos, George (ed.), Law, Rights and Discourse. The Legal Philosophy of Robert Alexy, Oxford, Hart Publishing, 2007

Vigo, Rodolfo, La injusticia extrema no es derecho. De Radbruch a Alexy, México, D. F., Fontamara, 2008

Jeremy Waldron, "The Core of the Case against Judicial Review", Yale Law Journal 115, 2006

Walter, Robert, "Der gegenwärtige Stand der Reinen Rechtslehre", en, Rechtstheorie, 1, 1970

Weinberger, Ota, Law, Institution and Legal Politics: Fundamental problems of Legal theory and Social Philosophy, Dordrecht, Kluwer Academic Publishers, 1991

, "Legal Validity, Acceptance of Law, Legitimacy. Some Critical Comments and Constructive Proposals", en, Ratio Juris, Vol. 12, No. 4, 1999

Welzel, Hans, An den Grenzen des Rechts. Die Frage nach der Rechtsgeltung, Colonia y Opladen, Westdeutscher Verlag, 1967

Williams, Bernard, Ethics and the Limits of Philosophy, Massachusetts, Harvard University press, 1985

Winscheid, Bernhard, "Über Recht und Rechtswissenschaft", 1854, en Gesammelte Abhandlungen, Leipzig, Duncker \& Humblot, 1904

Wróblewski, Jerzy, "Legal Syllogism and Rationality of Judicial Decision", en Rechtstheorie, n. 5, 1974 
, "Three Concepts of Validity of Law", en, Tidskrift utgiven av Juridiska Foreningen i Finland, 5-6, Finlandia, 1982

Vega, Luis, y Olmos, Paula (Eds.), Compendio de lógica, argumentación y retórica, Madrid, Trotta, 2011

Viehweg, Theodor, Tópica y jurisprudencia, Madrid, Taurus, 1964

Grundlagenforshung, Múnich, C. H. Beck'sche Verlagsbuchhandlung, 1978

Vigo, Rodolfo, La injusticia extrema no es derecho. De Radbruch a Alexy, México, Fontamara, 2008

Vinx, Lars, Hans Kelsen's Pure Theory of Law, Nueva York, Oxford University Press, 2007

Von Kutschera, Franz, Grundlagen der Ethik, Berlín, Walter de Gruyter, 1982

Wert und Wirklichkeit, Paderborn, Mentis, 2010

Yoon, Zai-Wang, Rechtsgeltung und Anerkennung. Probleme der Anerkennungstheorie am Beispiel von Ernst Rudolf Bierling, Baden-Baden, Nomos Verlagsgesellschaft, 2009 